Autorizo a reprodução e divulgação total ou parcial deste trabalho, por qualquer meio convencional ou eletrônico, para fins de estudo e pesquisa, desde que citada a fonte.

Catalogação na Publicação

Serviço de Biblioteca e Documentação

Faculdade de Educação da Universidade de São Paulo

375.35 Aparicio Pereda, Ana Sofia

A639a

Avaliação das atitudes no curso de estatística: contextos universitários latino-americanos / Ana Sofia Aparicio Pereda ; orientação Oscar João Abdounur. São Paulo: s.n., 2014. 189 p

Tese (Doutorado - Programa de Pós-Graduação em Educação. Área de Concentração: Ensino de Ciências e Matemática) -- Faculdade de Educação da Universidade de São Paulo)

1. Atitudes Estatística - Estudo e ensino 2. Ensino superior 3. Estudantes universitários I. Abdounur, Oscar João, orient. 


\section{UNIVERSIDADE DE SÃO PAULO \\ FACULDADE DE EDUCAÇÃO}

ANA SOFÍA APARICIO PEREDA

AVALIAÇÃO DAS ATITUDES NO CURSO DE ESTATÍSTICA: CONTEXTOS UNIVERSITÁRIOS LATINO-AMERICANOS 


\title{
AVALIAÇÃO DAS ATITUDES NO CURSO DE ESTATÍSTICA: CONTEXTOS UNIVERSITÁRIOS LATINO-AMERICANOS
}

\author{
ANA SOFÍA APARICIO PEREDA
}

Tese apresentada à Faculdade de Educação da Universidade de São Paulo como parte dos requisitos para a obtenção do título de Doutora em Educação.

Área de concentração: Ensino de Ciências e Matemática

Orientador: Prof. Dr. Oscar João Abdounur

São Paulo 2014 


\section{FOLHA DE APROVAÇÃO}

APARICIO PEREDA, Ana Sofía. Avaliação das atitudes no curso de Estatística: contextos universitários latino-americanos. Tese apresentada à Faculdade de Educação da Universidade de São Paulo para obtenção do título de Doutora em Educação.

Aprovado em:

Banca examinadora:

Prof. Dr.

Instituição: Assinatura:

Prof. Dr.

Instituição: Assinatura:

Prof. Dr.

Instituição: Assinatura:

Prof. Dr.

Instituição: Assinatura:

Prof. Dr.

Instituição: Assinatura: 
Dedico este trabalho a meus pais Luis Manuel e Clementina e a meus queridos filhos Paloma, Jorge Ernesto, Leonardo e William 


\section{Agradecimentos}

Agradeço a todos que de uma forma ou de outra possibilitaram a conclusão do meu doutorado. Em especial, gostaria de expressar a minha gratidão

A meu orientador Dr. Oscar João Abdounur por sua paciência e recomendações.

Às professoras Dra. Maria do Carmo Domite e Dra. Adriana Cesar de Mattos Marafon, grandes pessoas e educadoras, por suas acertadas observações e recomendações no exame de qualificação.

De maneira muito especial aos professores Me. Enver Tarazona de Peru, ao Dr. Luis Eduardo Pérez de Colômbia, ao professor Dr. Francisco Torres de Chile e ao professor Me. Carlos Huaira de Brasil, por suas importantes colaborações na investigação feita, através da avaliação dos alunos participantes e pelo interesse no ensino e na aprendizagem da Estatística em seus alunos. E muito especialmente ao professor Dr. Jorge Luis Bazán Guzmán, pelo apoio permanente.

Agradeço à Dra. Assumpta Estrada, professora da Universidade de Lleida da Espanha, com quem tenho compartilhado a publicação de pesquisas sobre as atitudes em estatística do qual ela é um importante referente. Também agradeço a ela e a Dra. Irene Cazorla, autoras das escalas usadas nesta pesquisa.

E meu agradecimento a todos os membros da comissão julgadora por ter aceitado fazer parte deste processo.

Também agradeço o apoio indireto de meus irmãos, Luis Enrique e María Rosa, sempre presentes.

Finalmente agradeço o apoio financeiro outorgado pela CAPES através do programa PECPG. 


\section{Resumo}

APARICIO PEREDA, Ana Sofía. Avaliação das atitudes no curso de Estatística: contextos universitários latino-americanos. 2014. 189 f. Tese (Doutorado em Educação). Faculdade de Educação, Universidade de São Paulo, São Paulo, 2014

O objetivo deste estudo é fornecer uma visão geral e atualizada da pesquisa empírica e transcultural das atitudes dos estudantes universitários em relação à Estatística.

A nossa enfases é a avaliação a nivel pessoal, especialmente o estudo do aspecto afetivo através das atitudes frente à Estatística para o qual fazemos uma revisão das escalas propostas assim como propomos uma escala originalmente desenvolvida para professores de escola e adaptada neste estudo. Considerando os resultados, fazemos um longo estudo das caracteristicas psicométricas desta escala em populaçoes de estudantes universitarios de diferentes especialidades e caracteristicas do Perú, Colombia, Chile e Brasil.

Antes de fazer a parte avaliativa e comparativa entre os países, fazemos uma proposta metodológica das práticas de avaliação do processo de ensino-aprendizagem em cursos de Estatística para uma instituição superior considerando uma adaptação da proposta do Enfoque Ontosemiotico da cognição e Instrução Matemática (EOS) de Godino et al, 2008. Também fazemos uma aproximação na avaliação institucional dos cursos de graduação e pós graduação em Estatística desenvolvidos pelo governo federal no Brasil e as políticas de avaliação no Peru, Colômbia e Chile.

Todos os capítulos são trabalhos a maneira de artigos trabalhados durante o período do doutorado.

Palavras chaves: Atitudes frente à Estatística, Estudantes universitários, comparação transcultural, Escala de atitudes, ensino universitário. 


\begin{abstract}
APARICIO PEREDA, Ana Sofía. evaluation of attitudes in the statistics course: Latin American university contexts.2014.189p. Doctorate Thesis. Department of Education, University of São Paulo, São Paulo, 2014.

The objective of this study is to provide a comprehensive and updated overview of empirical research and cross-cultural attitudes of college students towards Statistics . Our emphasis is on the personal level evaluation, especially through study of the affective aspect of attitudes toward statistics for which we review the proposed scales well as propose a scale originally developed for school teachers and adapted in this study. Considering the results, we made a long study of the psychometric characteristics of this scale in populations of college students from different specialties and characteristics of Peru, Colombia, Chile and Brazil.
\end{abstract}

Before doing the part evaluative and comparative between the countries, do a methodological proposal of the practices of evaluation of the process of educationlearning in courses of Statistics for an upper institution considering An adaptation of the proposal of the Approach Ontosemiotico of the cognition and Mathematical Instruction (EOS) of Godino et al, 2008. Also we make an approach to institutional assessment of undergraduate and graduate programs in Statistics developed by the federal government in Brazil and assessment policies in Peru, Colombia and Chile.

All the chapters are works the way of articles worked during the period of the doctored.

Keywords: Attitudes Statistics, college students , cross-cultural comparison attitude scale, attitudes, university education . 


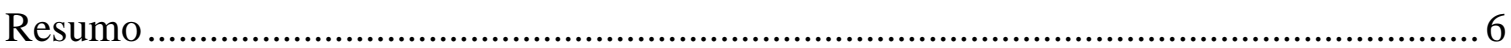

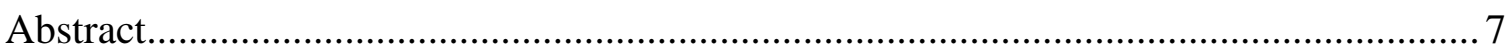

INTRODUÇÃ

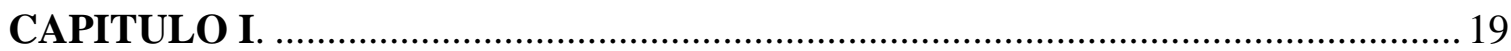

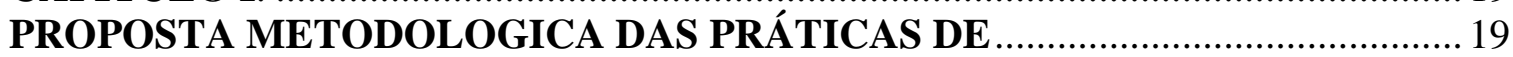

AVALIAÇÃO: SIGNIFICADOS INSTITUCIONAIS E SIGNIFICADOS PESSOAIS

1. Introdução 20

1.2 Conceptualização das práticas de avaliação 21

$\begin{array}{ll}1.3 \text { Caracterizando as práticas de avaliação } & 30\end{array}$

1.4 Comentarios finais 32

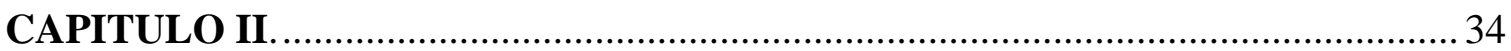

ATITUDES FRENTE A ESTATISTICA: APRENDIZAGEM E AVALIAÇÃO..... 34

2.1 Afetividade e aprendizagem 34

2.2 Atitude frente à estatística 37

2.3 As atitudes e a aprendizagem da estatística na universidade: Alguns estudos feitos 39

2.4 Comentarios finais $\quad 42$

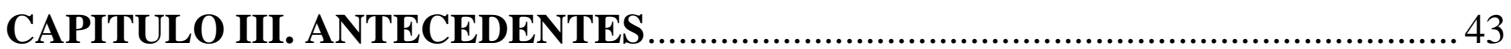

PROPOSTA DE UMA ESCALA DE ATITUDES FRENTE À ESTATÍSTICA PARA

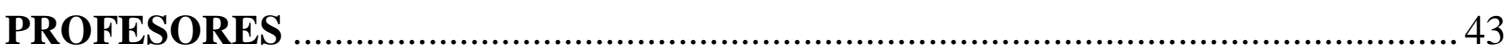

3.1 Introdução $\quad 44$

3.2. Metodología 44

3.3 Resultados 47

3.4 Comentarios finais $\quad 55$

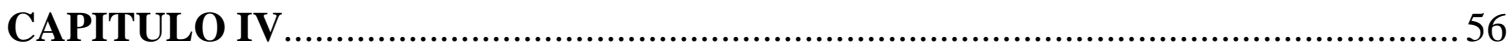

UMA PRIMEIRA APROXIMÃCAO NA AVALIAÇÃO DOS CURSOS DE GRADUAÇÃO E PÓS GRADUAÇÃO EM ESTATÍSTICA EM UNIVERSIDADES

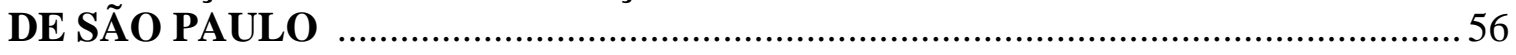

4.1 Introdução $\quad 56$

4.2 Uma breve historia da estadística no sistema universitário do Brasil 62

4.3 Curso de estadística no estado de São Paulo 65

4.4 Avaliação na graduação em estatística usando informação da avaliação ENADE do SINAES

4.5 Avalaiação na pós-graduaçã em estatística usando informação da avaliação trienal da

CAPES $\quad 71$

4.6 Comentarios finais 74 
CAPITULO V.

PANORAMA GERAL DA AVALIAÇÃO E DO CURSO DE ESTATÍSTICA EM

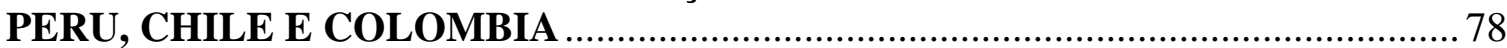

$\begin{array}{ll}\text { 5.1 Panorama Peru } & 78\end{array}$

5.2 Panorama Chile $\quad 81$

5.3 Panorama Colômbia 85

CAPITUlO VI. ATITUDES FRENTE A ESTATÍSTICA EM POBLAÇÕES NO ESTATISTICAS EM QUATRO PAISES LATINOAMERICANOS ……………..... 88

CASO 1: ATITUDES FRENTE A ESTATÍSTICA EM ESTUDANTES PERUANOS

ATITUDES FRENTE Á ESTATÍSTICA EM UNIVERSITÁRIOS PERUANOS DE

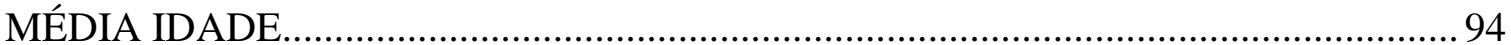

6.1 Metodología $\quad 94$

6.1.2 Instrumentos 96

6.2 Análises $\quad 96$

6.3 Resultados 98

$\begin{array}{ll}\text { 5.4 Comentarios finais } & 105\end{array}$

CASO 2: ATITUDES FRENTE A ESTATÍSTICA EM ESTUDANTES

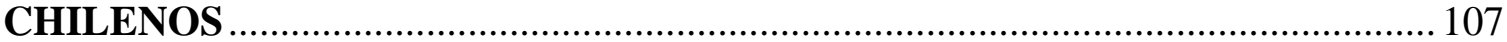

ATITUDES FRENTE À ESTATÍSTICA EM UNIVERSITÁRIOS DA ÁREA DAS CIÊNCIAS DE UMA UNIVERSIDADE PÚBLICA DE CHILE .................................. 107

6.5. Metodología 107

$\begin{array}{ll}\text { 6.5.1 Participantes } & 107\end{array}$

$\begin{array}{ll}\text { 6.6. Resultados } & 110\end{array}$

6.6.1 Análises de itens das escalas originais 110

6.7 Comentarios Finais 122

CASO 3: ATITUDES FRENTE A ESTATÍSTICA EM ESTUDANTES

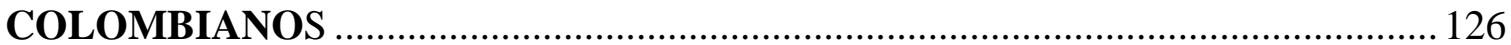

ATITUDES FRENTE À ESTATÍSTICA EM ESTUDANTES UNIVERSITÁRIOS DE UMA UNIVERSIDADE PRIVADA EM COLOMBIA ................................................ 126

6.8 Metodologia $\quad 126$

6.8.1 Instrumentos 126

6.8.2 População e Amostra Efetiva 126

$\begin{array}{ll}\text { 6.8.3 Criterios de incluso e exclusão } & 127\end{array}$

6.8.4 Procedimento de aplicação 129

6.8.5 Análises estatístico 130

6.9 Resultados 130

6.9.1 Características Psicométricas das escalas $\quad 130$

6.9.2 Análises final de itens das escalas corrigidas 133

6.9.3 Análises da Normalidade e fiabilidade das escalas finais 134

6.9.4 Análises da dimensionalidade das Escalas corrigidas de Estrada (2002) e Cazorla et al (1999) 135 
6.10.1 Comparação das atitudes frente à Estatística segundo o gênero dos avaliados $\quad 140$

6.10.2 Comparação das atitudes frente à Estatística segundo o Programa dos avaliados 141

6.11 Comentarios Finais

\section{CASO 4: ATITUDES FRENTE A ESTÍSTICA EM ESTUDANTES BRASILEIROS}

ATITUDE FRENTE À ESTATÍSTICA EM UNIVERSITÁRIOS DE UMA UNIVERSIDADE FEDERAL DE BRASIL ......................................................... 146

6.12.1 População e amostra efetiva 146

6.13 Resultados $\quad 150$

6.13.1 Análise psicometrico $\quad 150$

6.14 Comparação das atitudes frente à estatística segundo a área e o gênero dos $\begin{array}{ll}\text { avaliados } & 165\end{array}$

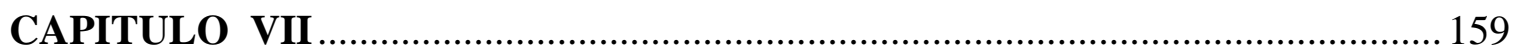

COMPARAÇÃO INTEGRADA PERU-CHILE-COLOMBIA E BRASIL : ATITUDES FRENTE A ESTATÍSTICA DE ALUNOS INICIANTES NA

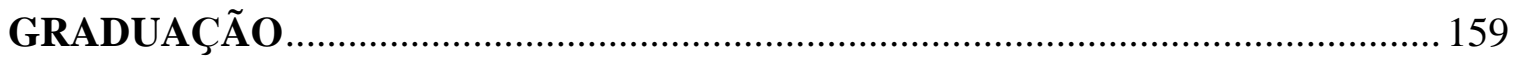

$\begin{array}{ll}7.1 \text { Analise integrado } & 171\end{array}$

$\begin{array}{ll}\text { 7.1.1 Características gerais da amostra integrada por países } & 171\end{array}$

7.1.2 Analises Globais e de itens das atitudes frente à estatística 172

7.1.3 Análise comparativo das atitudes frente à Estatística considerando o gênero, $\begin{array}{lr}\text { o pais e a orientação do curso. } & 179\end{array}$

7.1.4 Análises de multidimensionlidade da escala global de atitudes frente à $\begin{array}{ll}\text { Estatística } & 181\end{array}$

7.1.5 Comentários Finais 182

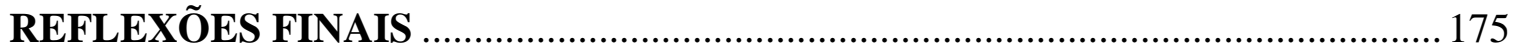

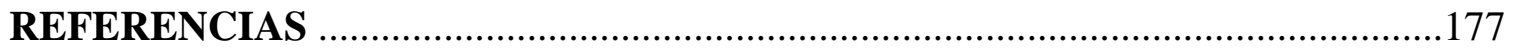

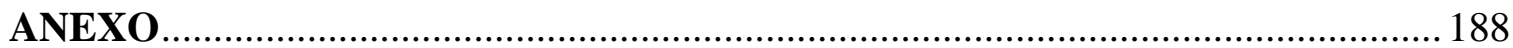




\section{INTRODUÇÃO}

A avaliação é importante na melhora continua no processo de ensino e aprendizagem onde diferentes atores do processo educativo participam. A avaliação faz parte comum do dia a dia nas instituições educativas.

No caso da disciplina de Matemática, o National Council of Teachers of Mathematics (NCTM, 2000) estabelece como princípio que a avaliação deve apoiar a aprendizagem de aspectos importantes da matemática e fornecer informação útil tanto a professores como a alunos. Neste sentido, a avaliação deve intensificar a aprendizagem dos alunos e constitui um instrumento para a tomada de decisões acerca do ensino.

A avaliação deve cumprir normas de compatibilidade, de diversidade na recolha de informação e recorrer a métodos e práticas de avaliação adequada. Na matemática ela deve centrar-se num variado nível de competências, designadamente o poder matemático, a resolução de problemas, a comunicação, o raciocínio, os conceitos matemáticos, os procedimentos matemáticos e a predisposição para a matemática (Abrantes e Leal, 1991; NCTM, 1994b).

De acordo com Teixeira (2007) a avaliação assume-se como uma temática importante no campo das Ciências da Educação, sendo as pesquisas nesta área bastante extensa. A avaliação não é algo de exógeno ao processo de ensino-aprendizagem, nem independente das diversas componentes que envolvem o mesmo processo e engloba aspectos tanto acadêmicos como emocionais ou afetivos dos participantes dela (professores, alunos, instituição educativa).

Quando falamos de avaliação não estamos falando de um fato pontual ou de um ato singular, mas de um conjunto de fases que se condicionam mutuamente. Esse conjunto de fases ordena-se sequencialmente e atua integradamente. Por sua vez a avaliação não é algo separado do processo de ensino-aprendizagem, não é um apêndice independente do referido processo e exerce um papel específico em relação ao conjunto de componentes que integram o ensino como um todo. 
Segundo Afonso (2007), a problemática teórica da avaliação em educação pode ser analisada partindo de olhares acadêmicos e enfoques muito distintos. Podemos, por exemplo, convocar os contributos da filosofa, da psicologia, da pedagogia, das teorias do currículo, da administração e gestão, da história, da antropologia, da política ou da sociologia, para compreender a avaliação. Trata-se por tanto, de um objeto aberto a diferentes abordagens, sejam elas mais circunscritas a fronteiras específicas ou, então, mas articuladas ou interdisciplinares.

O termo avaliação é muito diversa. A consulta ao significado de avaliação, avaliar e avaliador em dicionários mostra as diferentes acepções do termo. Assim Ferreira (1986) mostra que avaliação é o "ato ou efeito de avaliar (se), apreciação, análise. Valor determinado pelos avaliadores" e avaliar significa "apreciar ou estimar o merecimento. Determinar a valia ou valor, calcular, estimar” e avaliador é “..aquele que avalia”.

Segundo Hadji (1994: 27-28), “Avaliar pode significar, entre outras coisas: verificar, julgar, estimar, situar, representar, determinar, dar um conselho...(...) a pluralidade dos verbos que designam o ato de avaliar está acompanhada de uma multiplicidade de termos que designam o objeto deste ato, que pode incidir sobre saberes, saber-fazer, competências, produções, trabalhos...". A multiplicidade de designações confirma a polissemia do termo. Uma outra definição é proposta por De Ketele \& Roegiers (1999: 45), segundo a qual "avaliar significa «confrontar um conjunto de informações com um conjunto de critérios (referencial)»”. Há dois conceitos básicos que deverão estruturar e organizar qualquer avaliação: o conceito de referente, ou seja, o "conjunto das normas ou critérios que servem de grelha de leitura do objeto a avaliar", e o conceito de referido, que designa "aquilo que desse objeto será registrado através desta leitura" (Hadji, 1994: 31). O processo de avaliação pode ser visto em duas fases interligadas. Em primeiro lugar, deve estabelecer-se uma articulação entre o referido e o referente, "visto que avaliar consiste em atribuir um «valor» a uma situação real à luz de uma situação desejada, ao confrontar assim o campo da realidade concreta com o das expectativas" (op.cit.: 1994: 32); em segundo lugar, deve estabelecer-se uma articulação "entre o referido e o referente, e as «realidades» de que eles constituem um modelo reduzido. (...) O referente é um modelo ideal que articula as intenções consideradas significativas a partir de um 
ou de uma pluralidade de projetos. O referido é constituído pelo conjunto dos observáveis julgados representativos do objeto «lido»" (ibidem).

A avaliação é produção de sentidos, prática social, portanto, intersubjetiva, relacional, aberta, polissêmica e carregada de valores. Deve articular em um processo global e compreensivo os diversos aspectos constitutivos da educação, como os sentidos e valores da cognição, da autonomia moral, da vida social e pública e do conhecimento, que desenvolve a sociedade e eleva o espírito humano. Deve construir os campos sociais de discussão e valoração a respeito dos processos, contextos, produtos, objetivos, procedimentos, estruturas, causalidades, metas de superação, condições de produção das atividades educativas, sentidos e impactos na formação dos cidadãos e na construção da sociedade democrática (Dias Sobrinho, 2008p 193-4).

Consideramos importante estabelecer o desenho de uma proposta de avaliação do processo de ensino-aprendizagem, considerando ademais os aspectos afetivos nas práticas de avaliação (estudo das atitudes). Desta forma nos encontramos com diferentes pesquisas que falam dos problemas dos alunos com a estadística na universidade (ver Cazorla, I. 2002; Cordani, L.; 2002) sendo muitas vezes problemas que podem se dever a fatores pessoais de caráter cognitivos e afetivo, como é dito por Cazorla et al (2009) e também como é mencionado por Aparicio e Bazán (2006, 2007) e Aparicio, A. (2006), os aspectos afetivos, como a atitude do aluno de estatística na aula pode influenciar os aprendizagens e na forma como ele obtém resultados de seus avaliações e ao mesmo tempo a atitude do professor pode também influenciar.

A disciplinas de Estatística estão presentes nos currículos na maioria dos estudos universitários, fruto do papel importante concedida a ela $\mathrm{n}$ a formação técnica e científica para os profissionais de perfil muito variado. Como resultado, milhares de alunos nos programas de licenciatura e de especialidades não matemáticas tomam a disciplina de Estatística, tanto no nível de graduação como de pós-graduação. No entanto, a falta de um adequado logro acadêmico nesta área, é um tema recorrente que os professores e pesquisadores estão se manifestando nos mais diversos contextos culturais. E também de modo repetido tese informado das reações emocionais, atitudes e crenças negativas frente 
à Estatísticas nos alunos com pouco de interesse nesta área e uma formação quantitativa previa limitada (Blanco, 2004).

Como em outras áreas da pesquisa educacional, no ámbito estatístico tem sido justificada a necessidade de prestar atenção às atitudes dos alunos principalmente por considerar que elas têm uma influência importante nos processos de ensino e aprendizagem e no desempenho acadêmico imediato. Além disso, também podem ser olhadas como um resultado da formação (como variável de produto), constituindo um componente essencial da bagagem com que, ao termino dos processos formativos, estará enfrentando o desempenho de futuras atividades e tarefas acadêmicas e profissionais (Auzmendi, 1991;) Gal e Ginsburg, 1994, Gal, Ginsburg e Schau, 1997).

Consideramos que a avaliação deve ser holística (analisando os diversos 'intervenientes' no processo de ensino-aprendizagem), deve ter em conta as diferentes perspectivas e interpretações dois diversos participantes, devendo, também, contribuir a análise da própria avaliação nos participantes do processo de ensino e aprendizagem. É fundamental que a avaliação assuma uma vertente crítica e reflexiva da própria ação, a fim de analisar e melhorar essa mesma ação. Por isso achamos necessário que o professor tenha em conta as perspectivas alternativas e diferentes interpretações dos outros participantes do processo de ensino aprendizagem, a traves da avaliação na aula de Estatística, considerando não só aspectos metodológicos, informativos ou cognitivos si não também os aspectos pessoais e afetivos como são as atitudes.

Apesar da importância assinalada, é de conhecimento geral as dificuldades reportadas na aula de estatística, é conhecido que a avaliação do processo de ensino-aprendizagem ${ }^{1}$ e a preparação dos atores educativos constitui um dos âmbitos relativamente menos dinâmico e menos estudados desse processo. Assim Artiles, Mendoza e Yera (2008) indicam que "As grandes transformações parecem ir pela via dos objetivos, pelos métodos de ensino e pela estruturação dos conteúdos, não estando presente, em ocasiões, a relação que se estabelece entre eles e o componente avaliativo como partes inseparáveis de um mesmo processo: ensino aprendizagem".

\footnotetext{
1 A avaliações como a das instituições educativas, as avaliações docentes, a avaliação, do currículo entre outras.
} 
Nosso trabalho estuda as práticas de avaliação e as atitudes frente a Estatística a traves de diferentes publicações feitas por nós que abordam estes temas. Os capítulos que conformam nosso trabalho está desenhado por um formato de artigo, já que na maioria deles foram publicados e submetidos durante o período do doutorado.

O primeiro capítulo do trabalho inicia-se com uma proposta metodológica baseados em o enfoque ontosemiotico do conhecimento e a instrução matemática (Godino et al. 2008). Este primeiro artigo serve-nos como referente quando tentamos seguir o tema da avaliação. A proposta adaptada do enfoque propõe o estudo da avaliação através das práticas de avaliação incluindo a todos os participantes deste processo, como instituição de ensino, participantes na sala de aula, participantes da Comunidade, participantes da política educativa e à sociedade em geral. O diagnóstico das práticas de avaliação se faz através dos significados institucionais (focado na instituição interna e externa) e através dos significados pessoais, incluído aqui a parte afetiva (focado nos participantes ao interior da instituição educativo), neste último significado podemos incluir à avaliação das atitudes para a disciplina de estatística.

No segundo capítulo, contextualizamos sobre os trabalhos realizados sobre o tema das atitudes em frente à estatística e sobre as definições realizadas por diferentes autores.

No terceiro capítulo apresentamos um antecedente de um estudo transcultural comparativo das atitudes em frente a estatística entre um grupo de professores espanhóis e peruanos, realizada pela autora desta tese, e onde se faz uso de uma das escalas selecionadas para o estudo comparativo das atitudes em frente a estatística em grupo de estudantes universitários de Peru, Chile, Colômbia e Brasil que será apresentado no capítulo seis.

Antes de apresentar o estudo das atitudes em frente à estatística com os países mencionados, creimos que séria importante ver o panorama da profissão de estatístico e da avaliação da educação superior ao interior destes países.

Assim, no quarto capítulo, tratamos de aproximar-nos mais detalhadamente em a avaliação que se faz dos cursos de graduación e posgraduación no Brasil e em especial em São Paulo. 
Se opta por apresentar um estudo mais detalhado de Brasil, por ser este país onde há uma melhor sistematização da avaliação institucional da educação superior.

A seguir no quinto capítulo apresentamos um panorama mais geral da profissão de estatística e das maneiras de avaliação institucional nos demais países: Peru, Chile e Colômbia.

No sexto capítulo entramos em o tema principal, a traves de quatro estudos independentes a respeito da atitude em frente à estatística em grupos de estudantes universitários de diferentes especialidades de Peru, Chile, Colômbia e Brasil. Onde se faz um estudo psicométrico das escalas usadas para o estudo e das características descritivas e achados encontrados ao interior dos grupos com respeito à atitude frente à estatística.

No sétimo capitulo resumimos os resultados achados no capítulo anterior e fazemos um estudo integrado com uma amostra grande conformada por todos os participantes.

Finalmente no oitavo capitulo tratamos de reflexionar e propor alcances sobre o estudo realizado.

Nossos objetivos de estudo serão as seguintes:

1. Propor um marco de referência teórico para o diagnóstico das práticas de avaliação do processo de ensino-aprendizagem a través de uma metodologia para caracterizar os significados institucionais e pessoais a respeito da avaliação considerando o modelo EOS: referencial, pretendido, avaliado e implementado para o significado institucional e global, declarado e valorado para o significado pessoal.

2. Apresentar a avaliação institucional dos cursos de Estatística desenvolvidas pelo governo federal a traves ENADE na graduação e da Trienal-CAPES para a pós graduação 
3. Descrever os sistemas de avaliação no curso de Estatística nos países integrantes deste estúdio: Peru, Chile y Colômbia

4. Como parte da avaliação pessoal, estudar e propor uma escala de atitudes frente a Estatística desenvolvida em populações não estatísticas em diferentes países da América Latina como Brasil, Peru, Chile e Colômbia assim como aplicar dita escala para alunos da graduação em Estatística.

5. Refletir ao respeito dos resultados encontrados e desenhar uma proposta complementaria de avaliação do processo de ensino-aprendizagem em Estatística de uma instituição superior a nível institucional quanto a nível pessoal.

O trabalho estará organizado em oito capítulos, estes como já foi dito são a maneira de artigos:

Capítulo I:

"Proposta Metodologica das práticas de avaliação: significados institucionais e significados pessoais"

Capítulo II:

"Atitudes frente à Estatística: aprendizagem e aprendizagem e avaliação"

Capítulo III.

"Proposta de uma escala de atitudes frente à Estatística para professores"

Capítulo IV.

"Uma primeira aproximação na avaliação dos cursos de graduaçã e pós graduação em Estatística em universidades de São Paulo"

Capítulo V.

"Panorama geral da avaliação e do curso de Estatística em Peru, Chile e Colômbia"

Capítulo VI. Atitudes frente à Estatística em poblacões não estatísticas em quatro países latinoaericanos:

"Atitudes frente à Estatística em universitários peruanos de médiana idade"

"Atitudes frente à Estatística em universitários da área das ciências de uma universidade pública de Chile" 
"Atitudes frente à Estatística em estudantes universitários de una universidade privada em Colombia"

“Atitude frente à Estatística em universitários de uma universidade federal de Brasil "

Capítulo VII.

"Comparação integrada: Peru-Chile-Colombia e Brasil : Atitudes frente à Estatística de alunos iniciantes na graduação "

\section{Capítulo VIII.}

Reflexões finais 


\title{
CAPITULO I.
}

Neste capítulo tratasse de contextualizar as práticas de avaliação a partir do modelo do Enfoque Ontosemiotico do conhecimento matemático (EOS) de Godino et al (2008) e fazer uma proposta diagnósticas destas praticas através dos significados institucionais e pessoais e dos participantes no processo de avaliação.

\section{PROPOSTA METODOLOGICA DAS PRÁTICAS DE AVALIAÇÃO: SIGNIFICADOS INSTITUCIONAIS E SIGNIFICADOS PESSOAIS}

\begin{abstract}
Resumo
Neste trabalho fazemos uma proposta metodológica, baseados no enfoque ontosemiótico da instrução matemática (Godino et al 2007), para caracterizar as práticas de avaliação a través dos significados institucionais e pessoais, considerando aos atores do processo educativo.
\end{abstract}

Propomos ferramentas de avaliação ad hoc baseados na metodologia proposta e a elaboração de uma estratégia de abordagem que permita diagnosticar a avaliação do processo de ensino-aprendizagem em uma instituição educativa, considerando os instrumentos de avaliação e identificando as inconsistências entre os significados institucionais e pessoais através das práticas de avaliação.

Palavras-chave: Práticas de avaliação, Enfoque ontosemiótico, significados institucionais e pessoais.

\footnotetext{
${ }^{2}$ Baseado em Aparicio, Bazán e Abdounur (2013b). "Marco conceptual para el estudio de las practicas de evaluación en una institución educativa desde a teoría del EOS”, artigo aceito En Blanco \& Negro (2013) Vol. 4 Nº1. Pontificia Universidad Católica de Perú.
} 


\section{Introdução}

A avaliação é uma parte importante na melhora contínua do processo do ensinoaprendizagem em que os atores educacionais estão envolvidos e é uma parte inerente do trabalho das instituições de ensino, das quais é parte (Artiles et al 2008; Gonzáles, 2011).

No entanto, sabe-se que a avaliação tem na frente uma série de dificuldades devido à presença de concepções e práticas explícitas e implícitas bastante assentadas que fazem dela um instrumento de controle e não de formação.

Outras deficiências próprias da avaliação se dão em relação aos seus conteúdos, formas, fontes, agentes de avaliação; concepções reducionistas relativas ao objeto da avaliação e à existência de diferentes modelos de avaliação centradas quase exclusivamente em critérios de aplicação de cada professor. (Artiles et al 2008).

Como é referenciado por Gonzáles (2011), se nos centramos no estudo da avaliação desde a perspectiva da atividade humana e concretamente das práticas associadas com este processo considerando que cada componente deve ser tratado em sua inter-relação com um sistema maior.

Assim, tratamos de estabelecer uma proposta de avaliação a partir das principais características de como é que se desenvolve a avaliação do ensino aprendizagem (objeto de estudo) caracterizada por seu sistema de práticas e dos significados institucionais e pessoais associados a elas considerando aos atores deste processo avaliativo.

As noções de sistemas de práticas, significado pessoal, significado institucional e objeto de estudo, são tomadas e adaptadas do Enfoque Ontosemiótico do conhecimento e a instrução matemática (EOS) (Godino, Batanero, Font, 2007; 2008; Godino e Font, 2007). O EOS, é uma teoria integradora da didática da matemática no processo de elaboração, parte da noção primitiva de resolução de problemas matemáticos e considera um conjunto de noções (sistemas de práticas, configuração de objetos e processos, configuração 
didática, dimensão normativa, idoneidade didática) que permitem um nível de análise dos processos de ensino e aprendizagem de temas específicos da matemática.

Com referência específica nas noções dos significados sistêmicos do EOS, vamos a fazer um processo de adaptação, considerando a avaliação do ensino - aprendizagem como objeto de estudo ou interesse.

Quando nos referimos a avaliação como objeto de estudo, o sistema de práticas de avaliação se refere a critérios, processos, técnicas, ações e respostas definidas a nível institucional, que é uma referenca para avaliar as aprendizages dos alunos participantes destas práticas definidas institucionalmente, bem como a forma como esses significados institucionais são avaliados como significados pessoais pelos atores do processo de avaliação desde a perspectiva do ensino. Deste modo, reconhecemos o caráter discursivo, associado ao institucional, e o operativo associado ao pessoal, de qualquer prática.

A avaliação do processo ensino-aprendizagem centra-se em professores e alunos e é diferente de outras avaliações, tais como das instituições de ensino, avaliações docentes, avaliação de currículo, entre outras, as quais não são abordadas neste estudo.

\subsection{Conceptualização das práticas de avaliação}

\subsubsection{Conceito de sistemas de práticas de avaliação}

Segundo Artiles (2008), “quando a palavra avaliação é ouvida rapidamente, percebemos que é uma expressão polissêmica: poder ser interpretada como qualificação, medição, comparação, controle, análise, avaliação, apreciação, julgamento. Assim como tambem sao muitas suas possíveis consequências: classificar, selecionar, supervisionar, orientar e regular".

Esta polissemia também se estende a suas especificações, critérios, abordagens, procedimentos, momentos e instrumentos e mesmo quando a avaliação é um elemento comum em qualquer prática de ensino, como podese obsevar, existem várias definições e além disso, muito variaram, também, as formas de implementá-las. 
Temos que considerar que quando avaliamos os aprendizagems dos alumnos estamos tambem avaliando, quierasse ou nao o ensinado por nós. Como é falado por Artiles (2008), "avaliação nunca é, estritamente falando, avaliar o ensino e a aprendizagem, mas em vez disso, é avaliar o processo de ensino e aprendizagem. A avaliação das experiências de aprendizagem feitas pelos alunos dá ao professor ou tutor informações insubstituíveis para ajustar progressivamente a ajuda que esta le proporciona durante o processo".

Assim desde uma perspectiva diagnostica é mais apropriado estudar as práticas de avaliação antes que a avaliação em si, para reconhecê-la como uma atividade humana com os significados associadas a ela.

Para exemplificar a definição de prática, podemos citar a Godino e Fontes (2007), que dão uma concepção desde o enfoque EOS: no estudo da matemática, em vez de uma prática específica ante um problema concreto, interessa considerar os sistemas de práticas (operacionais e discursivas) feitas pelas pessoas em sua atuacao frente a tipos de situações problemáticas.

Em consequência, nos referiremos as práticas de avaliação a toda atuação o expressão (verbal, simbólica, gráfica, etc.) feita pelos atores do processo avaliativo para resolver situações problema o atividades de avaliação, comunicar aos outros a solução obtida o sua resposta, geralizandola a outros contextos, problemas o tarefas.

\subsubsection{Significados institucionais e pessoais de nas práticas de avaliação}

Podemos entender uma "instituição" como aquela formada de pessoas comprometidas nua mesma classe de situações problemáticas. O compromisso mutuo com a mesma problemática leva à realização de umas práticas sociais que tem características particulares e são geralmente condicionadas pelos instrumentos disponíveis, regras e formas de funcionamento (Godino et al, 2008).

Neste contexto, as práticas de avaliação podem ser copartilhadas no seio de uma instituição o podem ser idiossincrásicas de uma pessoa o conjunto de pessoas. Que te como resultante a manifestação de diferentes significados a nível institucional e a nível pessoal. 
A nível institucional, vamos a referirnos às práticas de avaliação compartilhadas, concordadas explicitamente ou implicitamente pelos diferentes atores no processo de avaliação. Por exemplo, uma prática de avaliação institucional é o uso de perguntas de escolha múltipla para avaliações na área de matemática acordados entre os diferentes atores do processo de avaliação que prticipam a nível institucional como os planejadores e coordenadores de áreas acadêmicas.

No nível pessoal, fazemos referença as práticas de avaliação idiossincráticas, próprias dos atores do processo avaliativo que tem uma relação mais direta com o ensino-aprendizagem, como são os professores e alunos. Por exemplo, uma prática de avaliação de um professor no nivel pessoal é o estilo ou estratégia que este utiliza e ensina para responder a perguntas de escolha múltipla.

\section{Significado Institucional}

No âmbito do EOS (Godino, et al 2008), os significados institucionais podem ser referencial, pretendido, implementado e avaliado (ou obtido). Por outro lado, significados pessoais podem ser global, declarado e atingido. Estes significados institucionais são inclusivos, isso significa, por exemplo, que o significado institucional obtido é uma parte do significado institucional implementado e este do pretendido e este último do referencial.

Numa instituição de ensino, o significado institucional referencial faz alusão dum significado holístico das práticas de avaliação, por exemplo, ao sistema de práticas acerca da avaliação definido pelos responsáveis do currículo. Este tipo de significado holístico requer, como e sinalado por Godino y Font (2007), fazer um estudo históricoepistemológico sobre a origem e evolução do objeto em questão, assim como considerar a diversidade de contextos de uso onde se coloca em jogo o referido objeto.

O significado institucional pretendido faz alusão ao sistema de práticas de avaliação definidos pelas áreas acadêmicas, incluídas no planejamento do processo de estudo.

O significado institucional implementado é o sistema de práticas de avaliação feitas pelos professores na sala de aula. 
O significado institucional avaliado faz alusão aos subsistemas de práticas de avaliação que usa o professor para avaliar a aprendizagem e é subceptible de ser analisado. Isso porque não todas as práticas de avaliação são avaliáveis.

Um resumo destes significados institucionais quando consideramos como objeto de estudo as práticas de avaliação adaptando do EOS aparece na seguinte tabela:

Tabela 1. Significados institucionais sobre a avaliação da adaptação do EOS

\begin{tabular}{ll}
\hline Significado & \multicolumn{1}{c}{ Descrição } \\
\hline Referencial & $\begin{array}{l}\text { É o significado que é usado como uma referência para elaborar o significado } \\
\text { pretendido. }\end{array}$ \\
$\begin{array}{l}\text { Pretendido } \\
\text { Implementado }\end{array}$ & $\begin{array}{l}\text { É o significado incluído no planejamento dos processo de estudo. } \\
\text { Em um processo de estudo específico é o significado pretendido efetivamente } \\
\text { implementado pelo professor }\end{array}$ \\
$\begin{array}{l}\text { Avaliado ou } \\
\text { obtido }\end{array}$ & \multicolumn{1}{c}{ Sao utilizadas pelo professor para avaliar a aprendizagem. } \\
\hline
\end{tabular}

\section{Significado Pessoal}

Os significados pessoais podem ser manifestos de forma explícita e/ou implícita. Estes significados pessoais podem ser classificados em: global, declarado e atingido (Godino et al, 2008). O significado atingido será renomeado como significado valorado, por nós e diante.

O significado pessoal global, é a totalidade do sistema de práticas de avaliação manifestas pelos participantes deste processo.

O significado pessoal declarado da conta das práticas de avaliação expressadas, considerando a aplicação de instrumentos de valoração nos diferentes participantes.

O significado pessoal valorado se refere as práticas de avaliação que são conformes com as pautas estabelecidas pela instituição. Isso também inclui as análises dos câmbios nos significados pessoais que tem lugar num processo de estudo quando se comparam os significados iniciais dos participantes com os que finalmente obtenham.

Um resumo destes significados pessoais, quando consideramos como objeto de estudo as práticas de avaliação, aparece na seguinte tabela: 
Tabela 2. Significados pessoais sobre a avaliação da adaptação do EOS

\begin{tabular}{ll}
\hline Significado & Descrição \\
\hline Global & $\begin{array}{l}\text { Corresponde à totalidade do sistema de práticas que é capaz de manifestar potencialmente o ator } \\
\text { (es) no processo de avaliação. }\end{array}$ \\
Declarado & $\begin{array}{l}\text { Dá conta das práticas efetivamente expressadas através dos instrumentos de avaliação aplicados } \\
\text { para analisar a conformidade com os significados institucionais, incluindo-se tanto as corretas }\end{array}$ \\
& $\begin{array}{l}\text { quanto as incorretas. } \\
\text { Corresponde ao significado pessoal (práticas manifestas) declarado que são coherentes com os } \\
\text { significados institucionais. }\end{array}$ \\
\hline Fonte: basado en Godino et al (2008)
\end{tabular}

\subsection{3 "Fundo ecológico" das práticas de avaliação}

Como é especificado em Godino et al 2008, "a parte central da Figura 1 indicam as relações dialéticas entre o ensino e aprendizagem, que supoe a ligacao progressiva entre os significados institucionais e pessoais. O ensino envolve também a participação do aluno na comunidade de práticas que incluem os significados institucionais; e o Aprendizagem, finalmente, envolve a apropriação dos alunos destes significados ". Essa dinâmica é mostrada na seguinte figura.

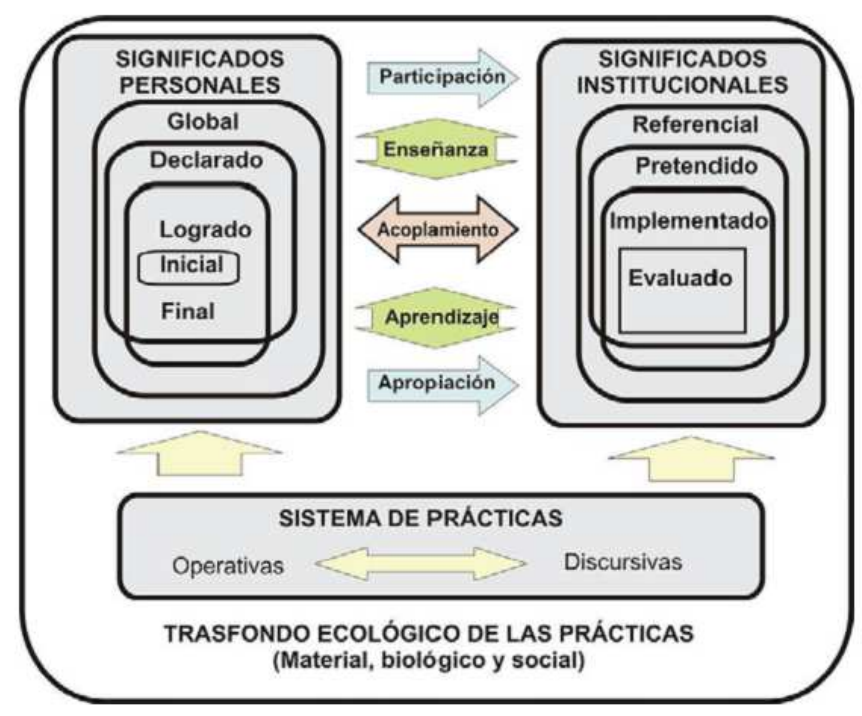

Figura 1. Significados institucionais e pessoais (Godino et al, 2008)

Nesta figura, também e introduzido o conceito de "Fundo ecológico das práticas", a qual faz referência de maneira implicita que as práticas sao feitas com o apoio e o condicionamento de um conjunto de elementos e fatores materiais, biológicos e sócioculturais que a tornam possível, para reforrzar ou limitar o desenvolvimento da atividade 
de avaliação. Este sistema de elementos, de maneira semelhante à proposta por Godino et al (2008), pode ser descrito como o "fundo ecológico das práticas de avaliação".

Um primeiro resultado a nível conceptual refere se à adaptação do modelo EOS às práticas de avaliação concretas para uma instituição educativa. Com base nesta abordagem, adaptamos uma proposta metodologica com o estabelecimento das relações dialéticas e significados associados com as práticas de avaliação baseada na proposta de Godino et al (2008) , que é resumida na sigunte figura:

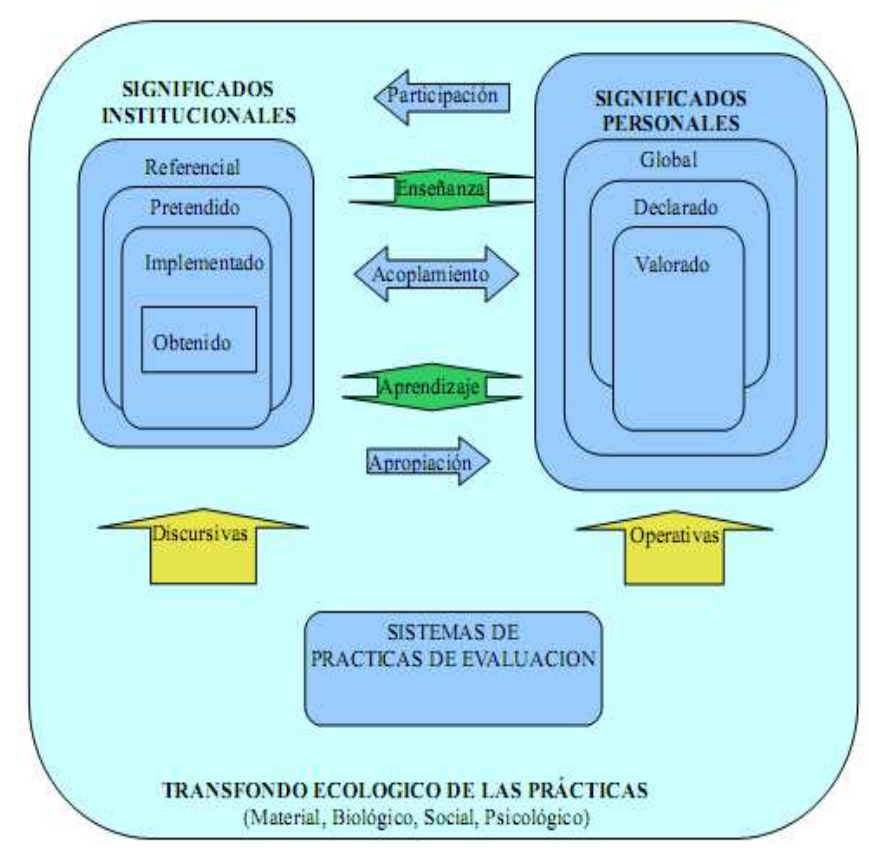

Figura 2. Relações dialéticas e significados associados às práticas de avaliação

Em resumo, obter informação dos significados pessoais e institucionais em relação as práticas de avaliação nos permite valorar o próprio processo de ensino-aprendizagem, assim como, a ligação que se estabelece entre estes significados. Por exemplo, é possível identificar a intervenção dos participantes do processo avaliativo em relação à comunidade de práticas onde são definidos os significados institucionais acerca da avaliação e também é possível estabelecer a apropriação que poder ter os participantes do processo avaliativo em relação aos significados institucionais. 


\subsubsection{Participantes do processo avaliativo}

Há diferentes participantes (ou atores) do processo educativo que podem ser distinguidas em cada instituição de ensino, como atores de sala de aula (professores e alunos), atores da escola (diretores, coordenadores, planejadores, professores, entre outros), participantes da Comunidade (pais, associações, grupos, entre outros), atores de política (promotores, supervisores, autoridades ou gestores educacionais onde a instituição é parte), sociedade em geral (comunicadores sociaisjornalistas, financiadores, funcionários e gerentes associados do esporte, saúde, segurança, entre outros).

Não entanto, no caso de avaliação, este grupo de atores é restringible a um número menor, considerando as práticas de avaliação em que estes participam.

Para compreender quais atores intervem na avaliação do processo de ensino-aprendizagem temos que dierenciar que a avaliação pode ser olhada em dois níveis: a nível de sistema $e$ ao nível da sala de aula. A avaliação do ensino-aprendizagem a nível de sistema é de caráter diagnóstico e muitas vezes servem como avaliação de políticas de educação no processo e fornece informações úteis para tomar decisões que melhorem o sistema de ensino, seja em um âmbito local, municipal, regional ou nacional.

Por outro lado, a avaliação do processo de ensino e de aprendizagem ao nível da sala de aula, os professores avaliam aos alunos, às vezes com o objetivo de conhecer o que aprenderam e quais são suas dificuldades, processar uma forma a apoiá-los na sua aprendizagem, ou com a finalidade de dar-lhes uma classificação, por exemplo, terminando com uma decisão sobre a qual os alunos passam o curso ou não. Os atores no processo de avaliação são diferentes em cada caso.

A Nivel de Sistema, que é a forma mais adequada para um diagnóstico inicial em uma instituição de ensino específico, são atores intervenientes no processo de avaliação por exemplo os professores, alunos, mas também os responsáveis pelo currículo, planejadores, tutores, coordenadores, entre outros, ou seja, as diferentes pessoas que tem a ver com o processo de avaliação implementado na sala de aula. 


\subsubsection{Avaliação do processo de ensino aprendizagem através do diagnóstico das práticas de avaliação}

O processo de ensino-aprendizagem é um processo único em que os participantes nele cumprem diferentes roles.

Por exemplo, o aluno participa da comunidade de práticas e se apropria dos significados institucionais, assim como professor. Mas o aluno tem o rol de aprender e o professor a de ensinar, e embora esses papéis são perfeitamente intercambiáveis em muitas situações, o rol reflete o principal objetivo que eles devem seguir quando se ensina e quando se aprende.

Desta maneira esperamos estabelecer alguns significados pessoais com os alunos e alguns significados institucionais com os professores a partir da análise das práticas de avaliação. No entanto, a partir da perspectiva do estudo das práticas de avaliação que transcendem a sala de aula, o professor pode também ter a função de fornecer seus significados pessoais sobre a avaliação, permitindo nos identificar os significados pessoais declarados e valorados por esses professores em relação ao institucionalmente estabelecida.

Outros participantes do processo de avaliação, fora de professores e alunos, como os designers de currículo, planejadores de atividades, coordenadores podem fornecer informações sobre as práticas de avaliação institucional.

As manifestações das práticas incluem "práticas eficazmente expressadas" que são aquelas em que o estudante faz representações verbais, simbólicas, gráficas, etc, chamadas de ostensivas na abordagem EOS e "práticas no expressadas", que são denominadas pelo EOS como representações não ostensivos.

\subsubsection{Níveis de avaliação nos significados no diagnóstico das práticas de avaliação}

Para fazer o análise dos significados nas práticas de avaliação as representações pessoais dos atores no processo de avaliação podem ocorrer em três níveis: (Jáuregui et al 2003, Pozo 1997, 1998):

Superficiais ou de resposta: formado por um conjunto de predições, sentenças, interpretações, ações e verbalizações que o indivíduo faz sobre situações que afronta. São respostas elaboradas são ad hoc frente a necessidades contextuais específicas. Eles 
respondem as características representacionais dose modelos mentais. É um nível mais acessível, consciente, explícito ou imediato e tem um caráter situacional.

Teorias de domínio: São um conjunto de diferentes representações que os indivíduos ativam em diferentes contextos que pertencem a um domínio ou área de conhecimento. Fornecer as características invariantes dos modelos mentais situacionais, mas eles são menos conscientes e explícitas e mais estáveis do que estas. Elas são inferidas das ações, expressões ou predições do nível anterior.

Teorias implícitas: são representações mentais, constituídas por um conjunto de restrições no processamento da informação que determinam na forma de um sistema operacional, a seleção da informação que é processada e as relações entre os elementos dessa informação. Tem uma carater mais geral e estáveil do que as teorias de domínio.

\subsubsection{Definições do âmbito do diagnóstico}

Baseandonos no marco conceptual desenvolvido, se pretende fazer um diagnóstico da avaliação do processo ensino-aprendizagem, Considerando que será um diagnóstico das práticas de avaliação e dos significados associados a estas práticas.

Um diagnóstico inicial das práticas de avaliação é uma referência para um diagnóstico futuro. Isto faz possível-por exemplo, que podamos fazer um processo de estudo das mudanças nesses significados quando definimos um novo currículo, porque supõe que um cur crículo determina um novo sistema de práticas de avaliação e, portanto, pode ser contrastado o diagnóstico inicial das práticas de avaliação.

Numa primeira aproximação diagnostica das práticas de avaliação é melhor enfocar-se nos significados institucionais pretendido e implementado, e no significado pessoal declarado.

Resumindo, podemos propor que o estudo das práticas de avaliação, por exemplo, sej feito primeiro a nível do significado institucional pretendido e implementado que vai estar em correspondência com o significado pessoal declarado e com algumas evidências do significado pessoal valorado. Isto é melhor observado na Figura 3. 

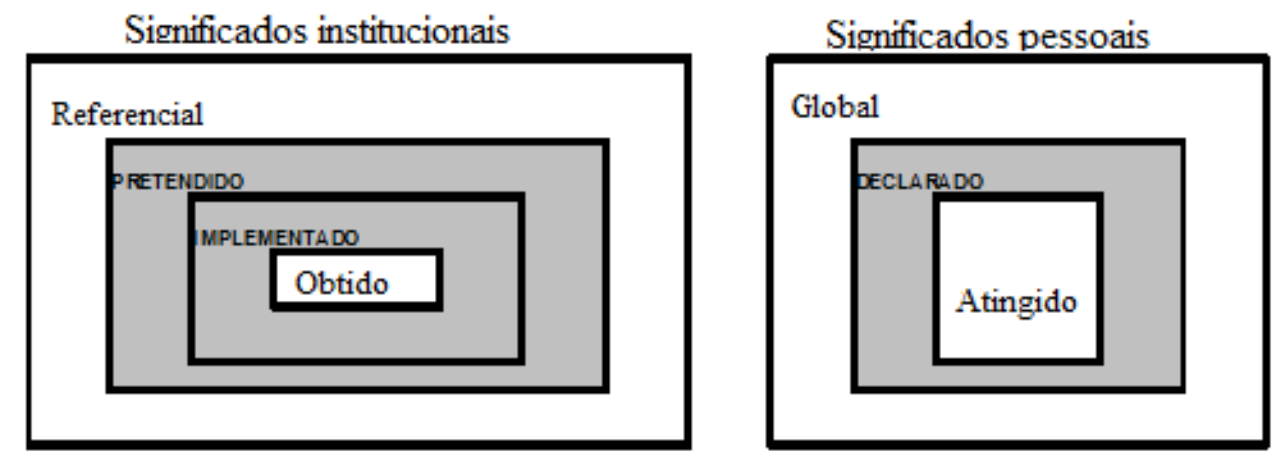

Figura 3. Significados pessoais e institucionais das práticas de avaliação, propostas para o primeiro estudo diagnóstico.

Por outro lado temos que precisar que as práticas de avaliação de interesse neste diagnóstico são ideológicas, atuativas, estilísticas e instrumentais.

\subsection{Caracterizando as práticas de avaliação}

\subsubsection{Dimensões das práticas de avaliação}

Agrupamos as práticas de avaliação de interesse em quatro dimensões:

Práticas ideológicas referem-se às práticas de avaliação definidos no âmbito de uma abordagem específica para a concepção de avaliação ou a especificação de um quadro teórico específico. Responde às perguntas: o que é avaliação? Por que avaliar?, o que é avaliado?.

Práticas atuativas referem-se as práticas de avaliação definidos pelos atores ou as funções que estes cumplem. Ele responde à questão de quem avalia?. Assim pode ser considerados coevaluativas, auto avaliativa e heteroevaluativas.

Práticas estilísticas referem-se aos diferentes estilos de práticas de avaliação consideradas. Responde à pergunta cómo se evalua?. Aqui, pode-se considerar os seguintes estilos que emergem de diferentes aspectos do processo de avaliação (ver quadro 3).

Práticas instrumentais referem-se aos modos específicos de como se desenvolvem os estilos de práticas de avaliação, que incluem procedimentos, técnicas, instrumentos, forma de qualificação, os tipos de relatórios e a utilização e divulgação dos resultados, entre outros. Ele responde a pergunta que é usado para avaliar?. 


\subsubsection{Estilos de práticas de avaliação}

Os estilos de práticas de avaliação podem ser agrupadas em diferentes estilos, de acordo com os aspectos do processo de avaliação. Isso podemos observarli na siguente tabela:

Tabela 3. Estilos de práticas de avaliação, de acordo com os aspectos do processo de avaliação

\begin{tabular}{ll}
\hline Aspectos do processo de avaliação & Estilos \\
\hline Pelo sistema de personalidade avaliado & Cognitivo / afetivo / Conativa \\
Pelo desenvolvimento da aprendizagem & Processo/resultado ou produto \\
Pelo desenvolvimento do ensino & Compreensiva / sumativa, \\
Pelos participantes da avaliação & Indivíduo/coletivo \\
Pela interpretação dos resultados & Criterial e regulamentares \\
Pelo tipo de dados & Quantitativos/qualitativos \\
Pelo momento da avaliação & No momento / diferido ou uso doméstico \\
Coleta de dados & Oral / escrita \\
Pelo formato de escrita & Objetivo / ensaio, \\
Pela duração & Velocidade/tempo \\
Pela frequência & Semanal, quinzenal, mensal, etc. \\
\hline
\end{tabular}

\subsubsection{Definição de estratégias para analisar os significados das práticas de avaliação no ambito diagnóstico}

Tanto a dimensão das práticas estilisticas como e instrumentais são bastante úteis, por si só, mas também pode ser útil para visualizar a informação cruzada de ambas. Portanto, presentamos a continuacao uma tabela de dupla entrada onde especificamos as duas dimensões: estilística e instrumental, com o objetivo de avaliar as práticas de avaliação em uma instituição de ensino. Neste caso torna-se uma ferramenta ou lista de verificação que pode ser usado para identificar as práticas de avaliação de acordo com as dimensões propostas.

Como exemplo, consideremos o caso de um curso de Estatística para alunos de Estudos Gerais de alguma universidade. A ideia de usar o instrumento é identificar quais são os procedimentos, técnicas. Instrumentos, formas de avaliação, tipos de relatórios, utilização e difusão dos resultados são feitas para cada estilo de avaliação dentro de cada aspecto. Considere, por exemplo, o estilo cognitivo de acordo ao sistema de personalidade avaliada. Neste caso, quando presente, será necessário descrever os procedimentos utilizados para a avaliação deste estilo, as técnicas e instrumentos utilizados, as formas de classificação utilizados pelos professores, o tipo de relatório que é entregue ao aluno e à utilização e difusão dos resultados para a comunidade acadêmica. Esta descrição deve ser feita para 
cada um dos estilos nos diferentes aspectos. Assim, este material poder ser uma fonte de diagnóstico para tomar decisões sobre o que está ausente, que está saturado e que é bem estruturada, formando assim um diagnóstico das práticas de avaliação para o processo ensino e aprendizagem. Informação que pode ser útil para os diferentes participantes do processo de avaliação.

A continuação apresentamos algumas estratégias que podem ser implementadas em uma instituição de ensino superior:

Tabela 4. Estratégias para analisar os significados das práticas de avaliação centrada nos professores que estão relacionados com o processo de ensino-aprendizagem

\begin{tabular}{|c|c|c|c|c|}
\hline \multirow{2}{*}{$\begin{array}{lr}\text { Dimensões } & \text { das } \\
\text { práticas } & \text { de } \\
\text { avaliação } & \end{array}$} & \multicolumn{4}{|c|}{ Significados pessoais e institucionais } \\
\hline & $\begin{array}{l}\text { Significado } \\
\text { institucional } \\
\text { Pretendido }\end{array}$ & $\begin{array}{l}\text { Significado } \\
\text { institucional } \\
\text { Implementado }\end{array}$ & $\begin{array}{l}\text { Significado } \\
\text { Declarado }\end{array}$ & $\begin{array}{l}\text { Significado } \\
\text { Pessoal Valorado }\end{array}$ \\
\hline $\begin{array}{l}\text { Ideológicas } \\
\text { Atuativas } \\
\text { Estilísticas } \\
\text { Instrumentais }\end{array}$ & $\begin{array}{l}\text { Revisão de } \\
\text { documentos } \\
\text { institucionais } \\
\text { Entrevistas e } \\
\text { questionários para } \\
\text { os responsáveis do } \\
\text { currículo focado no } \\
\text { professor }\end{array}$ & $\begin{array}{l}\text { Revisão de documentos } \\
\text { do professor e materiais } \\
\text { de ensino e avaliação } \\
\text { Entrevista com os } \\
\text { coordenadores focado } \\
\text { no professor }\end{array}$ & $\begin{array}{l}\text { Entrevistas e aplicação } \\
\text { de questionários e } \\
\text { inquéritos para os } \\
\text { professores/alunos. } \\
\text { Documentos sobre o } \\
\text { professor }\end{array}$ & $\begin{array}{l}\text { Testes ou } \\
\text { avaliações } \\
\text { aos professores } \\
\text { /alunos } \\
\text { materiais de ensino } \\
\text { e avaliações e } \\
\text { Analise de } \\
\text { conformidade }\end{array}$ \\
\hline
\end{tabular}

\subsection{Comentários finais}

A qualidade das instituições de ensino e, especialmente, o processo de ensinoaprendizagem é uma preocupação permanente da sociedade civil, governos, professores, pais e os próprios alunos. Assim, predominam diferentes processos diagnósticos de avaliação e mensuração do desempenho educacional. Sendo essas avaliações externas à instituição e, poucas veces úteis para caracterizar como a comunidade educativa de uma instituição particular faz as avaliações.

A avaliação é uma atividade que faz parte concomitante do processo educativo, no entanto, é uma parte na que se faz menor ênfase no diagnóstico. Neste trabalho, consideramos que é importante ter um diagnóstico desse processo a partir das práticas de avaliação de seus participantes. 
Nossa posição quer por ênfase no estudo da avaliação como atividade humana e, portanto, é importante contextualizar lha com a introdução de conceitos tomadas da teoria da educação matemática do EOS (Godino et al, 2008), mas adaptado para avaliação como um objeto de estudo e não como um objeto matemático.

Assim, na seção, uma conceituação sobre a avaliação do processo de ensino-aprendizagem, apresentamos cinco noções importantes sobre a avaliação do ensino-aprendizagem: conceito de práticas de avaliação, significado institucional e significado pessoal, "fundo ecológico" das práticas de avaliação, os participantes do processo de avaliação, e a avaliação do processo de ensino-aprendizagem através do diagnóstico das práticas de avaliação.

A importância deste marco, é que ele vai desenvolver um contexto apropriado para o diagnóstico das práticas de avaliação em um número ilimitado de situações. Por exemplo, podemos estar interessados em um diagnóstico das práticas avaliativas de uma disciplina de estatística para não estatísticos em uma universidade, ou podemos estar interessados nas práticas de avaliação global da especialidade de estatísticas para estatística (em diferentes disciplinas) ou ambos podem comparar entre várias instituições, países etc.

Na seção Caracterização das práticas de avaliação propomos as dimensões das práticas de avaliação e caracterizamos os estilos destas práticas. A partir dessa caracterização e, especialmente, na Tabela 4, podemos estabelecer uma lista exaustiva de caráter diagnóstico, que poderá identificar como são especificamente as práticas de avaliação no curso de Estatística numa instituição universitária determina.

Finalmente, acreditamos que o marco apresentado tem como finalidade contextualizar teórica e metodologicamente o diagnóstico para uma análise das práticas de avaliação no processo de ensino-aprendizagem através dos participantes deste processo identificando as inconsistências entre os significados institucionais e pessoais e entre estes atores quando se faz a avaliação. 


\title{
CAPITULO II.
}

Neste capítulo apresentamos um marco conceptual para definir as atitudes frente à Estatística e apresentamos alguns trabalhos desenvolvidos com professores de escola e estudantes universitários.

\section{ATITUDES FRENTE A ESTATISTICA: APRENDIZAGEM E AVALIAÇÃo³}

\begin{abstract}
Resumo
Atualmente, a presença da Estatística na vida das pessoas é notória, e hoje a Estatística pode ser considerada como uma ciência multidisciplinar com aplicabilidade em praticamente todas as aéreas do saber (Aparicio, 2006).

No presente artigo fazemos uma resenha dos diferentes trabalhos empíricos que temos vindo realizando na área de atitudes para a Estatística com amostras de universitários e professores, através da utilização e adaptação das escalas de Estrada et al (2003) e Cazorla et al (1999). Se faz ainda, uma breve revisão teórica sobre os aspectos afetivos e a atitude e sua importância na aprendizagem da Estatística.
\end{abstract}

Palavras-chave: afetividade, atitudes frente à a estatística, aprendizagem

\subsection{Afetividade e aprendizagem}

A afetividade, sempre aparece ligada à educação e o papel do educador é considerado importante e tem muita relação com questões da afetividade, embora não é uma tarefa fácil tratar de dar uma definição única. A definição sempre está acompanhada de outros conceitos como são os aspectos cognitivos e ambientais.

Existe uma grande divergência quanto à conceituação dos fenômenos afetivos. Na literatura encontra-se, eventualmente, a utilização dos termos afeto, emoção e sentimento, aparentemente como sinônimos. Entretanto, na maioria das vezes, o termo emoção encontra-se relacionado ao componente biológico do comportamento humano, referindose a uma agitação, uma reação de ordem física. Já a afetividade é utilizada com uma significação mais ampla, referindo-se às vivências dos indivíduos e às formas de expressão mais complexas e essencialmente humanas.

\footnotetext{
${ }^{3}$ Baseado em Aparicio, A. (2012). Afectividad y aprendizaje: estudios sobre actitud en Estadística. Memorias II Encuentro Internacional de Meta-Matemáticas. Universidad Sergio Bernales. Colombia.
} 
Para Wallon (1986), as emoções têm papel preponderante no desenvolvimento da pessoa. É por meio delas que o aluno exterioriza seus desejos e suas vontades. Em geral são manifestações que expressam um universo importante e perceptível, mas pouco estimulado pelos modelos tradicionais de ensino. A emoção causa impacto no outro e tende a se propagar no meio social e afetividade é um dos principais elementos do desenvolvimento humano. Vygotsky (1991) mencionam que um dos principais defeitos da psicologia tradicional é a separação entre os aspectos intelectuais, de um lado, e os volitivos e afetivos, de outro, propondo a consideração da unidade entre esses processos. Coloca que o pensamento tem sua origem na esfera da motivação, a qual inclui inclinações, necessidades, interesses, impulsos, afeto e emoção. Nesta esfera estaria a razão última do pensamento e, assim, uma compreensão completa do pensamento humano só é possível quando se compreende sua base afetivo volitiva.

Piaget (1980), preocupado com os níveis de complexidade do conhecimento na relação sujeito-objeto, trabalha com o sujeito da consciência, que constrói conhecimentos por meio de sua ação sobre o meio físico na interação com outras pessoas. Desse ponto de vista, o sujeito que aprende está diretamente vinculado ao outro, e é aqui que se situa a linguagem, o social e a cultura. Assim, todo aprendizado esta infundida de afetividade, já que acontece a partir de interações sociais em um processo que não é puramente cognitivo. Existe uma base afetiva permeando essas relações.

Em educação matemática, Mc Leod (1989) define o afeto ou domínio afetivo da seguinte maneira: "um extenso conjunto de sentimentos e humores (estado de ânimo) que são geralmente considerados como algo diferente da pura cognição".

Considera como descritores específicos deste domínio, as crenças, as atitudes e emoções. Em geral a relação entre domínio afetivo (crenças, as atitudes e emoções) e aprendizagem, não vai num único sentido, já que os afetos condicionam o comportamento e a capacidade de aprender e reciprocamente o processo de aprendizagem provoca reações afetivas. Como é observado na seguinte figura: 


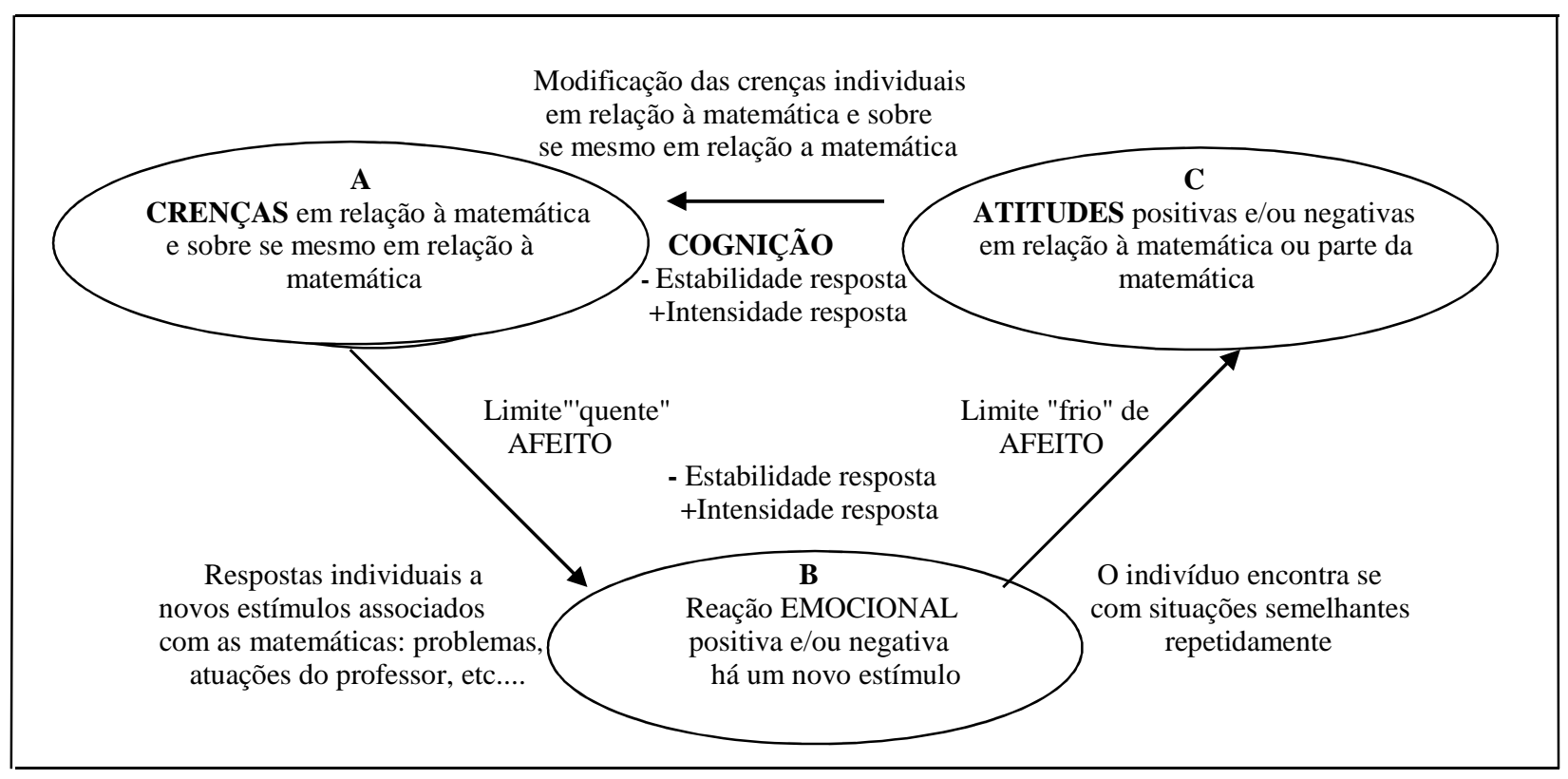

Figura 4. Descritores específicos do domínio afetivo em Matemática (Gómez, 2000)

Outro modelo para explicar o domínio afetivo é representado pela DeBellis \& Goldin (2006), que incluem um quarto componente que é o valor. Eles estavam interessados além de interação afeto-cognição nas estruturas afetivas, por si só, introduzindo a ideia-chave do meta-afeto.

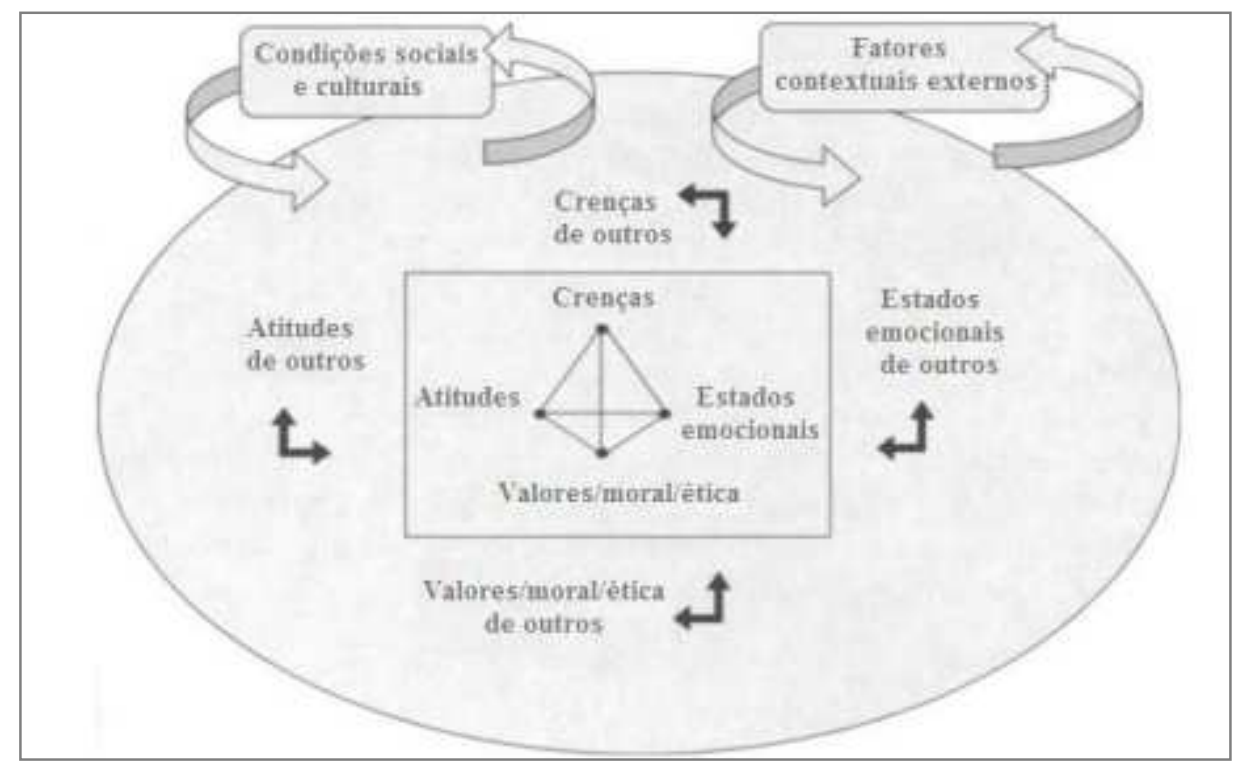

Figura 5. Modelo tetraédrico para describir el dominio afectivo DeBellis \& Goldin (2006)

Segundo Chacón (2000), a relação estabelecida entre afetos, emoções, atitudes e crenças, e aprendizagem é cíclica: por um lado, a experiência que o aluno tem quando aprendeu 
matemática provoca nele reações diferentes que podem influenciar a formação de suas crenças. Por outro lado, as crenças que tem o sujeito, têm um impacto direto sobre o seu comportamento em situações de aprendizagem e na sua capacidade de aprender.

O estudante, por exemplo, diante de uma situação de aprendizagem tem uma reação positiva ou negativa, de acordo com suas crenças acerca de si mesmo e da disciplina. Se a situação se repete muitas vezes, produzindo-se o mesmo tipo de reação afetiva (frustração, satisfação, etc), esta pode converter-se numa atitude. Essas atitudes geradas influem nas crenças e contribuem na sua formação. Esses sentimentos se desenvolvem lentamente e os fatores culturais desempenham um papel importante, são estáveis e resistentes às mudanças e têm um componente cognitiva importante e outro emocional.

\subsection{Atitude frente à estatística}

Uma atitude é uma predisposição aprendida para responder coerentemente de maneira favorável ou desfavorável frente a um objeto, ser vivo, atividade, conceito, pessoa ou seus símbolos (Fishbein e Ajzen, 1975; Oskamp, 1991). Assim, a atitude é uma predisposição frente a um objeto ou uma pessoa é e expressada em alguns casos na conduta, mas adquirida pelo conhecimento prévio sobre esse objeto ou pessoa.

Mcleod e Adams (1989) definem a ansiedade como um componente emocional, sentida na presença do objeto, no momento da experiência com esse, durando alguns segundos, minutos ou no máximo horas. Essas experiências emocionais que vão se acumulando em relação a um mesmo objeto podem desenvolver atitudes em relação ao mesmo. As atitudes são menos intensas que as emoções, porém mais duradouras. Segundo Ragazzi (1976), atitude é a prontidão de uma pessoa para responder a determinado objeto de maneira favorável ou desfavorável. Brito (1996) define atitude como uma disposição pessoal, idiossincrática, presente em todos os indivíduos, dirigida a objetos, eventos ou pessoas, que assume diferente direção e intensidade de acordo com as experiências do indivíduo Segundo Nunally (1978) citado por Morales (2006) a atitude é uma predisposição aprendida, não inata e estável, mas pode ser cambiar ou reagir de uma maneira valorativa, favorável ou desfavorável, frente de um objeto (indivíduos, grupos, ideias, situações, professores, alunos, etc). As atitudes têm os seguintes componentes: cognitivos, afetivos e 
comportamentais. O componente cognitivo é alimentado através das crenças e percepções. O componente afetivo são sentimentos a favor ou contra um objeto e o componente comportamental é a reação de uma determinada maneira frente aos a objetos.

As pessoas podem mostrar atitudes em maior ou menor intensidade de acordo com a assimilação que eles têm com específico objeto. De certa forma é um processo gradual e progressivo que começa com o conhecimento a través das percepções e crenças, esse conhecimento provoca sentimentos que, de acordo com sua intensidade, causam reações positivas ou negativas ao objeto em discussão. Uma coisa interessante sobre a medição das atitudes é que marcam uma tendência, apesar de ainda não ter havido efeitos na conduta, é possível encontrar os sintomas antes de uma reação, ou encontrar sinais conscientes ou inconscientes sobre as preferências de um determinado objeto (Vasquez, 2002).

Para McLeod (1992) indica que as atitudes são respostas positivas ou negativas, produzidas durante o processo da aprendizagem. As atitudes são respostas relativamente mais estáveis , ou sentimentos mais intensos que são formados pela repetição de respostas emocionais ao longo do tempo. A atitude desenvolve estes sentimentos lentamente e os fatores ambientais desempenham um papel importante. Sendo assim, mais estáveis e resistentes às mudanças.

Gal et al. (1997) define a atitude como a soma de emoções e sentimentos que experimentase durante o período do aprendizado da disciplina objeto de estudo. São bastante estáveis, de intensidade moderada e com um componente cognitivo menor que os sentimentos ou crenças. Sempre se expressam positiva ou negativamente e podem representar sentimentos vinculados externamente à disciplina (professor, atividade, livro, etc).

De acordo com Bazán (2008), as atitudes são sempre expressadas positiva ou negativamente e podem representar sentimentos ligados externamente à disciplina (professor, atividade, livro, etc), mas não se restringem ao afetivo, mas envolvem pensamentos, avaliações, valorações e disposições à ação que fazem parte de outros componentes da personalidade. Como é resumido na seguinte figura: 


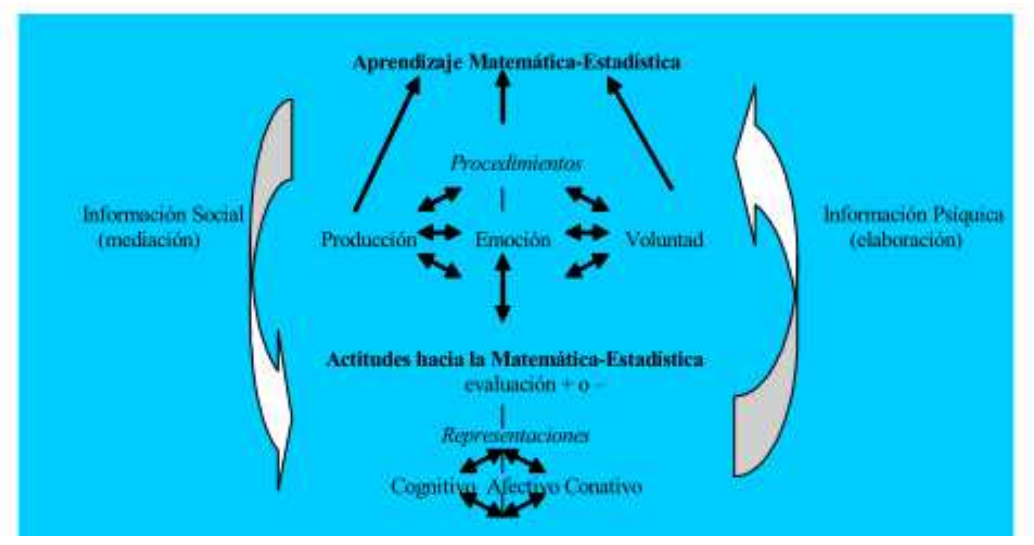

Figura 6. Atitudes frente à Matemática-Estatística num modelo de aprendizagem

(Bazán e Aparicio, 2007)

Assim, embora as atitudes tenham uma forte carga emocional, estas vão ser internalizadas como positivas ou negativas de acordo com o que o sujeito senta (considerando o componente afetivo), pense (considerando o componente cognitivo) e ideologize (considerando-se o componente de conativo) sobre o objeto (Bazán e Aparicio, 2007).

O estudo das atitudes por serem condutas mais estáveis ao longo do tempo e podem ser trabalhadas, servem como uma ferramenta importante, muitas vezes, uma atitude negativa (tanto do professor quanto o aluno) pode atrapalhar o aprendizado de Estatísticas, e influenciar em outras pessoas de uma forma negativa. E mesmo que uma atitude positiva não garante um melhor desempenho, aumenta a probabilidade de que isso aconteça e pode melhorar a aprendizagem de conceitos e habilidades.

É importante avaliar as atitudes dos alunos antes de iniciar um processo de formação, e isso significa também conhecer os instrumentos (válido e confiável) medida mais adequados a cada contexto e permitem identificar os fatores que interferem com a definição de atitudes.

\subsection{As atitudes e a aprendizagem da estatística na universidade: Alguns estudos feitos}

Podemos considerar 2 tipos de aproximações para classificar os instrumentos de avaliação das atitudes: o que a pessoa reporta e pelo tipo de resposta solicitado. Exemplo do primeiro são as entrevistas e questionários e do segundo as escalas. 


\subsubsection{Instrumentos de avaliação: Escalas $^{4}$}

Em geral, os instrumentos mais frequentemente usados na avaliação das atitudes são as escalas de atitudes. A continuação mostramos características das diversas escalas para avaliar as atitudes frente à Estatística, disponíveis na literatura internacional.

Características descritivas das escalas utilizadas na avaliação de atitudes em relação à estatística

\begin{tabular}{|c|c|c|c|c|c|}
\hline Escalas & Autores & $\begin{array}{l}\text { Nro de } \\
\text { itens }\end{array}$ & $\begin{array}{c}\text { Nro de } \\
\text { alternativas }\end{array}$ & Idioma & Dimensão \\
\hline SAS & Robert e Bilderback (1980) & 33 & 5 & Inglês & Não indicada \\
\hline ATS & Wise (1985) & 29 & 5 & Inglês & $\begin{array}{l}\text { Bidimensional: disciplina e } \\
\text { aplicação à área de atuação }\end{array}$ \\
\hline SASc & McCall et al.(1990) & 20 & 5 & Inglês & Unidimensional \\
\hline EAEA & Auzmentdi (1992) & 25 & 5 & Espanhol & $\begin{array}{c}\text { Multidimensional: utilidade, } \\
\text { ansiedade, confiança, agrado, } \\
\text { motivação }\end{array}$ \\
\hline SATS & Schau et al (1995) & 28 & 7 & Inglês & $\begin{array}{l}\text { Multidimensional: Afetividade, } \\
\text { competência, cognitiva, valor, } \\
\text { dificuldade para aprender }\end{array}$ \\
\hline EAEC & Cazorla et al (1999) & 20 & 4 & Português & $\begin{array}{l}\text { Bidimensional: afetivo, autovalor } \\
\text { Multidimensional: Afetiva, }\end{array}$ \\
\hline EAEE & Estrada et al (2001) & 25 & 5 & Espanhol & $\begin{array}{l}\text { perceptiva, comportamental, } \\
\text { social, educativa, instrumental }\end{array}$ \\
\hline SATSes & Estrada (2002) & 28 & 5 & Espanhol & $\begin{array}{l}\text { Multidimensional: Afetividade, } \\
\text { competência, cognitiva, valor, } \\
\text { dificuldade para aprender }\end{array}$ \\
\hline & & 45 & 5 & & \\
\hline EAEC/EAEE & Aparicio y Bazán (2006) & & & Espanhol & Unidimensional \\
\hline EARE & $\begin{array}{l}\text { Estrada, Bazán, Aparicio } \\
\text { (2010) }\end{array}$ & 22 & 5 & Espanhol & $\begin{array}{l}\text { Multidimensional: Afetiva, } \\
\text { perceptiva, comportamental, } \\
\text { social, educativa, instrumental }\end{array}$ \\
\hline
\end{tabular}

Figura 7. Escalas de atitudes frente a Estatística.

Fonte Aparicio (2006)

\subsubsection{Estudos prévios sobre as atitudes frente a estatística}

Faremos uma revisão de trabalhos empíricos feitos por nós últimos anos em relação as atitudes frente a Estatística com estudantes universitários e professores de escola.

\footnotetext{
${ }^{4}$ Pode revisar se Aparicio, Ana (2006). "Aspectos afetivos na aprendizagem da estatística: atitudes e suas formas de avaliação". Tesis de Mestrado. Universidade de São Paulo
} 
Aparicio, A.; Bazán, J.L.; Abdounur, O. (2004). “Atitude e desempenho em relação à estatística em professores de ensino fundamental no Peru: primeiros resultados". VII EPEM: Encuentro Paulista de Educación Matemática.

Se apresentaram os resultados da aplicação de duas escalas de atitudes frente à Estatística (Cazorla et al. 1.999, Estrada et al., 2003) e sua relação com o desempenho na disciplina da Estatística. A amostra foi de 44 professores com um desenho pré-teste e pós-teste. Encontra-se um cambio significativo na atitude e adequada confiabilidade.

Aparicio, A.; Bazán, J.L. (2006).“Actitud y rendimiento en Estadística en profesores peruanos”. Acta Latinoamericana de Matemática Educativa. Clame2005.

Se pesquisa a relação entre atitude e desempenho em Estatística de 87 professores peruanos através de um desenho pré teste e pós teste. As escalas apresentaram uma correlação significativa $(\mathrm{r}$ pré teste $=0.76, \mathrm{p}<0.01$; e $\mathrm{r}$ pós teste $=0.73, \mathrm{p}<0.01)$ e confiabilidades ótimas.

Estrada, A. ; Batanero, C.; Bazán, J.L.; Aparicio A. (2009). “As atitudes frente à estatística em professores: Um estudo comparativo de países". XIX Encontro de Investigação em Educação Matemática, Vila Real Portugal.

Comparam-se as atitudes frente à Estatística em 140 professores espanhóis e peruanos de ensino fundamental. Os resultados indicaram que as atitudes são diferentes considerando uma medida geral. A atitude frente à a estatística foi positiva em ambos países, embora que estas são mais positivas entre os professores espanhóis.

Estrada, A.; Bazán J.L.; Aparicio, A. (2010). "A cross-cultural psychometric evaluation of the attitude toward statistic scale Estrada's in the teachets". ICOTS-8. International conference on teaching statistic. Slovenia

São analisadas as propriedades psicométricas da escala de atitudes frente à estatística propostos por Estrada et al (2003). A escala foi aplicada a 288 professores em exercício e em formação, 140 da Espanha e 148 do Peru.

A análise de itens foi realizada a partir de uma perspectiva clássica e utilizando o modelo de escala de Rating (Andrich, 1978).

Os resultados indicaram que a escala é confiável e apresenta evidencia de multidimensionalidade, a versão final foi de 22 itens. 


\subsection{Comentários finais}

A partir de um rápido marco teórico queremos refletir sobre a importância da relação entre o afetivo (aqui representado por atitudes) e a aprendizagem da Estatísticas, considerando que as atitudes devem ter uma definição integrado que inclui os diferentes níveis da atividade humana, incluso ser considerada como parte da avaliação. Ressaltamos a importância de um adequado trabalho psicometrico dos instrumentos de avaliação (escalas), pois isso irá permitir-nos resultados confiáveis, válidos e adaptados para o contexto em que eles são usados. 


\title{
CAPITULO III. ANTECEDENTES
}

Neste capitulo fazemos um estudo psicométrico de uma escala de atitudes frente à Estatística em grupos de professores em exercício de dois países diferentes, comparando as atitudes e procedendo a adaptar um instrumento confiável e valido para professores, que pode ser usado em outras amostras diferentes. Este capitulo introduz o tema do estudo comparativo entre países em relação as atitudes a estatística.

\section{PROPOSTA DE UMA ESCALA DE ATITUDES FRENTE À ESTATÍSTICA PARA PROFESORES 5}

\begin{abstract}
Resumo
Neste estudo analisa-se as principais características psicométricas da Escala de Atitudes em relação à Estatística (EAEE) proposta por Estrada (2002). A amostra foi composta por 288 professores em exercício e formação, 140 de Espanha e 148 de Peru. A análise de itens realizou-se desde uma perspectiva clássica e usando o modelo da escala de rating (Andrich, 1978). Os resultados indicam que três itens não atingiram um comportamento satisfatório nos diferentes critérios considerados. A avaliação da dimensionalidade e confiabilidade indica que a escala resultante, composta por 22 itens, é confiável e apresenta evidências de multidimensionalidade.

Este estudo é um exemplo de avaliação psicométrica transcultural, que tem sido associada recentemente a uma estratégia de validade transcultural, e que usando a comparação entre países responde à pergunta de se um instrumento de avaliação é "o mesmo" em diferentes culturas. Isto é, se a medida tem o mesmo significado nos diferentes países baixo consideração. Seguindo esta ideia e para responder à necessidade proposta, em nossa investigação analisa-se psicometricamente a escala de Atitudes frente à Estatística de Estrada (2002) desde esta perspectiva transcultural, avaliando o comportamento psicométrico dos itens em uma amostra conjunta de professores em exercício e formação de Espanha e Peru.
\end{abstract}

Palavras chave: Escala, Atitudes em relação à Estatística, análise de itens, dimensionalidade, confiabilidade.

\footnotetext{
5 Baseado en Estrada, Bazán y Aparicio (2013c). Evaluación de las propiedades psicométricas de una escala de actitudes hacia la estadística en profesores. AIEM. Avances de Investigación en Educación Matemática - 2032, № 3, $5-23$
} 


\subsection{Introdução}

A análise das atitudes para a Estatística, em Espanha e a nível internacional, tem já uma verdadeira tradição sobretudo nas duas últimas décadas. Uma análise detalhada destas investigações prévias aparece em Estrada (2002; 2007; 2009), e é complementado por Carmona (2004) com o estudo das características psicométricas de uma série de escalas de medida de atitudes e das evidências de relação das atitudes com diferentes variáveis externas.

Em geral estas investigações orientaram-se fundamentalmente para a construção de escalas de medida de atitudes, entre as que destacamos o SAS de Roberts y Bilderback (1980), o ATS de Wise (1985) e o SATS de Schau, Stevens, Dauphine e Del Vecchio (1995), por ser as mais utilizadas. Outros trabalhos analisam a influência de diversas variáveis tais como o gênero (por exemplo, Anastasi e Urbina, 2000), o rendimento acadêmico (por exemplo, Nasser, 2004), a experiência formativa em Matemáticas e Estatística (como Elmore e Vasu, 1980, 1986; Auzmendi, 1992), a área de estudos (Gil Flores, 1999).

Dentro destes antecedentes são escassos os estudos referidos aos professores, possivelmente, porque a Estatística não é uma matéria obrigatória em sua formação. Só os trabalhos de Onwuegbuzie, (1998, 2003), Watson (2001), Nasser (2004), Lancaster (2008) e em Espanha os de Estrada e colaboradores (Estrada, 2002, 2007, Estrada, Batanero e Fortuny, 2003, 2004, Estrada e Batanero, 2008, Estrada, Batanero y Lancaster (2011) dedicam sua atenção a este coletivo estudando suas atitudes juntamente com outras variáveis.

\subsection{Metodologia}

\subsubsection{Participantes}

Um total de 288 sujeitos (140 em Espanha e 148 em Peru) de quatro especialidades (educação inicial, primária, ciências e ciências sociais) participaram no estudo, dos quais 127 eram professores em (66 em Espanha e 61 em Peru) e 161 professores em exercício em (74 Espanha e 87 em Peru). O 64,6 \% dos participantes foram mulheres. 


\subsubsection{Instrumento}

Na revisão realizada por Estrada (2002), a autora observou que todos os instrumentos disponíveis nessa data para medir as atitudes frente à a Estatística foram validados com estudantes universitários ou escolares. Por isso decidiu construir uma escala de atitudes para a estatística específica para docentes. A escala de atitudes para a Estatística de Estrada (2002), construiu-se combinando três instrumentos de medida de atitudes: Escala SAS (Statistics Attitudes Survey de Roberts e Bilderback, 1980); Escala ATS (Attitude Towards Statistics, de Wise, 1985) e a de Auzmendi (1992).

A partir das três escalas citadas, realizou-se uma seleção de itens, contemplando os diferentes componentes pedagógicos e antropológicos descritos anteriormente e, dando um peso equivalente à cada um. Os itens constam de um enunciado e uma escala de 5 pontos, que valorizam as respostas desde "muito em desacordo" (1 ponto) até "muito de acordo". Foi-se tentando incluir, tanto itens redigidos em forma afirmativa "a Estatística ajuda a entender o mundo de hoje"), como outros em forma negativa ("na escola não se teria que ensinar Estatística"). E todo isso para evitar o problema da aquiescencia (Morales, 1988), pelo que alguns sujeitos tendem a responder com a forma "de acordo" seja qual seja o conteúdo do item.

Conseguiu-se uma listagem de 36 enunciados, que se submeteram a um painel de cinco experientes que emitiram sua opinião com respeito à adequação e univocidade das sentenças, ficando após a valoração, a escala definitiva composta por 25 itens, 14 afirmativos em frente a 11 negativos, que se incluem como Anexo, tanto na versão da escala original (Estrada, 2002), como na versão adaptada utilizada com os professores peruanos (Aparicio e Bazán, 2006a). Em dito anexo observa-se que o texto dos itens 4, 9, 11, 14, 19 e 23 tem ligeiras modificações para ter em conta as diferenças linguísticas em ambos países. A distribuição segundo os componentes avaliados por cada item é a que aparece na seguinte Tabela. 
Tabela 5. Componentes das atitudes avaliadas pelos diferentes itens da escala

\begin{tabular}{lccc}
\hline Componente & \multicolumn{3}{c}{ Componente Antropológico } \\
\cline { 2 - 4 } Pedagógico & Social & Educativo & Instrumental \\
\hline Afetivo & $1,11,15$ & $7,12,23$ & $10,13,16,20$ \\
Cognitivo & $2,19,21$ & $4,6,17$ & 3,24 \\
Comportamental & 9,18 & $8,15,22$ & 5,14 \\
\hline
\end{tabular}

\subsubsection{Procedimento}

O procedimento para a aplicação dos questionários, tanto em Espanha como em Peru foi similar: No caso de professores em formação, os questionários completaram-se em forma de grupo e em forma individual (com visitas aos professores) no caso de professores em exercício. Em todos os casos se respeita o anonimato. Mais dados dos resultados em cada país podem ser encontrado em Estrada (2002), Aparicio e Bazán (2006a) e Aliaga (2009).

Dado que os itens não estão redigidos no mesmo sentido, para realizar a análise estatística todos eles têm sido codificados de modo que uma pontuação maior vá associada a uma atitude mais positiva e vice-versa. Por isso os itens 1, 6, 9, 11, 14, 15, 19 e 25 têm um enunciado desfavorável à atitude que tratamos de medir receberam uma pontuação contrária ao modo usado no resto dos itens, isto é, seguindo o seguinte critério ( 1 = muito de acordo, 2 = de acordo, 3 = indiferente, $4=$ em desacordo, $5=$ muito em desacordo).

Para obter informação sobre as propriedades psicométricas da Escala de Atitudes analisaram-se os dados obtidos com o modelo de escala graduadas do Rating Scale Model (RSM) (Andrich, 1978). RSM é um modelo empregado comumente para analisar dados de escalas tipo Likert (Smith, Rush, Fallowfield, Velikova, e Sharpe, 2008), e é um caso particular da família de modelos de Rasch, os quais descrevem a relação probabilística entre a dificuldade do j-ésimo item $\left(b_{j}\right)$ e a habilidade da i-ésima pessoa $\left(\theta_{i}\right)$.

Para a escala analisada temos $k=1, \ldots, 5$ categorias de resposta (com o critério já descrito) para a cada um dos $j=1, \ldots, 25$ itens que se aplicaram às $i=1,2, \ldots, 288$ pessoas. Em geral, para a categoria de resposta $k$, existem ombreiras derivadas, e a dificuldade da cada ombreira define-se como $\delta_{k}$. El RSM descreve a probabilidade $P_{i j k}$ de 
que uma pessoa com habilidade $\theta_{i}$ eleja uma determinada categoria de resposta com ombreira $\delta_{k}$ e dificuldade do item $b_{j}$ através da seguinte expressão:

$$
P_{i j k}=\frac{\exp \left(\theta_{i}-b_{j}-\delta_{k}\right)}{1+\exp \left(\theta_{i}-b_{j}-\delta_{k}\right)}
$$

ou expressada como logits (logaritmos de posibilidades):

$$
\ln \left(\frac{P_{i j k}}{1-P_{i j k}}\right)=\theta_{i}-b_{j}-\delta_{k}
$$

No estudo de atitudes a habilidade faz referência à atitude positiva dos examinados. A dificuldade do item refere-se ao fato de que se a a expressão do item supera a experiência real da pessoa esta exibirá uma atitude menos positiva. Finalmente a dificuldade das ombreiras das categorias de resposta indicam-nos quanto "custa" passar de uma categoria em frente a outra em qualquer item. Em variáveis ordinales assume-se que na medida que se obtém, um valor crescente na categoria de reposta (por exemplo, as pontuações de $1 \mathrm{a}$ 5) indica uma acumulação em direção a níveis mais altos de atitude, mas os avanços entre pontuações são constantes para todos os itens, sendo, portanto, adequado para ser utilizado nas escalas Likert.

Para obter informação sobre as propriedades psicométricas da Escala de Atitudes com o RSM utilizou-se o programa WINSTEPS (Wright e Linacre, 1998) a fim de estimar os parâmetros do modelo, usando a estimativa de máxima verosimilitude condicional. Para maiores detalhes pode ser consultado a Linacre (2004):

Atitude de cada enquestado: $\theta_{i}=\left(\theta_{1}, \ldots \theta_{288}\right)$

Dificuldade do item; $\mathrm{b}=\left(b_{1}, . . b_{25}\right)$

Dificuldade da categoria de resposta: $\delta=\left(\delta_{1}, \ldots \delta_{5}\right)$

\subsection{Resultados}

Para avaliar o ajuste dos itens, na Tabela 6 apresentamos os resultados da análise dos itens da escala considerando duas perspectivas: a perspectiva clássica e a perspectiva da Escala de Rating. 
Na perspectiva clássica (ver Muñiz, 2010), o que se procura é calcular a pontuação verdadeira de um indivíduo a partir de sua pontuação verdadeira e o erro que inerentemente tem a cada medida. Os índices para a análise de itens desde esta perspectiva são, para a cada um dos itens sua média, desvio padrão, a correlação item-total eliminando o item (que nos dá uma medida da capacidade de discriminação de dito item) e o coeficiente alfa de Cronbach da escala sem considerar o item, que nos proporciona uma medida da confiabilidade da escala excluído dito item.

Aplicando o modelo RSM obteve-se a estimativa dos parâmetros citados do modelo (atitudes, dificuldades de item e dificuldade de ombreiras de categorias de resposta). Adicionalmente analisou-se o ajuste ao modelo, tanto dos itens como dos participantes, pois, segundo Prieto e Delgado (2003), se não existe este ajuste, os valores dos parâmetros estimados careceriam de significado teórico.

Para isso se calcularam os seguintes indicadores: o índice de discriminação (Índice Dis), quadrado médio do estatístico de ajuste de item sensível a valores internos (Infit MNSQ) e externos (Outfit MNSQ), média padronizada do estatístico de ajuste sensível a valores internos (Infit ZSTD) e externos (Outfit ZSTD) (Para detalhes ver Linacre, 2008). 
Tabela 6. Análise de itens da versão original

\begin{tabular}{|c|c|c|c|c|c|c|c|c|c|}
\hline \multirow[b]{3}{*}{ Item } & \multicolumn{4}{|c|}{ Índices Clássicos } & \multicolumn{5}{|c|}{ Índices da escala de Rating } \\
\hline & \multirow[b]{2}{*}{ Media } & \multirow[b]{2}{*}{ D. Típica } & \multicolumn{2}{|c|}{ Se omite o item } & \multicolumn{2}{|c|}{ Infit } & \multicolumn{2}{|c|}{ Outfit } & \multirow[b]{2}{*}{ I,Dis } \\
\hline & & & $\begin{array}{l}\text { Corr. item- } \\
\text { total }\end{array}$ & Alfa & MNSQ & ZSTD & MNSQ & ZSTD & \\
\hline Item1 & 3,29 & 1,01 & 0,15 & 0,79 & 1,04 & 0,6 & 1,08 & 1 & 0,91 \\
\hline Item2 & 3,83 & 0,88 & 0,35 & 0,78 & 0,86 & $-1,7$ & 0,81 & $-2,3$ & 1 \\
\hline Item3 & 2,67 & 1,24 & $-0,16$ & $\mathbf{0 , 8 1}$ & 1,84 & 9,7 & 1,92 & 9,9 & 0,09 \\
\hline Item4 & 3,64 & 0,93 & 0,34 & 0,78 & 0,86 & $-1,8$ & 0,87 & $-1,6$ & 1,01 \\
\hline Item5 & 3,50 & 0,86 & 0,36 & 0,78 & 0,68 & $-4,7$ & 0,67 & $-4,7$ & 1,03 \\
\hline Item6 & 4,13 & 0,90 & 0,42 & 0,78 & 1,12 & 1,2 & 1,09 & 0,9 & 1,03 \\
\hline Item7 & 3,02 & 0,96 & 0,37 & 0,78 & 0,74 & $-4,1$ & 0,78 & $-3,4$ & 1,13 \\
\hline Item8 & 3,32 & 1,14 & 0,42 & 0,78 & 1,04 & 0,5 & 1,03 & 0,3 & 1,01 \\
\hline Item9 & 3,54 & 0,98 & 0,35 & 0,78 & 0,9 & $-1,3$ & 0,89 & $-1,3$ & 0,97 \\
\hline Item10 & 3,58 & 0,92 & 0,48 & 0,77 & 0,71 & $-4,1$ & 0,72 & $-3,9$ & 1,1 \\
\hline Item11 & 3,47 & 0,93 & 0,36 & 0,78 & 0,78 & $-3,1$ & 0,79 & $-2,8$ & 1,05 \\
\hline Item12 & 3,35 & 1,04 & 0,44 & 0,77 & 0,85 & $-2,2$ & 0,84 & $-2,2$ & 1,01 \\
\hline Item13 & 3,53 & 1,04 & 0,53 & 0,77 & 0,84 & $-2,2$ & 0,84 & $-2,1$ & 1,07 \\
\hline Item14 & 3,34 & 1,04 & 0,17 & 0,79 & 1,09 & 1,2 & 1,17 & 2,2 & 0,87 \\
\hline Item15 & 3,67 & 0,92 & 0,38 & 0,78 & 0,83 & $-2,2$ & 0,86 & $-1,7$ & 1,01 \\
\hline Item16 & 3,09 & 0,99 & 0,35 & 0,78 & 0,81 & $-2,9$ & 0,83 & $-2,5$ & 1,02 \\
\hline Item17 & 3,33 & 1,20 & 0,45 & 0,77 & 1,13 & 1,7 & 1,15 & 1,9 & 1,03 \\
\hline Item 18 & 3,91 & 0,96 & 0,37 & 0,78 & 1,07 & 0,8 & 1,05 & 0,5 & 1 \\
\hline Item19 & 3,44 & 1,04 & 0,19 & 0,79 & 1,13 & 1,6 & 1,23 & 2,8 & 1 \\
\hline Item20 & 3,62 & 1,10 & 0,44 & 0,77 & 1,08 & 1 & 1,12 & 1,5 & 1,03 \\
\hline Item21 & 3,57 & 1,15 & 0,14 & 0,79 & 1,47 & 5,2 & 1,55 & 5,8 & 0,97 \\
\hline Item22 & 3,48 & 1,07 & 0,44 & 0,77 & 0,96 & $-0,6$ & 0,96 & $-0,5$ & 1,1 \\
\hline Item23 & 3,30 & 1,19 & 0,06 & $\mathbf{0 , 8 0}$ & 1,51 & 6,1 & 1,6 & 6,8 & 0,76 \\
\hline Item24 & 3,72 & 0,92 & 0,43 & 0,78 & 0,81 & $-2,5$ & 0,79 & $-2,7$ & 1,04 \\
\hline Item25 & 3,81 & 0,98 & 0,40 & 0,78 & 0,99 & $-0,1$ & 0,98 & $-0,2$ & 1,04 \\
\hline
\end{tabular}

Neste caso espera-se um valor estimado de 1 , pois valores maiores que 1 indicam sobre discriminação, e valores menores que 1 baixa discriminação, ainda que a sobre discriminação seja considerada beneficiosa, tanto na análise de itens clássica, como na teoria de resposta ao item (Linacre, 2008).

Para as estatísticas de ajuste Infit e Outfit considerou-se o critério de Bond (2001) de considerar como não ajustados os itens com valores maiores a 1,3 ou menores e 0,7 respectivamente em mostras menores de 500 casos. 
Ao analisar os resultados da análise mediante o método clássico, encontramos que os itens 3, 21 e 23 apresentam correlação não significativa com o resto da escala, pois os valores por embaixo de 0,15 resultaram estatisticamente não significativos. Inclusive o item 3, "Através da Estatística pode ser manipulado a realidade" encontra-se correlacionado de maneira negativa com os demais, indicando de que se trata de um item que não mede o mesmo que o resto. Sobre a base desta evidência resulta conveniente excluir estes três itens. Considerando que resultam pouco discriminativos (correlação ponto bisserial), e também que ditos itens se saem da faixa sugerida por Bond e Fox (2001) nas estatísticas de ajuste; ademais, o item 3 também não discrimina em o RSM. Por outro lado, o item 23 apresentam uma baixa discriminação, o que indica que podem ser inapropriados para a elaboração de uma escala. Já em outros casos, como o item 5 que apresentar um Outfit relativamente baixo, ou o item 14 que apresenta baixa discriminação, consideramos que esta evidência não é suficiente para os excluir, pois o resto de parâmetros é adequado. O resto dos itens mostra estatísticas adequadas de ajuste no modelo Rating.

Considerando os resultados mostrados na Tabela 9 realizou-se uma segunda análise de itens com os dois métodos assinalados, excluindo os três itens com comportamento psicométrico inadequado. Os resultados mostram-se na Tabela 7, onde, com exceção do item 19, que mostra uma baixa correlação item total e um valor alto de Outfit Zstd, todos os itens resultam com comportamento psicométrico adequado nos dois modelos.

Ainda que há evidência de que o item 19 "A Estatística só serve para a gente de ciências" é inadequado na versão recortada, consideramos que é apropriado conservar ele na escala porque reflete um aspecto que consideramos importante conservar. Considerando estes resultados, decidiu-se conservar a escala conformada pelos 22 itens restantes.

Para completar a análise com o estudo da dimensionalidade da escala resultante, e a partir da matriz de correlações de Spearman dos 22 itens realizou-se uma análise fatorial, pois segundo Martínez-Arias (1995) a estrutura fatorial das respostas a um questionário permite, comprovar a dimensionalidade latente e interpretar os fatores em termos das dimensões supostas no mesmo. 
Tabela 7. Análise de itens da versão recortada

\begin{tabular}{|c|c|c|c|c|c|c|c|c|c|}
\hline \multirow[b]{3}{*}{ Item } & \multicolumn{4}{|c|}{ Índices Clássicos } & \multicolumn{5}{|c|}{ Índices da escala de Rating } \\
\hline & \multirow[b]{2}{*}{ Media } & \multirow[b]{2}{*}{ D. Típica } & \multicolumn{2}{|c|}{ Se omite o item } & \multicolumn{2}{|c|}{ Infit } & \multicolumn{2}{|c|}{ Outfit } & \multirow[b]{2}{*}{ I.Dis } \\
\hline & & & $\begin{array}{l}\text { Corr. item- } \\
\text { total }\end{array}$ & Alfa & MNSQ & ZSTD & MNSQ & ZSTD & \\
\hline Item1 & 3,29 & 1,01 & 0,14 & 0,83 & 1,2 & 2,5 & 1,26 & 3,1 & 0,83 \\
\hline Item2 & 3,83 & 0,88 & 0,34 & 0,82 & 0,97 & $-0,4$ & 0,92 & $-0,9$ & 0,97 \\
\hline Item4 & 3,64 & 0,93 & 0,32 & 0,82 & 0,98 & $-0,3$ & 0,99 & $-0,2$ & 0,97 \\
\hline Item5 & 3,50 & 0,86 & 0,34 & 0,82 & 0,79 & $-2,9$ & 0,79 & $-2,8$ & 0,98 \\
\hline Item6 & 4,13 & 0,90 & 0,40 & 0,82 & 1,26 & 2,4 & 1,2 & 2 & 1,02 \\
\hline Item7 & 3,02 & 0,96 & 0,34 & 0,82 & 0,87 & $-1,9$ & 1,04 & 0,5 & 0,98 \\
\hline Item8 & 3,32 & 1,14 & 0,50 & 0,81 & 1,04 & 0,5 & 1,03 & 0,4 & 1,03 \\
\hline Item9 & 3,54 & 0,98 & 0,37 & 0,82 & 0,98 & $-0,2$ & 0,95 & $-0,6$ & 0,95 \\
\hline Item10 & 3,58 & 0,92 & 0,51 & 0,81 & 0,75 & $-3,4$ & 0,78 & $-2,8$ & 1,09 \\
\hline Item11 & 3,47 & 0,93 & 0,40 & 0,82 & 0,83 & $-2,4$ & 0,84 & -2 & 1,04 \\
\hline Item 12 & 3,35 & 1,04 & 0,42 & 0,82 & 0,95 & $-0,7$ & 0,98 & $-0,2$ & 0,96 \\
\hline Item13 & 3,53 & 1,04 & 0,55 & 0,81 & 0,88 & $-1,6$ & 0,89 & $-1,3$ & 1,07 \\
\hline Item14 & 3,34 & 1,04 & 0,25 & 0,83 & 1,14 & 1,8 & 1,24 & 2,8 & 0,87 \\
\hline Item 15 & 3,67 & 0,92 & 0,33 & 0,82 & 0,97 & $-0,3$ & 1,04 & 0,5 & 0,97 \\
\hline Item16 & 3,09 & 0,99 & 0,34 & 0,82 & 0,93 & -1 & 0,98 & $-0,3$ & 0,93 \\
\hline Item 17 & 3,33 & 1,20 & 0,50 & 0,81 & 1,16 & 2,1 & 1,22 & 2,7 & 1,04 \\
\hline Item 18 & 3,91 & 0,96 & 0,41 & 0,82 & 1,14 & 1,5 & 1,11 & 1,2 & 1 \\
\hline Item19 & 3,44 & 1,04 & 0,09 & 0,83 & 1,39 & 4,5 & 1,57 & 6 & 0,88 \\
\hline Item20 & 3,62 & 1,10 & 0,52 & 0,81 & 1,09 & 1 & 1,12 & 1,4 & 1,05 \\
\hline Item 22 & 3,48 & 1,07 & 0,53 & 0,81 & 0,94 & $-0,8$ & 0,94 & $-0,8$ & 1,13 \\
\hline Item24 & 3,72 & 0,92 & 0,42 & 0,82 & 0,9 & $-1,2$ & 0,88 & $-1,5$ & 1,01 \\
\hline Item 25 & 3,81 & 0,98 & 0,41 & 0,82 & 1,09 & 1 & 1,08 & 0,9 & 1,03 \\
\hline
\end{tabular}

A extração de fatores levou-se a cabo mediante o método de componentes principais; com objeto de obter fatores estatisticamente independentes e de máxima variabilidade.

Como método de rotação se usou a rotação Varimax, método ortogonal, que conserva elogio percentagens de variância explicados pelos fatores (Afifi e Clark, 1990). Elegeramse estes métodos por ser os que menos deformam a estrutura de relações entre as variáveis. Todo isso usando o programa Systat.

Obtiveram-se um total de seis fatores com inércia superior à unidade, que em conjunto explicam o 57,27 \% da variância. Os resultados da matriz fatorial rotada e a percentagem de variância total explicado por cada fator mostram-se na Tabela 8, reordenados os itens em ordem de sua importância pela contribuição aos fatores. Como critério para nomear os 
fatores se considerou uma carga fatorial de ao menos 0.4. Dos 22 itens, 19 itens foram atribuídos aos diferentes fatores identificados de maneira unívoca, 2 itens (os itens 11 e 19) ainda que carregaram em mais de um fator foram atribuídos àquele fator onde a pontuação era mais alta (fator 4 para o item 11 e fator 3 para o item 19 respectivamente).

Finalmente, só o item 12, não apresenta nenhuma pontuação fatorial acima de $0.4 \mathrm{em}$ nenhum fator, o que indica que é um item muito específico.

Tabela 8. Pontuações fatoriais dos itens. Componentes principais e rotação VARIMAX

\begin{tabular}{|c|c|c|c|c|c|c|}
\hline & & & Fato & idos & & \\
\hline Itens & 1 & 2 & 3 & 4 & 5 & 6 \\
\hline Item 20 & 0,80 & & & & & \\
\hline Item 22 & 0,77 & & & & & \\
\hline Item18 & 0,66 & & & & & \\
\hline Item17 & 0,65 & & & & & \\
\hline Item8 & 0,64 & & & & & \\
\hline Item10 & 0,53 & & & & & \\
\hline Item4 & & 0,77 & & & & \\
\hline Item2 & & 0,71 & & & & \\
\hline Item6 & & 0,63 & & & & \\
\hline Item7 & & & 0,74 & & & \\
\hline Item16 & & & 0,69 & & & \\
\hline Item19 & & & 0,52 & & $-0,42$ & \\
\hline Item9 & & & & 0,68 & & \\
\hline Item11 & 0,42 & & & 0,59 & & \\
\hline Item 25 & & & & 0,58 & & \\
\hline Item15 & & & & 0,51 & & \\
\hline Item14 & & & & & 0,68 & \\
\hline Item1 & & & & & & 0,83 \\
\hline Item13 & 0,43 & & & & & \\
\hline Item5 & & & 0,49 & & & \\
\hline Item24 & & 0,41 & & & & \\
\hline Item12 & & & & & & \\
\hline $\begin{array}{l}\text { Percentage da } \\
\text { variância explicada }\end{array}$ & 16,69 & 10,62 & 9,10 & 8,92 & 6,22 & 5,72 \\
\hline $\begin{array}{l}\text { Porcentagem de } \\
\text { variância explicada } \\
\text { acumulada }\end{array}$ & 16,69 & 27,31 & 36,41 & 45,33 & 51,55 & 57,27 \\
\hline
\end{tabular}

Em consequência, os resultados indicam que a escala é multidimensional apresentando quatro fatores a mais de um item e dois fatores conformados por um item. O primeiro fator esta conformado pelos itens $20,22,18,17,8,10,11$, e 13 e pode ser denominado Concorrência e valoração acadêmica da Estatística, pois os itens fazem referência a aspectos da aprendizagem e exercício da Estatística. Nesse sentido, à medida que um 
sujeito presente uma concorrência e valoração acadêmica adequada espera-se que apresente uma atitude mais positiva para a Estatística.

O segundo fator esta conformado pelos itens 4, 2, 6, 24 e pode ser denominado Valoração do papel da Estatística dado que os itens referem-se à importância que tem a Estatística no mundo de hoje. Assim, à medida que um sujeito presente uma valoração positiva do papel da Estatística no mundo de hoje se espera que encontre mais exemplos de situações em que a Estatística pode e deve ser aplicado.

O fator 3 está formado pelos itens 7, 16, 19 e 5 e pode ser denominado Utilidade e gosto pessoal pela Estatística, dado que os itens fazem alusão à valoração individual, idiossincrática, em termos de uso e gosto que fazem os sujeitos da Estatística. Assim, à medida que um sujeito presente uma valoração e gosto pessoal positivo do papel da Estatística no mundo de hoje espera-se que pessoalmente faça maior uso da Estatística.

O fator 4 está formado pelos itens $9,11,25$ e 15 e pode ser denominado Disposição $e$ Entendimento da Estatística, dado que os itens fazem referência à disposição (evitamento, moléstia, intimidação) e entendimento que os professores têm em frente à Estatística. Desta maneira, à medida que um professor presente uma disposição e entendimento positivo do papel da Estatística espera-se que compreenda melhor e está mais disposto a estudar a Estatística.

O que medem os itens 14, sobre uso pessoal da estatística fora da escola, que se opõe ao 19 (sobre utilidade da estatística) no quinto fator e 6 (sobre disposição favorável ao ensino), que está isolado no sexto são aspectos de uso externo da Estatística. Por último, o item 12 não fica claramente atribuído a nenhum fator, ainda que tem um ligeiro peso nos três primeiros; poderíamos considerá-lo um item multicomponencial. Análises adicionais devem confirmar se estes itens podem ser deixados de lado. Neste trabalho nós preferimos os conservar porque conquanto eles não constituem um fator definido, também não se encontram nos quatro primeiros fatores identificados.

Finalmente na Tabela 9 apresentam-se algumas medidas descritivas e características psicométricas definitivas da pontuação da Atitude baixo o modelo clássico e baixo o 
modelo de resposta graduada. Calculam-se os valores mínimo, máximo, média e desvio típico, coeficientes de assimetria e curtoses das pontuações nos dois modelos. Também, medimos a consistência interna da escala por médio do coeficiente alfa de Cronbach, onde valores acima de 0,7 se consideram aceitáveis, entre 0,7 e 0,9 são bons, e acima de 0,9 são excelentes (ver por exemplo Nunnally e Bernstein, 1994). Adicionalmente, considerando o modelo de resposta graduada apresentam-se os índices de separação de pessoas e itens com seus correspondentes graus de confiabilidade. Os índices têm de ser maiores de 2 e a confiabilidade de 0,80 (ver Linacre, 2008).

Tabela 9. Características da escala definitiva

\begin{tabular}{lcc}
\hline & & Escore da escala de \\
& Escore Total & Rating \\
\hline Mínimo & 50 & -0.98 \\
Máximo & 103 & 2.74 \\
Media & 79.257 & 0.545 \\
D. Típica & 10.15 & 0.62 \\
Coeficiente de assimetria & -0.217 & 0.516 \\
Coeficiente de Kurtosis & -0.263 & 0.656 \\
Alfa de Cronbach & 0.826 & \\
Fiabilidade do Item & & 0.96 \\
Separação do Item & & 4.74 \\
Confiabilidade de Personas & & 0.79 \\
Separação de Personas & & 1.93 \\
\hline
\end{tabular}

Enquanto o mínimo e máximo teórico das pontuações de Atitude no modelo clássico é 22 e 110 e a média 55, nós encontramos um mínimo de 55 e um máximo de 103 com uma média de 79,3 o que indica uma atitude geral positiva nos participantes no estudo (assimetria ligeiramente negativa e distribuição platicurtica). Por outro lado, o mínimo e máximo teórico da medida da Atitude no RSM é -3 e 3 e a média 0 . Neste caso nós encontramos valores entre - 0,98 e 2,74 com uma média de 0,55 , que indica uma medida de atitude geral ligeiramente positiva e concentrada (assimetria ligeiramente positiva e distribuição leptocúrtica). Nós consideramos que a medida da Atitude baixo o modelo de resposta graduada é mais adequada. 
Também pode ser observado alta confiabilidade tanto desde a perspectiva clássica considerando o alfa de Cronbach como baixo o modelo de Rating Scale da escala de atitudes.

\subsection{Comentários finais}

Em geral os resultados sobre a escala de atitudes à estatística de Estrada (2002) em uma amostra transcultural de professores espanhóis e peruanos mostram-nos propriedades psicométricas adequadas para uma escala final de 22 itens.

A análise de itens permitiu identificar três itens com comportamento psicométrico inadequado considerando uma perspectiva de análise clássica bem como o ajuste ao modelo de Rating Scale. Assim mesmo e segundo os resultados do considerando uma análise fatorial que é de caráter exploratório, pôde ser agrupado a escala em quatro fatores principais que explicam o $45 \%$ da variância o que nos permite indicar que há evidência preliminar de multidimensionalidade da escala tal e como foi proposta em sua elaboração.

Consideramos que análises futuras, com mostras mais amplas e uma maior variedade de países, podem confirmar estes fatores. Adicionalmente os resultados também indicam que temos uma escala com confiabilidade bastante alta, considerando a perspectiva clássica e o modelo Rating Scale.

Estes resultados proporcionam-nos uma escala de atitudes para a estatística que a diferença da maioria de escalas desenhadas com estudantes permite valorizar as atitudes dos professores que ensinam a Estatística nos currículos escolares.

A escala de atitudes tem em conta unicamente as atitudes para a estatística (e não as correspondentes à docência em estatística), pelo que poderia ser utilizado com estudantes. No entanto consideramos que o estudo das atitudes nos professores pode nos dar maiores alcances para entender globalmente as dificuldades nesta matéria nos alunos, já que como é conhecido se relaciona o sucesso ou o fracasso escolar com a influência que possa transmitir o professor na sala atuando este como um fator primordial. 


\section{CAPITULO IV.}

Neste capitulo tratamos de exemplificar as práticas de avaliação institucional a traves das avaliações feitas pelo governo brasileiro nos cursos de ensino superior com o ENADE na graduação e da Trienal-CAPES par a pós graduação nos cursos de Estatística no estado de São Paulo.

\section{UMA PRIMEIRA APROXIMÃCAO NA AVALIAÇÃO DOS CURSOS DE GRADUAÇÃO E PÓS GRADUAÇÃO EM ESTATÍSTICA EM UNIVERSIDADES DE SÃO PAULO ${ }^{6}$}

\subsection{Introdução}

A partir da década de 90, o governo brasileiro iniciou um processo gradual de implementação de um sistema de avaliação do ensino superior, (Polidori et al, 2006). No ano 1993, é instituído a Avaliação Institucional das Universidades Brasileiras - PAIUB. Sustentado no princípio da adesão voluntária das universidades, concebia a auto avaliação como etapa inicial de um processo que, uma vez desencadeado, se estendia a toda a instituição e se completava com a avaliação externa (SINAES, 2003). Em 1995 com a lei 9131 que estabeleceu o Exame Nacional de Cursos (ENC), conhecido como o PROVÃO, a ser aplicado a todos os estudantes concluintes de cursos de graduação, em áreas prédefinidas pelo Ministério da Educação (Evan e Vinhaes, 2005) e em 1996 com a Lei nº 9394 foram progressivamente implementados novos mecanismos de avaliação como o Questionário sobre condições socioeconômicas do aluno e suas opiniões sobre as condições

\footnotetext{
${ }^{6}$ Baseado em Aparicio, Bazán e Abdounur (2013 $)$. "Uma primeira aproximação na avaliação dos Cursos de Graduação e Pós Graduação em Estatística em universidades de São Paulo", artigo apresentado para elaboração do libro eletrônico: "Educación Estadística en América Latina:Tendencias y Perspectivas". Universidad Central de Venezuela
} 
de ensino do curso frequentado; a Análise das Condições de Ensino (ACE); a Avaliação das Condições de Oferta (ACO); e a Avaliação Institucional dos Centros Universitário.

Desde a promulgação dessas Leis, a avaliação do ensino superior no Brasil ganhou maior destaque envolvendo muitas instituições e profissionais de diversas áreas, incluindo pesquisadores da educação. Este destaque influenciou, na época, mudanças relacionadas ao papel do ensino superior, às funções desenvolvidas pelo Estado e, também a definição do que à sociedade espera da universidade.

A avaliação vem assumindo papel extremamente importante na reforma da educação superior, principalmente no que diz respeito à "ampliação do controle por parte do Estado, bem como na implementação de princípios e parâmetros de mercado no tocante à reestruturação desse nível de ensino" (Catani et al, 2002: 99).

De acordo com Brito (2008), a avaliação, quando concebida como um processo dinâmico, pode ser usada como referencial para que as Instituições de Educação Superior disponham de evidências empíricas não apenas de suas debilidades, mas também de suas potencialidades e de suas realizações. Conhecendo e dando a conhecer os elementos que integram e interagem em cada IES, é possível transformá-la em direção às metas almejadas, organizando a instituição de modo que esta atue e forme profissionais engajados e comprometidos com uma sociedade em constante mudança.

De acordo com Schlickmann et al (2008), por conta de uma série de críticas, principalmente da comunidade acadêmica, o governo Luiz Inácio Lula da Silva propôs a substituição do ENC por um novo modelo de avaliação: o Sistema Nacional de Avaliação da Educação Superior-SINAES, instituído em 2004.

Assim, criado pela Lei $\mathrm{n}^{\circ}$ 10.861, de 14 de abril de 2004, ficou instituído o Sistema Nacional de Avaliação da Educação Superior - SINAES, com o objetivo de assegurar o processo nacional de avaliação das instituições de educação superior, dos cursos de graduação e do desempenho acadêmico de seus estudantes, nos termos do art $9^{\circ}$, VI, VIII e IX, da Lei $\mathrm{n}^{\circ}$ 9.394, de 20 de dezembro de 1996. O SINAES tem por finalidade a melhoria da qualidade da educação superior, a orientação da expansão da sua oferta, o aumento permanente da sua eficácia institucional, efetividade acadêmica e social, e especialmente, a promoção do aprofundamento dos compromissos e responsabilidades sociais das 
instituições de educação superior, por meio da valorização de sua missão pública, da promoção dos valores democráticos, do respeito à diferença e à diversidade, da afirmação da autonomia e da identidade institucional (Brasil, 2004).

A lei estabeleceu também que serão os resultados da avaliação de instituições, dos cursos e do desempenho dos estudantes que constituirão o referencial básico dos processos de regulação e supervisão da educação superior, neles compreendidos o credenciamento e a renovação de credenciamento de instituições de educação superior, a autorização, o reconhecimento e a renovação de reconhecimento de cursos de graduação e renovação de credenciamento das Instituições de Ensino Superior.

Como indicado por Brito (2008), o SINAES compreende os seguintes componentes: Avaliação Institucional; Avaliação de Curso e Avaliação do Desempenho dos estudantes ingressantes e concluintes. Este último componente é realizado através do ENADE, que é um exame em larga escala aplicado aos estudantes e avalia o rendimento dos alunos dos cursos de graduação, em relação aos conteúdos programáticos dos cursos em que estão matriculados. O exame é obrigatório para os alunos selecionados e condição indispensável para a emissão do histórico escolar. O Exame Nacional de Desempenho dos Estudantes (ENADE) é composto pela prova, o questionário de Avaliação Discente da Educação Superior (ADES) (antigo questionário socioeconômico), o questionário dos coordenadores de curso e a percepção do aluno sobre a prova.

Os processos avaliativos do SINAES são coordenados e supervisionados pela Comissão Nacional de Avaliação da Educação Superior (CONAES), sendo que nas instituições a responsabilidade é das respectivas Comissões Próprias de Avaliação - CPA. A operacionalização é de responsabilidade do Instituto Nacional de Estudos e Pesquisas Educacionais Anísio Teixeira (INEP).

Segundo Dias (2007), desde os anos de 1970, o Brasil tem desenvolvendo um forte sistema de pós-graduação (Stricto Sensu), majoritariamente público, que é o principal lugar de formação de pessoal de alto nível, investigação e formulação de políticas científicas e 
tecnológicas. $\dot{\mathrm{E}}$, seguramente, o grau educativo de mais alta qualidade no Brasil, titulando, cada ano, aproximadamente 10.000 doutores e 40.000 mestres.

O organismo central responsável de assegurar a qualidade no nível de pós-graduação é a CAPES (Coordenação de Aperfeiçoamento do Pessoal de Educação Superior). O Sistema de Avaliação da Pós Graduação foi implantado pela CAPES em 1976.

Este sistema abrange dois processos conduzidos por comissões de consultores, vinculados às instituições de ensino superior das diferentes regiões do país: a Avaliação das Propostas de Cursos Novos e a Avaliação dos Programas de Pós Graduação.

A avaliação é feita por especialistas de área do conhecimento afim ao programa considerado, cujo resultado é expresso em formato de uma nota que varia de 3 a 7 para os programas credenciados. A homologação deste resultado pelo Ministério de Educação assegura validade nacional aos títulos outorgados por programas com nota igual ou superior a três e equivale ao reconhecimento de que trata o artigo 46 da Lei de Diretrizes e Bases da Educação. Os programas que não constem desta lista não estão avaliados pela CAPES nem autorizados pelo MEC para a emissão de diplomas com validade nacional.

A Avaliação dos Programas de Pós-graduação compreende os processos de Acompanhamento Anual e de Avaliação Trienal do desempenho dos programas e cursos que integram o Sistema Nacional de pós-graduação, SNPG. O acompanhamento anual é realizado no período compreendido entre os anos de realização das avaliações trienais. Tem por objetivo o estabelecimento de um diálogo entre a CAPES e as instituições promotoras de cursos de mestrado e doutorado com vistas à orientação da atuação dos programas de forma que possam elevar a qualidade de seu desempenho e superar os problemas que eventualmente estejam enfrentando - se possível antes da Avaliação Trienal subsequente. O acompanhamento não implica na atribuição de conceitos aos programas, mas apenas na apresentação de um parecer com os comentários considerados pertinentes pela Comissão de Área, e não enseja que seus resultados sejam contestados mediante a apresentação de recursos ou pedidos de reconsideração. 
O presente trabalho, restrito ao estado de São Paulo, tem como objetivo analisar o processo de avaliação nos cursos de graduação de Estatística considerando dados obtidos do Sistema Nacional de Avaliação da Educação Superior (SINAES) através do ENADE (Exame Nacional de Desempenho de Estudantes) e da Avaliação Trienal nos cursos de pós graduação (Mestrado e Doutorado) realizada pela Coordenação de Aperfeiçoamento de Pessoal de Nível Superior (CAPES). Todos estes programas de avaliação promovidos pelo governo federal para definir políticas de financiamento e incentivos.

No presente trabalho, estamos interessados em apresentar os resultados da avaliação institucional dos cursos de Estatística no sistema universitário do Brasil, tanto na graduação quanto na pós-graduação, na perspectiva dos instrumentos criados pelo governo Brasileiro. Atualmente no Brasil, existem 37 Cursos de Graduação em Estatística: 26 em instituições federais, sete em estaduais e quatro privadas. Destes, nove têm cursos de mestrado (USP, UNICAMP, UFSCar, UFMG, UFV, UFRJ, UFPE, UNB e UFRN) e seis de doutorado (USP-São Paulo, USP-Piracicaba, UNICAMP, UFMG, UFRJ e UFSCar). Por outro lado, de acordo com Cordani (2001), no mundo acadêmico atual, praticamente todas as carreiras (exatas, biológicas ou humanas) tem em seu currículo uma disciplina introdutória de Estatística, prova de que o raciocínio estatístico e/ou probabilístico é considerado fundamental em quase todas as áreas do conhecimento. Assim, percebe-se a importância deste curso- no sistema universitário em geral.

De acordo com o portal do INEP, a avaliação Institucional é um dos componentes do Sistema Nacional de Avaliação da Educação Superior (SINAES) e está relacionada à melhoria da qualidade da educação superior; à orientação da expansão de sua oferta; ao aumento permanente da sua eficácia institucional e efetividade acadêmica e social; ao aprofundamento dos compromissos e responsabilidades sociais das instituições de educação superior, por meio da valorização de sua missão pública, da promoção dos valores democráticos, do respeito à diferença e à diversidade, da afirmação da autonomia e da identidade institucional.

Segundo Dias (1998), a avaliação institucional é hoje um dos temas de maior interesse e foco de conflitos no âmbito da educação superior. O interesse por ela não se deve somente 
a seu potencial de transformação qualitativa, de melhoramento pedagógico e de maior eficiência de gestão, como geralmente espera a comunidade acadêmica, mas também, e com crescente impacto, ela se impõe em função das exigências de regulação e de controle da educação superior por parte dos estados. E por isso que a avaliação faz parte de uma agenda internacional e ocupa um espaço de ampla importância no campo das políticas oficiais estabelecidas pelas instituições educacionais, pelos governos e por organismos internacionais de financiamento.

Para apresentar estes resultados, seguimos uma metodologia baseada na análise documental, com uma revisão de informação proporcionada em diferentes fontes bibliográficas e virtuais (Sánchez et al 2003; Chartier, 2002; Fox, 2005) referidos a avaliação institucional feita pelo governo brasileiro, dos cursos de Estatística na graduação e pós-graduação. Trata-se principalmente de um trabalho descritivo, o qual não segue um marco teórico pré-definido, porque apenas apresenta evidência empírica, que pode servir para futuros desenvolvimentos.

Para a coleta de Informação, são consideradas as listagens dos cursos de graduação em Estatística reconhecidos pelo MEC no estado de São Paulo, e pesquisamos as informações durante o mês de Maio de 2013 correspondente aos períodos 2004 a 2012.

As perguntas que nos guiam são: quais são as universidades do estado de São Paulo que têm graduação e pós-graduação em Estatística, destas, quais participaram das avaliações institucionais promovidas pelo governo brasileiro, quais resultados obtiveram nelas e qual é a informação disponível.

A importância desta análise é que, frente a outros países da América Latina, possivelmente o sistema universitário do Brasil é aquele que apresenta maior ênfase na avaliação institucional como parte da política do Estado. Assim, a divulgação destes resultados pode ajudar a constituir uma discussão sobre os cursos de Estatística nos sistemas universitários nos países latino americanos.

O artigo está organizado da seguinte maneira: Na seção um, apresentamos uma breve revisão histórica da Estatística com ênfases na sua origem no sistema universitário do 
Brasil. A seguir, na seção dois, apresentamos os cursos de graduação e pós-graduação oferecidos no Estado de São Paulo. Em seguida na seção três, apresentamos alguns resultados da avaliação na graduação em Estatística usando informação do ENADE do SINAES. Na seção quatro, são apresentados alguns resultados da avaliação na pósgraduação em Estatística usando informação da Avaliação Trienal da CAPES. Finalmente, refletimos a respeito destes resultados e sugerimos novas linhas de pesquisa.

\subsection{Uma breve história da estadística no sistema universitário do Brasil}

A seguinte seção está baseada nas publicações de história da Estatística no Brasil feita em Boletins da Associação Brasileira de Estatística disponível em http://www.redeabe.org.br/historia e do projeto pedagógico curso de bacharelado em Estatística da Universidade Federal de São Carlos disponível em http://www.ufscar.br/ des/ProPed.pdf. O propósito é apenas apresentar uma evolução histórica do curso de Estatística no Brasil.

A Estatística no Brasil tem sua história associada à história do Instituto Brasileiro de Geografia e Estatística - IBGE, cujas raízes foram fincadas ainda durante o Império. De acordo com o Calendário comemorativo dos 50 anos de sua fundação, quem primeiro coordenou e sistematizou atividades ligadas a levantamentos censitários, foi a Diretoria Geral de Estatística, criada em agosto de 1872, data do "primeiro Recenseamento Geral do Império do Brasil".

No período anterior a esta data (1750 - 1872), a Coroa Portuguesa era quem determinava levantamentos populacionais, realizados precariamente, com o objetivo maior de "conhecer a população livre e adulta apta a ser usada na defesa do território". A partir da segunda metade do século XIX, esses levantamentos passaram a ser realizados por juízes de paz e chefes de polícia dos municípios, mais com fins eleitoreiros, constituindo-se as paróquias, a base para as informações. 
Com o advento da República, a produção das estatísticas dispersou-se nas esferas Federal, Estadual e Municipal, quase impossibilitando a unificação dos resultados e dificultando as análises estatísticas.

Ainda de acordo com o Calendário, foi criado, em 1907, o Conselho Superior de Estatística, com vistas na padronização de conceitos e apuração de resultados em todo o território nacional.

Em 1934, foi criado o Instituto Nacional de Estatística, que só passou a existir de fato em 1936, mudando em 1938 para Instituto Brasileiro de Geografia e Estatística - IBGE, quando os serviços geográficos foram a ele vinculados. Foi a partir de 1940 que se iniciaram os "modernos censos" decenais, não ocorrendo apenas o de 1990 (foi adiado para 1991), devido à "falta de recursos" alegada pelo Governo Collor. Antes disso ocorreram os de 1872, 1890, 1900 e 1920.

Ainda, segundo Dantas (2002), o primeiro curso de Inferência Estatística foi ministrado em 1947, baseado no livro de Harald Cramer "Mathematical Methods of Statistics". Porém, somente em 1953 duas escolas iniciaram o ensino da ciência estatística no Brasil: a Escola Nacional de Ciências Estatísticas - ENCE, criada pelo IBGE e a Escola de Estatística da Bahia, fundada e mantida pela Fundação Visconde de Cairú (Silva, 1989).

Hoje, ele é chamado de Fundação Instituto Brasileiro de Geografia e Estatística - IBGE, sendo integrante da Administração Federal, subordinado diretamente à Secretaria de Planejamento e Coordenação Geral da Presidência da República - SEPLAN/PR, tendo seu Estatuto sido aprovado pelo Decreto número 97.434 de 05 de janeiro de 1989.

Seu principal veículo de comunicação é a Revista Brasileira de Estatística - RBEs, que a partir de 1995 passou a contar com a colaboração da Associação Brasileira de Estatística, no sentido de indicar editores para a Revista, bem como buscar bons artigos aplicados para serem submetidos à Associação.

No Brasil, a profissão de Estatístico foi reconhecida em 15/07/1965, pela Lei 4739, tendo a profissão sido organizada através do Conselho Federal de Estatística e dos Conselhos Regionais. Além da organização legal e sindical, os estatísticos estão ainda agrupados em 
Sociedades Científicas que promovem encontros, congressos e que são também encarregados da divulgação de pesquisas e resultados na área de Estatística.

Do ponto de vista acadêmico, o primeiro curso de Inferência oferecido no Brasil, ocorreu em 1947, mas, Em 1970, O Instituto de Matemática Pura e Aplicada - IMPA (Rio de Janeiro, RJ), a Universidade Estadual de Campinas e a Universidade Federal do Rio de Janeiro iniciaram a formação de grupos de pesquisa em probabilidades, constituindo-se num dos grandes passos para a criação de outros cursos nessa área.

Na Universidade de São Paulo, deu-se em 1972 a criação do Departamento de Estatística e do Curso de Bacharelado em Estatística, formando sua primeira turma em 1975. A finalidade básica do Bacharelado em Estatística era formar o profissional para atuar junto às empresas públicas e privadas, ou para prosseguir em estudos acadêmicos nos cursos de pós-graduação da área.

O ensino de Estatística, de acordo com Ribeiro et al (2010) é hoje obrigatório em quase todos os cursos das Universidades espalhadas pelo país, com pouquíssimas exceções. Além das Ciências Exatas, ela se difundiu como ferramenta para estudo e análise de objetos de pesquisa científicos nas Ciências Sociais, Humanas, Biomédicas e na área de Saúde.

Estima-se que haja entre 8.000 e 9.000 estatísticos no país. O número toma como base o Censo 2000 do Instituto Brasileiro de Geografia e Estatística (IBGE) que apontou que havia 5.300 profissionais da área no Brasil. A maior parte dos profissionais está concentrada nos estados de São Paulo e do Rio de Janeiro. Dados mais precisos do número de estatísticos atuando no Brasil poderiam ser obtidos dos Conselhos Regionais de Estatística (CONRE), no entanto esta informação estaria apenas restrita ao caso daqueles que têm graduação em Estatística. Em um estudo recente, Ara e Louzada (2012) e Louzada et al (2010) indicam que apenas o $46 \%$ dos docentes vinculados aos Departamentos de Estatística de instituições públicas de ensino com cursos de Graduação em Estatística credenciados pelo MEC, com início das atividades anterior ao ano de 2008 possui também Graduação em Estatística. No momento de apresentar nosso trabalho não nos foi possível obter uma distribuição dos estatísticos por estado ou por região, o qual daria sem dúvida uma melhor ideia do desenvolvimento dessa área no Brasil. 
O que pode ser indicado da história da Estatística apresentada é que ela está associada com o desenvolvimento do estado brasileiro e de sua necessidade de obter informação para diversas decisões de suas políticas de estado. No entanto, acreditamos que tornasse importante fazer uma avaliação institucional respeito dos cursos de Estatística públicos criados. Nesta pesquisa preliminar, é de interesse focar no estado de São Paulo.

\subsection{Curso de estadística no estado de São Paulo}

Na tabela 10 é apresentada a oferta de cursos em Estatística existentes (graduação e pósgraduação) no estado de São Paulo. Ainda é apresentado o Ranking Latino-americano 2012 para cada Universidade.

A informação foi obtida no mês de maio de 2013, dos sites do Conselho Regional de Estatística da terceira região.

http://conre3.org.br/novo_site/?q=content/institui\%C3\%A7\%C3\%B5es-de-ensino e dos Latin American University Rankings-2012. http://www.topuniversities.com/universityrankings/latin-american-university-rankings/2012. 
Tabela 10. Universidades públicas e privadas em São Paulo que oferecem atualmente o curso de Estatística na graduação e pós graduação

\begin{tabular}{|c|c|c|c|c|c|c|}
\hline Universidades & Cidade & Tipo & $\begin{array}{c}\text { Graduação } \\
\text { (Bacherelado) }\end{array}$ & Vagas* & $\begin{array}{c}\text { Pós } \\
\text { Graduação } \\
\text { (Mestrado e } \\
\text { Doutorado) }\end{array}$ & $\begin{array}{c}\text { Colocação no } \\
\text { Ranking QS } \\
\text { (Quacquarelli } \\
\text { Symonds) Latin } \\
\text { American University } \\
\text { Rankings } 2012 \\
\end{array}$ \\
\hline Universidade Estadual de Campinas (UNICAMP) & Campinas & Estadual & $\mathrm{X}$ & 70 Diurno & $\mathrm{X}$ & 3 \\
\hline $\begin{array}{l}\text { Universidade Estadual Paulista } \\
\text { Julio de Mesquita Filho (UNESP) }\end{array}$ & Presidente Prudente & Estadual & $\mathrm{X}$ & 30 Diurno & - & 11 \\
\hline $\begin{array}{l}\text { Universidade Federal de São Carlos (UFSCAR) } \\
\text { Universidade de São Paulo (USP) }\end{array}$ & São Carlos & $\begin{array}{l}\text { Federal } \\
\text { Estadual }\end{array}$ & $\mathrm{X}$ & 45 Diurno & $\mathrm{X}$ & $\begin{array}{c}29 \\
1\end{array}$ \\
\hline Sede São Paulo & São Paulo & & $\mathrm{X}$ & 40 Diurno & $\mathrm{X}$ & \\
\hline Sede São Carlos & São Carlos & & $\mathrm{X}$ & 40 Noturno & $\mathrm{X}^{* *}$ & \\
\hline Sede Piracicaba & Piracicaba & & - & - & $\mathrm{X}^{* * *}$ & \\
\hline Centro Universitário Capital (UNI CAPITAL) & São Paulo & Privada & $\mathrm{X}$ & $\begin{array}{l}50 \text { Diurno } \\
150 \\
\text { Noturno }\end{array}$ & - & \\
\hline $\begin{array}{l}\text { Pontifícia Universidade Católica de São Paulo } \\
\text { (PUCSP) }\end{array}$ & São Paulo & Privada & $\mathrm{X}$ & 50 Noturno & - & 28 \\
\hline $\begin{array}{l}\text { Centro Universitário Fundação } \\
\text { Santo André }\end{array}$ & Santo André & Privada & $\mathrm{X}$ & 53 Noturno & - & - \\
\hline
\end{tabular}


De acordo com a tabela 10, encontramos que o estado de São Paulo tem uma universidade federal, três universidades estaduais e três universidades privadas oferecendo cursos em Estatística na graduação e pós-graduação oferecendo um total de 528 vagas anuais no país de um total de $2137(17.7 \%)$.

Destaca-se o caso da universidade de São Paulo que oferece a graduação em duas sedes (São Paulo e São Carlos) e a pós-graduação em três sedes (São Paulo, São Carlos e Piracicaba). No caso de Piracicaba, o nome da pós-graduação é Estatística e Experimentação Agronômica e no caso de São Carlos, a partir de 2013, o programa de pós-graduação é compartilhado entre esta sede e a UFSCAR. Observe-se também que as universidades privadas não apresentam pós-graduação e tendem a oferecer uma grande quantidade de vagas especialmente no horário noturno.

Das sete universidades, cinco universidades aparecem no ranking latino americano 2012, onde se destacam a USP na primeira posição e a UNICAMP na terceira posição.

Por outro lado, se encontra diferença nas vagas oferecidas na grande São Paulo (USP sede São Paulo; UNI-CAPITAL, PUC-SP) no 2011 para a graduação, com 290 vagas frente a 238 no interior de São Paulo(UNESP, UFSCAR , USP sede São Carlos, Fundação Santo André ).

Um aspecto a ressaltar é que as três universidades estaduais (UNICAMP, UNESP, USP) apresentam o curso de Estatística em diferentes sedes do estado, em contraste com o fato da UFSCAR ser a única federal das três existentes (Universidade Federal de São Paulo e a Universidade Federal de $\mathrm{ABC}$ ) que tem o curso. Isto pode significar um maior investimento do governo estadual no curso de Estatística.

\subsection{Avaliação na graduação em estatística usando informação da avaliação ENADE do SINAES}

O ensino superior brasileiro tem sido objeto de avaliações em larga escala desde a instituição do Exame Nacional de Cursos (ENC) em 1996. O Provão, como era mais conhecido, passou a ter caráter obrigatório para os concluintes de cursos superiores por força de lei aprovada pelo Congresso Nacional, tendo sido realizado anualmente entre os anos 1996 e 2003 (Vianna, 2003). De acordo com INEP (2003), o Provão foi criado com 
o propósito de avaliar o processo de ensino-aprendizagem de cursos de graduação, tendo como principal objetivo contribuir para a melhoria da qualidade de ensino.

O Provão consistia na aplicação de provas para alunos concluintes dos cursos que estavam sendo avaliados. O desempenho nas provas deveria refletir a qualidade do curso realizado pelo aluno. Na última edição do Provão, realizada em 2003, participaram mais de 420 mil formandos em aproximadamente seis mil cursos de 26 áreas. Mesmo assim, o Provão, foi alvo de muitas críticas, especialmente de alunos e professores (Verhine et al, 2006).

A despeito das críticas originadas dentro da própria comunidade acadêmica, vários gestores universitários passaram a divulgar os resultados do Provão quando lhes parecia conveniente. Por outro lado, a insatisfação por parte de alunos de alguns cursos incentivou a realização de boicotes e protestos cujo mote residia no fato de que um exame realizado unicamente no final do curso não refletia a realidade do processo de formação acadêmica. Alunos de cursos mal avaliados temiam a desvalorização de seu diploma depois de todo esforço para chegar à colação de grau.

Em 2004, o Provão foi substituído pelo Exame Nacional de Desempenho de Estudantes (ENADE) que procurou atender a algumas reivindicações. A avaliação dos cursos passou a ser realizada em dois momentos, no início e no final dos mesmos, e os alunos passaram a ser selecionados por amostragem. Com um ciclo de avaliações de cada curso a cada três anos, houve um alinhamento à periodicidade de avaliação trienal adotada pela Coordenação de Aperfeiçoamento de Pessoal de Nível Superior (CAPES) para os cursos de pós-graduação stricto-sensu.

O SINAES também inclui outras dimensões, tais como uma autoavaliação das IES, uma avaliação externa e uma avaliação específica de cada curso de graduação, realizada por avaliadores selecionados pelo Ministério de Educação (MEC). De acordo com Bittencourt et al. (2008), ainda que o SINAES consista de um processo completo de avaliação, a maioria das IES e os meios de comunicação dão mais destaque aos resultados derivados do ENADE. Esse aspecto é destacado por Ristoff e Giolo (2006) que afirmam que grande parte da sociedade, da imprensa e até mesmo os próprios alunos pensam que o SINAES se resume ao ENADE. 
Com todos os esforços do INEP para aperfeiçoar o processo do ENADE nos últimos anos, as outras dimensões do SINAES tornaram-se coadjuvantes menos lembradas. Dias Sobrinho (2008), Barreyro (2006, 2008), Brito (2008) e Giolo (2008) são enfáticos ao relatar a perda de foco original do SINAES e a exagerada importância ao ENADE. Para Brito (2008), o ENADE regrediu desde a sua concepção em 2004, no entanto, percebe-se que o mesmo vem passando por modificações que buscam aprimorar o processo de avaliação, como o aumento gradual no número de cursos avaliados, a universalização do exame e a criação de novos conceitos.

De acordo com Brito (2008), é importante destacar que o ENADE, que é um exame em larga escala, não avalia a ênfase do curso, mas sim os itens que constam das diretrizes curriculares nacionais, comuns a todos os cursos e a partir dos quais os projetos são construídos. Compete ao avaliador de curso verificar a compatibilidade entre a ênfase, a realidade social e o perfil do profissional graduado pela IES.

A prova do ENADE é composta por 10 questões de formação geral e 30 de conteúdos específicos, elaboradas com o objetivo de aferir as habilidades acadêmicas, as competências profissionais básicas das áreas, o conhecimento sobre conteúdos básicos e profissionalizantes, além de questões transdisciplinares.

O ENADE avalia a trajetória do estudante, a partir do potencial de aprendizagem (desempenho dos ingressantes), o domínio da área e as competências profissionais (desempenho dos concluintes). O ponto principal do ENADE é, em primeiro lugar, a mudança de foco do exame. Na avaliação dinâmica, o foco de interesse é o progresso dos estudantes nos diversos temas que compõem as diretrizes do curso.

Os resultados do ENADE são considerados um conceito na avaliação do curso, mas também ele faz parte na composição de índices de qualidade relativos aos cursos e às instituições como Conceito Preliminar de Curso (CPC) e o Conceito de Curso (CC) e o Índice Geral de cursos (IGC) os quais são definidos a seguir:

- CPC: é composto a partir dos resultados do ENADE e por fatores que consideram a titulação dos professores, o percentual de docentes que cumprem regime parcial ou integral (não horistas), recursos didático-pedagógicos, infraestrutura e instalações físicas. 
O conceito, que vai de 1 a 5 (sendo 5 o valor máximo), é um indicador preliminar da situação dos cursos de graduação no país.

- CC: composto a partir da avaliação in loco do curso pelo MEC, pode confirmar ou modificar o• Conceito de Curso (CC): composto a partir da avaliação in loco do curso pelo MEC, pode confirmar ou modificar o CPC. A necessidade de avaliação in loco para a renovação do reconhecimento dos cursos é determinada pelo CPC: cursos que obtiverem CPC 1 e 2 serão automaticamente incluídos no cronograma de avaliação in loco. Cursos com conceito igual ou maior que três podem optar por não receber a visita dos avaliadores e, assim, transformar o CPC (Conceito Preliminar de Curso) em CC, que é um conceito permanente.

- IGC: sintetiza em um único indicador a qualidade de todos os cursos de graduação e pós-graduação stricto sensu (mestrado e doutorado) de cada universidade, centro universitário ou faculdade do país. No que se refere à graduação, é utilizado o CPC dos cursos, e no que se refere à pós-graduação, é utilizada a Nota Capes, que expressa os resultados da Avaliação dos Programas de Pós-graduação, realizada pela Coordenação de Aperfeiçoamento de Pessoal de Nível Superior (Capes). O IGC vai de um até cinco.

A área de Estatística só foi incluída no ENADE no ano 2009, conforme a Portaria Normativa no 1, de 29 de janeiro desse ano, junto com cursos da área de humanas de Administração, Arquivologia, Biblioteconomia, Ciências Contábeis, Ciências Econômicas, Comunicação Social, Design, Direito, Música, Psicologia, Relações Internacionais, Secretariado Executivo, Teatro e Turismo, que já tinham sido avaliadas no 2006 (com exceção de Relações Internacionais).

O ENADE é uma avaliação implementada desde o 2004, onde a periodicidade máxima com que cada área do conhecimento é avaliada é trienal, embora a área de Estatística não tenha sido considerada no ano 2006 nem 2012, diferentemente da área de Matemática avaliada nos anos 2005, 2008 e 2011.

Sendo deste modo, limitante no momento de avaliar os diferentes cursos de Estatísticas reportados na Tabela 1. Isto é ainda mais complicado, devido ao fato de que as universidades de São Paulo (USP) e de Campinas (Unicamp) não participaram em dita avaliação em 2009. A UNICAMP só tem participado do ENADE a partir do ano 2010 e a USP é a única universidade estadual que não tem participação até hoje das avaliações do SINAES e dentre elas o ENADE. 
Só por fazer referência a esta negativa, cabe lembrar que as universidade estaduais não são obrigadas a fazer parte do sistema de avaliação do governo federal, mas poderiam participar se quisessem, mas preferiram ficar de fora porque não concordaram com a metodologia adotada.

$\mathrm{Na}$ seguinte tabela, temos incluídas as universidades de São Paulo com curso de Estatística que participaram da avaliação do SINAES no ano 2009. Se reporta tanto o conceito ENADE quanto o conceito CPC, além do IGC da Universidade. Como pode ser apreciado, as universidades públicas (estadual e federal) apresentam avaliações razoáveis (no ENADE) e boa (no CPC) no curso de Estatística, as quais se correspondem com a avaliação da universidade (obtido pelo IGC). Isto contrasta com a avaliação obtida pela universidade privada, a qual apresenta resultados insatisfatórios em todos estes critérios.

Tabela 11. Faixas do Conceito ENADE e do conceito CPC no curso de Estatística e do IGC da universidade ano 2009

\begin{tabular}{|c|c|c|c|c|c|c|c|}
\hline Instituiç̧ão & Tipo & $\begin{array}{l}\text { Conceito } \\
\text { ENADE } \\
\text { Estatística }\end{array}$ & $\begin{array}{l}\text { Avaliação } \\
\text { do Conceito } \\
\text { ENADE } \\
\text { Estatística }\end{array}$ & $\begin{array}{l}\text { Conceito } \\
\text { CPC } \\
\text { Estatística }\end{array}$ & $\begin{array}{l}\text { Avaliação } \\
\text { do } \\
\text { Conceito } \\
\text { CPC } \\
\text { Estatística }\end{array}$ & $\begin{array}{c}\text { IGC } \\
\text { da } \\
\text { Universidade }\end{array}$ & $\begin{array}{c}\text { Avaliação } \\
\text { do IGC da } \\
\text { Universidade }\end{array}$ \\
\hline $\begin{array}{l}\text { Universidade } \\
\text { Federal de São } \\
\text { Carlos }\end{array}$ & Federal & 3 & Razoável & 4 & Bom & 5 & Bom \\
\hline $\begin{array}{l}\text { Universidade } \\
\text { Estadual } \\
\text { Paulista Julio } \\
\text { de Mesquita } \\
\text { Filho }\end{array}$ & Estadual & 3 & Razoável & 4 & Bom & 4 & Bom \\
\hline $\begin{array}{l}\text { Centro } \\
\text { Universitário } \\
\text { Capital } \\
\end{array}$ & Privada & 2 & Insatisfatório & 2 & $\begin{array}{c}\text { Insatisfatór } \\
\text { io }\end{array}$ & 2 & Insatisfatório \\
\hline
\end{tabular}

\subsection{Avaliação na pós-graduação em estatística usando informação da avaliação trienal da CAPES}

De acordo com o Instituto Nacional de Educação e Pesquisa (INEP) a avaliação dos Programas de Pós-graduação, realizada pela Coordenação de Aperfeiçoamento de Pessoal de Nível Superior (CAPES), compreende a realização do acompanhamento anual e da 
avaliação trienal do desempenho de todos os programas e cursos que integram o Sistema Nacional de Pós-graduação. Os resultados desse processo, expressos pela atribuição de uma nota na escala de um a sete fundamentam a deliberação do Conselho Nacional de Educação e a Ministério da Educação (CNE/MEC) sobre quais cursos obterão a renovação de reconhecimento, a vigorar no triênio subsequente. A medida de qualidade da pós-graduação que compõe o IGC é uma conversão das notas fixadas pela CAPES. O Sistema de Avaliação da Pós-graduação foi implantado pela CAPES em 1976.

Os resultados da Avaliação Trienal realizada pela CAPES, além de indicarem a qualidade do desempenho e a posição relativa de cada programa no contexto de sua respectiva área, servem de referência para as decisões dos órgãos governamentais de investimento na pesquisa e na pós-graduação e fundamentam as deliberações do Conselho Nacional de Educação sobre quais cursos de mestrado e de doutorado obterão, para vigência no triênio seguinte, a renovação de seu "reconhecimento".

O curso de Estatística, na avaliação feita pela CAPES, está na área de "Matemática/Estatística e Probabilidade". Diferentemente da categorização feita no ENADE 2009 para cursos de graduação, onde a Estatística foi considerada junto com cursos de humanas.

Atualmente, são avaliados, no curso de Estatística, 9 programas de mestrado e 5 de doutorado no Brasil, nesta área. No estado de São Paulo no curso de Estatística, estão habilitadas as seguintes universidades: IME-USP (M/D), UFSCAR(M/D) e UNICAMP (M/D), todas elas públicas.

Os Critérios de Avaliação Trienal (2007), publicado na página da CAPES para a área de "Matemática/Estatística e Probabilidade" foram usados os seguintes indicadores gerais (extraída de http://www.capes.gov.br/images/stories/download/AVALIAÇÃO/CA2007_Matematica ProbabilidadeEstatistica.pdf):

1. Corpo docente permanente a cada ano do triênio.

2. Critérios utilizados para o credenciamento de seus docentes como orientadores de mestrado e de doutorado. 
3. Bolsistas de produtividade em pesquisa do CNPq e respectivos níveis.

4. Relação dos titulados por cada ano do triênio, por área e por orientador.

5. Publicações resultantes das teses/dissertações dos titulados.

6. Participação dos alunos nos projetos de pesquisa do programa.

7. Relação das publicações do corpo docente permanente, por ano do triênio.

8. Dados referentes à inserção nacional e internacional do programa, interação com outros centros, atividades de pós-doutoramento, professores visitantes e participação em projetos financiados pelas agências de fomento.

E indicadores específicos divididos em três critérios: I - Proposta do Programa, II - Corpo Docente, III - Corpo discente, teses e dissertações, IV - Produção Intelectual, V - Inserção Social. Cada uno deles com especificações. Já os Critérios para atribuição das notas seis e sete, para as instituições e os cursos na área "Matemática/Estatística e Probabilidade" foram (extraída de http://www.capes.gov.br/images/stories/download/AVALIAÇÃO/CA2007_Matematica ProbabilidadeEstatistica.pdf):

1. Qualidade e quantidade dos artigos publicados em periódicos muito seletivos.

2. Comentários de artigos ou pesquisas recentes em revistas de destaque internacional.

3. Apresentação de palestras convidadas em conferências internacionais reconhecidas pela comunidade.

4. Patentes internacionais.

5. Pesquisas em temas de fronteira.

6. Participação de membros do programa em comissões de programas de conferências internacionais.

7. Participação de membros do programa em comissões editoriais de revistas com circulação internacional.

8. Participação em convênios internacionais (cooperações bilaterais e convênios obtidos diretamente no exterior).

9. Organização de eventos internacionais pela instituição (congressos, workshops, cursos de verão/inverno com alcance internacional).

10. Atração de pós-doc nacionais e estrangeiros.

11. Presença regular de visitantes seniors de instituições internacionais. 
12. Presença de alunos do exterior na PG.

13. Página da WEB do programa em inglês.

No curso de pós-graduação em Estatística no estado de São Paulo, restringimo-nos aos resultados para os programas que apresentam mestrado e doutorado avaliados na trienal 2004, 2007 e 2010. Estes resultados são apresentados na seguinte tabela:

Tabela 12. Avaliação Trienal 2004, 2007 e 2010 no curso de Estatística em universidades do Estado de São Paulo

\begin{tabular}{|c|c|c|c|c|}
\hline & & & & Avaliação \\
\hline Trienal & Universidade & Nível & Conceito & Global \\
\hline \multirow[t]{4}{*}{2004} & UFSCAR & $\mathrm{M}$ & 4 & Bom \\
\hline & UNICAMP & $\mathrm{M}$ & 4 & Bom \\
\hline & IME-USP & $\mathrm{M} / \mathrm{D}$ & 6 & Muito Bom \\
\hline & UFSCAR & $\mathrm{M} / \mathrm{D}$ & 4 & Bom \\
\hline \multirow[t]{3}{*}{2007} & UNICAMP & $\mathrm{M}$ & 4 & Bom \\
\hline & IME-USP & $\mathrm{M} / \mathrm{D}$ & 7 & Muito Bom \\
\hline & UFSCAR & $\mathrm{M} / \mathrm{D}$ & 4 & Bom \\
\hline \multirow[t]{2}{*}{2010} & UNICAMP & $\mathrm{M} / \mathrm{D}$ & 5 & Bom \\
\hline & IME-USP & $\mathrm{M} / \mathrm{D}$ & 7 & Muito Bom \\
\hline
\end{tabular}

Observou-se que a USP tem se mantido na avaliação global "muito bom" inclusive atingindo o conceito máximo de sete desde o ano 2007, enquanto que a UNICAMP e a UFSCAR têm se mantido no nível "bom”.

\subsection{Comentários finais}

O presente trabalho ainda é uma etapa inicial de uma pesquisa mais ampla. O interesse do presente trabalho centra-se nos resultados da avaliação institucional dos cursos de graduação e pós-graduação stricto sensu em Estatística realizadas pelo governo brasileiro desde o 2004 até 2012, restrito às universidades do estado de São Paulo. 
De modo específico, queremos responder a pergunta de quais instituições participaram destas avaliações e quais resultados obtiveram nelas. Para responder a esta pergunta, seguimos uma metodologia baseada na análise documental com uma revisão de informação proporcionada em diferentes fontes bibliográficas e virtuais.

A principal oferta é dada pelas universidades estaduais como UNESP, UNICAMP e USP, as quais evidenciam um forte investimento do Estado que contrasta com o investimento do governo federal, pois este oferece o curso em apenas uma entre as três universidades federais do estado. No entanto, encontramos que o curso também é oferecido em três instituições privadas em São Paulo: UNI CAPITAL, PUC São Paulo e Centro Universitário Fundação Santo André, embora a Estatística seja uma profissão que permite ter acolhimento a nível universitário- acadêmico e empresarial para seus alunos concluintes. Cabe mencionar que tanto o curso de Estatística dado na PUC São Paulo e na Fundação Santo André foram implementados recentemente, no ano 2012 e 2011 respectivamente, portanto ainda não possuem avaliação junto ao INEP.

De acordo com Barreyro (2008), o SINAES pretende organizar a avaliação das instituições de educação superior como um sistema que articule a avaliação e a regulação. Consta de três eixos: Avaliação dos cursos, das instituições e dos estudantes. Nosso trabalho oferece apenas informação a respeito do terceiro componente considerando o ENADE.

Recentemente, se dispõe de relatórios de avaliação desses cursos como os apresentados no ENADE 2009 e as diferentes avaliações da CAPES nos programas de avaliação. No entanto, não se tem pesquisas que tratem da avaliação no curso de Estatística e da importância deste para o desenvolvimento da área no Brasil.

O trabalho apresenta os resultados de dois instrumentos usados por dois entes do governo do Brasil, dedicados a avaliação de cursos. O SINAES, através do ENADE e índices complementares, oferece uma avaliação dos cursos de graduação e a CAPES, através da avaliação dos programas de pós-graduação trienal, oferece informação dos cursos de pósgraduação. 
Quando olhamos as avaliações do ENADE desde sua criação no ano 2004 até o ano 2013, o curso de Estatística só tem sido considerado na avaliação no ano 2009, diferentemente da Matemática que vem sido avaliada em mais anos. Não podemos precisar porque isto acontece, mas podemos indicar que a maioria dos cursos de bacharelado foram criados recentemente e porque os programas tradicionais como o da USP e a UNICAMP decidiram não aderir a avaliação. Então, desconsiderando os cursos destas universidades e das novas que foram criadas posteriormente, encontramos um nível bom no curso de Estatística da UNESP e da UFSCAR, que contrasta com um nível insatisfatório da universidade privada Centro Universitário Capital. No entanto, os dados encontrados são insuficientes e defasados no tempo.

No caso da avaliação CAPES, por serem cursos de pós-graduação, a avaliação tem abarcado um maior número de anos, mas menor número de universidades, já que só três universidades públicas no estado de São Paulo oferecem pós graduação e nenhuma privada (ver tabela 1). No caso da USP que oferece três programas de pós-graduação, apenas o IME-USP é considerado em nosso análise desde que o programa de pósgraduação conjunto entre a USP São Carlos e a UFSCAR só se iniciasse neste ano e o programa da USP- Piracicaba é desconsiderado pois trata-se de um programa em Estatística mas dirigido a carreiras agrônomas.

Os resultados da avaliação da CAPES destacam o programa de pós-graduação do IME USP como sendo o programa com melhor avaliação do país. Logo, a UNICAMP apresenta o seguinte melhor desempenho só comparável com outras três universidades do país, Universidade Federal de Rio de Janeiro, Universidade Federal de Minas Gerais e Universidade Federal de Pernambuco.

Já o programa da UFSCAR, encontra se em uma situação intermediária espera-se uma melhora de seu desempenho a partir de 2013 na parceria com o a USP São Carlos. Assim, encontramos na pós-graduação uma melhor avaliação no tempo, a qual deve continuar com a avaliação trienal a ser publicada neste ano.

A partir da exploração inicial neste trabalho, identificamos que a avaliação institucional do curso de Estatística na graduação apresenta menos dados que os cursos de pósgraduação no Estado de São Paulo. Na graduação, achamos que ainda é preciso contar com resultados do ENADE mais recentes e que as universidades participem deles. E no 
caso da pós-graduação, novos resultados a serem publicados este ano, incluindo o novo programa conjunto entre a USP- São Carlos e a UFSCAR devem ajudar na avaliação institucional.

A abordagem apresentada até agora é uma visão a respeito do curso de Estatística através dos resultados das avaliações institucionais; isto é, uma visão que apresenta dados bastante gerais e que resulta insuficiente para caracterizar vários aspectos deste curso e das formas próprias do processo de aprendizagem incluindo suas próprias formas de avaliação. Além disso, como tem se observado, os dados nem sempre estão disponíveis, pois estas avaliações governamentais nem sempre incluem o curso de Estatística.

Em futuros trabalhos, pretendemos estender o presente trabalho para todos os cursos de Estatística no Brasil (além de não serem muitos), tanto na graduação como de pósgraduação e a partir daí, propor modelos de avaliação pertinentes e oportunos para estes programas, que permitam ter um maior conhecimento do desenvolvimento e do perfil do curso, assim como de maior informação. Pretende-se considerar aspectos de avaliação que podem ser desenvolvidos por organizações como a Associação Brasileira de Estatística ou os Conselhos Regionais de Estatística.

Achamos que no futuro, devem existir modelos que incluam tanto os aspectos institucionais e pessoais, incluindo todos os participantes do processo de avaliação (como pode ser revisado em Aparicio e Bazán, 2010) e um marco maior, para melhor entendimento da avaliação e do curso de Estatística que possa caracterizar a dinâmica da aprendizagem do curso, já que não se tem um marco ad-hoc próprio do curso, nem dados contínuos se não dados quantitativos baseados em índices que não falam acerca da dinâmica interna, nem informação mais detalhada a nível de professores e alunos e instituição.

Finalmente, notamos uma carência de investigações que tratem sobre as avaliações nesta área, tanto em publicações como teses. Não tem um marco ad-hoc próprio do curso, não se tem dados contínuos, só dados quantitativos baseados em índices que não falam da dinâmica interna e não se tem uma informação mais detalhada a nível de professores e alunos. 


\section{CAPITULO V.}

\section{PANORAMA GERAL DA AVALIAÇÃO E DO CURSO DE ESTATÍSTICA EM PERU, CHILE E COLOMBIA}

No capitulo anterior, o artigo da um panorama sobre a avaliação na universidade no Brasil, tomando como referencia ao curso de Estatística no estado de São Paulo. Temos feito isso porque é o Brasil a nivel de latinoamerica quem tem um modelo mais institucionalizado da avaliação universitaria, que abrange tanto à graduação como a pós graduação.

Achamos importante fazer este panorama geral para uma melhor contextualização da comparação das atitudes e relacao à Estatística em grupos de universitarios de difrentes paises de latinoamerica como Peru, Chile, Colombia e Brasil considerando a escala apresentada no capítulo IV.

A continuação apresentamos um breve panorama da avaliação nas universidades e o curso de Estadística no Perú, Chile, Colombia e Brasil.

\subsection{Panorama Peru}

Atualmente no Peru não tem uma lei que regule a educação superior em conjunto. A antiga Lei Universitária que data de 1983 y a nova Lei Universitária promulgada em 2014 tem um conjunto de normas de distinto nível que regulam os diferentes aspectos das instituições de educação superior não universitária (institutos pedagógicos, institutos tecnológicos, Escolas superiores).

A estrutura da educação universitária peruana tem tido uma variação substancial nos últimos anos. Antes de 1960 tinha 9 universidades públicas e 1 universidade privada. Já entre os anos 60 e 85 as universidades públicas foram criando se progressivamente, até quase chegar a implementar uma universidade por departamento geográfico do país. As universidades privadas criam-se ao início deste período e mantêm-se em 10 universidades até mediados dos anos 80`s (Adaniya, 2000; Arregui, 2002; Nava ,2002; ANR, 2002). 
E é nesta década até passado o ano 95 que há um incremento acelerado das universidades privadas, tratando de assimilar a demanda não coberta pelas universidades nacionais (Nava, 2002).

É acontecendo este crescimento, a Assembleia Nacional de Reitores cria o Sistema Nacional de Acreditação Universitária em 1994 (ResoluciónNº1029-94-ANR) e o Conselho Nacional para a Autorização de Funcionamento de Universidades (CONAFU) com Lei $N^{\circ} 26439$ para regular o funcionamento de as novas universidades. A CONAFU, avalia em forma permanente e durante o tempo que estime conveniente o funcionamento das universidades, autorizando o denegando o funcionamento definitivo. A autorização de funcionamento definitivo não pode ser concedida antes de decorridos cinco anos, contados a partir da data da autorização provisória de funcionamento.

O 11 de Julio de 1999, criou-se a CAFME (Comissão para a Acreditação de Faculdades ou Escolas de Medicina) por Lei do Congresso No 27154 e no mesmo ano por Resolução No 179-99-ANR/P encarrega-se ao Instituto de Investigação e Fomento da Modernização e Acreditação das Universidades Peruanas (IFOMACU), as tarefas de acreditação.

A partir do ano 2000, a ANR sugere que as universidades promovam a cultura da acreditação a fim de que os integrantes compreendam sua importância e tome-se conhecimento de quanto ocorre a nível internacional e latino-americano. No 2002, a ANR solicitou a todas as universidades que conformem uma Comissão própria de Acreditação para formar núcleos de trabalho, deste modo mediante Resolução No 085-2002-ANR do 12 de fevereiro do 2002, constitui-se a Comissão Nacional de Reitores para a Acreditação para revisar e formular propostas de requisitos mínimos de acreditação e avaliação das universidades do país, orientando o processo de melhoria contínua da qualidade acadêmica das mesmas, mediante um processo de auto avaliação, avaliação externa por pares e a acreditação de entidades especializadas a nível de pré e pós grado.

Em 2006 por resolução presidencial mediante a Lei $N^{\circ} 28740$, o cria-se o Sistema Nacional de Avaliação, Acreditação e Certificação da Qualidade Educativa(SINEACE), que norma os processos de avaliação, acreditação e certificação da qualidade educativa, define a participação do Estado neles e regula o âmbito, a organização e o funcionamento do Sistema Nacional de Acreditação Universitária. O SINEACE, é um organismo público adscrito ao Ministério de Educação. 
Em maio de 2014 mediante resolução ministerial N³37-2014 é criada a Superintendência Nacional de Educação Superior Universitária (SUNEDU) que substitui à Assembleia Nacional de Reitores (ANR) como ente regulador da oferta universitária e que tem como principal função o licenciamento das universidades, o outorgamento de títulos e o controle de qualidade do ensino. Este ente só funcionara a partir de dezembro de 2014.

Segundo a Assembleia Nacional de Reitores a través da Direção de Estatística e Planificação Universitária, no Peru no ano 2011 existiam 129 universidades, sendo 50 universidades estaduais, 78 universidades privadas e 1 universidade municipal distribuídas em todo o território nacional. Dentro de estas o curso de Estatística é dado numa pequena quantidade de instituições.

Cabe lembrar que a formação no curso de Estatística no Peru começou no final dos anos 60, nas universidades públicas como a Universidade Nacional Maior de São Marcos, Universidade Agrária da Molina (UNALM) e a Universidade Nacional de Trujillo (UNT). A este grupo uniu-se a Universidade Nacional de Engenharia (UNI) e a Universidade Nacional Pedro Ruiz Galo (UNPRG).

Posteriormente formaram-se estatísticos nas universidades privadas como a Pontifícia Universidade Católica de Peru (PUCP), Universidade Peruana Caetano Heredia (UPCH) e a Universidade de São Martín de Porres (USMP). Destas três atualmente só a UPCH continua oferecendo esta formação e a PUCP só oferece a modalidade de Mestrado em Estatística Aplicada desde o 2007. Posteriormente, nos anos 90 foram-se ampliando as universidades que oferecem esta especialidade, em especial nas universidades públicas (Bazán, 2007).

Segundo o Conselho Nacional de Estadísticos do Peru (2014) só 11 universidades públicas e uma privada tem o curso de Estatística na graduação. E 1 universidade privada que só tem o curso de Mestrado e 1 universidade pública que só tem o programa de doutorado. Como se pode observar a continuação: 


\section{Capital (Lima)}

Universidade Nacional Agraria a Molina (UNALM)

Universidade Nacional de Engenheira (UNI)

Universidade Nacional Federico Villarreal (UNFV)

Universidade Nacional Maior de São Marcos (UNMSM)

Universidade Nacional José Faustino Sánchez Carrión de Huacho (UNJFSC)

Universidade Peruana Cayetano Heredia (privada) (UPCH)

*Pontificia Universidade Católica de Peru (Privada) (PUCP)

\section{Região Norte}

Universidad Nacional de Trujillo (UNT)

Universidad Nacional Pedro Ruiz Gallo (UNPRG)

Universidad Nacional de Piura (UNP)

Universidad Nacional Santiago Antúnez de Mayolo (UNSAM)

**Universidade Nacional del Santa (UNS)

\section{Região Sur}

Universidade Nacional do Altiplano de Puno

Universidade Nacional Sao Antonio de Abad de Cusco

*Só dá o curso de Mestrado.

** Só dita o curso de Doutorado em Estatística Matemática

De todas estas universidades só é dado o curso de Mestrado em 4 universidades públicas: UNMSM, UNT, UNALM, 2 privadas: UPCH e PUCP. O doutorado em Estatística Matemática só é ditado na UNS, mas sua criação é recente.

\subsection{Panorama Chile}

A Educação Superior em Chile está constituída por um sistema diversificado, integrado por três tipos de instituições que se oferecem aos alunos que finalizam o ensino médio: Universidades, Institutos Profissionais e Centros de Formação Técnica, reconhecidas pelo governo mediante o artigo 29 da Lei Orgânica Constitucional do ensino (LOCE). 
Quem ingressa à educação superior universitária podem optar entre universidades tradicionais, que foram criadas antes de 1981 e que estão agrupadas no Conselho de Reitores das Universidades Chilenas $(\mathrm{CRUCH})$ ou nas universidades privadas. As primeiras recebem vários tipos de fundos do Estado, como o contribua promotor direto (AFD) e o contribua promotor indireto (AFI).

As universidades do $\mathrm{CRUCH}$ são 25 , este grupo inclui às 16 universidades estatais criadas por lei e 9 universidades com personalidade jurídica privada, 6 das quais obtiveram seu reconhecimento por leis especiais e as três restantes são derivadas da Pontifícia Universidade Católica de Chile. A seleção para o ingresso a estas universidades efetua-se através da Prova de Seleção Universitária (PSU). No ano 2011, o CRUCH convidou as universidades privadas a formar parte do sistema de ingresso.

Dependendo da universidade eleita, o estudante pode optar por diferentes bolsas ou créditos com condições muito diferentes entre si para o financiamento de seus estudos. Os estudantes das universidades do $\mathrm{CRUCH}$ podem postular ao Fundo Solidário de Crédito Universitário e os demais estudantes de educação superior ao Crédito com Garantia do Governo (ou Crédito com aval do Governo, CAE).

Até 1980, a educação superior chilena só estava composta por universidades, algumas das quais tinham sedes em diferentes cidades do país. Todas elas contavam com financiamento público, ainda que várias pertenciam a organizações privadas. A partir desse ano, o sistema chileno de educação superior experimentou mudanças significativas quanto ao número e tipo de instituições, o volume de matrícula e a oferta de carreiras, entre outros aspectos. Isso porque um novo marco normativo permitiu a criação e funcionamento de instituições privadas sem financiamento estatal e dispôs a reestruturação das universidades estatais existentes na época. As primeiras instituições de educação privada foram supervisionadas através do sistema de examinacão [Decreto Lei 1/80 e Decreto Lei 5/1980, de Educação], administrado por uma universidade examinadora.

Em 1990, o Conselho Superior de Educação, organismo público, criado pela Lei Orgânica Constitucional de Ensino (LOCE), com a missão de administrar um novo sistema de supervisão de universidades e institutos profissionais privados denominado, nesse então, 
como acreditação. Por sua vez, a supervisão dos centros de formação técnica ficou então por conta da Ministério de Educação.

A grande quantidade de instituições de educação superior que obteve sua autonomia durante a década do 90 fez necessária a definição de um sistema que avaliasse sua qualidade e posterior autonomia e desse, em definitiva, um marco que regulara os mecanismos da garantia da qualidade da educação superior.

Em 1999, nasce a Comissão Nacional de Acreditação de Pré grado (CNAP), com a finalidade de desenhar e propor um sistema nacional de garantia da qualidade da educação superior e de direcionar os processos da acreditação, entendido isto como a avaliação periódica da qualidade de instituições de educação superior autônomas. Esta comissão cria a lei 20.129, publicada o 17 de novembro de 2006, que estabelece um Sistema Nacional de Garantia da Qualidade da Educação Superior (SNAC) e cria a Comissão Nacional de Acreditação (CNA), organismo público de caráter autônomo encarregado de verificar e promover a qualidade das universidades, institutos profissionais e centros de formação técnica autônomos e dos cursos e programas de estudos que eles oferecem.

O 12 de setembro de 2009, foi publicada a Lei Geral de Educação (20.370 que criou o Conselho Nacional de Educação (CNED), sucessor legal do Conselho Superior de Educação.

Atualmente, de acordo ao CNA existem 59 universidades reconhecidas em funcionamento e $2 \mathrm{em}$ processo de licenciamento.

Dentro destas universidades o curso de Estatística é dado em 8 universidades.

Cabe lembrar que a formação no curso de Estatística em Chile iniciasse a meados do século vinte onde se inicia o ensino formal da Estatística na educação superior em Chile (Ferreiros, 1991).

Em 1962 é criado o Centro de Estudos Estatísticos Matemáticos (CEDEM) como um organismo da Faculdade de Ciências Econômicas da Universidade de Chile. No CEDEM criou-se a primeira carreira de Estatística que existiu no Chile. No ano 1971, na Pontifícia Universidade Católica de Chile, inicia-se um programa de Técnicos estatísticos. Este programa tinha 4 anos de duração. 
Aos poucos anos observa-se a necessidade de fazer mais forte a formação dos profissionais estatísticos e é criada a carreira de Estatística em várias universidades.

$\mathrm{Na}$ atualidade segundo a Sociedade Chilena de Estatística (SOCHE) o curso de estatística em Chile e ditado em 5 universidades estaduais e em 3 universidades privadas. Ainda é ditado o curso de pós graduação com título de Mestre numa universidade estadual:

\section{Região Metropolitana- Santiago de Chile}

Pontifícia Universidade Católica de Chile (UC)- Licenciatura em Estatística, Título de Estatístico. Privada

Universidade de Santiago de Chile (USACH)- Engenheira Estatística. Publica Universidade de Chile (UCHILE)- Mestrado em en Bioestatística. Publica

\section{Segunda Região - Antofagasta}

Universidade de Antofagasta (UANTOF)- Licenciatura em Estatística, Engenheira Estatística. Publica

\section{Quinta Região - Valparaiso}

Pontifícia Universidade Católica de Valparaíso (PUCV)- Licenciatura em Ciência Estatística, Título de Estatístico. Privada

Universidade de Valparaíso (UV)- Licenciatura em Estatística, Engenheira Estatística. Publica

Universidade de Playa Ancha (UPLA) - Licenciatura em Ciências da Engenheira, Engenheira Estatística. Publica

\section{Oitava Região- Bio-Bio}

Universidade de Bío-Bío (UBB)- Licenciatura em Estatística, Engenheira Estatística. Publica

Universidade de Concepção (UDEC)- Licenciatura em Estatística, Engenheira Estatística. Privada

Destas 8 universidades 6 tem o programa de pós graduação, Destas 4 oferecem só o Mestrado em Estatística (PUCV, UANTOF, UDEC, UBB) e 2 (CC, UV), oferecem 
Mestrado e Doutorado. Ainda é dado o curso de graduação com grado de Mestre na Universidade de Chile (UCHILE), pese a que não é dado o pré grado nela.

\subsection{Panorama Colômbia}

A educação superior em Colômbia inicia-se no período colonial, e particularmente nos séculos XVI e XVII, com a fundação em Bogotá das universidades Santo Tomás, São Francisco Javier, hoje Universidade Javeriana, e o Colégio Maior de Nossa Senhora do Rosário

Com a expedição da Constituição Política de 1991 consagra-se a liberdade de ensino e reconhece-se a educação como um direito e um serviço público que pode ser prestado pelo Estado ou pelos particulares. Assim mesmo, para assegurar a qualidade do sistema educativo, se atribuiu ao Estado a função de inspeção e vigilância. A Constituição também garantiu a autonomia universitária e estabeleceu que as universidades poderiam expedir seus próprios estatutos.

A educação Superior é regulada pela Lei 30 de 1992, que constitui a base normativa do sistema de educação superior colombiano. Esta norma definiu os princípios e objetivos da educação superior, classificou os programas acadêmicos e as instituições públicas e privadas. A classificação institucional realizou-se com base em uma tipologia que inclui instituições técnicas profissionais, instituições universitárias ou escolas tecnológicas e universidades.

Com esta Lei, estabeleceram-se como órgãos reitores ao Ministério da Educação Nacional (MEN) e ao Conselho Nacional de Educação Superior (CESU). Dentro do CESU incluiuse a organização do Sistema Nacional de Acreditação (SNA), como uma estratégia para a melhoria da qualidade da educação superior e do Sistema Nacional de Informação $(\mathrm{SEM})$

Para o ingresso à educação superior o postulante deve ter o Título de bacharel que certifica ter culminado ao ensino médio e ter apresentado a Prova de Estado que realiza o Instituto Colombiano de Fomento à Educação Superior (ICFES).

Durante a década de 2000 se fortaleceu a formação técnica e tecnológica, e se criou o Vice Ministério da Educação Superior, ao qual se lhe encarregou a inspeção e vigilância do setor e adotaram-se algumas medidas em matéria de acreditação e de qualidade. Sobre 
estas últimas medidas cabe destacar a criação da Comissão Intersetorial para a Garantia da Qualidade (CONACES) e o fortalecimento do Conselho Nacional de Acreditação (CNA).

Também criam-se um conjunto de sistemas de informação, com o fim de contribuir ao conhecimento e a tomada de decisões do setor, dentro dos quais se encontram o Sistema Nacional da Informação da Educação Superior (SNIES), o Sistema de Informação de Garantia da Qualidade da Educação Superior (SACES), o Sistema para a Prevenção da Deserção em Educação Superior (SPADIES) e o Observatório Laboral para a Educação.

De outro lado, o Instituto Colombiano para a Avaliação da Educação Superior (ICFES) transformou-se em uma entidade pública especializada nos serviços da avaliação da educação em todos seus níveis e a geração de informação sobre a qualidade da educação. E por sua vez, o Instituto Colombiano de Crédito Educativo e Estudos Técnicos no Exterior (ICETEX) é transformado em uma entidade financeira de natureza especial, que a partir de 2010 fortaleceu os programas de créditos educativos e melhorou as condições financeiras dos empréstimos aos estudantes.

Em março de 1956 a Universidade Nacional de Colômbia cria o departamento de Matemáticas e Estatística e Um ano após da sua fundação, em 1957, o Departamento converteu-se na Faculdade de Matemáticas e Estatística. A criação da carreira de estatística ocorreu em 1958 e vinho a reforçar o sentido e objetivos do Departamento.

Atualmente na Colômbia, de acordo com o Ministério da Educação Nacional (MINEDUCACOPN) existem 32 universidades públicas que compõem o Sistema Universitário Estatal e 48 universidades privadas.

O curso de Estatística só é oferecido no pré grado em 5 universidades públicas (una delas é em Matemática com ênfase em estatística) e 1 universidade privada. O pós grado é oferecido em 4 universidades, mas só uma delas tem doutorado e o restante mestrado:

\section{Região Distrito Capital (Bogotá)}

Universidade Nacional de Colômbia (pública). Pré grado em Estatística e Maestria e Doctorado en Ciências - Estatística.

Universidade São Tomás (privada) Pré grado en Estatística 
Universidade Autónoma de Colômbia (privada) Mestrado en Investigação operativa e Estatística

\section{Região Boyacá}

Universidade Pedagógica e Tecnológica de Colômbia (Publica). Licenciatura em Matemáticas e Estatística.

\section{Região Cauca}

Universidade do Valle (Publica). Pré grado em Estatística. Mestrado em Estatística

\section{Região Córdoba}

Universidade de Cordoba (pública) Pré grado Estadistica

\section{Região Tolima}

Universidade de Tolima (privada) Pré grado em Matemáticas com Énfase em Estatística

\section{Região Atlántico}

Universidade do Norte (privada) Mestrado em Estatística Aplicada 


\section{CAPITULO VI.}

\section{ATITUDES FRENTE A ESTATÍSTICA EM POBLAÇÕES NO ESTATISTICAS EM QUATRO PAISES LATINOAMERICANOS}

Se faz un trabalho comparativo das atitudes e relacao à Estatística em grupos de universitarios de difrentes paises de latinoamerica como Brasil, Peru, Chile e Colombia. considerando duas escalas de atitudes frente a estatística (a Escala de Estrada (2002) e a escala de Cazorla et al (1999)). Se faz um estudo psicometrico ds propiedades de validade e confibilidade e adaptação da escala usada e se comparam os resultados para os alunos de diferentes cursos avaliados.

Segundo Rocha, Bayer, Bittencourt e Cheveste (2004), a Estatística tem um papel relevante em quase todas as atividades da sociedade moderna; muitos estudantes, durante e depois de finalizar seus estudos vão fazer uso dos seus conhecimentos de probabilidade e estatística como instrumentos em suas profissões, independentemente da área de trabalho. Assim sabendo que as experiências, interesses e objetivos influem nas percepções dos estudantes sobre a aprendizagem da Estatística o ensino dela tem que favorecer às atitudes positivas tanto no aprendizado quanto no seu uso prático.

Por outro lado a Estatística tem sido reconhecida nos últimos anos como um componente básico na formação cidadã (Batanero, 1999) e sua incorporação no currículo escolar de diversos países confirma a importância de aprende-la.

Por isso, como bem assinalam Estrada, Batanero e Fortuny (2003), assistimos a um interesse recente pela problemática da formação de professores em relação à Estatística. Para alguns autores (Heaton, 2002; Gattuso, e Pannone, 2002; Mendonça, Coutinho, e Almouloud, 2006) a escassa preparação estatística com a que, em ocasiões, o professor termina seus estudos, faz que conte com poucos recursos à hora de dar suas classes e, ele tende a omitir o tema; encurtá-lo ou, no melhor dos casos, a apresentar com uma metodologia inadequada. Ademais, ao não dar os conteúdos de Estatística o professor não pode completar seus conhecimentos com a prática docente e suas atitudes em relação à 
disciplina podem ser pouco adequadas ou negativas. Estas atitudes negativas podem condicionar o ensino e repercutir nas futuras atitudes de seus alunos (Estrada, 2007; Estrada, Batanero e Lancaster, 2011). Investigações como as de Phillips (1993) e Agne, Greenwood e Miller (1994), asseguram que existem relações entre as atitudes, as crenças do professor e seu rendimento e também entre as atitudes, crenças e o desempenho de seus alunos. Para Gómez (2000), a forma de organizar as atividades de ensino e aprendizagem seleciona e reforça certas atitudes nos alunos.

Não entanto a Estatística, é uma disciplina frequentemente esquecida pelo professor no ensino obrigatório e para alguns autores como Heaton, 2002; Gattuso e Pannone, 2002; Mendonça, Coutinho e Almouloud, 2006), deve-se em parte, à escassa preparação estatística com a que o professor termina seus estudos, o que faz que tenha poucos recursos na hora de dar suas aulas. Isso pode predispor ao professor a ignorar o tema; encurtá-lo ou, no melhor dos casos, apresentado com uma metodologia inadequada e com isso gerar atitudes limitadas e negativas que condicionam o ensino e afeta as futuras atitudes de seus alunos.

De acordo com Cabral e Nick (2003), a definição de atitude varia de acordo com vários contextos psicológicos. Implicando em uma predisposição para responder de maneira coerente a um objeto, pessoa ou situação. Para Anastasi e Urbina (2000), a atitude é um componente importante da personalidade, sempre é usada em referência a um objeto, representando uma tendência de resposta favorável ou desfavorável a uma categoria de estímulos, sendo que, a mesma não pode ser diretamente observável, sendo inferida através do comportamento manifestado pelo indivíduo.

Assim as atitudes são adquiridas no processo de integração do indivíduo com a sociedade onde sendo parte de uma cultura, comunidade ou família, adquire, sem geralmente ter consciência, as atitudes predominantes destes grupos (Cabral y Nick, 2003).

De acordo com Freedman et al. (1970), as atitudes quando estabelecidas tiendem a ser resistentes às mudanças. Uma atitude inicialmente negativa só se tornará mas positiva se existissem maiores estímulos para adotar esta nova posição, o que significa que a atitude pode ser determinada pela soma dos elementos positivos ou negativos que envolvem o objeto, pessoa ou situação. Nesta linha, estudos como as de Vendramini (2000), dão 
importância ao entendimento das variáveis tanto cognitivas quanto comportamentais que iram a subsidiar as atitudes dos alunos que em um contexto escolar podem orientar aos professores sobre estratégias de ensino.

O estudo das atitudes frente à a Estatística em estudantes é um tema que tem despertado o interesse dos educadores e pesquisadores desde faz alguns anos. No caso particular do ensino da Estatística resulta especialmente significativo, dado que, estabeleceu-se uma relação empírica entre as atitudes e a aprendizagem.

Phillips (1980), destacou que a atitude do aluno em frente à estatística pode ser um obstáculo ou constituir uma grande vantagem para sua aprendizagem, por isso aspectos como as atitudes são estudadas por diferentes autores do mundo. Estudos como os de Aparicio e Bazán (2005), Auzmendi (1992), Carmona (2004), Wise (1985) y Gil (1999), têm corroborado a existência de correlação positiva entre as atitudes dos estudantes e seu rendimento nesta disciplina.

No entanto, como menciona Blanco (2004), a produção nesta linha de investigação é ainda quantitativamente modesta. Encontramos algumas investigações em Brasil como as de Cazorla et al (1999), Silva (2000), Aparicio (2006), Vendramini e Silva (2012).

Esta preocupação pelo estudo das atitudes reflete-se nas diversas escalas de atitudes para a estatística que têm sido propostas para a medir elas adequadamente (ver Carmona, 2004), achamos por isso importante contar com instrumentos validos e fiáveis que permitam avaliar estas atitudes na população de professores em exercício e em formação e para os diferentes níveis educativos.

Nessa linha, Estrada (2002) propôs e elaborou uma escala de atitudes para a Estatística (EAEE), especificamente dirigida para ser aplicada no contexto de professores em exercício e formação que validou em Espanha. Cazorla et al (2009), faz uma adaptação da escala de atitudes para a Matemática de Brito (1998) para o Brasil para medir as atitudes frente à estatística em estudantes universitários de diferentes especialidades. A escala de Cazorla tem sido amplamente usada em estudos sobre a atitude frente à Estatística no Brasil em mostras de universitários, professores universitários, e estudantes dos últimos anos de ensino médio, como os reportados em Bonafé et al (2010); Evangelista y Arno (2012); Oliveira (2011). Também, no Peru, Aparicio et al (2004), 
Aparicio y Bazán (2006a, 2006b, 2008) tem aplicado ambas escalas em professores em exercício e Aliaga (2009) em estudantes universitários de ciências naturais, matemáticas e de ensino.

Estes estudos têm reportado alguns indicadores básicos do comportamento psicométrico de dita escala para suas respectivas populações, mas não se dispõe de um estudo no que possa ser mostrado suas características psicométricas, quando se aplica simultaneamente em contextos de países diferentes.

Nosso interesse especial é pela aprendizagem da Estatística e pelos instrumentos usados para medir as atitudes frente a ela, querendo assim contribuir a um melhor entendimento desta relação.

Assim, o estudo apresentado utiliza duas escalas para medir as atitudes frente à Estatística, a escala de Estrada (2002) e a escala de Cazorla et al (1999). Analisamos tanto as atitudes de alunos de graduação de diferentes países latino-americano (Peru, Chile, Colômbia e Brasil) como as adequadas propriedades psicométricas que permitam ter instrumento válidos e confiáveis para ser usados tanto na medição como no planejamento de atividades que possam corrigir atitudes negativas frente a Estatística possibilitando a probabilidade de criar uma aprendizagem mais positivo.

As características das escalas usadas para avaliar aos alunos participantes d a pesquisa nas 4 universidades (Peru, Chile, Colômbia e Brasil) são as seguintes:

\section{Escala de atitudes em relação à Estatística de Estrada (AEE)}

Como se descreve em Estrada (2002, 2009), esta escala se construiu combinando três escalas: Escala SAS (Roberts y Bilderback, 1980); Escala ATS (Wise, 1985) e a escala de Auzmendi (1992).

A partir das três escalas, elaborou-se uma primeira listagem de itens; seguidamente realizou-se uma seleção contemplando os diferentes componentes pedagógicos e antropológicos (Estrada 2002) e, dando um peso equivalente à cada um, se incluíram tanto itens afirmativos ("item 2: " A estatística ajuda a compreender o mundo de hoje"), como outros negativos. ("item 6: " Na universidade não deveriam ensinar Estatística"). 
A AEE é uma escala Likert, os itens constam de um enunciado numa escala de 5 pontos, que valorizam as respostas desde "muito em desacordo" (1 ponto) até "muito de acordo" (5 pontos).

A escala definitiva esta composta por 25 itens, 14 afirmativos (itens 2, 4, 5, 7, 8, 10, 12, $13,16,17,18,20,22,23$ ) e 11 negativos (itens $1,3,6,9,11,14,15,19,21,23,25$ ). (ver Estrada, 2002). Com uma confiabilidade alfa de Cronbach de 0.774 em uma mostra de 140 professores.

De acordo a resultados anteriores, Estrada (2002) encontrou um alfa de Cronbach de 0.774 em uma mostra de 140 professores espanhóis em exercício e formação. $\mathrm{Na}$ investigação feita por Aparicio et al. (2004) encontrou-se um alfa de Cronbach para um estudo pré teste - pós teste de 0.84 (pré-teste) e 0.83 (pós-teste) aplicado a 46 professores em exercício de Peru, e em um estudo similar Aparicio e Bazán (2006) com 87 professores atingiram um alfa de 0.83 (pré-teste) e 0.81 (pós-teste). Adicionalmente, Estrada et al. (2010) têm reportado um valor de alfa de 0.84 para uma amostra conjunta de 140 professores em exercício e formação de Peru e Espanha. Adicionalmente Aliaga (2009) tem encontrado uma fiabilidade de 0.84 em uma mostra de 234 estudantes universitários de uma universidade pública peruana enquanto Tarazona (2013) tem encontrado um alfa de Cronbach de 0.88 para 137 estudantes de média idade de uma universidade privada. Indicando desta maneira que a escala é confiável.

\section{Escala de atitudes frente à Estadística de Cazorla et al. (1999) (EAC).}

Foi introduzida no Brasil por Cazorla (1999) e Brito (2001). A validação das atitudes foi obtida mediante a adaptação de uma escala de atitudes em relação às matemáticas criada por Aiken (1974) traduzida e adaptada por Brito (1998). É uma escala de tipo Likert (unidimensional), composta por 20 itens, 10 afirmativas $(3,4,5,9,11,14,15,18,19,20)$ frente a 10 negativas $(1,2,6,7,8,10,12,13,16,17)$. Cada item apresenta quatro possibilidades de respostas: totalmente desacordo, desacordo, totalmente de acordo e de acordo que recebem uma pontuação de 1 a 4 . A soma das pontuações dos 20 itens da escala de atitudes pode variar de 20 a 80.

A escala apresenta uma fiabilidade de 0.95 , trabalhou-se com uma mostra de 1154 alunos de 15 cursos de graduação, de duas universidades privadas no Brasil. 
Em outros trabalhos, as fiabilidades encontradas em Aparicio et al. (2004) foram de 0.94 (pré-teste) e 0.92 (pós-teste) em uma mostra de 46 professores em um estudo de tipo pré experimental. Finalmente, também com um estudo pré experimental de 87 professores (Aparicio e Bazán, 2006), se encontrou um alfa de 0.92 (pré-teste) e 0.86 (pós-teste). Vendramini e Brito (2001) reportam um alfa de 0.93 em uma mostra de 319 universitários de diferentes especialidades. Aliaga (2009) reporta uma fiabilidade de 0.93 para uma mostra de 234 estudantes universitários.

Neste trabalho apresenta-se uma versão de 5 opções de resposta incluindo a opção de alternativa neutra, não considerada na escala original. Esta proposta foi originalmente provada por Aparicio et al (2004), Aparicio e Bazán (2006), Aliaga (2009) e por Tarazona et al. (2013). No Anexo 1 apresenta-se a descrição dos enunciados correspondentes para a versão desta escala. Optou-se esta estratégia para ter os itens da AEE e AEC na mesma escala de possíveis respostas.

A continuação apresentamos a maneira de artigos os estudos feitos em relação as atitudes frente à estatística com alunos ingressantes em 4 diferentes universidades em 4 casos: Peru, Chile, Colômbia e Brasil. 


\title{
CASO 1: ATITUDES FRENTE A ESTATÍSTICA EM ESTUDANTES \\ PERUANOS
}

\section{ATITUDES FRENTE Á ESTATÍSTICA EM UNIVERSITÁRIOS PERUANOS DE MÉDIA IDADE7}

\begin{abstract}
Resumo
Analisa-se as atitudes para a estatística de estudantes universitários que levam um primeiro curso de Estatística no marco do programa Estudante Adulto trabalhador de uma universidade privada de Lima em Peru. São consideradas duas escalas: Atitudes para a Estatística de Estrada (2002) (AEE) e Atitudes para a Estatística de Cazorla et ao (1999) (AEC).

A mostra corresponde a 137 estudantes de quatro especialidades de Engenharia, com idades entre 32 e 42 anos, sendo um $84 \%$ do sexo masculino e um $16 \%$ de sexo feminino.

A análise de itens foi feita considerando a Teoria Clássica dos Teste (TCT) e a Teoria de Resposta ao Item (TRI) baixo inferência bayesiana do modelo de resposta graduada de Samejima (Tarazona, 2013).

Os resultados mostram que AEC tem uma fiabilidade de 0.93, em contraste AEE tem 0.88 para uma versão recortada eliminando dois itens, e que ambas apresentam uma forte correlação. Não obstante AEE é a única que mostra diferenças por especialidade, especialmente entre os estudantes de Engenharia Industrial (atitudes mais positivas) e os estudantes de Engenharia de Telecomunicações e Redes (atitudes menos positivas). Finalmente outros fatores como sexo do estudante, permanência a diferentes grupos etários e experiência em um curso prévio de Estatística não resultaram significativos para explicar as atitudes para a Estatística em nenhuma escala
\end{abstract}

Palavras chave: atitude, psicometría, estudante adulto, ensino da estadística, medição.

\subsection{Metodologia}

\subsubsection{Participantes}

Os participantes deste estudo são de um programa de educação para adultos de média idade numa universidade privada de Lima, a qual convoca 3 vezes ao ano para seu exame de admissão para seus 11 cursos.

\footnotetext{
7 Baseado em Tarazona, Bazán e Aparicio (2013). “Actitudes hacia la estadística en universitarios peruanos de mediana edad". Artigo submetido para Revista Digital de Investigación en Docencia Universitaria, Universidad de ciencias aplicadas (UPC). Peru
} 
A população objetivo do estudo foram os estudantes da Faculdade de Engenharia que se encontravam matriculados num primeiro curso de estatística (Estatística para Engenharia I). Para o primeiro módulo do semestre 2012-II, os alunos matriculados nas cinco seções disponíveis desta disciplina encontravam-se distribuídos em quatro especialidades: Engenharia Industrial, Engenharia de Sistemas, Engenharia Civil e Engenharia de Redes e Comunicações como se aprecia na Tabela 13.

Foram estabelecidos alguns critérios de inclusão e exclusão.

Os critérios de inclusão foram:

- Estudantes que estavam presentes durante a semana do 20 ao 26 da agosto do 2012 nos horários correspondentes às cinco seções da disciplinas de Estatística para Engenharia I:

- Estudantes matriculados no curso de Estatística para Engenharia I.

Os critérios de exclusão foram:

- Estudantes que não tenham respondido mais de cinco itens na escala

- Estudantes que não consignaram dados do curso

- Estudantes que não responderam à pergunta sobre se já tinham tido experiência prévia com alguma disciplina de estatística

- Estudantes que não consignaram sua idade

- Estudantes maiores de 42 anos

- Estudantes que não consignaram dados sobre seu gênero.

A população efetiva e a percentagem de cobertura atingido mostram-se na Tabela 13. Conseguiu-se avaliar ao $66 \%$ dos estudantes dos 4 cursos de engenharia, tendo-se conseguido uma maior cobertura para o curso de Engenharia Industrial (70\%) e uma menor em Telecomunicações. (53\%). 
Tabela 13. População, população efetiva e percentagem de cobertura no estudo.

\begin{tabular}{llccc}
\hline \multicolumn{1}{c}{ Curso } & População & $\begin{array}{c}\text { Total de } \\
\text { avaliados }\end{array}$ & $\begin{array}{c}\text { População } \\
\text { Efetiva }\end{array}$ & \% de Cobertura \\
\hline Engenharia Industrial & 121 & 99 & 85 & $70 \%$ \\
Engenharia de Sistemas & 59 & 42 & 36 & $61 \%$ \\
Engenharia Civil & 9 & 7 & 6 & $67 \%$ \\
Engenharia de Redes em & 19 & 11 & 10 & $53 \%$ \\
Telecomunicações & & & 137 & $66 \%$ \\
\hline Total & 208 & 159 & 10 & \\
\hline
\end{tabular}

Os participantes do estudo estiveram conformados por 137 estudantes entre 32 e 42 anos, dos quais o $84 \%$ é de sexo masculino e um $52 \%$ que já tinham levado um curso de estatística anteriormente. Os estudantes foram agrupados por grupos etários, dos quais o $35 \%$ dos estudantes se encontra entre os 22 e 26 anos, $39.4 \%$ entre os 27 e 31 anos, $17.5 \%$ entre 32 e 36 anos e o $8 \%$ maiores a 37 anos.

\subsubsection{Instrumentos}

São usadas as escalas de Escala de atitudes em relação à Estatística de Estrada (AAE) e a Escala de atitudes frente à Estadística de Cazorla et al. (1999) (AAC).

\subsection{Análises}

Para a cada escala foi desenvolvido uma análise psicométrico baseado em uma análise de itens. A qualidade dos itens das duas escalas de atitude, foi avaliada usando tanto o enfoque da Teoria Clássica dos Teste (TCT) como da Teoria de Resposta ao Item (TRI) através do Modelo de Resposta graduado logístico de dois parâmetros (2PL-GRM) de Samejima (1969) considerando que os itens das escalas são policotómicos. Para o caso da TCT consideraram-se à média (Me), Desvio padrão (De), correlação item-total eliminando o item (rit) e alfa de Cronbach da escala sem considerar o item (alpha) e de toda a escala (ver Pasquali, 2003). Estes indicadores foram obtidos usando a livraria psych do programa R. Para o modelo 2PL-GRM se obtiveram os parâmetros de discriminação e dificuldade dos itens. Este modelo é descrito a continuação. 
Modelo de Resposta Graduada Logístico de dois Parâmetros (2PL-GRM).

Considerando um conjunto de $\mathrm{i}=1, \ldots, \mathrm{n}$ sujeitos avaliados em um instrumento com $\mathrm{j}=$ $1, \ldots, \mathrm{J}$ itens, onde a cada item tem $\mathrm{m}$ categorias com resposta policotómica ordinal, o modelo 2PL-GRM fica definido como:

$$
\begin{gathered}
Y_{i j} \mid u_{i}, \varepsilon_{j} \sim \text { Categórica }\left(P_{i j 1}, \ldots, P_{i j m}\right) \\
P_{i j k} \equiv P\left(Y_{i j}=k \mid u_{i}, \varepsilon_{j}\right)= \begin{cases}\Psi\left(\eta_{i j k}\right) & \text { si } k=1 \\
\Psi\left(\eta_{i j k}\right)-\Psi\left(\eta_{i j(k-1)}\right) & \text { si } 2<k<m \\
1-\Psi\left(\eta_{i j(k-1)}\right) & \text { si } k=m \\
\eta_{i j k}=\mathrm{a}_{\mathrm{j}}\left(b_{j k}-u_{i}\right)\end{cases} \\
-\infty=b_{j 0}<b_{j 1}<\cdots<b_{j(m-1)}<b_{j m}=\infty \\
\mathrm{i}=1, \ldots, \mathrm{n} ; \mathrm{j}=1, \ldots \mathrm{J} ; \mathrm{k}=1, \ldots, \mathrm{m}
\end{gathered}
$$

Donde $Y_{i j}$ é uma variável aleatória manifesta condicional que modela a resposta politómica do indivíduo i no item $\mathrm{j}$, tomando diferentes valores categóricos ordinais $k \in$ $\{1, \ldots m\}$, que neste caso são as categorias resposta com $m=5, P_{i j k}$ são as probabilidades condicionais de responder a categoria $\mathrm{k}$ no item $\mathrm{j}, \eta_{i j k}$ o predictor latente linear relacionado com a habilidade (atitude) $u_{i} \in \mathbb{R}, \varepsilon_{j}=\left(\mathrm{a}_{\mathrm{j}}, b_{j 1}<\cdots<b_{j(m-1)}\right)^{\prime}$ o vetor de parâmetros do item j relacionado ao parâmetro de discriminação $a_{j}$ e os parâmetros de discriminação $b_{j k}$ y $\Psi(\quad)$ a função de densidade acumulada da distribuição logística padrão.

Para estimar os parâmetros do modelo aplicou-se inferência Bayesiana com MCMC (Métodos Montecarlo via Correntes de Markov) usando a livraria R2WinBUGS del programa R (R Core Team, 2013) e códigos implementados no programa WinBUGS (Lunn et al., 2000). Maiores detalhes sobre a estimativa do modelo podem ser revisados em Tarazona (2013).

Depois da análise de itens é analisada as propriedades das versões finais das escalas. Esta análise inclui a descrição das pontuações como valores mínimo, máximo, média, desviarão padrão, simetria e curtosis, bem como um reporte da fiabilidade usando alfa de Cronbach (Pasquali,2003). 
Finalmente a relação entre ambas escalas é analisada considerando uma análise de correlação e diferentes comparações das pontuações totais são feitas considerando especialidade, sexo, experiência prévia em um grupo de Estatística e grupos etários.

\subsection{Resultados}

\subsubsection{Analise psicométrico da escala de Estrada}

A análise dos itens da Escala de Atitudes frente à Estatística de Estrada foi realizado usando os enfoques da TCT e da TRI. É importante realçar que os itens foram codificados de modo que uma pontuação maior vá associada a uma atitude mais positiva e vice-versa, pelo que nos itens $1,3,6,9,11,14,15,19,21,23$ y 25 , que têm um enunciado desfavorável à atitude que tratamos de medir, a pontuação outorgada foi a contrária ao resto de perguntas; isto é, que para eles se considerou a $1=$ muito de acordo, $2=$ de acordo, $3=$ indiferente, $4=$ em desacordo e $5=$ muito em desacordo. Os resultados da estimativa dos parâmetros segundo ambas perspectivas são mostrados na Tabela 14 . 
Tabela 14. Análise de itens da versão original de Estrada

\begin{tabular}{|c|c|c|c|c|c|c|c|c|c|}
\hline \multirow[b]{2}{*}{ Ítem } & \multicolumn{3}{|c|}{ Índices Clássicos } & \multicolumn{6}{|c|}{ Índices do Modelo de Resposta Graduada } \\
\hline & $\mathrm{Me}$ & De & Rit & Alpha & b1 & b2 & b3 & b4 & $\mathrm{A}$ \\
\hline 1 & 3.511 & 1.008 & 0.331 & 0.855 & -4.037 & -2.214 & 0.214 & 2.695 & 0.800 \\
\hline 2 & 4.044 & 0.930 & 0.354 & 0.854 & -3.051 & -1.752 & -1.409 & 1.264 & 1.159 \\
\hline 3 & 2.540 & 1.098 & -0.104 & 0.871 & -103.297 & 24.009 & 66.339 & 158.041 & 0.091 \\
\hline 4 & 3.737 & 0.877 & 0.240 & 0.857 & -7.033 & -3.549 & -0.815 & 3.356 & 0.630 \\
\hline 5 & 3.591 & 0.967 & 0.304 & 0.856 & -4.902 & -2.108 & -0.426 & 3.300 & 0.738 \\
\hline 6 & 4.277 & 0.913 & 0.360 & 0.854 & -3.705 & -2.478 & -1.442 & 0.425 & 1.031 \\
\hline 7 & 3.270 & 0.827 & 0.527 & 0.849 & -2.658 & -1.248 & 0.840 & 2.873 & 1.345 \\
\hline 8 & 3.022 & 0.903 & 0.477 & 0.850 & -2.894 & -0.483 & 1.022 & 3.889 & 1.163 \\
\hline 9 & 3.657 & 1.025 & 0.454 & 0.851 & -2.989 & -1.129 & -0.234 & 1.740 & 1.269 \\
\hline 10 & 3.796 & 0.806 & 0.510 & 0.849 & -3.131 & -1.623 & -0.345 & 1.806 & 1.455 \\
\hline 11 & 3.526 & 0.908 & 0.563 & 0.847 & -2.429 & -1.228 & 0.262 & 1.894 & 1.630 \\
\hline 12 & 3.803 & 0.794 & 0.613 & 0.846 & -2.147 & -1.511 & -0.185 & 1.530 & 2.040 \\
\hline 13 & 3.803 & 0.736 & 0.627 & 0.847 & -2.474 & -1.648 & -0.212 & 1.710 & 1.873 \\
\hline 14 & 2.927 & 1.109 & 0.388 & 0.853 & -2.725 & -0.060 & 1.025 & 3.418 & 0.935 \\
\hline 15 & 3.788 & 0.935 & 0.522 & 0.848 & -2.903 & -1.482 & -0.390 & 1.679 & 1.322 \\
\hline 16 & 3.467 & 0.892 & 0.555 & 0.847 & -2.258 & -1.164 & 0.330 & 2.177 & 1.624 \\
\hline 17 & 3.036 & 0.950 & 0.311 & 0.855 & -3.603 & -0.807 & 1.290 & 4.370 & 0.847 \\
\hline 18 & 3.956 & 0.923 & 0.144 & 0.861 & -10.456 & -5.573 & -2.540 & 2.811 & 0.523 \\
\hline 19 & 3.934 & 1.038 & 0.414 & 0.852 & -3.024 & -1.837 & -0.639 & 1.105 & 1.121 \\
\hline 20 & 3.474 & 0.768 & 0.459 & 0.851 & -3.601 & -1.659 & 0.411 & 2.868 & 1.241 \\
\hline 21 & 4.584 & 0.764 & 0.439 & 0.851 & -2.609 & -2.090 & -1.239 & -0.340 & 1.598 \\
\hline 22 & 3.102 & 0.816 & 0.368 & 0.853 & -4.143 & -1.609 & 1.653 & 4.644 & 0.823 \\
\hline 23 & 4.058 & 0.998 & 0.596 & 0.845 & -2.063 & -1.202 & -0.419 & 0.660 & 2.013 \\
\hline 24 & 4.029 & 0.795 & 0.448 & 0.851 & -3.550 & -1.928 & -1.073 & 1.419 & 1.274 \\
\hline 25 & 3.730 & 0.827 & 0.596 & 0.847 & -2.615 & -1.471 & -0.061 & 1.603 & 1.774 \\
\hline
\end{tabular}

Nota: $\mathrm{Me}=$ media, $\mathrm{De}=$ desvio padrão, rit = correlação ítem-total eliminando el item, alpha = alfa de Cronbach da escala sem considerar o item, $b_{j}=$ parâmetro de dificuldade, $a=$ parâmetro de discriminação.

Encontramos que os itens 3 e 18 são os itens que apresentam correlação não significativa com o resto da escala. Inclusive o item 3, "Através da Estatística se pode manipular a realidade" encontra-se correlacionado de maneira negativa com os demais itens indicando de que se trata de um item que não mede o mesmo que os demais. A escala apresenta uma confiabilidade (índice alfa de Cronbach) de 0.857 e a eliminação dos itens anteriores incrementaria ligeiramente esta confiabilidade. 
Em relação aos parâmetros obtidos com o modelo 2PL-GRM; Zickar et al (2002) indicam que se a 1 > o item proporciona uma discriminação aceitável entre pessoas e Hafsteinsson, Donovan e Breland (2007) consideram que um a > 2 é um indicador de alta discriminação do item. Por outro lado, Thiessen (1986) recomenda eliminar da escala aos itens que tenham um poder de discriminação demasiado baixo $(\mathrm{a}<0.50)$. Considerando estes critérios encontrou-se que os itens $1,3,4,5,14,17,18$ e 22 apresentaram um poder discriminativo baixo, tendo um deles um valor inferior a 0.50 (item 3) que ademais apresenta parâmetros de dificuldade estimados muito altos.

Sobre a base destes resultados resulta conveniente excluir da escala aos itens 3 e 18 como resultam muito pouco discriminativos, além de ter uma correlação não significativa. Considerando esta evidência realizou-se uma segunda análise de itens excluindo os dois itens com comportamento psicométrico inadequado. Os resultados mostram-se na Tabela 15.

Consideramos que a evidência de baixa discriminação dos itens $1,4,5,17$ e 22 é insuficiente para retirar lhos da escala (a 0.50) > além de que todos os itens apresentam correlação significativa com o resto da escala. Seguindo os resultados reportados por Estrada, Bazán e Aparicio (2010, 2013) para uma mostra de professores, confirma-se que a escala está conformada por 23 itens, com os quais se obtém uma confiabilidade igual a 0.875. O item 12, "Encontro interessante o mundo da Estatística", foi o que mostrou uma discriminação mais alta $(\mathrm{a}=2.014)$. 
Tabela 15. Análise de itens da versão recortada de Estrada

\begin{tabular}{llllllllll}
\hline & \multicolumn{6}{l}{ Índices Clássicos } & \multicolumn{7}{l}{ Índices do Modelo de Resposta Graduada } \\
Ítem & Me & De & rit & Alpha & b1 & b2 & b3 & b4 & A \\
\hline 1 & 3.511 & 1.008 & 0.313 & 0.875 & -4.094 & -2.249 & 0.203 & 2.710 & 0.789 \\
2 & 4.044 & 0.930 & 0.384 & 0.872 & -3.106 & -1.783 & -1.442 & 1.259 & 1.150 \\
4 & 3.737 & 0.877 & 0.268 & 0.875 & -7.018 & -3.558 & -0.833 & 3.334 & 0.629 \\
5 & 3.591 & 0.967 & 0.324 & 0.874 & -4.979 & -2.133 & -0.438 & 3.314 & 0.733 \\
6 & 4.277 & 0.913 & 0.376 & 0.872 & -3.703 & -2.477 & -1.453 & 0.410 & 1.027 \\
7 & 3.270 & 0.827 & 0.531 & 0.868 & -2.692 & -1.275 & 0.835 & 2.880 & 1.335 \\
8 & 3.022 & 0.903 & 0.489 & 0.869 & -2.918 & -0.495 & 1.015 & 3.904 & 1.156 \\
9 & 3.657 & 1.025 & 0.451 & 0.870 & -3.042 & -1.151 & -0.248 & 1.751 & 1.252 \\
10 & 3.796 & 0.806 & 0.510 & 0.868 & -3.179 & -1.662 & -0.364 & 1.810 & 1.445 \\
11 & 3.526 & 0.908 & 0.569 & 0.866 & -2.441 & -1.245 & 0.249 & 1.887 & 1.621 \\
12 & 3.803 & 0.794 & 0.619 & 0.866 & -2.190 & -1.541 & -0.205 & 1.527 & 2.014 \\
13 & 3.803 & 0.736 & 0.612 & 0.866 & -2.530 & -1.694 & -0.230 & 1.721 & 1.835 \\
14 & 2.927 & 1.109 & 0.399 & 0.872 & -2.716 & -0.066 & 1.021 & 3.418 & 0.938 \\
15 & 3.788 & 0.935 & 0.512 & 0.868 & -2.941 & -1.519 & -0.417 & 1.675 & 1.312 \\
16 & 3.467 & 0.892 & 0.563 & 0.867 & -2.280 & -1.188 & 0.316 & 2.178 & 1.616 \\
17 & 3.036 & 0.950 & 0.321 & 0.874 & -3.618 & -0.830 & 1.271 & 4.344 & 0.849 \\
19 & 3.934 & 1.038 & 0.404 & 0.872 & -3.089 & -1.892 & -0.664 & 1.106 & 1.101 \\
20 & 3.474 & 0.768 & 0.463 & 0.870 & -3.622 & -1.689 & 0.397 & 2.872 & 1.236 \\
21 & 4.584 & 0.764 & 0.440 & 0.870 & -2.671 & -2.140 & -1.282 & -0.366 & 1.565 \\
22 & 3.102 & 0.816 & 0.355 & 0.873 & -4.153 & -1.623 & 1.649 & 4.665 & 0.819 \\
23 & 4.058 & 0.998 & 0.597 & 0.865 & -2.109 & -1.234 & -0.439 & 0.653 & 1.979 \\
24 & 4.029 & 0.795 & 0.451 & 0.870 & -3.650 & -1.989 & -1.115 & 1.447 & 1.241 \\
25 & 3.730 & 0.827 & 0.587 & 0.866 & -2.636 & -1.491 & -0.072 & 1.611 & 1.755 \\
\hline & & & & &
\end{tabular}

Nota: $\mathrm{Me}=$ media, $\mathrm{De}=$ desvio padrão, rit = correlação item-total eliminando o item, alpha = alfa de Cronbach da escala sem considerar $\mathrm{o}$ item, $\mathrm{b}_{\mathrm{j}}=$ parâmetro de dificuldade, $a=$ parâmetro de discriminação.

\subsubsection{Analise psicométrica da escala de Cazorla}

A análise dos itens da Escala de Atitudes frente à Estatística de Cazorla foi feito de maneira similar à escala de Estrada usando os enfoques da TCT e da TRI.

Do mesmo modo, os itens que apresentaram uma atitude negativa (itens 26, 27, 31, 32, $33,35,37,38,41$ e 42) foram codificados de maneira inversa. Os resultados da estimação dos parâmetros são mostrados na Tabela 16. 
Tabela 16. Análise de itens da versão original de Cazorla

\begin{tabular}{|c|c|c|c|c|c|c|c|c|c|}
\hline \multirow[b]{2}{*}{ Ítem } & \multicolumn{3}{|c|}{ Índices Clássicos } & \multicolumn{6}{|c|}{ Índices do Modelo de Resposta Graduada } \\
\hline & $\mathrm{Me}$ & De & rit & Alpha & b1 & b2 & b3 & b4 & $\mathrm{a}$ \\
\hline 26 & 3.599 & 0.966 & 0.551 & 0.932 & -2.663 & -1.324 & 0.027 & 1.846 & 1.423 \\
\hline 27 & 3.788 & 0.973 & 0.727 & 0.929 & -2.357 & -1.110 & -0.166 & 1.256 & 2.013 \\
\hline 28 & 3.628 & 0.805 & 0.657 & 0.930 & -2.971 & -1.333 & -0.122 & 2.254 & 1.623 \\
\hline 29 & 3.307 & 0.782 & 0.630 & 0.931 & -2.512 & -1.356 & 0.685 & 3.024 & 1.536 \\
\hline 30 & 3.234 & 0.740 & 0.534 & 0.932 & -3.507 & -1.527 & 1.080 & 3.514 & 1.210 \\
\hline 31 & 3.891 & 0.863 & 0.648 & 0.930 & -2.656 & -1.639 & -0.203 & 1.199 & 1.822 \\
\hline 32 & 3.774 & 0.866 & 0.600 & 0.931 & -2.923 & -1.405 & -0.269 & 1.618 & 1.634 \\
\hline 33 & 3.766 & 0.941 & 0.721 & 0.929 & -2.428 & -1.075 & -0.176 & 1.288 & 2.116 \\
\hline 34 & 3.745 & 0.697 & 0.613 & 0.931 & -2.838 & -1.905 & -0.465 & 2.489 & 1.530 \\
\hline 35 & 3.861 & 0.901 & 0.700 & 0.929 & -2.509 & -1.347 & -0.209 & 1.182 & 2.020 \\
\hline 36 & 3.358 & 0.774 & 0.570 & 0.932 & -2.874 & -1.835 & 0.781 & 3.030 & 1.288 \\
\hline 37 & 3.810 & 0.871 & 0.605 & 0.931 & -2.984 & -1.431 & -0.343 & 1.580 & 1.585 \\
\hline 38 & 3.745 & 0.900 & 0.642 & 0.930 & -2.857 & -1.378 & -0.168 & 1.524 & 1.676 \\
\hline 39 & 3.416 & 0.854 & 0.764 & 0.928 & -2.320 & -0.959 & 0.358 & 2.229 & 2.050 \\
\hline 40 & 3.307 & 0.791 & 0.589 & 0.931 & -2.902 & -1.355 & 0.691 & 3.089 & 1.378 \\
\hline 41 & 3.650 & 0.854 & 0.555 & 0.932 & -3.020 & -1.522 & -0.133 & 2.119 & 1.417 \\
\hline 42 & 3.839 & 0.933 & 0.604 & 0.931 & -2.899 & -1.467 & -0.148 & 1.199 & 1.662 \\
\hline 43 & 3.088 & 0.732 & 0.482 & 0.933 & -3.439 & -1.668 & 1.719 & 4.321 & 1.007 \\
\hline 44 & 3.277 & 0.829 & 0.530 & 0.932 & -2.985 & -1.213 & 0.718 & 3.011 & 1.340 \\
\hline 45 & 3.445 & 0.795 & 0.711 & 0.929 & -2.379 & -1.334 & 0.344 & 2.506 & 1.796 \\
\hline
\end{tabular}

Nota: $\mathrm{Me}=$ media, $\mathrm{De}=$ desvio padrão, rit $=$ correlação item-total eliminando o item, alpha $=$ alfa de Cronbach da escala sem considerar o item, $b_{j}=$ parâmetro de dificuldade, $a=$ parâmetro de discriminação.

Temos encontrado que todos os itens apresentam correlação adequada e a exclusão de algum deles não incrementa a confiabilidade obtida com a escala (alfa de Cronbach igual a 0.934). Em relação aos indicadores obtidos com o GRM, todos os itens mostraram uma discriminação aceitável segundo o critério de Zickar et al. (2002), com estes resultados se confirma que a escala está conformada pelos 20 itens. O item 33, “A Estatística me deixa inquieto(a), descontente, irritado(a) e impaciente", tem a discriminação mais alta (a $=2.116)$.

\subsubsection{Analise das escalas finais}

$\mathrm{Na}$ Tabela 17 são apresentadas as características psicométricas definitivas das duas escalas de atitude frente à estatística tanto desde a perspectiva clássica, considerando as pontuações totais, como da TRI com a escala de atitude estimada baixo o GRM. Para este 
último caso, a atitude foi estimada pelo modelo usando uma escala normal regular (média igual a 0 e variância igual a 1). Posteriormente se fiz uma transformação linear dos valores obtidos com o fim de que a escala tenha uma média de 300 e um desvio regular de 50 .

Tabela 17. Características definitivas da escala

\begin{tabular}{lllll}
\hline & \multicolumn{2}{l}{ Escala de Estrada } & \multicolumn{2}{l}{ Escala de Cazorla } \\
& Escore & $\begin{array}{l}\text { Escala } \\
\text { Transformada }\end{array}$ & ERM & Escala GRM \\
& & & Transformada \\
\hline Mínimo & 60.00 & 237.55 & 44.00 & 218.35 \\
Máximo & 110.00 & 456.53 & 99.00 & 480.25 \\
Media & 84.17 & 319.54 & 71.53 & 318.83 \\
Des. Padrão & 10.69 & 44.14 & 11.28 & 49.36 \\
Simetría & 0.10 & 0.66 & -0.14 & 0.48 \\
Curtosis & -0.42 & 0.61 & -0.22 & 0.65 \\
Alfa de Cronbach & 0.88 & & 0.93 & \\
\hline
\end{tabular}

A distribuição das duas escalas é mostrada na figura 7, onde podemos observar que as atitudes se encontram distribuídas em pontuações altas, se destacando maior variabilidade da atitude na escala de Cazorla.

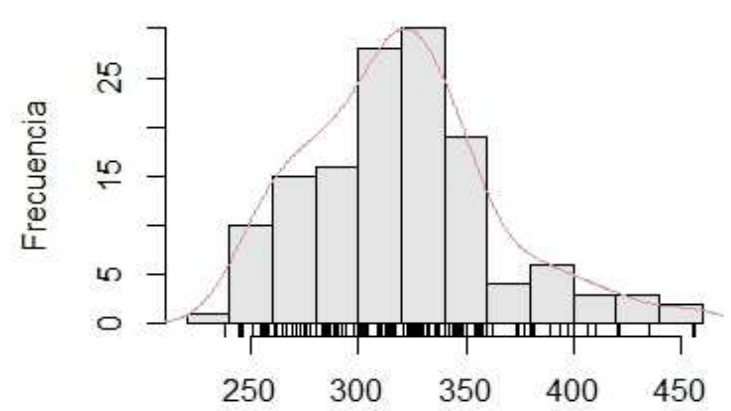

Escala de Estrada Transformada

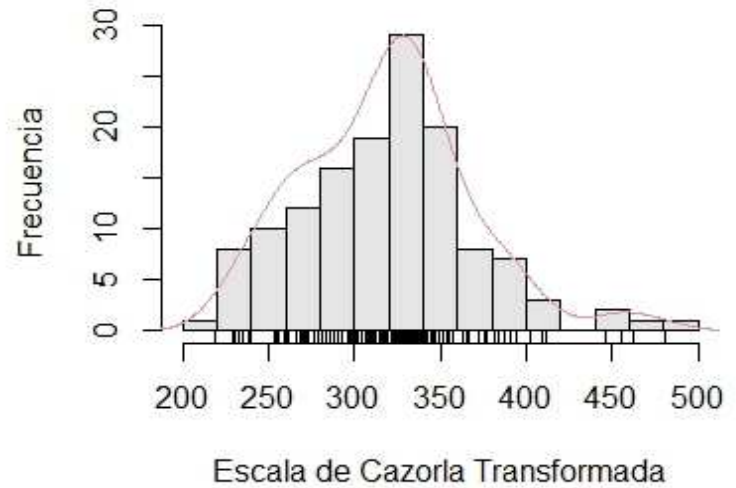

Figura 7. Distribución de puntajes de la escala de Actitudes de Estrada y de Cazorla usando la escala transformada del Modelo de Respuesta Graduada

A Figura 8 apresenta um diagrama de dispersão das atitudes medidas nas duas escalas. O coeficiente de correlação de Pearson foi calculado para avaliar a relação existente entre as escalas. Encontrou-se uma associação positiva significativa entre ambas variáveis, $r=$ $0.791, \mathrm{p}<0.001$. Em geral, teve uma forte correlação positiva entre as duas escalas de 
atitudes, isto é, que os incrementos na atitude na escala de Estrada estão associados com incrementos na atitude na escala de Cazorla e por tanto são intercambiáveis.

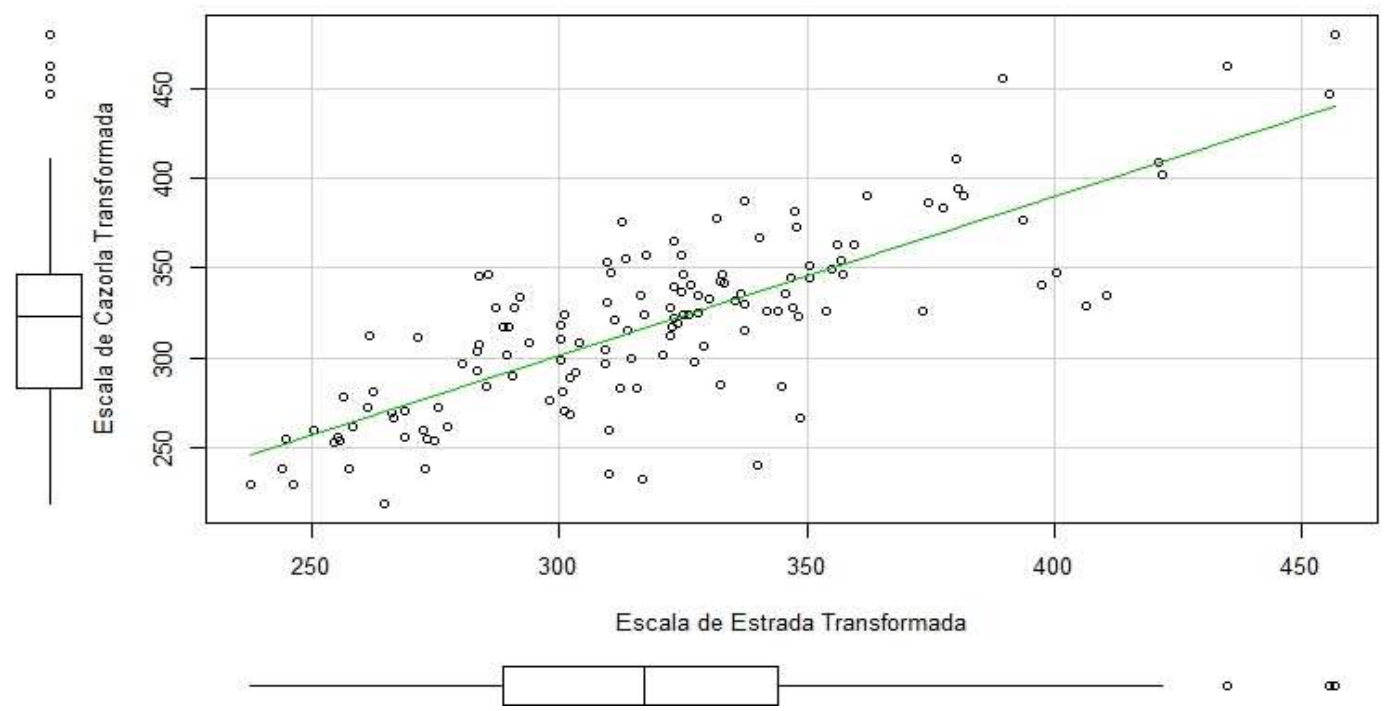

Figura 8. Diagrama de dispersão dos escores da escala de Atitudes de Estrada e de Cazorla usando a escala transformada do Modelo de Resposta Graduada

Realizou-se uma análise de variância (ANVA) de uma via para avaliar o efeito do curso nas escalas de atitude. Para a escala de Estrada, o ANVA mostrou diferenças significativas entre as atitudes dos estudantes dos quatro cursos de engenharia, $\mathrm{F}(3,133)$ $=3.839, \mathrm{p}=0.011$. As provas de comparações múltipla HSD de Tukey indicaram diferenças significativas $(\mathrm{p}=0.008$ ), entre os cursos de Engenharia Industrial (atitude mais positiva) e Engenharia de Telecomunicações e Redes (atitudes menos positivas) mas não indicaram diferenças significativas entre os demais cursos (Tabela 18). No caso da escala de Cazorla, não tem evidência significativa de que existam diferenças na atitude entre os diferentes cursos, $\mathrm{F}(3,133)=1.216, \mathrm{p}=0.306$.

Tabela 18. Médias e desvios padrão da atitude na escala transformada de Estrada por cursos

\begin{tabular}{llccc}
\hline & $\begin{array}{c}\text { Engenharia de Redes e } \\
\text { Telecomunicações }\end{array}$ & $\begin{array}{c}\text { Engenharia de } \\
\text { Sistemas }\end{array}$ & $\begin{array}{c}\text { Engenharia } \\
\text { Civil }\end{array}$ & $\begin{array}{c}\text { Engenharia } \\
\text { Industrial }\end{array}$ \\
\hline $\begin{array}{l}\text { Media } \\
\text { Desvio }\end{array}$ & $280.544_{\mathrm{a}}$ & $312.927_{\mathrm{ab}}$ & $326.307_{\mathrm{ab}}$ & $326.455_{\mathrm{b}}$ \\
Padrão & 24.668 & 46.092 & 44.112 & 11.178 \\
\hline
\end{tabular}

* Nota. Las desviaciones estándar se encuentran entre paréntesis. Las medias que no comparten el mismo subíndice difieren para $\mathrm{p}<0.05$ de acuerdo a las prueba de comparación múltiple HSD de Tukey. 
$\mathrm{Na}$ Tabela 19 mostram-se os resultados obtidos da aplicação das provas t e F para comparar a atitude por gênero, experiência prévia com uma disciplina de estatística e grupo etário, os quais indicam que não há evidência de que existam diferenças significativas entre os grupos considerados para ditas variáveis. Os quais indicam que não há evidência de que existam diferenças significativas entre os grupos considerados para essas variáveis.

Tabela 19. Resultados das provas t e F para as atitudes nas escalas de Estrada e Cazorla por gênero, experiência prévia com uma disciplina de estatística e grupo etário

\begin{tabular}{lllc}
\hline Variável & Escala & Estatístico de Prova & $\mathrm{p}$ \\
\hline Gênero & Estrada & $\mathrm{t}(135)=-0.583$ & 0.561 \\
Experiência previa com & Cazorla & $\mathrm{t}(135)=-1.213$ & 0.227 \\
Uma disciplina de Estadística & Estrada & $\mathrm{t}(135)=-1.719$ & 0.088 \\
Grupo etário & Cazorla & $\mathrm{t}(135)=-1.395$ & 0.165 \\
& Estrada & $\mathrm{F}(3,133)=0.478$ & 0.698 \\
& Cazorla & $\mathrm{F}(3,133)=1.682$ & 0.174 \\
\hline
\end{tabular}

\subsection{Comentários finais}

Neste estudo propusemos-nos avaliar as características psicométricas de duas escalas de atitudes: A escala proposta por Estrada et al (2003) e a escala proposta por Cazorla et al (1999), em uma população de estudantes de média idade em uma universidade privada de Lima-Peru.

Os resultados mostram que a escala de Cazorla de 20 itens mostra uma confiabilidade de 0.93, em contraste com a escala de Estrada que mostra uma confiabilidade de 0.88 para uma versão recortada eliminando dois itens.

Estes resultados confirmam os achados por Aparicio, Bazán e Abdounur (2004), Aparicio e Bazán (2006). Estrada, Bazán e Aparicio (2010, 2013), Aliaga e Bazán (2009) e Aliaga (2009) para estas mesmas escalas em professores de escola e em universitários de uma faculdade de Ciências.

Para o estudo das características psicométricas foi incluído o uso da TRI, especificamente o modelo de resposta graduada. Este uso contrasta com o uso de outros modelos da TRI 
considerados para outras escalas de atitudes como é o caso do modelo de créditos parciais usado por Vendramini e Silva (2012) para a análise psicométrico de outra escala de atitudes adaptada ao português.

De um modo geral os resultados indicam um ajuste bom para ambas escalas, sugerindo no caso da Escala de Estrada a eliminação de dois itens. Desta maneira, esta pesquisa proporciona evidência de dois instrumentos adaptados ao meio peruano que podem ser usados em populações de média idade e equivalentes.

Os resultados também confirmam uma forte correlação entre as duas escalas, sendo por tanto intercambiáveis, não obstante a escala de Estrada é a única que mostra diferenças por curso, especialmente entre os estudantes de Engenharia Industrial (atitudes mais positivas) e os estudantes de Engenharia de Telecomunicações e Redes (atitudes menos positivas).

Outros fatores como gênero do estudante, pertencia a diferentes grupos etários e experiência em uma disciplina de Estatística não resultaram significativos para explicar as atitudes para a Estatística em nenhuma escala.

Em geral encontramos atitudes mais positivas que negativas na amostra de estudantes, aspecto que também é encontrado por exemplo por Vendramini e Silva (2012) para estudantes de graduação de diferentes cursos no Brasil, e por Aliaga (2009) para estudantes de graduação no Peru.

Consideramos que este aspecto é relevante tendo em conta que este tipo de estudantes decide que, como e quando aprende como assinala Caraballo (2007). Assim, este resultado deve ser valorizado pelos docentes desta especialidade para desenhar um conteúdo didático que responda a estas expectativas favoráveis frente à disciplina de Estatística. 


\title{
CASO 2: ATITUDES FRENTE A ESTATÍSTICA EM ESTUDANTES CHILENOS
}

\section{ATITUDES FRENTE À ESTATÍSTICA EM UNIVERSITÁRIOS DA ÁREA DAS CIÊNCIAS DE UMA UNIVERSIDADE PÚBLICA DE CHILE ${ }^{8}$}

\begin{abstract}
Resumo
A Avaliação das atitudes para as Ciências é importante para explicar o desempenho nestas áreas do conhecimento. Neste estudo são revisadas duas escalas de Atitudes para a Estatística, as propostas por Estrada (2002) (AEE) e Cazorla et al. (1999) (AEC), usadas na Espanha e no Brasil, e pela primeira vez são aplicadas em universitários chilenos.

A mostra definitiva compreende 113 universitários ingressantes das especialidades de Ing. Estatística, Ing. Matemática, Licenciatura em Ciência da Computação e Licenciatura/Pedagogia em Educação Matemática e Computação e Licenciatura/Pedagogia em Educação Matemática e Computação que não tinham seguido elou completado ainda alguma disciplina relacionada com Estatística. A mostra apresenta uma idade entre 17 a 25 anos e está formado por um 61.9\% de sexo masculino e $38.1 \%$ de sexo feminino.

A análise de itens para as escalas e uma versão composta AECom sugere eliminar 4 itens da escala AEE. As versões recortadas da AEE e AECom apresentam uma ótima fiabilidade, de 0.84 e 0.95 respectivamente, enquanto a AEC apresenta 0.94 .

Através de uma análise fatorial encontra-se evidência de multidimensionalidade nas escalas finais, a AECom com 4 fatores, a AEE com 5 fatores e a AEC com 2 fatores.

Não foram encontradas diferenças nas atitudes por sexo mas sim por especialidades a favor da especialidade da Ing. Estatística em relação às outras três especialidades, confirmando a menor atitude esperada dos estudantes destas especialidades. Finalmente algumas sugestões de uso das escalas são apresentadas.
\end{abstract}

Palavras Chave: Escala, atitudes frente à estatística, análise de itens, dimensionalidad, fiabilidade, ingressantes universitários.

\subsection{Metodologia}

\subsubsection{Participantes}

A população de interesse pertence a uma universidade pública da cidade de Santiago de Chile, a qual convoca uma vez ao ano as respectivas matrículas, através do exame de admissão nacional chileno, a qual é denominado Prova de Seleção Universitária (PSU). Existe uma única forma de postulação que se realiza através deste exame geral e que inclui a todas as universidades estatais e privadas tradicionais do país.

\footnotetext{
${ }^{8}$ Artigo submetido a revista Educação Matemática Pesquisa. PUCPSP
} 
O exame nacional de admissão para o ano 2013, teve 272 mil 266 inscritos, registrandose 233.302 provas efetivamente rendidas. Foram 118 mil 208 as postulações às carreiras a nível nacional, dos quais 95.300 foram selecionados em algum curso do sistema universitário tradicional. Finalmente se matricularam 74.990 no país.

A Universidade de Santiago de Chile contou com 26 mil 485 postulantes. Destas, 12.108 foram selecionadas ou em lista de espera (postulações efetivas), os quais competiram para uma das 3 mil 535 vagas de 65 especialidades agrupadas em 7 Faculdades, a Escola de Arquitetura e o Programa de Bacharelato.

No Departamento de Matemática e Ciência da Computação, unidade menor dependente da Faculdade de Ciência, registrou-se uma matrícula de 45 estudantes em Engenharia Estatística, 42 para a Engenharia Matemática, 40 na Licenciatura de Ciência da Computação e 34 para a Licenciatura em Matemática e Computação, totalizando um total de 161 estudantes pertencentes à área de Ciência na instituição.

A população objetivo do estudo foram os estudantes ingressantes dos cursos previamente mencionados, que tenham registrado matrícula de rendimento na universidade o ano 2013, dado que não têm uma atitude definida para a estatística e que poderiam permanecer durante o desenvolvimento do curso.

Na Tabela 20 se observa a população avaliada e a população efetiva (depois do processo de depuração do banco de dados) e também a percentagem de cobertura atingido.

Tabela 20. População, população efetiva e percentagem de cobertura do estudo em alunos de ciências 1er ano

\begin{tabular}{lccccc}
\hline \multicolumn{1}{c}{ Especialidade } & $\begin{array}{c}\text { Amostra } \\
\text { 1er año }\end{array}$ & $\begin{array}{c}\text { Amostra } \\
\text { outros } \\
\text { ciclos }\end{array}$ & $\begin{array}{c}\text { Amostra } \\
\text { Total }\end{array}$ & $\begin{array}{c}\text { Amostra } \\
\text { Efetiva }\end{array}$ & $\begin{array}{c}\text { Percentagem } \\
\text { de } \\
\text { Cobertura }\end{array}$ \\
\hline Engenharia Estatística & 37 & 40 & 77 & 37 & 100.00 \\
Engenharia Matemática & 29 & - & 29 & 25 & 86.21 \\
Licenciatura em Ciências da Computação & 33 & - & 33 & 25 & 100.00 \\
Licenciatura/Pedagogia em Educação & 29 & - & 29 & 26 & 89.66 \\
Matemática e Computação & 128 & 40 & 168 & 113 & 88.28 \\
\hline Total & & & & & \\
\hline
\end{tabular}

$\mathrm{Na}$ Tabela 20, pode ser apreciado que se tive uma mostra final de 113 avaliados das especialidades segundo suas percepções com respeito à estatística, sem que necessariamente tenham cursado um curso de estatística na Universidade. A eliminação 
de casos deveu-se a falta de respostas e dados descritivos bem como aos critérios de exclusão e inclusão.

Tabela 21. Distribuição de Frequências dos estudantes por especialidad de acordo a seu sexo (N=113)

\begin{tabular}{lcccccc}
\hline Especialidade & \multicolumn{2}{c}{ Masculino } & \multicolumn{2}{c}{ Feminino } & \multicolumn{2}{c}{ Total } \\
\cline { 2 - 7 } & $\mathrm{N}$ & $\%$ & $\mathrm{~N}$ & $\%$ & $\mathrm{~N}$ & $\%$ \\
\hline Engenharia Estatística & 21 & 18.6 & 16 & 14.2 & 37 & 32.7 \\
Engenharia Matemática & 18 & 15.9 & 7 & 6.2 & 25 & 22.1 \\
Licenciatura em Ciências da Computação & 19 & 16.8 & 6 & 5.3 & 25 & 22.1 \\
Licenciatura/Pedagogia em Educação & 12 & 10.6 & 14 & 12.4 & 26 & 23.0 \\
Matemática e Computação & & & & & & \\
Total & 70 & 61.9 & 43 & 38.1 & 113 & 100.0 \\
\hline
\end{tabular}

Na Tabela 21, pode ser observado que se teve maior número de estudantes avaliados na especialidade de Ing. Estatística (32.7\%). Há uma maior percentagem de homens avaliados $(61.9 \%)$ com respeito às avaliadas que alcançaram um $38.1 \%$.

\subsubsection{Instrumento}

São usadas as escalas de Escala de atitudes em relação à Estatística de Estrada (AAE) e a Escala de atitudes frente à Estadística de Cazorla et al. (1999) (AAC).

\subsubsection{Procedimentos}

Solicitaram-se as permissões correspondentes em Departamento de Matemática e Ciência da Computação da Universidade de Santiago de Chile. Aplicou-se o questionário que se elaborou usando a escala global composta pela escala de Cazorla et al. (1999) e de Estrada (2002) aos estudantes.

Para ter acesso aos alunos das quatro especialidades foi solicitada uma permissão para o diretor-adjunto de ensino do departamento, que foi aceite. O questionário foi administrado aos alunos do primeiro ano (Ingresso 2013) e de maneira adicional, considerou-se uma mostra não probabilística de estudantes de quarto e quinto ano da carreira Engenharia Estatística, para estudos futuros de comparação, que no presente estudo não são apresentados.

Solicitou-se aos estudantes indicar o semestre em que levou a disciplina de estatística. Tendo já os horários dos alunos, a técnica utilizada para a coleta de dados foi conversar com o professor da sala antecipadamente, para poder contar com seu apoio e assim poder dirigir recém às salas para realizar os questionários aos estudantes.

O instrumento aplicou-se de maneira coletiva, nas salas de classes dos estudantes, ao final da classe. Informou-se respeito da voluntariedade do estudo e do caráter anônimo da 
investigação. Advertiu-lhes aos estudantes da presença de uma série de afirmações que pretendiam avaliar suas atitudes para a estatística.

Pedia-lhes também, não passassem muito tempo na cada afirmação para se assegurar de dar resposta a todas elas. Finalmente agradecia-lhes a colaboração nesta investigação antes e após a aplicação das escalas apresentadas em um único formato.

\subsection{Resultados}

\subsubsection{Análises de itens das escalas originais}

Nas Tabelas 22 e 23 apresentamos os resultados da análise de itens da Escala de Atitudes Composta (AECom) e das escalas AEE e AEC. Os índices clássicos considerados são: média (Me), desvio padrão (De), correlação item-total eliminando o item (rit) e alfa de Cronbach da escala sem considerar o item (alpha). Como é considerado por vários autores, entre eles Kline, (1998), os itens que apresentam uma baixa correlação com o resto dos itens na escala, são considerados inadequados para medir o constructo de interesse. Assim, um valor de correlação inferior a 0.20 é considerado inaceitável.

Os resultados da Tabela 22 mostram que considerando os itens como componentes em uma escala global, apresentam 4 itens da AEE (itens 1, 3, 17 e 18) que não satisfazem os critérios indicados anteriormente e consequentemente podem ser eliminados para a construção de uma escala global. Neste caso ficaríamos com uma versão da escala de 41 itens. 
Tabela 22. Análise de itens da Escala Global de Atitudes frente à Estatística AECcom

\begin{tabular}{|c|c|c|c|c|c|c|c|c|c|}
\hline Item & $\mathrm{Me}$ & $\mathrm{De}$ & rit & Alpha & Item & $\mathrm{Me}$ & $\mathrm{De}$ & rit & Alpha \\
\hline 1 & 3.15 & 0.98 & 0.16 & 0.94 & 26 & 3.79 & 1.03 & 0.59 & 0.94 \\
\hline 2 & 4.04 & 0.86 & 0.36 & 0.94 & 27 & 3.85 & 1.09 & 0.68 & 0.94 \\
\hline 3 & 2.10 & 1.05 & 0.00 & 0.94 & 28 & 3.48 & 0.97 & 0.64 & 0.94 \\
\hline 4 & 3.65 & 0.93 & 0.38 & 0.94 & 29 & 3.19 & 0.94 & 0.61 & 0.94 \\
\hline 5 & 3.38 & 1.01 & 0.33 & 0.94 & 30 & 3.19 & 0.91 & 0.58 & 0.94 \\
\hline 6 & 4.42 & 0.84 & 0.29 & 0.94 & 31 & 3.87 & 0.95 & 0.63 & 0.94 \\
\hline 7 & 3.40 & 0.93 & 0.49 & 0.94 & 32 & 3.59 & 0.95 & 0.59 & 0.94 \\
\hline 8 & 3.26 & 0.83 & 0.42 & 0.94 & 33 & 3.72 & 1.07 & 0.62 & 0.94 \\
\hline 9 & 3.88 & 0.93 & 0.38 & 0.94 & 34 & 3.46 & 0.96 & 0.59 & 0.94 \\
\hline 10 & 3.67 & 0.91 & 0.56 & 0.94 & 35 & 3.76 & 1.06 & 0.52 & 0.94 \\
\hline 11 & 3.94 & 1.02 & 0.53 & 0.94 & 36 & 3.12 & 0.90 & 0.54 & 0.94 \\
\hline 12 & 3.67 & 1.01 & 0.53 & 0.94 & 37 & 3.74 & 1.21 & 0.67 & 0.94 \\
\hline 13 & 3.72 & 0.97 & 0.50 & 0.94 & 38 & 3.69 & 0.96 & 0.58 & 0.94 \\
\hline 14 & 2.94 & 1.06 & 0.34 & 0.94 & 39 & 3.27 & 0.94 & 0.67 & 0.94 \\
\hline 15 & 3.80 & 1.06 & 0.62 & 0.94 & 40 & 3.12 & 1.02 & 0.61 & 0.94 \\
\hline 16 & 3.29 & 0.99 & 0.50 & 0.94 & 41 & 3.56 & 1.04 & 0.61 & 0.94 \\
\hline 17 & 2.73 & 0.98 & 0.17 & 0.94 & 42 & 3.89 & 1.05 & 0.68 & 0.94 \\
\hline 18 & 3.72 & 1.05 & 0.09 & 0.94 & 43 & 2.89 & 0.99 & 0.35 & 0.94 \\
\hline 19 & 4.33 & 1.00 & 0.37 & 0.94 & 44 & 3.20 & 0.91 & 0.70 & 0.94 \\
\hline 20 & 3.19 & 0.79 & 0.63 & 0.94 & 45 & 3.25 & 1.05 & 0.68 & 0.94 \\
\hline 21 & 4.58 & 0.81 & 0.53 & 0.94 & & & & & \\
\hline 22 & 2.86 & 0.82 & 0.37 & 0.94 & & & & & \\
\hline 23 & 4.08 & 1.11 & 0.65 & 0.94 & & & & & \\
\hline 24 & 3.93 & 0.95 & 0.27 & 0.94 & & & & & \\
\hline 25 & 3.81 & 0.89 & 0.55 & 0.94 & & & & & \\
\hline
\end{tabular}

$\mathrm{Me}=$ media, $\mathrm{De}=$ desvio padrão, rit $=$ correlação item -total eliminando o item alpha $=$ alfa de Cronbach da escala sem considerar o item 
Tabela 23. Análise de itens das Escalas AEE e AEC

\begin{tabular}{|c|c|c|c|c|c|c|c|c|c|}
\hline \multicolumn{3}{|c|}{ AEE } & \multicolumn{6}{|c|}{ AEC } & \multirow[b]{2}{*}{ Alpha } \\
\hline Item & $\mathrm{Me}$ & De & rit & Alpha & Item & $\mathrm{Me}$ & De & rit & \\
\hline 1 & 3.15 & 0.98 & 0.16 & 0.86 & 26 & 3.79 & 1.03 & 0.56 & 0.93 \\
\hline 2 & 4.04 & 0.86 & 0.47 & 0.85 & 27 & 3.85 & 1.09 & 0.65 & 0.93 \\
\hline 3 & 2.10 & 1.05 & -0.03 & 0.86 & 28 & 3.48 & 0.97 & 0.60 & 0.93 \\
\hline 4 & 3.65 & 0.93 & 0.41 & 0.85 & 29 & 3.19 & 0.94 & 0.67 & 0.93 \\
\hline 5 & 3.38 & 1.01 & 0.39 & 0.85 & 30 & 3.19 & 0.91 & 0.61 & 0.93 \\
\hline 6 & 4.42 & 0.84 & 0.41 & 0.85 & 31 & 3.87 & 0.95 & 0.62 & 0.93 \\
\hline 7 & 3.40 & 0.93 & 0.41 & 0.85 & 32 & 3.59 & 0.95 & 0.66 & 0.93 \\
\hline 8 & 3.26 & 0.83 & 0.36 & 0.85 & 33 & 3.72 & 1.07 & 0.67 & 0.93 \\
\hline 9 & 3.88 & 0.93 & 0.41 & 0.85 & 34 & 3.46 & 0.96 & 0.58 & 0.93 \\
\hline 10 & 3.67 & 0.91 & 0.62 & 0.84 & 35 & 3.76 & 1.06 & 0.58 & 0.93 \\
\hline 11 & 3.94 & 1.02 & 0.41 & 0.85 & 36 & 3.12 & 0.90 & 0.51 & 0.94 \\
\hline 12 & 3.67 & 1.01 & 0.55 & 0.84 & 37 & 3.74 & 1.21 & 0.66 & 0.93 \\
\hline 13 & 3.72 & 0.97 & 0.58 & 0.84 & 38 & 3.69 & 0.96 & 0.63 & 0.93 \\
\hline 14 & 2.94 & 1.06 & 0.34 & 0.85 & 39 & 3.27 & 0.94 & 0.71 & 0.93 \\
\hline 15 & 3.80 & 1.06 & 0.55 & 0.84 & 40 & 3.12 & 1.02 & 0.65 & 0.93 \\
\hline 16 & 3.29 & 0.99 & 0.51 & 0.84 & 41 & 3.56 & 1.04 & 0.66 & 0.93 \\
\hline 17 & 2.73 & 0.98 & 0.09 & 0.86 & 42 & 3.89 & 1.05 & 0.67 & 0.93 \\
\hline 18 & 3.72 & 1.05 & 0.16 & 0.86 & 43 & 2.89 & 0.99 & 0.43 & 0.94 \\
\hline 19 & 4.33 & 1.00 & 0.42 & 0.85 & 44 & 3.20 & 0.91 & 0.71 & 0.93 \\
\hline 20 & 3.19 & 0.79 & 0.58 & 0.84 & 45 & 3.25 & 1.05 & 0.73 & 0.93 \\
\hline 21 & 4.58 & 0.81 & 0.59 & 0.84 & & & & & \\
\hline 22 & 2.86 & 0.82 & 0.24 & 0.85 & & & & & \\
\hline 23 & 4.08 & 1.11 & 0.61 & 0.84 & & & & & \\
\hline 24 & 3.93 & 0.95 & 0.34 & 0.85 & & & & & \\
\hline 25 & 3.81 & 0.89 & 0.62 & 0.84 & & & & & \\
\hline
\end{tabular}

$\mathrm{Me}=$ media, $\mathrm{De}=$ desvio padrão, rit = correlação item -total eliminando o item alpha = alfa de Cronbach da escala sem considerar o item

AEE: Escala de Atitudes frente à estatística de Estrada (2002), AEC: escala de Atitudes frente à Estatística de Cazorla et al (2009)

De acordo aos resultados mostrados na Tabela 23, encontramos novamente que os itens 1, 3, 17 e 18 ao interior da AEE são os itens com comportamento inadequado, portanto, susceptíveis de não ser considerados uma versão recortada da AEE. Para a AEC não encontramos nenhum item que fosse eliminado dentro da escala. Notamos também que a AEC apresenta melhor alfa de Cronbach que a AEE indicando que é uma escala mais confiável. 
De acordo à análise de itens feito, observamos que a AEC é uma escala confiável que pode ser mantido integralmente enquanto a AEE é uma escala que requer eliminar cuatros itens para manter um bom nível de fiabilidade. Os itens que podem ser eliminados são: item 1: "Me incomoda a informação Estatística que aparece em alguns programas de T.V." ; item 3:"Através da Estatística pode ser manipulada a realidade"; item 17: A Estatística é fácil"; item 18: "inteiro-me mais do resultado das eleições quando aparecem representações gráficas”. Consideramos que os itens 1, 3 e 18 expressam aspectos valorativos do papel da Estatística nos meios de comunicação e sociedade enquanto o item 17 é impreciso.

Os resultados encontrados em relação a estes itens são coincidentes com os resultados de Estrada et ao (2013), Aparicio (2006), Aparicio e Bazán (2006) e Aliaga (2009) ou Tarazona et a o. (2013), onde também têm indicado que os itens 1, 3, 17 e 18 podem ser eliminados de uma versão corrigida da escala.

Por outro lado, em relação à AEC, os resultados contrastam com os resultados de Tarazona et a o. (2013) e Aliaga (2009) e Aparicio (2006).

\subsubsection{Análise de itens das escalas corrigidas}

Nas Tabelas 24 e 25 apresentamos os resultados da análise de itens da escala com os itens eliminados no ponto 5.6.1 na escala de atitudes composta e na escala de atitudes de Estrada et al (2002). Na Escala de Cazorla não teve eliminação de itens. As escalas serão denominadas AECom corrigida e AEE corrigida.

Os resultados mostram que com a eliminação de itens tanto em AECom corrigida e AEE corrigida há um aumento na fiabilidade. 
Tabela 24. Análisis de itens de la AECom corregida

\begin{tabular}{cccccccccc}
\hline Item & Me & \multicolumn{1}{c}{ De } & rit & Alpha & Item & Me & De & rit & Alpha \\
\hline 2 & 4.04 & 0.86 & 0.36 & 0.95 & 26 & 3.79 & 1.03 & 0.60 & 0.94 \\
4 & 3.65 & 0.93 & 0.39 & 0.95 & 27 & 3.85 & 1.09 & 0.67 & 0.94 \\
5 & 3.38 & 1.01 & 0.33 & 0.95 & 28 & 3.48 & 0.97 & 0.65 & 0.94 \\
6 & 4.42 & 0.84 & 0.29 & 0.95 & 29 & 3.19 & 0.94 & 0.61 & 0.94 \\
7 & 3.40 & 0.93 & 0.50 & 0.95 & 30 & 3.19 & 0.91 & 0.59 & 0.94 \\
8 & 3.26 & 0.83 & 0.40 & 0.95 & 31 & 3.87 & 0.95 & 0.64 & 0.94 \\
9 & 3.88 & 0.93 & 0.37 & 0.95 & 32 & 3.59 & 0.95 & 0.59 & 0.94 \\
10 & 3.67 & 0.91 & 0.56 & 0.95 & 33 & 3.72 & 1,073 & 0.62 & 0.94 \\
11 & 3.94 & 1.02 & 0.52 & 0.95 & 34 & 3.46 & 0.96 & 0.59 & 0.94 \\
12 & 3.67 & 1.01 & 0.54 & 0.95 & 35 & 3.76 & 1.06 & 0.52 & 0.95 \\
13 & 3.72 & .97 & 0.50 & 0.95 & 36 & 3.12 & 0.90 & 0.55 & 0.95 \\
14 & 2.94 & 1.06 & 0.35 & 0.95 & 37 & 3.74 & 1.21 & 0.67 & 0.94 \\
15 & 3.80 & 1.06 & 0.62 & 0.94 & 38 & 3.69 & 0.96 & 0.58 & 0.94 \\
16 & 3.29 & 0.99 & 0.51 & 0.95 & 39 & 3.27 & 0.94 & 0.67 & 0.94 \\
19 & 4.33 & 1.00 & 0.38 & 0.95 & 40 & 3.12 & 1.02 & 0.61 & 0.94 \\
20 & 3.19 & 0.79 & 0.62 & 0.94 & 41 & 3.56 & 1.04 & 0.61 & 0.94 \\
21 & 4.58 & 0.81 & 0.53 & 0.95 & 42 & 3.89 & 1.05 & 0.68 & 0.94 \\
22 & 2.86 & 0.82 & 0.38 & 0.95 & 43 & 2.89 & 0.99 & 0.35 & 0.95 \\
23 & 4.08 & 1.11 & 0.65 & 0.94 & 44 & 3.20 & 0.91 & 0.70 & 0.94 \\
24 & 3.93 & 0.95 & 0.27 & 0.95 & 45 & 3.25 & 1.05 & 0.68 & 0.94 \\
25 & 3.81 & 0.89 & 0.55 & 0.95 & & & & & \\
\hline & & & & & & & & &
\end{tabular}

$\mathrm{Me}=$ media, $\mathrm{De}=$ desvio padrão, rit $=$ correlação item -total eliminando o item alpha $=$ alfa de Cronbach da escala sem considerar o item

Tabela 25. Análisis de itens de las Escalas AEE corregida

\begin{tabular}{|c|c|c|c|c|}
\hline \multicolumn{3}{|c|}{ AEE } & \multirow[b]{2}{*}{ rit } & \multirow[b]{2}{*}{ Alpha } \\
\hline Item & $\mathrm{Me}$ & $\mathrm{De}$ & & \\
\hline 2 & 4.04 & 0.86 & 0.49 & 0.87 \\
\hline 4 & 3.65 & 0.93 & 0.44 & 0.87 \\
\hline 5 & 3.38 & 1.01 & 0.40 & 0.87 \\
\hline 6 & 4.42 & 0.84 & 0.40 & 0.87 \\
\hline 7 & 3.40 & 0.93 & 0.42 & 0.87 \\
\hline 8 & 3.26 & 0.83 & 0.32 & 0.88 \\
\hline 9 & 3.88 & 0.93 & 0.40 & 0.87 \\
\hline 10 & 3.67 & 0.91 & 0.63 & 0.87 \\
\hline 11 & 3.94 & 1.02 & 0.39 & 0.87 \\
\hline 12 & 3.67 & 1.01 & 0.58 & 0.87 \\
\hline 13 & 3.72 & 0.97 & 0.58 & 0.87 \\
\hline 14 & 2.94 & 1.06 & 0.35 & 0.88 \\
\hline 15 & 3.80 & 1.06 & 0.57 & 0.87 \\
\hline 16 & 3.29 & 0.99 & 0.53 & 0.87 \\
\hline 19 & 4.33 & 1.00 & 0.45 & 0.87 \\
\hline 20 & 3.19 & 0.79 & 0.55 & 0.87 \\
\hline 21 & 4.58 & 0.81 & 0.60 & 0.87 \\
\hline 22 & 2.86 & 0.82 & 0.24 & 0.88 \\
\hline 23 & 4.08 & 1.11 & 0.62 & 0.87 \\
\hline 24 & 3.93 & 0.95 & 0.34 & 0.88 \\
\hline 25 & 3.81 & 0.89 & 0.62 & 0.87 \\
\hline
\end{tabular}

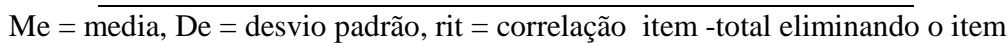
alpha = alfa de Cronbach da escala sem considerar o item AEE: Escala de Atitudes frente à estatística de Estrada (2002) 


\subsubsection{Análises de Normalidade e fiabilidade das escalas corrigidas}

Na Tabela 26 apresenta-se alguns resultados para a avaliação da normalidade na pontuação de Atitudes nas escalas AEE e AEC, bem como na escala unida AEC. São apresentadas ademais as fiabilidades, a média e desvio regular. A partir da análise de normalidade de Kolgomorov Smirnov, é possível evidenciar que as pontuações distribuem normalmente.

Tabela 26. Prova de Normalidade para o escore das Atitudes, AEE, AEC e AECom corrigidas $(\mathrm{N}=113)$

\begin{tabular}{lcccccc}
\hline Escala & Itens & Estadística (KS) & $\begin{array}{c}\text { Significância } \\
(\text { KS })\end{array}$ & $\begin{array}{c}\text { Fiabilidade } \\
\text { Alfa de } \\
\text { Cronbach }\end{array}$ & Media & DS \\
\hline AEE corrigida & 21 & 0.81 & 0.54 & 0.88 & 77.82 & 10.66 \\
AEC & 20 & 0.72 & 0.67 & 0.94 & 69.63 & 13.47 \\
AECom corrigida & 41 & 0.59 & 0.88 & 0.95 & 147.45 & 22.45 \\
\hline \multicolumn{2}{r}{} & KS: Kolgomorov Smirnov Test & Significância*: $<0.05$ & &
\end{tabular}

\subsubsection{Análises da dimensionalidade das Escalas corrigidas}

Para avaliar a dimensionalidade das escalas AECom corrigida, AEE corrigida e AEC realizou-se uma análise fatorial usando o método de máxima verosimilitude com rotação varimax usando a matriz de correlações policóricas (Freiberg et al 2013).

As análises foram feitas aplicando as ferramentas disponíveis no software R. As Tabelas 27, 2829 apresentam valores fatoriais superiores a 0.10 nos diferentes fatores identificados bem como os valores próprios e percentagens de variância explicados para cada fator para a cada uma das escalas analisadas.

Na Tabela 27 mostra-se a distribuição de itens nos sete fatores iniciais que arrojo a análise fatorial para a AECom corrigida. Os resultados para este caso sugerem que a escala é multidimensional, caracterizados em sete fatores com quatro fatores principais com quatro itens ou mais e três fatores com até um item que podem ser redistribuídos nos os fatores principais.

Assim fazendo a redistribuição destes itens, identificamos quatro fatores principais distribuídos da seguinte maneira: Fator 1: formado por 16 itens: 8, 15, 22, 26, 27, 31, 32, 
33, 35, 37, 38, 41, 42 (adicionalmente 9, 11 e 23) e pode ser denominado "Valoração negativa da Estatística”, porque aqui agrupam-se grande parte dos itens negativos da escala, onde se manifestam uma predisposição negativa para à Estatística. O Fator 2, formado por 10 itens: 14, 28, 29, 30, 34, 39, 40, 43, 44, 45, pode ser denominado "Afetividade para a Estatística", porque estes itens manifestam sentimentos ou reações afetivas para a Estatística. O Fator 3: formado por 11 itens: 2, 4, 5, 7, 10, 12, 13, 16, 20, 25, 36, pode ser denominado "Valoração Positiva da Estatística", porque aqui agrupamse grande parte dos itens positivos da escala, onde se manifestam uma predisposição positiva e o Fator 4 formado por 4 itens: 6, 19, 21, 24, e pode ser denominado "Utilidade da Estatística", porque os itens indicam o uso positivo ou não da Estatística. 
Tabela 26. Análise de itens (41 itens) da escala AEC usando Análise Fatorial com correlações Policóricas e Rotação Varimax.

\begin{tabular}{|c|c|c|c|c|c|c|c|}
\hline Ítem & Fator 1 & Fator 2 & Fator 3 & Fator 4 & Fator 5 & Fator 6 & Fator 7 \\
\hline 2 & & & 0.66 & 0.239 & 0.125 & 0.143 & \\
\hline 4 & & 0.11 & 0.56 & 0.109 & 0.155 & & \\
\hline 5 & & 0.12 & 0.49 & & & & \\
\hline 6 & 0.17 & -0.19 & 0.28 & 0.595 & 0.102 & & \\
\hline 7 & 0.35 & 0.30 & 0.36 & & & & 0.32 \\
\hline 8 & 0.48 & 0.17 & & & & & 0.21 \\
\hline 9 & 0.36 & & 0.13 & 0.191 & 0.121 & & 0.42 \\
\hline 10 & 0.17 & 0.15 & 0.68 & 0.244 & 0.212 & & 0.13 \\
\hline 11 & 0.49 & 0.16 & & 0.244 & 0.578 & & \\
\hline 12 & & 0.36 & 0.66 & 0.257 & & & \\
\hline 13 & & 0.31 & 0.68 & 0.196 & & & 0.14 \\
\hline 14 & 0.13 & 0.28 & 0.19 & 0.171 & & & \\
\hline 15 & 0.61 & 0.22 & 0.18 & 0.388 & & -0.14 & 0.14 \\
\hline 16 & 0.12 & 0.34 & 0.62 & 0.137 & & 0.19 & -0.14 \\
\hline 19 & 0.25 & & 0.38 & 0.671 & & & -0.15 \\
\hline 20 & 0.41 & 0.35 & 0.42 & & 0.229 & & 0.22 \\
\hline 21 & 0.18 & 0.25 & 0.26 & 0.856 & 0.272 & & 0.16 \\
\hline 22 & 0.40 & 0.27 & & -0.122 & & 0.261 & 0.11 \\
\hline 23 & 0.43 & 0.26 & 0.35 & 0.34 & 0.467 & & 0.22 \\
\hline 24 & & 0.14 & 0.35 & 0.375 & & 0.265 & \\
\hline 25 & 0.30 & & 0.44 & 0.417 & & 0.192 & 0.37 \\
\hline 26 & 0.56 & 0.19 & 0.21 & 0.325 & 0.109 & & \\
\hline 27 & 0.50 & 0.25 & 0.25 & 0.273 & 0.395 & & 0.11 \\
\hline 28 & 0.27 & 0.61 & 0.48 & 0.21 & -0.20 & -0.11 & 0.11 \\
\hline 29 & 0.17 & 0.84 & 0.20 & & 0.19 & 0.23 & \\
\hline 30 & 0.25 & 0.54 & 0.32 & & & 0.73 & \\
\hline 31 & 0.73 & 0.12 & 0.29 & 0.17 & & & \\
\hline 32 & 0.80 & 0.24 & & 0.23 & & & 0.16 \\
\hline 33 & 0.77 & 0.24 & 0.10 & & 0.11 & & 0.13 \\
\hline 34 & 0.37 & 0.46 & 0.38 & & & 0.11 & \\
\hline 35 & 0.87 & 0.11 & & & -0.14 & & \\
\hline 36 & 0.22 & 0.50 & 0.42 & & & & 0.16 \\
\hline 37 & 0.61 & 0.19 & 0.27 & 0.12 & 0.43 & & \\
\hline 38 & 0.78 & 0.15 & & & 0.25 & & -0.19 \\
\hline 39 & 0.31 & 0.70 & 0.30 & & 0.32 & & -0.14 \\
\hline 40 & 0.23 & 0.78 & 0.30 & & 0.22 & -0.12 & -0.10 \\
\hline 41 & 0.69 & 0.23 & & 0.10 & 0.34 & & 0.12 \\
\hline 42 & 0.66 & 0.21 & 0.31 & 0.17 & 0.40 & -0.10 & -0.13 \\
\hline 43 & 0.10 & 0.63 & & & & 0.39 & 0.30 \\
\hline $\begin{array}{l}44 \\
45\end{array}$ & 0.43 & 0.70 & 0.22 & & & 0.18 & $\begin{array}{r}0.19 \\
-0.11\end{array}$ \\
\hline$\frac{45}{\text { Cargas }}$ & $\frac{0.31}{7661.0}$ & $\begin{array}{c}\mathbf{0 . 8 3} \\
5941.0\end{array}$ & $\begin{array}{c}0.26 \\
5222.0\end{array}$ & 2924.0 & 1774.0 & 1164.0 & $\begin{array}{c}-0.11 \\
1056.0\end{array}$ \\
\hline Prop. Varianza & 0.19 & 0.15 & 0.13 & 0.07 & 0.043 & 0.03 & 0.033 \\
\hline$\%$ Variabilidad & 0.19 & 0.33 & 0.46 & 0.53 & 0.574 & 0.60 & 0.63 \\
\hline
\end{tabular}


Na Tabela 27 mostra-se a distribuição de itens nos nove fatores iniciais que arrojo a análise fatorial da AEE corrigida. Os resultados sugerem que esta escala também é multidimensional, caracterizada por nove fatores que contêm mais de um item, com quatro fatores principais com quatro itens ou mais e cinco fatores com até dois itens e com alguns itens que podem ser distribuídos nos fatores principais.

Assim fazendo a redistribuição destes itens, identificamos quatro fatores principais, distribuídos da seguinte maneira: Fator 1: formado por 8 itens: 2, 4, 10, 13 e 16 (adicionalmente 6,12, 24), o qual pode ser denominado "Valoração Positiva da Estatística”, porque aqui agrupam-se grande parte dos itens positivos da escala, onde se manifestam uma predisposição positiva. O Fator 2, formado por 5 itens 15, 19, 21 e 25 (adicionalmente 9), pode ser denominado "Valoração Negativa da Estatística", porque aqui agrupam-se grande parte dos itens negativos da escala, onde se manifestam uma predisporão negativa para a Estatística. O Fator 3, formado por 4 itens 7, 8, 20 e 22, podendo ser denominado "Habilidade para a Estatística", porque os itens indicam, aptidão para resolver problemas de Estatística. O Fator 4 formado por 2 itens 11 e 23, denominado "Afetividade para a Estatística", porque estes itens manifestam sentimentos ou reações afetivas para a Estatística. Finalmente um Fator 5 formado por 2 itens, 5 e 14 e pode ser denominado "Utilidade da Estatística", porque os itens indicam o uso positivo ou não da Estatística. 
Tabela 27. Análise de itens (21 itens) da escala AEE usando Análise Fatorial com correlações Policóricas e Rotação Varimax.

\begin{tabular}{cccccccccc}
\hline Ítem & Fator 1 & Fator 2 & Fator 3 & Fator 4 & Fator 5 & Fator 6 & Fator 7 & Fator 8 & Fator 9 \\
\hline 2 & $\mathbf{0 . 6 3}$ & 0.15 & & & 0.13 & 0.16 & 0.17 & 0.18 & \\
4 & $\mathbf{0 . 5 2}$ & 0.17 & & & 0.15 & & 0.11 & & \\
5 & 0.29 & & & & $\mathbf{0 . 9 4}$ & 0.11 & & & \\
6 & $\mathbf{0 . 2 5}$ & 0.23 & & 0.165 & & 0.16 & & $\mathbf{0 . 8 1}$ & \\
7 & 0.41 & 0.10 & $\mathbf{0 . 6 3}$ & & & & -0.18 & 0.10 & \\
8 & & 0.36 & $\mathbf{0 . 5 1}$ & & & 0.25 & -0.12 & & -0.26 \\
9 & & $\mathbf{0 . 2 3}$ & 0.14 & 0.156 & & $\mathbf{0 . 9 3}$ & & 0.14 & \\
10 & $\mathbf{0 . 8 3}$ & & & 0.361 & & & & 0.19 & 0.16 \\
11 & & 0.15 & 0.25 & $\mathbf{0 . 7 4 7}$ & & 0.12 & & 0.12 & \\
12 & $\mathbf{0 . 5 0}$ & 0.17 & 0.12 & & 0.21 & & 0.11 & 0.10 & $\mathbf{0 . 7 9}$ \\
13 & $\mathbf{0 . 6 2}$ & 0.25 & & & & 0.12 & 0.18 & -0.15 & 0.42 \\
14 & & 0.24 & 0.155 & 0.138 & $\mathbf{0 . 3 3}$ & & & & 0.21 \\
15 & 0.12 & $\mathbf{0 . 6 5}$ & 0.35 & 0.275 & 0.13 & 0.16 & & & \\
16 & $\mathbf{0 . 6 3}$ & 0.12 & 0.16 & & 0.33 & -0.12 & 0.23 & & \\
19 & 0.31 & $\mathbf{0 . 5 7}$ & -0.16 & & & 0.13 & 0.18 & 0.32 & 0.16 \\
20 & 0.3 & 0.22 & $\mathbf{0 . 5 6}$ & 0.274 & 0.18 & 0.13 & & -0.28 & 0.18 \\
21 & 0.30 & $\mathbf{0 . 6 3}$ & & 0.457 & & & 0.27 & 0.35 & 0.18 \\
22 & & & $\mathbf{0 . 6 8}$ & 0.19 & & & 0.16 & & \\
23 & 0.41 & 0.41 & 0.13 & $\mathbf{0 . 6 0 5}$ & & & & & 0.10 \\
24 & $\mathbf{0 . 3 0}$ & & & & 0.15 & & $\mathbf{0 . 9 2}$ & & 0.11 \\
25 & 0.34 & $\mathbf{0 . 5 5}$ & 0.16 & 0.125 & 0.11 & 0.35 & & 0.11 & 0.10 \\
\hline Cargas & 3.42 & 2.16 & 1.80 & 1.57 & 1.30 & 1.25 & 1.21 & 1.14 & 1.10 \\
Prop. Variancia & 0.16 & 0.10 & 0.09 & 0.08 & 0.06 & 0.06 & 0.06 & 0.05 & 0.05 \\
\% Variabilidad & 0.16 & 0.27 & 0.35 & 0.43 & 0.49 & 0.55 & 0.61 & 0.66 & 0.71 \\
\hline
\end{tabular}

Na Tabela 28 mostra-se a distribuição de itens nos cinco fatores iniciais que arrojo a análise fatorial para a Escala AEC. Os resultados sugerem que esta escala é também multidimensional, caracterizados em cinco fatores com dois fatores principais com oito itens ou mais e três fatores com até um item que podem ser distribuídos nos fatores principais. Assim fazendo a redistribuição dos fatores com até dois itens, ficam finalmente os dois fatores principais, distribuídos da seguinte maneira: Fator 1: formado por 10 itens: $26,31,32,33,35,37,38,41,42$ (adicionalmente 27 ), o qual pode ser denominado "Valoração Negativa da Estatística", porque aqui agrupam-se todos os itens negativos da escala AEC e o Fator 2, formado por 10 itens: 28, 29, 30, 36, 39, 40, 44, 45 (adicionalmente 34, 43). Este fator pode ser denominado "Valoração Positiva da Estatística”. Porque aqui agrupam-se todos os itens positivos da escala. 
Tabela 28. Análise de itens (20 itens) da escala AEC usando Análise Fatorial com correlações Policóricas e rotação Varimax.

\begin{tabular}{|c|c|c|c|c|c|}
\hline Ítem & Fator1 & Fator2 & Fator3 & Fator4 & Fator5 \\
\hline 26 & 0.56 & 0.23 & & 0.14 & 0.26 \\
\hline 27 & 0.50 & 0.27 & 0.12 & 0.10 & 0.80 \\
\hline 28 & 0.24 & 0.61 & 0.15 & 0.38 & \\
\hline 29 & 0.18 & 0.88 & 0.42 & -0.13 & \\
\hline 30 & 0.22 & 0.56 & 0.53 & & \\
\hline 31 & 0.70 & 0.25 & & 0.18 & \\
\hline 32 & 0.79 & & 0.27 & 0.28 & \\
\hline 33 & 0.75 & 0.20 & 0.21 & 0.13 & \\
\hline 34 & 0.28 & 0.46 & 0.14 & 0.63 & \\
\hline 35 & 0.81 & & 0.13 & 0.26 & \\
\hline 36 & 0.15 & 0.50 & 0.24 & 0.33 & 0.17 \\
\hline 37 & 0.65 & 0.33 & & & 0.3 \\
\hline 38 & 0.80 & 0.22 & & & 0.16 \\
\hline 39 & 0.33 & 0.80 & 0.13 & & 0.22 \\
\hline 40 & 0.20 & 0.83 & & 0.19 & 0.20 \\
\hline 41 & 0.77 & 0.20 & 0.23 & & 0.14 \\
\hline 42 & 0.72 & 0.41 & -0.17 & & 0.18 \\
\hline 43 & & 0.37 & 0.66 & 0.10 & \\
\hline 44 & 0.36 & 0.60 & 0.49 & 0.30 & 0.11 \\
\hline 45 & 0.28 & 0.80 & 0.23 & 0.23 & \\
\hline Cargas & 5.66 & 5.00 & 1.536 & 1.095 & 1.053 \\
\hline Prop. Variancia & 0.28 & 0.25 & 0.077 & 0.055 & 0.053 \\
\hline$\%$ Variabilidad & 0.28 & 0.53 & 0.61 & 0.665 & 0.717 \\
\hline
\end{tabular}

Outra possibilidade de obter o estudo de multidimensionalidade é realizar uma análise fatorial a partir das correlações de Spearman como o realizado por Estrada et a o. (2011), no entanto, no presente estudo encontramos correlações de Spearman menores e em consequência a análise fatorial a partir dessa matriz de correlações levaria a um número maior de fatores que os apresentados aqui.

Cabe advertir que se trata de um resultado exploratório que deve ser confirmado com estudos adicionais em amostras de estudantes de diferentes carreiras e incluir uma análise de itens e fiabilidade para a cada um destes fatores identificados.

\subsubsection{Análises das Atitudes segundo as características dos avaliados}

Na Tabela 29 se faz uma análise das médias obtidas nas escalas de Atitude considerando o gênero do estudante mas não foram encontradas diferenças significativas considerando esta variável. 
Tabela 29. Comparação de médias nas Escalas de Atitudes usando o teste t-Student considerando o gênero dos avaliados $(\mathrm{N}=113)$

\begin{tabular}{lllcccc}
\hline Escala Atitudes & Gênero & $\mathrm{N}$ & Media & DS & $\mathrm{T}$ & Sig. \\
\hline AEE Corrigida & Masculino & 70 & 77.47 & 11.60 & 0.47 & 0.64 \\
& Feminino & 43 & 78.40 & 9.02 & & \\
AEC Corrigida & Masculino & 70 & 70.20 & 13.52 & 0.57 & 0.57 \\
& Feminino & 43 & 68.70 & 13.50 & & \\
AECom Corrigida & Masculino & 70 & 147.7 & 23.68 & 0.14 & 0.89 \\
& Feminino & 43 & 147.1 & 20.55 & & \\
\hline
\end{tabular}

Por outro lado, realiza-se uma comparação da média das atitudes frente à Estatística considerando à Especialidade dos avaliados, como se mostra na Tabela 30, desprende-se que sim existem diferenças significativas na atitude para a estatística entre as especialidades dos avaliados. A especialidade de Ing. Estatística é a que apresenta os médias mais altos e a de Ing. Matemática os médias mais baixos. Isto é mostrado na Figura 9, se identificaram dois grupos: os da especialidade de Estatística que apresentam as melhores atitudes como esperados e o outro grupo formado pelas outras especialidades.

Tabela 30. Comparación de los Promedios de las Actitudes usando ANOVA considerando la Especialidad de los evaluados $(\mathrm{N}=113)$

\begin{tabular}{|c|c|c|c|c|c|c|}
\hline Escala Actitudes & Especialidade & $\mathrm{N}$ & Media & DS & $\mathrm{F}$ & Sig \\
\hline \multirow[t]{5}{*}{ AEE Corrigida } & Ing. Estatística & 37 & 85.24 & 7.51 & 12.45 & $0.00 * *$ \\
\hline & Pedagogía em Matemática & 26 & 76.54 & 10.23 & & \\
\hline & Lic. em Ciência Computação & 25 & 73.24 & 9.31 & & \\
\hline & Ing. Matemática & 25 & 72.76 & 10.71 & & \\
\hline & Ing. Estatística & 37 & 79.46 & 9.34 & & \\
\hline \multirow[t]{4}{*}{ AEC Corrigida } & Pedagogía em Matemática & 26 & 65.00 & 11.98 & 13.78 & $0.00 * *$ \\
\hline & Lic. en Ciência Computação & 25 & 67.08 & 8.30 & & \\
\hline & Ing. Matemática & 25 & 62.44 & 16.27 & & \\
\hline & Ing. Estatística & 37 & 164.70 & 15.59 & 15.59 & $0.00 * *$ \\
\hline \multirow[t]{3}{*}{ AECom Corrigida } & Pedagogía em Matemática & 26 & 141.54 & 20.81 & & \\
\hline & Lic. em Ciência Computação & 25 & 140.32 & 15.42 & & \\
\hline & Ing. Matemática & 25 & 135.20 & 24.34 & & \\
\hline
\end{tabular}



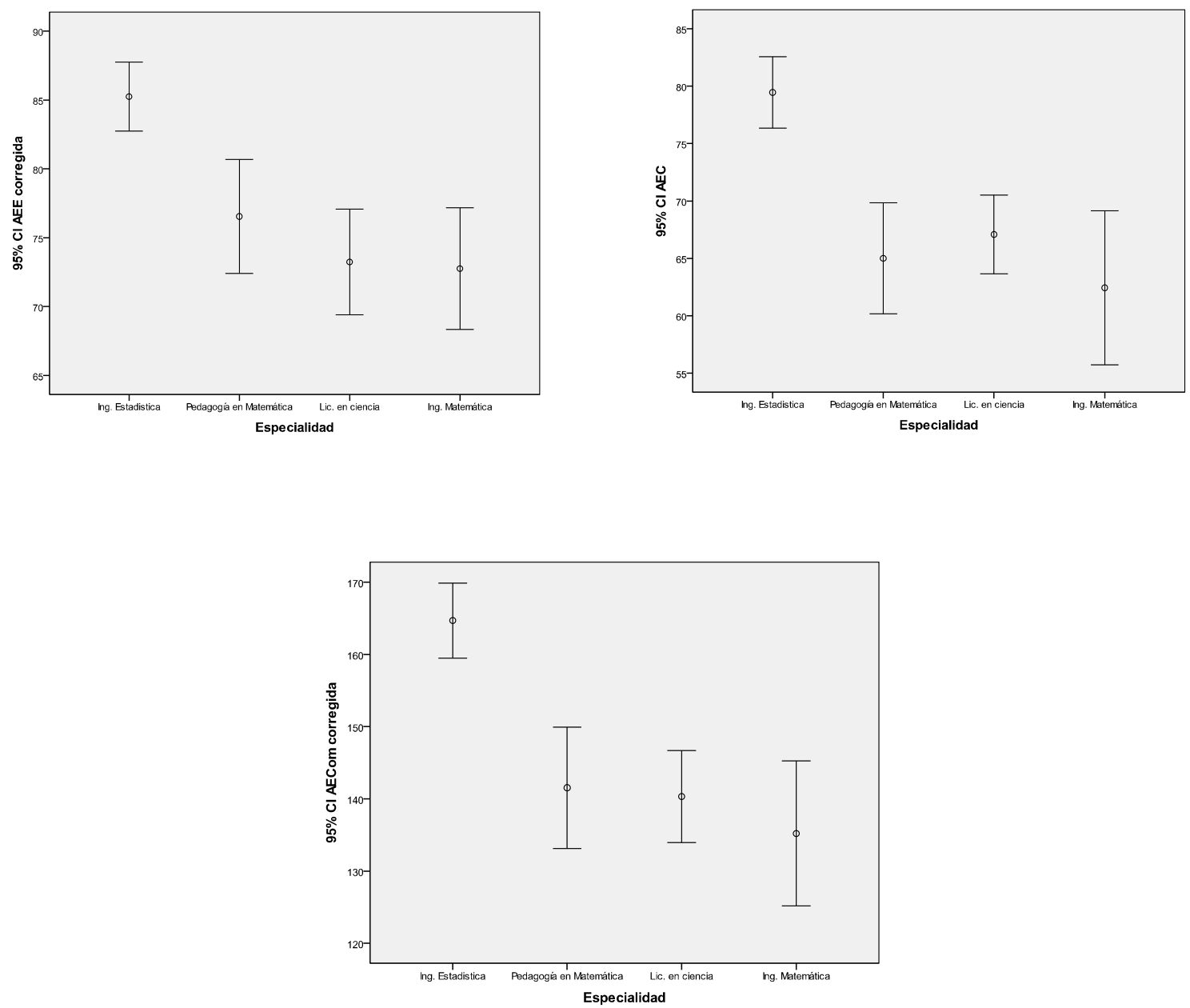

Figura 9. Barras de Erros (Intervalos de confiança) para as pontuações das escalas de Atitudes frente a Estatística segundo a Especialidade $(\mathrm{N}=113)$

\subsection{Comentários Finais}

O ensino da Estatística tem uma importância reconhecida, sendo que ela é implementada desde a escola até grande parte do ensino universitário. A aprendizagem da Estatística é necessária para entender as informações quantitativas que diariamente nos é dada por diferentes meios de comunicação e também é útil para que os profissionais em formação e formados possam fazer uso e interpretar os dados de suas investigações de maneira confiável e valida.

Achamos que as escalas de atitudes, como as usadas em nossa investigação podem permitir um diagnóstico inicial no estabelecimento de estratégias encaminhadas a melhorar atitudes negativas detectadas para ter uma melhora na predisposição dos alunos, como por exemplo, na percepção da utilidade que a Estatística tanto em sua vida quotidiana como em sua vida profissional como investigador. 
Por outro lado não esqueçamos que estas escalas têm que ser instrumentos psicométricamente válidos para poder obter um diagnóstico valido.

Nosso estudo dispôs de um instrumento composto por duas escalas de atitudes para a Estatística, a escala de Estrada et ao (2002, AEE) e a escala de Cazorla et ao (1999, AEC). O principal objetivo foi determinar potenciais indicadores do comportamento psicométrico usando estas escalas em estudantes universitários de Chile.

Se inclui uma análise de itens, uma análise da dimensionalidad e adicionalmente estudouse aspectos descritivos e mais qualitativos sobre o comportamento das atitudes na mostra de estudo. Para efeitos de análises estuda-se as escalas de maneira independente e também como uma escala composta (AECom).

As escalas foram aplicadas a quatro carreiras de pré grado da Universidade de Santiago de Chile. Ambos questionários usam um escalamento de tipo Lickert de cinco valores que é confiável, válido e permite obter diferença por dimensões.

Em geral os resultados sobre as escalas de atitudes à estatística nesta mostra mostram-nos propriedades psicométricas adequadas, tanto quando se analisa a Escala de Atitudes Composta (AECom) e as escalas AEE (Estrada et al 2013) e AEC (Cazorla et ao 1999). Com uma versão final de 41, 21 e 20 itens, respectivamente.

A análise de itens permitiu identificar quatro itens com comportamento psicométrico inadequado considerando uma perspectiva de análise clássica na Escala AECom e na Escala AEE. Na Escala AEC não foi eliminado nenhum item. Todas as escalas apresentam alta fiabilidade e el se incrementa depois dá eliminação duas itens, com um alfa final de $0.95,0.88$ e 0.94 respectivamente.

Depois da análise de itens estuda-se a dimensionalidad das escalas através de uma análise fatorial. Identifica-se evidência de dimensionalidad, tanto na Escala de Atitudes Composta (AECom) como as escalas de Atitudes AEE e AEC de maneira independente. Achamos que este estudo de dimensionalidad prévio poderia ser ampliado com uma análise fatorial confirmatório em mostras mais variadas 
$\mathrm{Na}$ Escala AECom identificaram-se quatro fatores principais que descrevem principalmente aspectos da atitude para a estatística como a Valoração Negativa (Ex. Item 42: "Eu nunca goste da Estatística e é a matéria que mais me dá medo"); Afetividade (Ex. Item 30: "A Estatística faz-me sentir seguro(a) e é ao mesmo tempo estimulante"); Valoração Positiva (Ex. Item 2: “A Estatística ajuda a entender o mundo de hoje”) e Utilidade (Ex. Item 24: “A Estatística ajuda a tomar decisões mais documentadas”).

$\mathrm{Na}$ escala AEE, apresenta cinco fatores principais que descrevem principalmente aspectos da atitude para a estatística como a Valoração Positiva (Ex. Item 4: “A Estatística é fundamental na formação básica do futuro cidadão"); Valoração Negativa (Ex. Item 25: "Evito as informações Estatísticas quando as leio"); Habilidade (Ex. Item 8: “Os problemas da Estatística resultam-me fáceis"); Afetividade (Ex. Item 11: "Sento-me intimidado em frente aos dados estatísticos") e utilidade (Ex. Item 5: "Uso a Estatística para resolver problemas da vida cotidiana").

A escala AEC apresenta duas dimensões ou constructos que medem essencialmente a Valoração Negativa e Positiva dos estudantes novatos para a Estatística, descrita principalmente pela escala AEC, pois apresenta melhores propriedades, é mais confiável, tem menos dimensões e um número razoável de itens.

Considerando as pontuações das escalas corrigidas descobriram-se diferenças significativas entre as carreiras que fazem parte do estudo. A partir do instrumento encontrou-se que em geral a atitude frente à estatística é positiva nos estudantes de Ing. Estatística, seguido por Lic. Em Ciência da Computação. Isto não é de surpreender, pois são áreas que se potenciam de maneira complementar, ainda que suas respostas podem refletir muita intuição em frente a esta associação. A Pedagogia em Matemática mostra uma atitude moderada em frente a esta disciplina, enquanto os estudantes de primeiro ano de Ing. Matemática sugerem uma atitude mais negativa, ainda que em algumas dimensões, apresenta-se uma alta variabilidade em relação com seus pares. Este resultado é razoável considerando os enfoques das diferentes carreiras consideradas no estudo.

Sendo no curso de Ing. Estatística os únicos estudantes da especialidade, reflete-se numa muito boa atitude frente à especialidade que se está estudando. Alguns dados que poderiam respaldar este fato são as aprovações e notas promedio dos avaliados do 
primeiro ano no curso de Engenharia Estatística do ano 2013, ano em que se tomou a escala. No primeiro semestre registra-se que 28/44 aprovaram a matéria de Introdução à Probabilidade e Estatística com uma média de 3.7 de 7.0, enquanto no segundo semestre do mesmo ano, registra-se 22/28 aprovados com uma média 3.8 de 7.0. Isto sugere que há um 50\% do total dos ingressantes a Engenharia Estatística, conseguem aprovar as disciplinas do curso, tendo condições e atitudes acadêmicas para continuar desenvolvendo seus estudos na área. Respeito aos outros cursos, ainda não se tem registros, pois estão cursando seus primeiros programas na especialidade.

Achamos que o presente estudo nos permitiu fazer uma aproximação ao conhecimento das atitudes frente à Estatística em futuros profissionais da área de ciências, permitindo orientar futuras ações didáticas a desenvolver, já que as atitudes positivas é um dos mais importantes resultados Um obter no processo de ensino da Estatística.

Finalmente sugerimos ampliar este estudo para mostras de universitários mais amplas que incluam profissões das áreas de ciências como humanas, para poder contrastar melhor os resultados e estabelecer melhores propostas na melhora da aprendizagem da Estatística através do diagnóstico inicial das atitudes com instrumentos de avaliação confiáveis e válidos. 


\title{
CASO 3: ATITUDES FRENTE A ESTATÍSTICA EM ESTUDANTES COLOMBIANOS
}

\section{ATITUDES FRENTE À ESTATÍSTICA EM ESTUDANTES UNIVERSITÁRIOS DE UMA UNIVERSIDADE PRIVADA EM COLOMBIA 9}

\begin{abstract}
Resumo
$O$ artigo analisa as atitudes para a Estatística em universitários colombianos de uma universidade privada em Bogotá. São usadas as escalas de Atitudes frente à Estatística de Estrada (2002) (AEE) e de Cazorla et al (1999) (AEC).

A mostra efetiva foi de 545 avaliados entre 17 e 25 anos, das escolas de Ciências Exatas e Engenharia, Economia e a Escola Internacional de Administração e Marketing distribuídos em 14 programas.

Encontrou-se diferenças significativas ( $p<0.05)$ nas atitudes de acordo Um a escola e programa dos avaliados, com maiores médias na Escola de Economia e no Programa de Ambiental. Foram eliminados dois itens com baixa correlação item Total (<0.20) tendo uma escala Final de 43 itens para a escala global e de 23 itens em de a escala AEE. A análise psicométrica mostra adequadas correlações dos itens com a escala final (>0.20) e adequada fiabilidade. A análise de dimensionalidade indica cinco fatores na escala AEE e de dois fatores na escala AEC.
\end{abstract}

Palavras chave: Escala de atitudes frente à estatística, análise de itens, fiabilidade, universitários

\subsection{Metodologia}

\subsubsection{Instrumentos}

São usadas as escalas de Escala de atitudes em relação à Estatística de Estrada (AAE) e a Escala de atitudes frente à Estadística de Cazorla et al. (1999) (AAC).

\subsubsection{População e Amostra Efetiva}

A universidade conta com sete escolas que agrupam 21 programas dos quais 14 têm em seus planos de estudo dois cursos de estatística.

\footnotetext{
${ }^{9}$ Artigo submetido na revista Revista Educación Matemática de México
} 
A população objetivo do estudo foram os estudantes das escolas de Economia, Ciências Exatas e Engenharia e a Escola Internacional de Administração e Marketing, já que seus programas incluíam a disciplina de Estatística.

A universidade onde foram avaliados os participantes está conformada pelas seguintes Escolas e Programas:

Tabela 31. Escolas e Programas ditados na Universidade de estudo

\begin{tabular}{ll}
\hline \multicolumn{1}{c}{ Escola } & \multicolumn{1}{c}{ Programas } \\
\hline & Administração de empresas \\
& Administração de negócios \\
& Administração ambiental \\
Internacional de Administração e Marketing & Comércio internacional \\
(EIAM) & Finanças e comércio exterior \\
& Contadoria pública \\
& Logística empresarial \\
& Marketing e negócios internacionais \\
\hline & \\
Ciências Exatas e Ingenhería & Engenharia ambiental \\
& Engenharia industrial \\
& Engenharia eletrônica \\
& Engenharia de sistemas e telecomunicações \\
Comunicação Social e periodismo & Matemáticas \\
Filosofía y Humanidades & Comunicação social \\
Política e Relaciones Internacionales & Publicidad internacional \\
Economía & Filosofía e humanidades \\
Direito & Licenciatura filosofía e humanidades \\
& Política e relações internacionais \\
& \\
\hline
\end{tabular}

\subsubsection{Critérios de incluso e exclusão}

Critérios de inclusão:

- Estudantes que ingressam ao primeiro semestre acadêmico ou que ainda não têm tomado a matéria de estatística.

- Estudantes que tendo contestado o questionário aplicado deixem sem contestar cinco ou menos itens.

Criterios de exclusão:

- Estudantes que deixaram sem resposta mais de cinco itens da escala.

- Estudantes que já cursaram um curso de estatística.

Estudantes das Escolas de Comunicação Social e jornalismo, Filosofia e Humanidades, Política e Relações Internacionais e Direito por não contar em seus planos de estudo com a matéria de estatística. 
Considerando os critérios de inclusão e exclusão para a população avaliada chegamos a uma população efetiva. Na Tabela 32 apresentamos a percentagem de cobertura atingido para as diferentes escolas e programas considerados.

Tabela 32. População, população efetiva e percentagem de cobertura do estudo

\begin{tabular}{|c|c|c|c|c|}
\hline Escola & Programa & $\begin{array}{c}\text { Amostra } \\
\text { Total }\end{array}$ & $\begin{array}{l}\text { Amostra } \\
\text { efetiva }\end{array}$ & $\begin{array}{c}\% \text { de } \\
\text { cobertura }\end{array}$ \\
\hline \multirow{4}{*}{$\begin{array}{l}\text { Internacional de } \\
\text { Administração e } \\
\text { Marketing }\end{array}$} & Administração de empresas & 82 & 70 & 85.37 \\
\hline & Contaduría & 73 & 47 & 64.83 \\
\hline & Finanzas & 85 & 64 & 75.29 \\
\hline & $\begin{array}{l}\text { Marketing e negocios } \\
\text { internacionais }\end{array}$ & 109 & 86 & 78.90 \\
\hline \multirow{4}{*}{$\begin{array}{l}\text { Ciencias Exactas e } \\
\text { Engenharia }\end{array}$} & Ambiental & 34 & 29 & 85.29 \\
\hline & Industrial & 121 & 97 & 80.17 \\
\hline & Eletrônica & 48 & 35 & 72.92 \\
\hline & Sistemas e telecomunicação & 72 & 58 & 80.56 \\
\hline Economía & Economía & 76 & 59 & 77.63 \\
\hline Total & & 700 & 545 & \\
\hline
\end{tabular}

Na Tabela 32 pode ser apreciado que se avaliou inicialmente uma população total de 700 alunos dos quais 545 estudantes ficaram como uma população efetiva. Esta população distribuiu-se em nove programas. Os avaliados não tinham cursado ainda nenhuma disciplina de estatística a nível de educação superior.

Tabela 33. Distribuição da mostra efetiva por programa segundo o gênero $(\mathrm{N}=545)$

\begin{tabular}{|c|c|c|c|c|c|c|c|}
\hline \multirow[t]{2}{*}{ Escola } & \multirow[t]{2}{*}{ Programa } & \multicolumn{2}{|c|}{ Masculino } & \multicolumn{2}{|c|}{ Feminino } & \multicolumn{2}{|c|}{ Total } \\
\hline & & $\mathrm{N}$ & $\%$ & $\mathrm{~N}$ & $\%$ & $\mathrm{~N}$ & $\%$ \\
\hline \multirow{4}{*}{$\begin{array}{l}\text { Internacional de } \\
\text { Administração e } \\
\text { Marketing } \\
(\mathrm{N}=267)\end{array}$} & $\begin{array}{l}\text { Administração de } \\
\text { empresas }\end{array}$ & 44 & 8.1 & 26 & 4.8 & 70 & $1 ., 8$ \\
\hline & Contaduría & 28 & 5.1 & 19 & 3.5 & 47 & 8.6 \\
\hline & Finanzas & 32 & 5.9 & 32 & 5.9 & 64 & 11.7 \\
\hline & $\begin{array}{l}\text { Marketing e negocios } \\
\text { internacionais }\end{array}$ & 46 & 8.4 & 40 & 7.3 & 86 & 15.8 \\
\hline \multirow{4}{*}{$\begin{array}{l}\text { Ciências Exatas e } \\
\text { Engenharia } \\
(\mathrm{N}=219)\end{array}$} & Ambiental & 16 & 2.9 & 13 & 2.4 & 29 & 5.3 \\
\hline & Industrial & 64 & 11.7 & 33 & 6.1 & 97 & 17.8 \\
\hline & Eletrônica & 31 & 5.7 & 4 & 0.7 & 35 & 6.4 \\
\hline & $\begin{array}{l}\text { Sistemas e } \\
\text { telecomunicações }\end{array}$ & 49 & 9.0 & 9 & 1.7 & 58 & 10.6 \\
\hline $\begin{array}{l}\text { Economía } \\
(\mathrm{N}=59)\end{array}$ & Economía & 40 & 7.3 & 19 & 3.5 & 59 & 10.8 \\
\hline Total & & 350 & 64.2 & 195 & 35.8 & 545 & 100.0 \\
\hline
\end{tabular}

Na Tabela 33, pode ser observado que a maior percentagem de avaliados é de sexo masculino $(64.2 \%)$ enquanto o feminino $(35.8 \%)$. Ademais pode ser visto que a maioria de avaliados está localizado na Escola Internacional de Administração e Marketing (267) 
seguida pela de Ciências Exatas e Engenharia (219) e Economia (59). Esta distribuição é melhor apreciada na Figura 10.

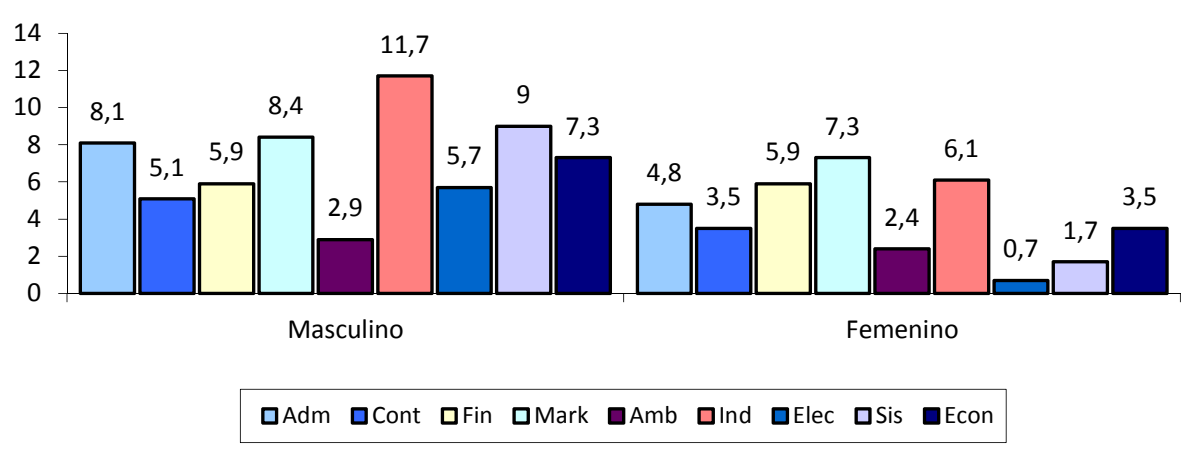

Figura 10. Distribuição de avaliados por programa segundo o gênero

\subsubsection{Procedimento de aplicação}

Para a aplicação das escalas de Cazorla et ao (1999) e Estrada (2002) aos estudantes, solicitaram-se a permissão ao departamento de matemáticas adscrito à Escola de Ciências Exatas e Engenharia quem apoio o estudo para avaliar aos estudantes que levam um primeiro e segundo semestre acadêmico das escolas de Economia, Ciências Exatas e Engenharia e a Escola Internacional de Administração e Marketing, pois os programas que oferecem a cada uma destas Escolas os estudantes contassem com dois cursos de estatística a nível superior no terceiro e quarto semestre.

Para a localização dos estudantes e a aplicação da escala recorreu-se aos professores que dão cálculo diferencial e integral na cada um dos programas do primeiro semestre acadêmico do 2013, para conhecer o número de questionários a aplicar na cada salão consulto-se ao coordenador de matemáticas quem conta com suporte-os técnicos para esta informação, uma vez conhecido o número de estudantes na cada curso organizaram-se as questionários em envelopes e se falou pessoalmente com cada professor a quem indicávamos as instruções a seguir, a aplicação se realizo em horários destes cursos ao início da aula. A aplicação da escala se fez coletivamente é se indico que era voluntario e anônimo.

Também se indico que se desejava conhecer sua opinião em relação à estatística e o contato prévio que teve na escola antes de chegar à universidade, se repartiu o questionário de maneira simultânea e se leu as instruções em voz alta, se reitero em responder tudo o questionário e não analisar cada item finalmente se agradeceu a 
participação na pesquisa. Para a coleta dos dados a cada professor entrego em nos envelopes questionários aplicados à secretaria do departamento de matemáticas.

\subsubsection{Análises estatístico}

Realiza-se uma análise psicométrico baseado em uma análise de itens. A qualidade dos itens de ambas escalas de atitude foi avaliada usando o enfoque da Teoria Clássica dos Teste (para detalhes ver Pasquali, 2003: 1-397). Os índices clássicos considerados foram: média (Me), desvio padrão (De), correlação item-total eliminando o item (rit) e alfa de Cronbach da escala sem considerar o item (alpha).

Para as versões finais das escalas reporta-se as médias e desvios padrão bem como uma análise da normalidade dos escores. Posteriormente avaliou-se a dimensionalidad das versões finais das escalas considerando uma análise fatorial com rotação varimax.

Se faz uma análise descritiva por perguntas bem como uma comparação das atitudes nas escalas segundo alguns critérios como escola, programa e sexo dos estudantes considerando comparação de duas médias usando prova-a T e comparação a mais de duas médias usando um Anova. Todas as análises foram desenvolvidas no programa estatístico SPSS versão 20.0

\subsection{Resultados}

\subsubsection{Características Psicométricas das escalas}

Nas tabelas 34 e 35 apresentamos os resultados das análises de itens da Escala de Atitudes para a estatística considerando uma escala global (45 itens) e das escalas AEE (25 itens) e AEC (20 itens) separadamente. As correlações inferiores a 0.20 indicam baixa relação do item com a escala total. 
Tabela 34. Análises de itens das escalas AEE e AEC analisadas globalmente (45 itens)

\begin{tabular}{|c|c|c|c|c|c|c|c|c|c|}
\hline ítem & $\mathrm{Me}$ & DS & rit & Alpha & ítem & $\mathrm{Me}$ & DS & rit & Alpha \\
\hline 1 & 3.32 & 0.99 & 0.18 & 0.92 & 26 & 3.49 & 0.95 & 0.54 & 0.92 \\
\hline 2 & 3.79 & 1.02 & 0.28 & 0.92 & 27 & 3.60 & 0.99 & 0.55 & 0.92 \\
\hline 3 & 2.56 & 1.14 & -0.17 & 0.93 & 28 & 3.34 & 0.91 & 0.65 & 0.92 \\
\hline 4 & 3.47 & 0.99 & 0.33 & 0.92 & 29 & 3.10 & 0.86 & 0.54 & 0.92 \\
\hline 5 & 3.24 & 1.03 & 0.26 & 0.92 & 30 & 3.07 & 0.84 & 0.45 & 0.92 \\
\hline 6 & 3.91 & 1.14 & 0.43 & 0.92 & 31 & 3.69 & 1.00 & 0.56 & 0.92 \\
\hline 7 & 3.22 & 0.91 & 048 & 0.92 & 32 & 3.53 & 0.96 & 0.46 & 0.92 \\
\hline 8 & 3.23 & 0.96 & 0.51 & 0.92 & 33 & 3.59 & 0.98 & 0.54 & 0.92 \\
\hline 9 & 3.54 & 1.01 & 0.28 & 0.92 & 34 & 3.45 & 0.87 & 0.54 & 0.92 \\
\hline 10 & 3.42 & 0.88 & 0.47 & 0.92 & 35 & 3.68 & 1.00 & 0.60 & 0.92 \\
\hline 11 & 3.62 & 1.02 & 0.42 & 0.92 & 36 & 3.10 & 0.81 & 0.50 & 0.92 \\
\hline 12 & 3.35 & 0.94 & 0.52 & 0.92 & 37 & 3.59 & 0.99 & 0.58 & 0.92 \\
\hline 13 & 3.54 & 0.97 & 0.49 & 0.92 & 38 & 3.56 & 0.95 & 0.55 & 0.92 \\
\hline 14 & 2.74 & 1.08 & 0.20 & 0.92 & 39 & 3.21 & 0.87 & 0.57 & 0.92 \\
\hline 15 & 3.58 & 0.91 & 0.45 & 0.92 & 40 & 3.04 & 0.84 & 0.53 & 0.92 \\
\hline 16 & 3.25 & 0.94 & 0.46 & 0.92 & 41 & 3.45 & 0.98 & 0.45 & 0.92 \\
\hline 17 & 3.26 & 1.01 & 0.43 & 0.92 & 42 & 3.70 & 1.02 & 0.57 & 0.92 \\
\hline 18 & 3.72 & 1.04 & 0.29 & 0.92 & 43 & 2.89 & 0.78 & 0.32 & 0.92 \\
\hline 19 & 3.95 & 1.06 & 0.42 & 0.92 & 44 & 3.18 & 0.80 & 0.58 & 0.92 \\
\hline 20 & 3.04 & 0.90 & 0.43 & 0.92 & 45 & 3.26 & 0.87 & 0.56 & 0.92 \\
\hline 21 & 4.23 & 1.02 & 0.54 & 0.92 & & & & & \\
\hline 22 & 2.79 & 0.88 & 0.24 & 0.92 & & & & & \\
\hline 23 & 3.68 & 1.09 & 0.61 & 0.92 & & & & & \\
\hline 24 & 3.76 & 0.93 & 0.42 & 0.92 & & & & & \\
\hline 25 & 3.62 & 0.97 & 0.48 & 0.92 & & & & & \\
\hline
\end{tabular}

$\mathrm{Me}=$ media, $\mathrm{De}=$ desvio padrão, rit $=$ correlação item -total eliminando o item alpha $=$ alfa de Cronbach da escala sem considerar o item

Os resultados da Tabela 34 mostram que considerando os itens como componentes em uma escala global apresentam 2 itens da AEE (itens 1e 3) que não satisfazem os critérios indicados anteriormente e consequentemente podem ser eliminados para a construção de uma escala global. Neste caso ficaríamos com uma versão da escala de 43 itens. 
Tabela 35. Análises de itens das Escalas AEE e AEC por separado

\begin{tabular}{|c|c|c|c|c|c|c|c|c|c|}
\hline \multicolumn{3}{|c|}{ AEE } & \multicolumn{7}{|c|}{$\mathrm{AEC}$} \\
\hline Ítem & $\mathrm{Me}$ & $\mathrm{De}$ & rit & Alpha & Îtem & $\mathrm{Me}$ & $\mathrm{De}$ & rit & Alpha \\
\hline 1 & 3.32 & 0.99 & 0.19 & 0.83 & 26 & 3.49 & 0.95 & 0.54 & 0.90 \\
\hline 2 & 3.79 & 1.02 & 0.32 & 0.82 & 27 & 3.60 & 0.99 & 0.56 & 0.90 \\
\hline 3 & 2.56 & 1.14 & -0.22 & 0.85 & 28 & 3.34 & 0.91 & 0.61 & 0.90 \\
\hline 4 & 3.47 & 0.99 & 0.35 & 0.82 & 29 & 3.10 & 0.86 & 0.57 & 0.90 \\
\hline 5 & 3.24 & 1.03 & 0.27 & 0.82 & 30 & 3.07 & 0.84 & 0.46 & 0.90 \\
\hline 6 & 3.91 & 1.134 & 0.43 & 0.82 & 31 & 3.69 & 1.00 & 0.56 & 0.90 \\
\hline 7 & 3.22 & 0.91 & 0.46 & 0.82 & 32 & 3.53 & 0.96 & 0.50 & 0.90 \\
\hline 8 & 3.23 & 0.96 & 0.46 & 0.82 & 33 & 3.59 & 0.98 & 0.57 & 0.90 \\
\hline 9 & 3.54 & 1.01 & 0.29 & 0.82 & 34 & 3.45 & 0.87 & 0.53 & 0.90 \\
\hline 10 & 3.42 & 0.88 & 0.49 & 0.82 & 35 & 3.68 & 1.00 & 0.61 & 0.90 \\
\hline 11 & 3.62 & 1.02 & 0.41 & 0.82 & 36 & 3.10 & 0.81 & 0.51 & 0.90 \\
\hline 12 & 3.35 & 0.94 & 0.51 & 0.81 & 37 & 3.59 & 0.99 & 0.60 & 0.90 \\
\hline 13 & 3.54 & 0.97 & 0.52 & 0.81 & 38 & 3.56 & 0.95 & 0.54 & 0.90 \\
\hline 14 & 2.74 & 1.08 & 0.16 & 0.83 & 39 & 3.21 & 0.87 & 0.58 & 0.90 \\
\hline 15 & 3.58 & 0.91 & 0.42 & 0.82 & 40 & 3.04 & 0.84 & 0.50 & 0.90 \\
\hline 16 & 3.25 & 0.94 & 0.47 & 0.82 & 41 & 3.45 & 0.98 & 0.51 & 0.90 \\
\hline 17 & 3.26 & 1.01 & 0.39 & 0.82 & 42 & 3.70 & 1.02 & 0.60 & 0.90 \\
\hline 18 & 3.72 & 1.04 & 0.32 & 0.82 & 43 & 2.89 & 0.78 & 0.33 & 0.91 \\
\hline 19 & 3.95 & 1.06 & 0.45 & 0.82 & 44 & 3.18 & 0.80 & 0.59 & 0.90 \\
\hline 20 & 3.04 & 0.90 & 0.38 & 0.82 & 45 & 3.26 & 0.87 & 0.58 & 0.90 \\
\hline 21 & 4.23 & 1.02 & 0.54 & 0.81 & & & & & \\
\hline 22 & 2.79 & 0.88 & 0.22 & 0.83 & & & & & \\
\hline 23 & 3.68 & 1.09 & 0.57 & 0.81 & & & & & \\
\hline 24 & 3.76 & 0.93 & 0.40 & 0.82 & & & & & \\
\hline 25 & 3.62 & 0.97 & 0.46 & 0.82 & & & & & \\
\hline
\end{tabular}

Alfa de Cronbach:0.83 Alfa de Cronbach:0.91

$\mathrm{Me}=$ media, $\mathrm{De}=$ desvio padrão, rit = correlação item -total eliminando o item alpha $=$ alfa de Cronbach da escala sem considerar o item

AEE: Escala de Atitudes frente à estatística de Estrada (2002), AEC: escala de Atitudes frente à Estatística de Cazorla et al (2009)

Observando a Tabela 35, encontramos novamente que os itens 1 e 3 ao interior da AEE são os itens com comportamento inadequado e por tanto susceptível de não ser considerados uma versão recortada da AEE. Para a AEC não encontramos nenhum item que se elimine dentro da escala.

A escala AEC apresenta melhor alfa de Cronbach que a AEE indicando que é uma escala mais confiável, é de anotar que o alfa de Cronbach é um número entre -1 y 1, quando mais perto se encontre o valor de alfa a 1 maior é a consistência interna e os itens analisados. 


\subsubsection{Análises final de itens das escalas corrigidas}

Nas Tabelas 36 e 37 apresentamos os resultados das análises de itens das escalas já com os itens eliminados no anterior ponto. Os resultados demonstram que a eliminação dos itens incrementa a fiabilidade da escala Global de 0.92 para 0.93 e na Escala de Estrada (2002) de 0.83 a 0.85 .

Tabela 36. Análises de itens das escalas AEE e AEC analisadas globalmente versão final (43 itens)

\begin{tabular}{|c|c|c|c|c|c|c|c|c|c|}
\hline Ítem & $\mathrm{Me}$ & $\mathrm{De}$ & rit & Alpha & Ítem & $\mathrm{Me}$ & $\mathrm{De}$ & rit & Alpha \\
\hline 2 & 3.79 & 1.02 & 0.30 & 0.93 & 26 & 3.49 & 0.95 & 0.54 & 0.93 \\
\hline 4 & 3.47 & 0.99 & 0.34 & 0.93 & 27 & 3.60 & 0.99 & 0.55 & 0.93 \\
\hline 5 & 3.24 & 1.03 & 0.27 & 0.93 & 28 & 3.34 & 0.91 & 0.65 & 0.93 \\
\hline 6 & 3.91 & 1.14 & 0.43 & 0.93 & 29 & 3.10 & 0.86 & 0.54 & 0.93 \\
\hline 7 & 3.22 & 0.91 & 0.48 & 0.93 & 30 & 3.07 & 0.84 & 0.45 & 0.93 \\
\hline 8 & 3.23 & 0.96 & 0.50 & 0.93 & 31 & 3.69 & 1.00 & 0.56 & 0.93 \\
\hline 9 & 3.54 & 1.01 & 0.27 & 0.93 & 32 & 3.53 & 0.96 & 0.46 & 0.93 \\
\hline 10 & 3.42 & 0.88 & 0.48 & 0.93 & 33 & 3.59 & 0.98 & 0.54 & 0.93 \\
\hline 11 & 3.62 & 1.02 & 0.41 & 0.93 & 34 & 3.45 & 0.87 & 0.55 & 0.93 \\
\hline 12 & 3.35 & 0.94 & 0.52 & 0.93 & 35 & 3.68 & 1.00 & 0.59 & 0.93 \\
\hline 13 & 3.54 & 0.97 & 0.49 & 0.93 & 36 & 3.10 & 0.81 & 0.49 & 0.93 \\
\hline 14 & 2.74 & 1.08 & 0.20 & 0.93 & 37 & 3.59 & 0.99 & 0.58 & 0.93 \\
\hline 15 & 3.58 & 0.91 & 0.45 & 0.93 & 38 & 3.56 & 0.95 & 0.55 & 0.93 \\
\hline 16 & 3.25 & 0.94 & 0.47 & 0.93 & 39 & 3.21 & 0.87 & 0.57 & 0.93 \\
\hline 17 & 3.26 & 1.01 & 0.43 & 0.93 & 40 & 3.04 & 0.84 & 0.53 & 0.93 \\
\hline 18 & 3.72 & 1.04 & 0.29 & 0.93 & 41 & 3.45 & 098 & 0.45 & 0.93 \\
\hline 19 & 3.95 & 1.06 & 0.42 & 0.93 & 42 & 3.70 & 1.02 & 0.57 & 0.93 \\
\hline 20 & 3.04 & 0.90 & 0.43 & 0.93 & 43 & 2.89 & 0.78 & 0.32 & 0.93 \\
\hline 21 & 4.23 & 1.02 & 0.54 & 0.93 & 44 & 3.18 & 0.80 & 0.58 & 0.93 \\
\hline 22 & 2.79 & 0.88 & 0.23 & 0.93 & 45 & 3.26 & 0.87 & 0.56 & 0.93 \\
\hline 23 & 3.68 & 1.09 & 0.61 & 0.93 & & & & & \\
\hline 24 & 3.76 & 0.93 & 0.42 & 0.93 & & & & & \\
\hline 25 & 3.62 & 0.97 & 0.48 & 0.93 & & & & & \\
\hline
\end{tabular}

\section{Alfa Escala Global: 0.93}

$\mathrm{Me}=$ media, $\mathrm{De}=$ desvio padrão, rit $=$ correlação item -total eliminando o item alpha $=$ alfa de Cronbach da escala sem considerar o item 
Tabela 37. Análises de itens da Escala AEE versão (23 itens)

\begin{tabular}{|c|c|c|c|c|}
\hline \multicolumn{3}{|c|}{ AEE } & \multirow[b]{2}{*}{ rit } & \multirow[b]{2}{*}{ Alpha } \\
\hline Ítem & $\mathrm{Me}$ & $\mathrm{De}$ & & \\
\hline 2 & 3.79 & 1.02 & 0.36 & 0.84 \\
\hline 4 & 3.47 & 0.99 & 0.38 & 0.84 \\
\hline 5 & 3.24 & 1.03 & 0.28 & 0.85 \\
\hline 6 & 3.91 & 1.14 & 0.43 & 0.84 \\
\hline 7 & 3.22 & 0.91 & 0.47 & 0.84 \\
\hline 8 & 3.23 & 0.96 & 0.45 & 0.84 \\
\hline 9 & 3.54 & 1.01 & 0.28 & 0.85 \\
\hline 10 & 3.42 & 0.88 & 0.50 & 0.84 \\
\hline 11 & 3.62 & 1.02 & 0.39 & $0 ., 84$ \\
\hline 12 & 3.35 & 0.94 & 0.52 & $0 ., 84$ \\
\hline 13 & 3.54 & 0.97 & 0.52 & $0 ., 84$ \\
\hline 14 & 2.74 & 1.08 & 0.16 & $0 ., 84$ \\
\hline 15 & 3.58 & 0.91 & 0.42 & $0 ., 84$ \\
\hline 16 & 3.25 & 0.94 & 0.48 & $0 ., 84$ \\
\hline 17 & 3.26 & 1.01 & 0.38 & $0 ., 84$ \\
\hline 18 & 3.72 & 1.04 & 0.32 & 0.85 \\
\hline 19 & 3.95 & 1.06 & 0.45 & $0 ., 84$ \\
\hline 20 & 3.04 & 0.90 & 0.38 & $0 ., 84$ \\
\hline 21 & 4.23 & 1.02 & 0.55 & $0 ., 84$ \\
\hline 22 & 2.79 & 0.88 & 0.21 & 0.85 \\
\hline 23 & 3.68 & 1.09 & 0.56 & $0 ., 84$ \\
\hline 24 & 3.76 & 0.93 & 0.41 & $0 ., 84$ \\
\hline 25 & 3.62 & 0.97 & 0.46 & $0 ., 84$ \\
\hline
\end{tabular}

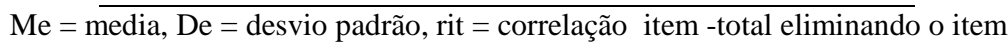
alpha $=$ alfa de Cronbach da escala sem considerar o item

\subsubsection{Análises da Normalidade e fiabilidade das escalas finais}

$\mathrm{Na}$ Tabela 38 apresentamos algumas estatísticas para a avaliação da normalidade no escore de Atitudes nas escalas de Estrada (2002) e Cazorla et al (1999) por separado e como escala global. Também são apresentadas as medias, desvio padrão e os escores mínimos e máximos obtidos na atitude frente à Estatística.

Tabela 38. Avaliação da Normalidade no escore de Atitudes nas escalas finais $(\mathrm{N}=545)$

\begin{tabular}{lccccccc}
\hline \multirow{2}{*}{ Escala } & \multicolumn{2}{c}{ Prova de Normalidade } & & & MS \\
\cline { 2 - 5 } & $\begin{array}{c}\text { Estatística } \\
(\text { KS })\end{array}$ & $\begin{array}{c}\text { Significancia } \\
(\text { KS })\end{array}$ & $\begin{array}{c}\text { Alfa de } \\
\text { Cronbach }\end{array}$ & Media & DS & Min. & Max. \\
\hline Estrada (2002)-AEE & 1.14 & 0.15 & 0.85 & 85.83 & 10.93 & 35 & 114 \\
Cazorla et al (1999)-AEC & 1.64 & 0.09 & 0.91 & 67.54 & 10.99 & 24 & 97 \\
Global & 0.90 & 0.39 & 0.93 & 153.37 & 20.56 & 59 & 210 \\
\hline & KS: Kolgomorov Smirnov Test & \multicolumn{2}{c}{ Significância *:<0.05 } & &
\end{tabular}


De acordo à Tabela 38 nenhum dos níveis de significância é menor que 0.05 se consideram que os dados são normais. Isto é a distribuição de pontuações da atitude para a estatística distribui-se normalmente.

Assim mesmo observamos que os índices de fiabilidade são maiores a 0.84. A distribuição de normalidade para o caso da escala global pode ser apreciada melhor na Figura 11.

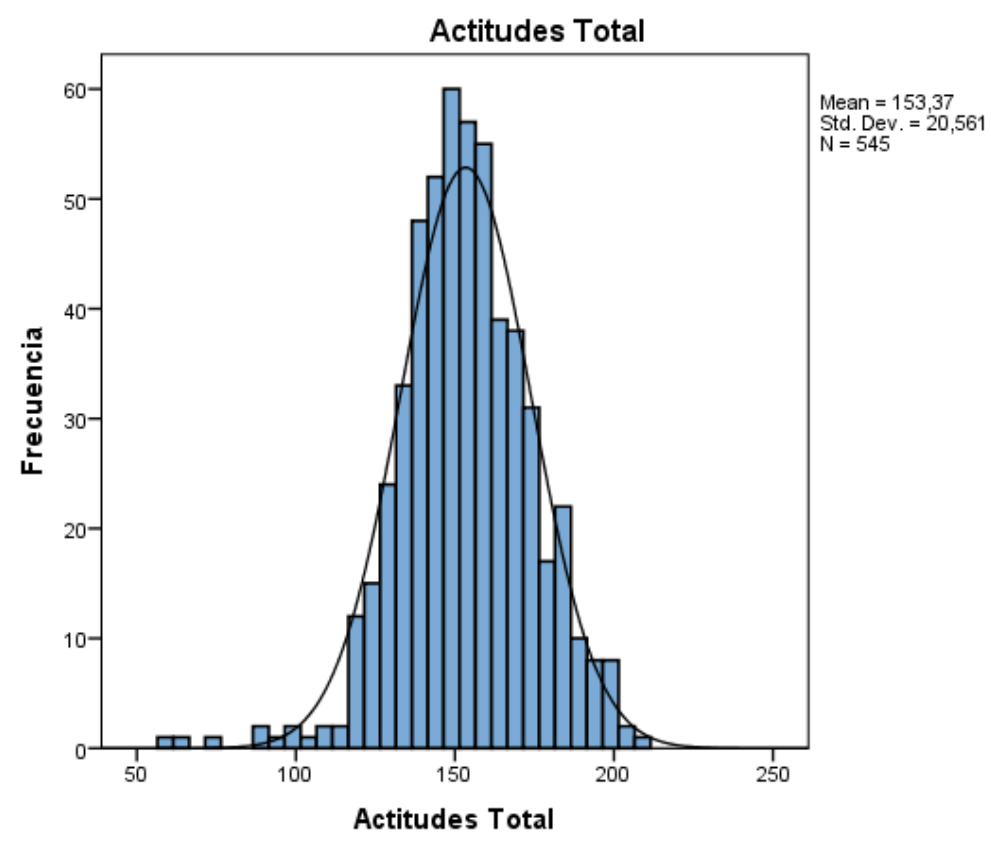

Figura 11.Distribuição de escores na Escala de Atitudes Global Final

\subsubsection{Análises da dimensionalidade das Escalas corrigidas de Estrada (2002) e Cazorla et al (1999)}

Para avaliar a dimensionalidad das escalas realizou-se uma análise fatorial com rotação varimax. As Tabelas 39 e 40 apresentam valores fatoriais superiores a 0.50 nos diferentes fatores identificados bem como os valores próprios e percentagens de variância explicados para cada fator para a cada uma das escalas analisadas.

A Tabela 39 mostra a distribuição de itens nos cinco fatores iniciais que arrojo a análise fatorial para a AEE final. Os resultados para este caso sugerem que a escala é multidimensional e se distribui da seguinte maneira: Fator 1: formado por 8 itens: 6, 9, 11, 15, 19, 21, 23 y 25 e pode ser denominado “Aversão frente à Estatística". O Fator 2, esta formado por 6 itens: 7, 10, 12, 13, 16 y 20, e pode ser denominado "Gosto pela 
Estadística". O Fator 3, formado por 6 itens 2, 4 y 5 pode ser denominado "Utilidade da

Estatística". O Fator 4 formado por 4 itens: 8, 14, 17 y 22 e pode ser denominado

"Capacidade para a Estatística" e o Fator 5 formado por 2 itens: 18 e 24, que podemos denominar "Informação da Estatística"

Tabela 39. Análises Fatorial da Escala de Atitudes frente à Estatística de Estrada (2002) - AEE

\begin{tabular}{|c|c|c|c|c|}
\hline Itens & Fatores & $\begin{array}{l}\text { Carga } \\
\text { Fatorial }\end{array}$ & $\begin{array}{c}\% \\
\text { Variância }\end{array}$ & $\begin{array}{l}\text { \%Variância } \\
\text { Acumulada }\end{array}$ \\
\hline \multicolumn{3}{|c|}{ Fator 1: Aversão frente à Estatística } & 13.63 & 13.63 \\
\hline p6 & Na universidade não deveriam ensinar Estatística & 0.59 & & \\
\hline p9 & Não entendo as informações Estatísticas que aparecem no jornal & 0.65 & & \\
\hline p11 & Eu me sento intimidado com os dados estatísticos & 0.58 & & \\
\hline p15 & $\mathrm{Na}$ aula de Estatística nunca entendo do que estão falando & 0.51 & & \\
\hline p19 & A Estatística só serve para as pessoas de ciências & 0.60 & & \\
\hline $\mathrm{p} 21$ & A Estatística não serve para nada & 0.67 & & \\
\hline p23 & Se pudesse eliminar alguma disciplina seria a Estatística & 0.59 & & \\
\hline $\mathrm{p} 25$ & Evito as informações Estatísticas quando as leio & 0.55 & & \\
\hline \multicolumn{3}{|c|}{ Fator 2: Gosto pela Estatística } & 11.58 & 25.21 \\
\hline $\mathrm{p} 7$ & Eu me divirto nas aulas em que se explica Estatística & 0.61 & & \\
\hline p10 & $\begin{array}{l}\text { Eu gosto da Estatística porque me ajuda compreender mais } \\
\text { profundamente a complexidade de certos temas }\end{array}$ & $\begin{array}{l}0.42 \\
0.57\end{array}$ & & \\
\hline p12 & Eu acho interessante o mundo da Estatística & & & \\
\hline p13 & Eu gosto dos trabalhos sérios onde apareçam estudos estatísticos & 0.46 & & \\
\hline p16 & Eu adoro a Estatística porque ajuda a ver os problemas objetivamente & 0.44 & & \\
\hline p20 & Eu gosto de fazer problemas quando uso a Estatística & 0.71 & & \\
\hline \multicolumn{3}{|c|}{ Fator 3: Utilidade da Estatística } & 8.60 & 33.80 \\
\hline $\mathrm{p} 2$ & A estatística ajuda a compreender o mundo de hoje & 0.59 & & \\
\hline $\mathrm{p} 4$ & A estatística é fundamental na formação básica do futuro cidadão & 0.71 & & \\
\hline p5 & Eu uso a Estatística para resolver problemas da vida cotidiana & 0.71 & & \\
\hline \multicolumn{3}{|c|}{$\begin{array}{l}\text { Fator 4: Capacidade para Estatística } \\
\end{array}$} & 8.23 & 42.03 \\
\hline $\mathrm{p} 8$ & Acho que os problemas da Estatística são fáceis & 0.66 & & \\
\hline p14 & Utilizo pouco a Estatística fora de meu centro de estudo & 0.39 & & \\
\hline p17 & A Estatística é fácil & 0.65 & & \\
\hline p22 & $\begin{array}{l}\text { Muitas vezes explico a meus colegas problemas de Estatística que eles } \\
\text { não entenderam }\end{array}$ & 0.55 & & \\
\hline \multicolumn{3}{|c|}{$\begin{array}{l}\text { Fator 5: Informação da Estatística } \\
\end{array}$} & 7.66 & 49.69 \\
\hline p18 & $\begin{array}{l}\text { Compreendo melhor sobre o resultado das eleições quando aparecem } \\
\text { representações gráficas }\end{array}$ & 0.68 & & \\
\hline p24 & A Estatística ajuda a tomar decisões mais fundamentadas & 0.52 & & \\
\hline
\end{tabular}


$\mathrm{Na}$ Tabela 40 mostra-se a distribuição de itens nos dois fatores que arrojo a análise fatorial para a Escala AEC. O Fator 1 está formado por 10 itens 26, 27, 31, 32, 33, 35, 37, 38, 41 y 42, o qual pode ser denominado "Valoração Negativa da Estatística", porque aqui agrupam-se todos os itens negativos da escala AEC e o Fator 2, formado por 10 itens: 28, 29, 30, 34, 36, 39, 40, 43, 44, 45. Este fator pode ser denominado "Valoração Positiva da Estatística”. Porque aqui agrupam-se todos os itens positivos da escala.

Tabela 40. Análises Fatorial da Escala de Atitudes frente à Estatística de Cazorla et al (1999)-AEC

\begin{tabular}{|c|c|c|c|}
\hline Items & Fatores & $\begin{array}{l}\text { Carga } \\
\text { Fatorial }\end{array}$ & $\begin{array}{c}\% \\
\text { Variância }\end{array}$ \\
\hline \multicolumn{3}{|c|}{ Fator 1: Valoração Negativa da Estadística } & 25.38 \\
\hline p26 & Eu fico sob uma terrível tensão na aula de Estatística & 0.64 & \\
\hline p27 & Eu não gosto de Estatística e me assusta ter que fazer essa matéria & 0.64 & \\
\hline p31 & $\begin{array}{l}\text { "Dá um branco" na minha cabeça e não consigo pensar claramente } \\
\text { Quando estudo Estatística }\end{array}$ & 0.73 & \\
\hline p32 & Eu tenho a sensação de insegurança quando me esforço em Estatística & 0.76 & \\
\hline p33 & $\begin{array}{l}\text { A Estatística me deixa inquieto(a), descontente, irritado(a) e } \\
\text { impaciente }\end{array}$ & 0.74 & \\
\hline $\mathrm{p} 35$ & $\begin{array}{l}\text { A Estatística me faz sentir como se estivesse perdido(a) em uma } \\
\text { selva de números e sem encontrar saída }\end{array}$ & 0.72 & \\
\hline p37 & $\begin{array}{l}\text { Quando eu ouço a palavra Estatística, eu tenho um sentimento de } \\
\text { aversão }\end{array}$ & 0.63 & \\
\hline p38 & $\begin{array}{l}\text { Eu encaro a Estatística com um sentimento de indecisão, que é } \\
\text { resultado do medo de não ser capaz em Estatística }\end{array}$ & 0.65 & \\
\hline $\mathrm{p} 41$ & $\begin{array}{l}\text { Pensar sobre a obrigação de resolver um problema Estatística me } \\
\text { deixa nervoso(a) }\end{array}$ & 0.68 & \\
\hline $\mathrm{p} 42$ & Eu nunca gostei de Estatística e é a matéria que me dá mais medo & 0.68 & \\
\hline \multicolumn{3}{|c|}{ Fator 2: Valoração Positiva da Estatística } & 25.01 \\
\hline p28 & $\begin{array}{l}\text { Eu acho a Estatística muito interessante e gosto das aulas de } \\
\text { Estatística }\end{array}$ & 0.69 & \\
\hline p29 & A Estatística é fascinante e divertida & 0.76 & \\
\hline $\mathrm{p} 30$ & $\begin{array}{l}\text { A Estatística me faz sentir seguro(a) e é, ao mesmo tempo, } \\
\text { estimulante }\end{array}$ & 0.68 & \\
\hline p34 & O sentimento que eu tenho com relação à Estatística é bom & 0.62 & \\
\hline p36 & A Estatística é algo que eu aprecio grandemente & 0.66 & \\
\hline p39 & Eu gosto realmente da Estatística. & 0.76 & \\
\hline $\mathrm{p} 40$ & $\begin{array}{l}\text { A Estatística é uma das matérias que eu realmente gosto de estudar na } \\
\text { universidade }\end{array}$ & 0.64 & \\
\hline $\mathrm{p} 43$ & $\begin{array}{l}\text { Eu fico mais feliz na aula de Estatística que na aula de qualquer outra } \\
\text { matéria }\end{array}$ & 0.58 & \\
\hline p44 & Eu me sinto tranquilo(a) em Estatística e gosto muito dessa matéria & 0.71 & \\
\hline $\mathrm{p} 45$ & $\begin{array}{l}\text {.Eu tenho uma reação definitivamente positiva com relação a } \\
\text { Estatística. Eu gosto e aprecio essa matéria }\end{array}$ & 0.72 & \\
\hline
\end{tabular}




\subsection{Análises Descritivo e comparativo das escalas finais}

Uma análise descritiva das respostas dado pelos avaliados são mostradas na Tabela 41. São apresentados os resultados referentes ao cada um dos 43 itens da escala global corrigida. Reportamos o número de casos na cada uma das categorias ( $1=$ muito em desacordo, $2=$ em desacordo, $3=$ indiferente, $4=$ de acordo, $5=$ muito de acordo), a média e o desvio padrão para o total da amostra.

Entre os itens positivos melhor valorizados pelos participantes estão: item 2 ("A estatística ajuda a compreender o mundo de hoje") com uma média de 3.79, item 18 ("Compreendo melhor sobre o resultado das eleições quando aparecem representações gráficas”) com uma média de 3.72, item 24 (“A Estatística ajuda a tomar decisões mais fundamentadas") com uma média de 3.76 e item 34 ("O sentimento que eu tenho com relação à Estatística é bom”) com uma média de 3.45. Estes itens estão relacionados com a importância que lhe damos à informação e utilidade da Estatística no mundo de hoje.

Em contraste, os itens negativos mas valorizados são: item 6 ("Na universidade não deveriam ensinar Estatística”) com una média de 3.91; item 19 (“A Estatística só serve para as pessoas de ciências") com uma média de 3.95, item 21 ("A Estatística não serve para nada") com uma média de 4.23 e o item 42 ("Eu nunca gostei de Estatística e é a matéria que me dá mais medo") com uma média de 3.70. Estes itens refletem sentimento de rejeição e temor para a Estatística, apesar de que se reconhece a importância desta no parágrafo anterior. 
Tabela 41. Frequências de resposta, média e desvio padrão de cada item que conformam a Escala Global corrigida (43 itens)

\begin{tabular}{|c|c|c|c|c|c|c|c|c|}
\hline Itens & Enunciado del Ítem & 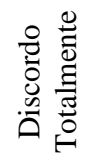 & 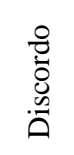 & 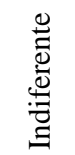 & 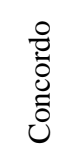 & 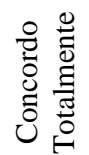 & 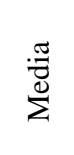 & $\tilde{A}$ \\
\hline 2 & A estatística ajuda a compreender o mundo de hoje & 21 & 58 & 53 & 294 & 119 & 3.8 & 1.0 \\
\hline 4 & A estatística é fundamental na formação básica do futuro cidadão & 26 & 66 & 139 & 255 & 59 & 3.5 & 1.0 \\
\hline 5 & Eu uso a Estatística para resolver problemas da vida cotidiana & 30 & 101 & 169 & 199 & 46 & 3.2 & 1.0 \\
\hline 6 & Na universidade não deveriam ensinar Estatística $(*)$ & 27 & 38 & 103 & 168 & 209 & 3.9 & 1.1 \\
\hline 7 & Eu me divirto nas aulas em que se explica Estatística & 30 & 56 & 254 & 174 & 31 & 3.2 & 0.9 \\
\hline 8 & Acho que os problemas da Estatística são fáceis & 26 & 90 & 199 & 194 & 36 & 3.2 & 0.9 \\
\hline 9 & $\begin{array}{l}\text { Não entendo as informações Estatísticas que aparecem no jornal } \\
(*)\end{array}$ & 18 & 71 & 135 & 238 & 83 & 3.5 & 1.0 \\
\hline 10 & $\begin{array}{l}\text { Eu gosto da Estatística porque me ajuda compreender mais } \\
\text { profundamente a complexidade de certos temas }\end{array}$ & 17 & 51 & 207 & 227 & 43 & 3.4 & 0.9 \\
\hline 11 & Eu me sento intimidado com os dados estatísticos $(*)$ & 15 & 56 & 170 & 185 & 119 & 3.6 & 1.0 \\
\hline 12 & Eu acho interessante o mundo da Estatística & 26 & 56 & 210 & 208 & 45 & 3.4 & 0.9 \\
\hline 13 & Eu gosto dos trabalhos sérios onde apareçam estudos estatísticos & 19 & 54 & 160 & 235 & 77 & 3.5 & 0.9 \\
\hline 14 & Utilizo pouco a Estatística fora da universidade $(*)$ & 53 & 212 & 140 & 105 & 35 & 2.7 & $1 ., 1$ \\
\hline 15 & Na aula de Estatística nunca entendo do que estão falando $(*)$ & 13 & 35 & 206 & 206 & 85 & 3.6 & 0.1 \\
\hline 16 & $\begin{array}{l}\text { Eu adoro a Estatística porque ajuda a ver os problemas } \\
\text { objetivamente }\end{array}$ & 26 & 69 & 240 & 165 & 45 & 3.3 & 0.9 \\
\hline 17 & A Estatística é fácil & 25 & 102 & 170 & 200 & 48 & 3.3 & 1.0 \\
\hline 18 & $\begin{array}{l}\text { Compreendo melhor sobre o resultado das eleições quando } \\
\text { aparecem representações gráficas }\end{array}$ & 23 & 45 & 116 & 237 & 124 & 3.7 & 1.0 \\
\hline 19 & A Estatística só serve para as pessoas de ciências $(*)$ & 17 & 38 & 101 & 188 & 201 & 3.9 & 1.1 \\
\hline 20 & Eu gosto de fazer problemas quando uso a Estatística & 36 & 83 & 270 & 136 & 20 & 3.0 & 0.9 \\
\hline 21 & & 17 & 21 & 72 & 145 & 290 & 4.2 & 1.0 \\
\hline 22 & $\begin{array}{l}\text { Muitas vezes explico a meus colegas problemas de Estatística } \\
\text { que eles não entenderam }\end{array}$ & 52 & 113 & 283 & 89 & 8 & 2.8 & 0.9 \\
\hline 23 & Se pudesse eliminar alguma disciplina seria a Estatística $(*)$ & 23 & 45 & 163 & 167 & 147 & 3.7 & 1.1 \\
\hline 24 & A Estatística ajuda a tomar decisões mais fundamentadas & 16 & 39 & 103 & 291 & 96 & 3.8 & 0.9 \\
\hline 25 & Evito as informações Estatísticas quando as leio $\left(^{*}\right)$ & 13 & 50 & 174 & 204 & 104 & 3.6 & 0.9 \\
\hline 26 & Eu fico sob uma terrível tensão na aula de Estatística $(*)$ & 15 & 47 & 223 & 176 & 84 & 3.5 & 0.9 \\
\hline 27 & $\begin{array}{l}\text { Eu não gosto de Estatística e me assusta ter que fazer essa } \\
\text { matéria } \\
(*)\end{array}$ & 8 & 62 & 189 & 168 & 118 & 3.6 & 1.0 \\
\hline 28 & $\begin{array}{l}\text { Eu acho a Estatística muito interessante e gosto das aulas de } \\
\text { Estatística }\end{array}$ & 25 & 47 & 227 & 207 & 39 & 3.3 & 0.9 \\
\hline 29 & A Estatística é fascinante e divertida. & 30 & 62 & 296 & 135 & 22 & 3.1 & 0.9 \\
\hline 30 & $\begin{array}{l}\text { A Estatística me faz sentir seguro(a) e é, ao mesmo tempo, } \\
\text { estimulante }\end{array}$ & 24 & 81 & 293 & 126 & 21 & 3.1 & 0.8 \\
\hline 31 & $\begin{array}{l}\text { "Dá um branco" na minha cabeça e não consigo pensar } \\
\text { claramente Quando estudo Estatística }(*)\end{array}$ & 16 & 44 & 156 & 206 & 123 & 3.7 & 1.0 \\
\hline 32 & $\begin{array}{l}\text { Eu tenho a sensação de insegurança quando me esforço em } \\
\text { Estatística }(*)\end{array}$ & 13 & 60 & 183 & 204 & 85 & 3.5 & 0.9 \\
\hline 33 & $\begin{array}{l}\text { A Estatística me deixa inquieto(a), descontente, irritado(a) e } \\
\text { impaciente }(*)\end{array}$ & 17 & 49 & 171 & 212 & 96 & 3.6 & 0.9 \\
\hline 34 & O sentimento que eu tenho com relação à Estatística é bom & 17 & 49 & 185 & 258 & 36 & 3.5 & 0.9 \\
\hline
\end{tabular}




\begin{tabular}{|c|c|c|c|c|c|c|c|c|}
\hline 35 & $\begin{array}{l}\text { A Estatística me faz sentir como se estivesse perdido(a) em uma } \\
\text { selva de números e sem encontrar saída (*) }\end{array}$ & 16 & 43 & 165 & 199 & 122 & 3.7 & 1.0 \\
\hline 36 & A Estatística é algo que eu aprecio grandemente & 21 & 71 & 302 & 133 & 18 & 3.1 & 0.8 \\
\hline 37 & $\begin{array}{l}\text { Quando eu ouço a palavra Estatística, eu tenho um sentimento de } \\
\text { aversão (*) }\end{array}$ & 13 & 56 & 181 & 187 & 108 & 3.6 & 0.9 \\
\hline 38 & $\begin{array}{l}\text { Eu encaro a Estatística com um sentimento de indecisão, que é } \\
\text { resultado do medo de não ser capaz em Estatística }(*)\end{array}$ & 12 & 52 & 191 & 198 & 92 & 3.6 & 0.9 \\
\hline 39 & Eu gosto realmente da Estatística & 26 & 56 & 269 & 168 & 26 & 3.2 & 0.9 \\
\hline 40 & $\begin{array}{l}\text { A Estatística é uma das matérias que eu realmente gosto de } \\
\text { estudar na universidade }\end{array}$ & 31 & 71 & 303 & 124 & 16 & 3.0 & 0.8 \\
\hline 41 & $\begin{array}{l}\text { Pensar sobre a obrigação de resolver um problema Estatística me } \\
\text { deixa nervoso(a) }\left(^{*}\right)\end{array}$ & 19 & 64 & 186 & 203 & 73 & 3.5 & 0.9 \\
\hline 42 & $\begin{array}{l}\text { Eu nunca gostei de Estatística e é a matéria que me dá mais } \\
\text { medo }(*)\end{array}$ & 15 & 40 & 178 & 171 & 141 & 3.7 & 1.0 \\
\hline 43 & $\begin{array}{l}\text { Eu fico mais feliz na aula de Estatística que na aula de qualquer } \\
\text { outra matéria }\end{array}$ & 33 & 89 & 337 & 75 & 11 & 2.9 & 0.8 \\
\hline 44 & $\begin{array}{l}\text { Eu me sinto tranquilo(a) em Estatística e gosto muito dessa } \\
\text { matéria }\end{array}$ & 20 & 56 & 291 & 161 & 17 & 3.1 & 0.8 \\
\hline 45 & $\begin{array}{l}\text { Eu tenho uma reação definitivamente positiva com relação a } \\
\text { Estatística. Eu gosto e aprecio essa matéria }\end{array}$ & 25 & 45 & 271 & 171 & 33 & 3.3 & 0.9 \\
\hline
\end{tabular}

\subsubsection{Comparação das atitudes frente à Estatística segundo o gênero dos avaliados}

Realiza-se uma análise comparativa através de diferenças de médias das atitudes para a estatística considerando características de interesse da mostra como gênero, Escola e Programa de estudo. Os resultados são mostrados desde a Tabela 42 até a Tabela 44.

Em geral os resultados indicam-nos que as atitudes dos avaliados não diferem com respeito ao gênero, mas se com respeito à escola e programa ao que pertencem.

Tabela 42. Comparação de escores nas Atitudes usando T de Student considerando o gênero dos

\begin{tabular}{lcccccc}
\multicolumn{7}{c}{ avaliados $(\mathrm{N}=545)$} \\
\hline Escala Atitudes & Género & $\mathrm{N}$ & Media & $\mathrm{DS}$ & $\mathrm{T}$ & Significancia \\
\hline Estrada final -AEE & Masculino & 350 & 85.38 & 11.06 & -1.30 & 0.20 \\
& Feminino & 195 & 86.64 & 10.66 & & \\
Cazorla -AEC & Masculino & 350 & 66.89 & 10.48 & -1.83 & 0.07 \\
& Feminino & 195 & 68.69 & 11.82 & & \\
Global final & Masculino & 350 & 152.27 & 20.06 & -1.67 & 0.09 \\
& Feminino & 195 & 155.33 & 21.34 & & \\
\hline
\end{tabular}

De acordo à Tabela 42, as médias das atitudes não apresentam diferenças significativas nem na escala considerada globalmente nem nas escalas consideradas por separado (AEE e AEC) considerando o gênero dos avaliados, isto se vê contemplado nos níveis de significância superior a $5 \%$ da última coluna. Uma melhor visão da distribuição de atitudes de acordo a gênero pode ser apreciada na Figura 12. 


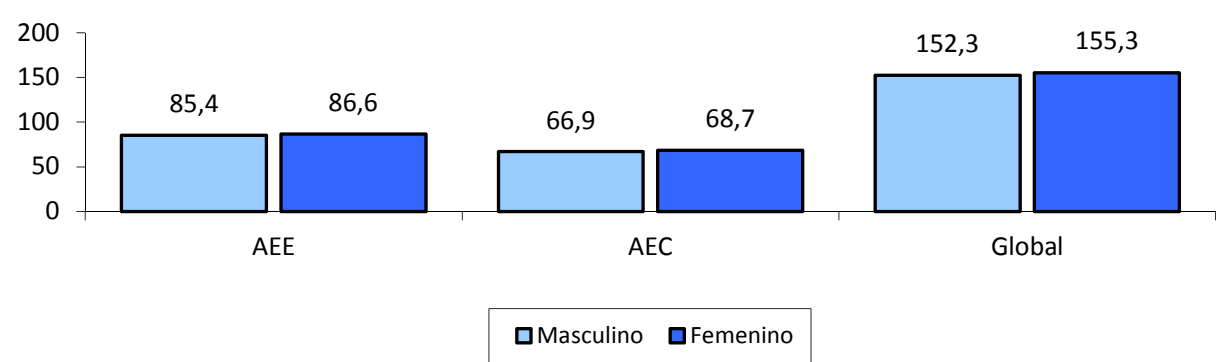

Figura 12. Distribuição das atitudes segundo o gênero dos avaliados

\subsubsection{Comparação das atitudes frente à Estatística segundo o Programa dos avaliados}

Tabela 43. Comparação de escores das Atitudes usando ANOVA considerando a Escola dos avaliados

$$
(\mathrm{N}=545)
$$

\begin{tabular}{|c|c|c|c|c|c|c|}
\hline Escala Atitudes & Escola & $\mathrm{N}$ & Media & DS & $\mathrm{F}$ & Significancia \\
\hline \multirow{3}{*}{$\begin{array}{l}\text { Estrada corrigida } \\
\text { AEE }\end{array}$} & EIAM & 267 & 84.48 & 11.13 & 4.32 & $0.014 *$ \\
\hline & Engenharia & 219 & 86.88 & 10.64 & & \\
\hline & Economía & 59 & 88.03 & 10.39 & & \\
\hline \multirow[t]{3}{*}{ Cazorla - AEC } & EIAM & 267 & 65.91 & 11.09 & 5.86 & $0.003 * *$ \\
\hline & Engenharia & 219 & 69.02 & 10.96 & & \\
\hline & Economía & 59 & 69.41 & 9.70 & & \\
\hline \multirow[t]{3}{*}{ Global corrigida } & EIAM & 267 & 150.39 & 21.03 & 5.72 & $0.003 * *$ \\
\hline & Engenhería & 219 & 155.90 & 20.31 & & \\
\hline & Economia & 59 & 157.44 & 17.46 & & \\
\hline
\end{tabular}

$*: \mathrm{p}<0.05 * * \mathrm{p}<0.01$

EIAM: Escola Internacional de Administração e Marketing

De acuerdo à Tabela 43 podemos observar que hay diferencias significativas entre los promedios de la actitud de acuerdo a la Escuela de los evaluados, siendo más altos en la escuela de Economía y más bajos en el programa de Escuela Internacional de Administración y Marketing (EIAM). Una mejor visión de la distribución de actitudes de acuerdo a Escuela puede apreciarse en la Figura 13.

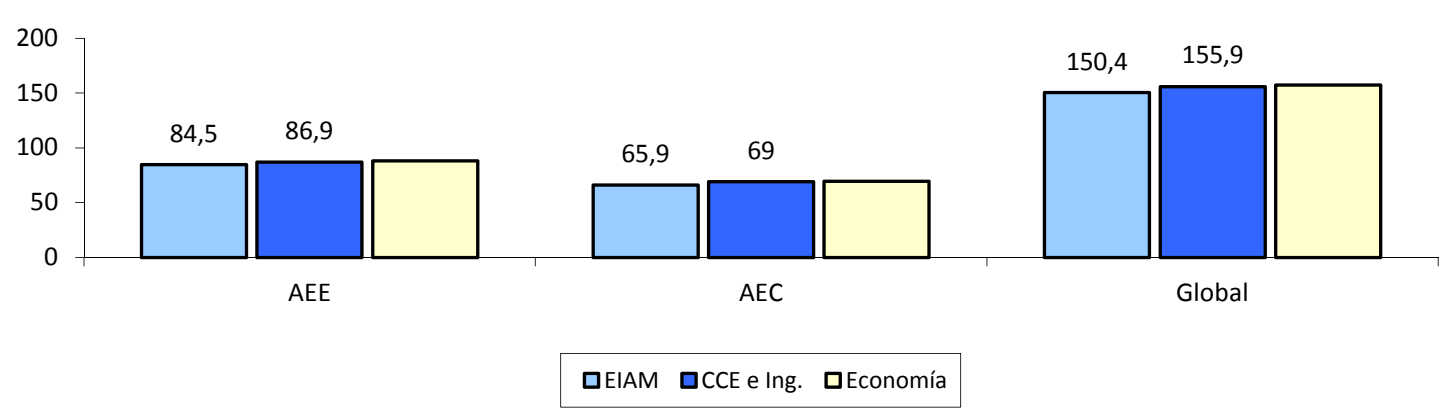

Figura 13. Distribuição das atitudes segundo a escola dos avaliados 


\subsubsection{Comparação das atitudes frente à Estatística segundo o Programa dos avaliados}

Tabela 44. Comparação de escores nas Atitudes usando ANOVA considerando o Programa dos avaliados $(\mathrm{N}=545)$

\begin{tabular}{|c|c|c|c|c|c|c|}
\hline Escala Atitudes & Programa & $\mathrm{N}$ & Media & DS & $\mathrm{F}$ & Sign \\
\hline \multirow{9}{*}{ Estrada corrigida-AEE } & Administração de Empresas & 70 & 84.87 & 10.54 & \multirow{9}{*}{2.10} & \multirow{9}{*}{$0.035^{*}$} \\
\hline & Contaduría & 47 & 84.40 & 12.79 & & \\
\hline & Finanzas & 64 & 85.81 & 10.14 & & \\
\hline & Marketing e Negocios Internacionais & 86 & 83.20 & 11.40 & & \\
\hline & Ambiental & 29 & 89.48 & 10.82 & & \\
\hline & Industrial & 97 & 87.80 & 10.43 & & \\
\hline & Eletrônica & 35 & 83.69 & 8.42 & & \\
\hline & Sistemas & 58 & 85.97 & 11.76 & & \\
\hline & Economía & 59 & 88.03 & 10.39 & & \\
\hline \multirow{9}{*}{ Carzorla-AEC } & Administração de Empresas & 70 & 65.40 & 10.74 & \multirow{9}{*}{4.67} & \multirow{9}{*}{$0.000 * *$} \\
\hline & Contaduría & 47 & 67.15 & 11.55 & & \\
\hline & Finanzas & 64 & 68.00 & 10.33 & & \\
\hline & Marketing e Negocios Internacionais & 86 & 64.09 & 11.52 & & \\
\hline & Ambiental & 29 & 73.28 & 9.65 & & \\
\hline & Industrial & 97 & 70.59 & 10.72 & & \\
\hline & Eletrônica & 35 & 62.63 & 9.00 & & \\
\hline & Sistemas & 58 & 68.12 & 11.52 & & \\
\hline & Economía & 59 & 69.41 & 9.70 & & \\
\hline \multirow{9}{*}{ Global corregida } & Administração de Empresas & 70 & 150.27 & 20.09 & \multirow{9}{*}{3.62} & \multirow{9}{*}{$0.000 * *$} \\
\hline & Contaduría & 47 & 151.55 & 23.07 & & \\
\hline & Finanzas & 64 & 153.81 & 19.12 & & \\
\hline & Marketing e Negocios Internacionais & 86 & 147.29 & 21.87 & & \\
\hline & Ambiental & 29 & 162.76 & 18.84 & & \\
\hline & Industrial & 97 & 158.39 & 20.16 & & \\
\hline & Electrónica & 35 & 146.31 & 16.06 & & \\
\hline & Sistemas & 58 & 154.09 & 21.69 & & \\
\hline & Economía & 59 & 157.44 & 17.46 & & \\
\hline
\end{tabular}

$*: \mathrm{p}<0.05 * *: \mathrm{p}<0.01$

De acordo com a Tabela 13, encontramos diferenças significativas nas médias da Atitude de acordo ao programa seguido pelos avaliados, sendo mais altos para o programa de Ambiental e mais baixos no programa de Marketing e Negócios Internacionais. Uma melhor apreciação desta distribuição e observada na Figura 14.

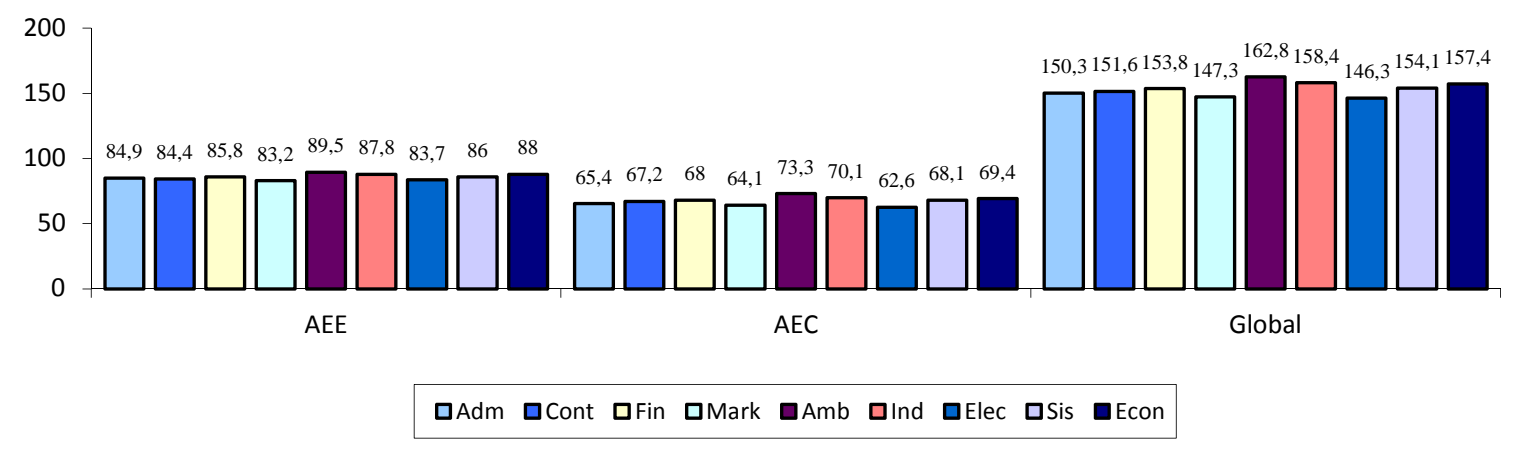

Figura 14. Distribuição das atitudes segundo o Programa dos avaliados 


\subsection{Comentários Finais}

Nossa pesquisa se focou em fazer uma avaliação sobre as atitudes de ingressantes universitários de Colômbia frente à Estatística ao iniciar o primeiro semestre acadêmico e que ainda não têm cursado esta matéria e confirmar as propriedades psicometrica das escalas usadas.

Achamos que as escalas de atitudes, como as usadas em nossa pesquisa podem permitir um diagnóstico inicial no estabelecimento de estratégias encaminhadas a melhorar as atitudes negativas detectadas e melhorar a predisposição dos alunos.

Os resultados nos permitem concluir que os estudantes iniciam o curso com uma série de atitudes frente à Estatística que requerem ser pesquisadas mais a fundo. Sendo que é percebido por elas a importância da Estatística na vida cotidiana mais guardam uma série de temores e rejeições que podem dificultar um adequado desempenho acadêmico.

Por outro lado, o estudo nos confirma a importância de contar com instrumentos adequados que facilitem a identificação destas atitudes. Assim, os resultados da análise de fiabilidade e validade das Escalas utilizadas para medir as atitudes frente à Estatística são positivos. Os coeficientes obtidos sugerem escalas com adequada consistência interna, tanto quando analisadas como uma escala global como quando analisadas como escalas separadas e constituem uma medida adequada para a avaliação das atitudes.

Nosso estudo uso um instrumento composto por duas escalas de atitudes frente à Estatística, a escala de Estrada (2002, AEE) e a escala de Cazorla et ao (1999, AEC). O propósito foi determinar as propriedades psicometricas delas usando numa amostra de estudantes universitários de Colômbia. Incluiu-se uma análise de itens, uma análise da dimensionalidad e adicionalmente aspectos descritivos e comparativos do comportamento das atitudes na amostra de estudo. Para efeitos de análises estuda-se as escalas de maneira independente e também como uma escala global.

Em geral os resultados sobre as escalas de atitudes à estatística em nossa mostra apresentam propriedades psicométricas adequadas, tanto quando se analisa a Escala de Atitudes Global e as escalas AEE (Estrada 2012) e AEC (Cazorla et al 1999). Com uma 
versão final de 43, 23 e 20 itens, resultante de uma análise de itens considerando uma perspectiva de análise clássica, onde se eliminaram dois itens (item 1 e item 3) com uma baixa correlação. Todas as escalas têm alta fiabilidade e ela se incrementa depois da eliminação destes itens, com um alfa final de 0.95, 0.88 e 0.94 respectivamente. Estes resultados são semelhantes aos achados em Tarazona et al (2013), Aliaga (2009), Estrada et ao (2013) e nos achados em Aparicio e Bazán (2006). Por outro lado identifica-se evidência de dimensionalidad, analisando as escalas de maneira independente.

Considerando as pontuações das escalas corrigidas (com itens eliminados) não se identificaram diferenças significativas nas atitudes considerando o gênero dos avaliados, estes resultados também são reportados em Tarazona et al (2013). Por outro lado se identificaram diferenças significativas na atitude frente à estatística nas Escolas de Economia e a Escola Internacional de Administração e Marketing. Observou-se que os estudantes da Escola de Economia apresentam a maior média nas diferentes escalas o que se traduz em uma atitude alta ou positiva, enquanto os estudantes da Escola Internacional de Administração e Marketing apresentaram a pontuação mais baixa nas diferentes escalas. Uma atitude que poderíamos considerar mediamente positiva a tem a Escola de Engenharia, este comportamento se manteve em todo o estudo.

A partir do instrumento se encontrou que em geral a atitude para a estatística é mais positiva nos estudantes do programa de Engenharia Ambiental e Industrial, sendo que pela natureza destas carreiras usarão a estatística de maneira mais constante.

A atitude que podemos considerar moderada com tendência positiva e que se manteve na análise foi o programa de Economia, por outro lado os programas de Engenharia de Sistema, Finanças, Administração de Empresas e Contadoria mostraram uma tendência mediamente positiva. As atitudes mais baixas identificaram-se nos programas de Engenharia Eletrônica e de Marketing e Negócios Internacionais, que em contraste terá um menor uso da Estatística.

O estudo das atitudes fazia a estatística é um insumo de um alto valor ao interior da Universidade avaliada, em particular pela mortalidade acadêmica que se apresenta nos cursos de estatística. Em vários estudos sobre o ensino e aprendizagem da estatística enfatizam o papel que desempenha o professor, mas desafortunadamente não se 
considerou um dos fatores que tem que ver com a mortalidade acadêmica e que depende primordialmente do estudante, a atitude com que chegam ao iniciar seus cursos de estatística.

Por último achamos que a presente pesquisa nos permite conhecer as atitudes frente à Estatística em futuros profissionais da área de ciências, podendo no futuro orientar-nos para o planejamento de ações didáticas a considerar no ensino desta disciplina y também nos permite ter uma escala global de atitudes para a Estatística com propriedades psicometricas ótimas. 


\title{
CASO 4: ATITUDES FRENTE A ESTÍSTICA EM ESTUDANTES \\ BRASILEIROS
}

\section{ATITUDE FRENTE À ESTATÍSTICA EM UNIVERSITÁRIOS DE UMA UNIVERSIDADE FEDERAL DE BRASIL}

\begin{abstract}
Resumo
Neste estudo são analisadas as atitudes frente à estatística num grupo de estudantes de uma universidade pública na cidade de Minas Gerais no Brasil.

São utilizadas duas escalas de atitudes tipo lickert: A escalas de Estrada (2002) (AEE) e a Escala de Cazorla et al (1999) (AEC). Para fines da avaliação das escalas foram utilizadas como uma escala global.

Os estudantes avaliados são dos primeiros anos de estudos e das áreas de ciências e de letras ou humanas. A amostra final estive conformada por 177 alunos avaliados de ambos sexos.

$O$ análise psicometrico tanto da escala global como separada em duas, demonstra uma escala final de 42 itens com uma adequada confiabilidade e validade de construto. Se encontraram diferencias nas atitudes frente a Estatística entre os estudantes da área de ciências e de humanas e entre homes e mulheres.
\end{abstract}

Palavras chave: Escala, atitudes frente a estatística, análises de itens, dimensionalidad, confiabilidade, universitários

\subsection{Metodologia}

\subsubsection{População e amostra efetiva}

A população considerada corresponde aos estudantes de graduação de uma universidade federal brasileira que dentro do programa curricular da carreira considera ao menos um curso de estatística. A aplicação do questionário foi realizada no meio do semestre em que os estudantes cursavam o curso de estatística.

A universidade em estudo tem aproximadamente 10.800 alunos que estudam na graduação. Para a admissão do ano 2012 ofereceram-se 1821 vagas distribuídas em 32 especialidades, divididas pela universidade em três grandes áreas: Área de exatas que oferece dez especialidades, área de saúde que oferece oito especialidades e área de humanas/ sociais que oferece catorze especialidades. 
Todos os cursos de exatas têm pelo menos um curso obrigatório de estatística dentro do programa curricular, especificamente, o curso de Cálculo de Probabilidades é considerado para todos eles. Para o caso das áreas de saúde e ciências humanas sociais é considerado a disciplina de Estatística Básica. Uma situação a ser realçar é que algumas especialidades da área de ciências humanas/sociais não consideram cursos de estatística, como exemplos destes temos direito e música.

A quantidade de cursos distribuídos pelas áreas específicas consideradas na admissão do ano 2012 e os considerados na amostra deste estudo são apresentados na Tabela 45.

Tabela 45. Distribuição das especialidades por áreas

\begin{tabular}{lcccccc}
\hline Área & $\begin{array}{c}\text { Consideradas } \\
\text { admissão } 2012\end{array}$ & \multicolumn{2}{c}{$\begin{array}{c}\text { Consideradas } \\
\text { na amostra } \\
\text { inicial }(\mathrm{N}=266)\end{array}$} & $\begin{array}{c}\text { Consideradas na } \\
\text { amostra final } \\
(\mathrm{N}=177)\end{array}$ \\
\cline { 2 - 8 } & $\mathrm{n}$ & $\%$ & $\mathrm{n}$ & $\%$ & $\mathrm{n}$ & $\%$ \\
\hline Exatas & 10 & 31.3 & 10 & 62.5 & 8 & 57.1 \\
Saúde & 8 & 25.0 & 2 & 12.5 & 2 & 14.3 \\
Humanas/Sociais & 14 & 43.8 & 4 & 25.0 & 4 & 28.6 \\
Total & 32 & 100.00 & 16 & 100.00 & 14 & 100.00 \\
\hline
\end{tabular}

$\mathrm{Na}$ Tabela 45, aprecia-se que todos as especialidades de ciências exatas foram consideradas na mostra, enquanto no caso de ciências da saúde e ciências humanas/sociais foram consideram aproximadamente $25 \%$ de todas as especialidades na amostra. Esta situação é explicada porque no semestre em questão poucas especialidades das áreas de saúde e humanas/sociais tinham o curso de estatística oferecido.

Desta forma, a população objetivo do estudo são os estudantes da universidade que no semestre em que se realizou o questionário estavam matriculados regularmente no curso de estatística oferecido como parte do programa curricular cursado e que frequentavam regularmente as aulas administradas.

Alguns critérios foram considerados para considerar a alunos como parte da mostra, estes são apresentados a seguir.

\section{Critérios de inclusão:}

- Estudantes de graduação da universidade que estejam regularmente matriculados na disciplina de estatística oferecido no semestre em que foi feito o estudo. 
- Estudantes que frequentaram regularmente a disciplina até o dia da aplicação do questionário.

- Estudantes que tenham respondido tudo o questionário e que não tenham respondido no mínimo 5 itens.

\section{Critérios de exclusão:}

- Estudantes que não tenham respondido mais de cinco itens do questionário.

- Estudantes que não estiveram presentes no dia da aplicação do questionário.

- Dados descritivos faltantes como idade, sexo, ano de estudos

- Estudantes que tenham cursado mais de uma disciplina de Estatística

A mostra inicial esteve conformada por 266 alunos e seguindo os critérios de inclusão e exclusão mostra-a final para o estudo combino com 177 alunos de diferentes especialidades como é mostrado na seguinte Tabela:

Tabela 46. Distribuição das especialidades por faculdade $(\mathrm{N}=177)$

\begin{tabular}{llcc}
\hline Área & \multicolumn{1}{c}{ Faculdade } & $\mathrm{N}$ & $\%$ \\
\hline \multirow{2}{*}{ Exatas } & Engenharia de Produção & 25 & 57.1 \\
& Engenharia Elétrica & 47 & \\
& Engenharia Ambiental & 7 & \\
& Engenharia Civil & 1 & \\
& Computação & 5 & \\
& Física & 12 & \\
& Engenharia Mecânica & 2 & \\
& Ciências Exatas & 5 & \\
& & & \\
Saúde & Farmácia & 9 & \\
& Química & 9 & \\
& Educ. Física & 14 & \\
Total & & 18 & $\mathbf{1 0 0 . 0}$ \\
\hline
\end{tabular}


Tabela 47. Distribuição da amostra por gênero

\begin{tabular}{lcc}
\hline Género & $\mathrm{n}$ & $\%$ \\
\hline Masculino & 100 & 56.5 \\
Feminino & 77 & 43.5 \\
Total & 177 & 100.0 \\
\hline
\end{tabular}

\subsubsection{Instrumentos}

São usadas as escalas de Escala de atitudes em relação à Estatística de Estrada (AAE) e a Escala de atitudes frente à Estadística de Cazorla et al. (1999) (AAC).

\subsubsection{Procedimento}

Se solicitaram permissões correspondentes na Faculdade de Ciências Naturais e Matemáticas e a Faculdade de Educação-Secundária.

Aplicou-se uma escala global de 45 itens, composta pelas escalas de Estrada (2002) e de Cazorla et al (1999) aos estudantes. Para poder aceder aos estudantes solicitou-se permissão ao Decano da Faculdade de Ciências Naturais e Matemáticas e à Diretora de Escola de Educação - Secundária, os quais foram aceites.

Teve-se que aceder ao plano curricular para saber em que semestre eles tiveram um primeiro contato com a Estatística e de acordo a isso começar a localizar em suas salas para poder ser avaliados. Se pediu aos estudantes indicar em que ano curso a disciplina de Estatística.

Conhecendo os semestres nos quais devíamos avaliar estudantes universitários se procedeu a solicitar os horários da cada uma das especialidades em seu respectivo ciclo para poder localizar eles na sala de aula. Tendo já os horários dos alunos, a técnica utilizada para a coleta de dados foi conversar com o professor antecipadamente, para poder contar com seu apoio. O instrumento foi aplicado de maneira coletiva, nas salas de classes dos estudantes, ao final da classe. Informou-se respeito da voluntariedade do estudo e do caráter anônimo da investigação. 


\subsection{Resultados}

\subsubsection{Análise psicometrico}

Nas Tabelas 48 e 49 apresentamos os resultados da análise de itens da escala global e por separado respectivamente. São considerados os índices clássicos: média $(\mathrm{Me})$, desvio padrão (De), correlação item-total eliminando o item (rit) e alfa de Cronbach da escala sem considerar o item (alpha). É considerado uma correlação inadequada valores inferiores a 0.20

Tabela 48. Análise de itens das escalas AEE e AEC analisadas globalmente

\begin{tabular}{|c|c|c|c|c|c|c|c|c|c|}
\hline Item & $\mathrm{Me}$ & $\mathrm{De}$ & rit & Alpha & Item & $\mathrm{Me}$ & $\mathrm{De}$ & rit & Alpha \\
\hline 1 & 3.36 & 0.97 & 0.13 & 0.92 & 26 & 3.87 & 0.90 & 0.42 & 0.91 \\
\hline 2 & 4.13 & 0.75 & 0.19 & 0.92 & 27 & 3.90 & 0.98 & 0.57 & 0.91 \\
\hline 3 & 27 & 1.15 & 0.03 & 0.92 & 28 & 3.32 & 0.89 & 0.62 & 0.91 \\
\hline 4 & 3.44 & 0.93 & 0.33 & 0.92 & 29 & 2.95 & 0.88 & 0.61 & 0.91 \\
\hline 5 & 3.06 & 1.13 & 0.37 & 0.91 & 30 & 2.81 & 0.86 & 0.54 & 0.91 \\
\hline 6 & 4.19 & 0.99 & 0.34 & 0.92 & 31 & 3.50 & 0.95 & 0.60 & 0.91 \\
\hline 7 & 2.93 & 1.03 & 0.29 & 0.92 & 32 & 3.51 & 0.95 & 0.47 & 0.91 \\
\hline 8 & 2.33 & 0.91 & 0.28 & 0.92 & 33 & 3.71 & 0.98 & 0.56 & 0.91 \\
\hline 9 & 3.88 & 0.88 & 0.27 & 0.92 & 34 & 3.36 & 0.84 & 0.64 & 0.91 \\
\hline 10 & 3.58 & 0.90 & 0.47 & 0.91 & 35 & 3.79 & 0.89 & 0.52 & 0.91 \\
\hline 11 & 3.59 & 0.95 & 0.29 & 0.92 & 36 & 2.92 & 0.87 & 0.60 & 0.91 \\
\hline 12 & 3.54 & 0.81 & 0.52 & 0.91 & 37 & 3.81 & 0.86 & 0.42 & 0.91 \\
\hline 13 & 3.77 & 0.81 & 0.38 & 0.91 & 38 & 3.74 & 0.99 & 0.42 & 0.91 \\
\hline 14 & 2.76 & 1.22 & 0.32 & 0.92 & 39 & 2.82 & 0.88 & 0.70 & 0.91 \\
\hline 15 & 3.91 & 0.85 & 0.41 & 0.91 & 40 & 2.69 & 0.88 & 0.57 & 0.91 \\
\hline 16 & 3.31 & 0.94 & 0.52 & 0.91 & 41 & 3.49 & 0.91 & 0.45 & 0.91 \\
\hline 17 & 2.42 & 0.98 & 0.32 & 0.92 & 42 & 3.92 & 0.90 & 0.52 & 0.91 \\
\hline 18 & 3.72 & 1.04 & 0.22 & 0.92 & 43 & 2.20 & 0.88 & 0.43 & 0.91 \\
\hline 19 & 4.35 & 0.82 & 0.32 & 0.92 & 44 & 2.86 & 0.92 & 0.61 & 0.91 \\
\hline 20 & 2.85 & 0.85 & 0.49 & 0.91 & 45 & 3.08 & 0.91 & 0.59 & 0.91 \\
\hline 21 & 4.53 & 0.81 & 0.37 & 0.91 & & & & & \\
\hline 22 & 2.73 & 1.01 & 0.34 & 0.92 & & & & & \\
\hline 23 & 3.92 & 0.91 & 0.55 & 0.91 & & & & & \\
\hline 24 & 3.66 & 0.84 & 0.29 & 0.92 & & & & & \\
\hline 25 & 3.73 & 0.86 & 0.42 & 0.91 & & & & & \\
\hline
\end{tabular}

Alfa : 0.91

Os resultados da tabela 48 mostram que considerando os itens como componentes em uma escala global apresentam 3 itens da AEE (itens 1, 2 e 3) que não satisfazem os 
critérios de uma correlação igual ou maior a 0.20 e são eliminados escala global. Neste caso ficaríamos com uma versão da escala de 42 itens.

Tabela 49. Análise de itens das Escalas AEE e AEC por separado

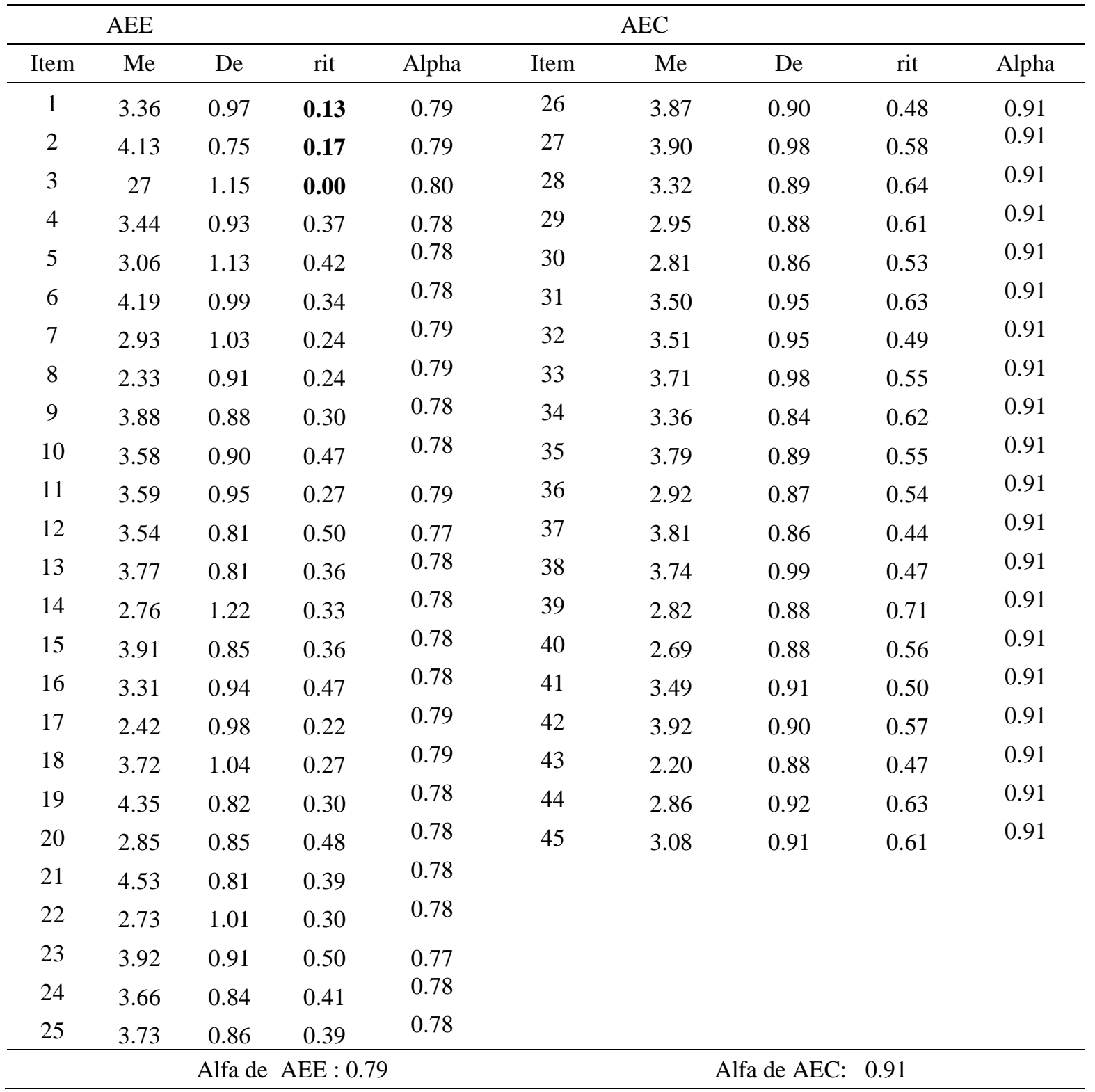

De acordo aos resultados mostrados na Tabela 49, encontramos novamente que os itens 1,2 e 3 ao interior da AEE são itens com comportamento inadequado e por tanto susceptível de não ser considerados em uma versão recortada da AEE. Para a AEC não encontramos nenhum item que se eliminou dentro da escala. 


\subsubsection{Análises das escalas finais}

Nas Tabelas 50 e 51 apresentamos os resultados da análise de itens da com os itens eliminados no ponto anterior. Os resultados mostram que com a eliminação de itens 1,2 e 3 há um aumento na fiabilidade tanto da escala global de 0.91 para 0.92 e na Escala de Estrada (2002) de 0.79 a 0.81. Esta escala demonstra ser mais confiável na construção dos itens.

Tabela 50. Análise de itens das escalas AEE e AEC analisadas globalmente versão final (42 itens)

\begin{tabular}{|c|c|c|c|c|c|c|c|c|c|}
\hline Item & $\mathrm{Me}$ & $\mathrm{De}$ & rit & Alpha & Item & $\mathrm{Me}$ & De & rit & Alpha \\
\hline 4 & 3.44 & 0.93 & 0.32 & 0.92 & 26 & 3.87 & 0.90 & 0.43 & 0.92 \\
\hline 5 & 3.06 & 1.13 & 0.37 & 0.92 & 27 & 3.90 & 0.98 & 0.58 & 0.92 \\
\hline 6 & 4.19 & 0.99 & 0.34 & 0.92 & 28 & 3.32 & 0.89 & 0.61 & 0.92 \\
\hline 7 & 2.93 & 1.03 & 0.29 & 0.92 & 29 & 2.95 & 0.88 & 0.60 & 0.92 \\
\hline 8 & 2.33 & 0.91 & 0.29 & 0.92 & 30 & 2.81 & 0.86 & 0.54 & 0.92 \\
\hline 9 & 3.88 & 0.88 & 0.28 & 0.92 & 31 & 3.50 & 0.95 & 0.60 & 0.92 \\
\hline 10 & 3.58 & 0.90 & 0.461 & 0.92 & 32 & 3.51 & 0.95 & 0.49 & 0.92 \\
\hline 11 & 3.59 & 0.95 & 0.29 & 0.92 & 33 & 3.71 & 0.98 & 0.56 & 0.92 \\
\hline 12 & 3.54 & 0.81 & 0.40 & 0.92 & 34 & 3.36 & 0.84 & 0.64 & 0.92 \\
\hline 13 & 3.77 & 0.81 & 0.39 & 0.92 & 35 & 3.79 & 0.89 & 0.53 & 0.92 \\
\hline 14 & 2.76 & 1.22 & 0.33 & 0.92 & 36 & 2.92 & 0.87 & 0.59 & 0.92 \\
\hline 15 & 3.91 & 0.85 & 0.42 & 0.92 & 37 & 3.81 & 0.86 & 0.42 & 0.92 \\
\hline 16 & 3.31 & 0.94 & 0.52 & 0.92 & 38 & 3.74 & 0.99 & 0.42 & 0.92 \\
\hline 17 & 2.42 & 0.98 & 0.33 & 0.92 & 39 & 2.82 & 0.88 & 0.70 & 0.92 \\
\hline 18 & 3.72 & 1.04 & 0.22 & 0.92 & 40 & 2.69 & 0.88 & 0.56 & 0.92 \\
\hline 19 & 4.35 & 0.82 & 0.32 & 0.92 & 41 & 3.49 & 0.91 & 0.45 & 0.92 \\
\hline 20 & 2.85 & 0.85 & 0.50 & 0.92 & 42 & 3.92 & 0.90 & 0.53 & 0.92 \\
\hline 21 & 4.53 & 0.81 & 0.36 & 0.92 & 43 & 2.20 & 0.88 & 0.43 & 0.92 \\
\hline 22 & 2.73 & 1.01 & 0.34 & 0.92 & 44 & 2.86 & 0.92 & 0.61 & 0.92 \\
\hline 23 & 3.92 & 0.91 & 0.55 & 0.92 & 45 & 3.08 & 0.91 & 0.59 & 0.92 \\
\hline 24 & 3.66 & 0.84 & 0.28 & 0.92 & & & & & \\
\hline 25 & 3.73 & 0.86 & 0.43 & 0.92 & & & & & \\
\hline \multicolumn{10}{|c|}{ Alfa Escala Global: 0.92} \\
\hline
\end{tabular}


Tabela 51. Análise de itens das Escalas AEE versão final (22 itens)

\begin{tabular}{|c|c|c|c|c|}
\hline \multicolumn{3}{|c|}{ AEE } & \multirow[b]{2}{*}{ rit } & \multirow[b]{2}{*}{ Alpha } \\
\hline Item & $\mathrm{Me}$ & $\mathrm{De}$ & & \\
\hline 4 & 3.44 & 0.93 & 0.35 & \multirow{2}{*}{$\begin{array}{l}0.80 \\
0.80\end{array}$} \\
\hline 5 & 3.06 & 1.13 & 0.44 & \\
\hline 6 & 4.19 & 0.99 & 0.33 & 0.80 \\
\hline 7 & 2.93 & 1.03 & 0.24 & 0.81 \\
\hline 8 & 2.33 & 0.91 & 0.25 & \multirow{2}{*}{$\begin{array}{l}0.81 \\
0.80\end{array}$} \\
\hline 9 & 3.88 & 0.88 & 0.31 & \\
\hline 10 & 3.58 & 0.90 & 0.46 & 0.80 \\
\hline 11 & 3.59 & 0.95 & 0.28 & 0.80 \\
\hline 12 & 3.54 & 0.81 & 0.47 & 0.80 \\
\hline 13 & 3.77 & 0.81 & 0.37 & 0.80 \\
\hline 14 & 2.76 & 1.22 & 0.35 & 0.80 \\
\hline 15 & 3.91 & 0.85 & 0.37 & 0.80 \\
\hline 16 & 3.31 & 0.94 & 0.47 & 0.80 \\
\hline 17 & 2.42 & 0.98 & 0.24 & 0.81 \\
\hline 18 & 3.72 & 1.04 & 0.27 & 0.81 \\
\hline 19 & 4.35 & 0.82 & 0.31 & 0.80 \\
\hline 20 & 2.85 & 0.85 & 0.50 & 0.80 \\
\hline 21 & 4.53 & 0.81 & 0.38 & 0.80 \\
\hline 22 & 2.73 & 1.01 & 0.30 & 0.80 \\
\hline 23 & 3.92 & 0.91 & 0.50 & 0.80 \\
\hline 24 & 3.66 & 0.84 & 0.41 & 0.80 \\
\hline 25 & 3.73 & 0.86 & 0.41 & 0.80 \\
\hline & & de $\mathrm{AE}$ & & \\
\hline
\end{tabular}

\subsubsection{Análise da Normalidade e fiabilidade das escalas corrigidas}

Na Tabela 52 apresenta-se alguns resultados para a avaliação da normalidade na pontuação de Atitudes nas escalas AEE e AEC, bem como na escala global. São apresentadas ademais as fiabilidades, a média e desvio regular. A partir da análise de normalidade de Kolgomorov Smirnov, é possível evidenciar que as pontuações distribuem normalmente.

Como podemos observar, na Tabela 52 nenhum dos níveis de significância é menor que 0.05 e se consideram que as pontuações da atitude para a estatística têm uma distribuição normal (curva normal). 
Assim mesmo observamos que os índices de fiabilidade (Alfha de Cronbach) são superiores a 0.80, o que indica um nível ótimo para as escalas usadas. A distribuição da normalidade para a escala global pode ser melhor apreciada na Figura 15.

Tabela 52. Prova de Normalidade no escore de Atitudes, AEE, AEC e AECom (escala global) corrigidas $(\mathrm{N}=)$

\begin{tabular}{|c|c|c|c|c|c|c|}
\hline \multirow[b]{2}{*}{ Escala } & \multicolumn{3}{|c|}{ Prova de Normalidade } & \multirow[b]{2}{*}{$\begin{array}{c}\text { Fiabilidade } \\
\text { Alfa de } \\
\text { Cronbach }\end{array}$} & \multirow[b]{2}{*}{ Media } & \multirow[b]{2}{*}{ DS } \\
\hline & Itens & Estatística (KS) & $\begin{array}{l}\text { Significância } \\
(\mathrm{KS})\end{array}$ & & & \\
\hline EGlobal & & 0.72 & 0.67 & 0.92 & 152.42 & 19.17 \\
\hline $\mathrm{EE}$ & & 1.00 & 0.27 & 0.81 & 86.16 & 9.55 \\
\hline $\mathrm{EC}$ & & 0.77 & 0.60 & 0.91 & 66.26 & 11.10 \\
\hline
\end{tabular}

KS: Kolgomorov Smirnov Test Significância*: <0.05

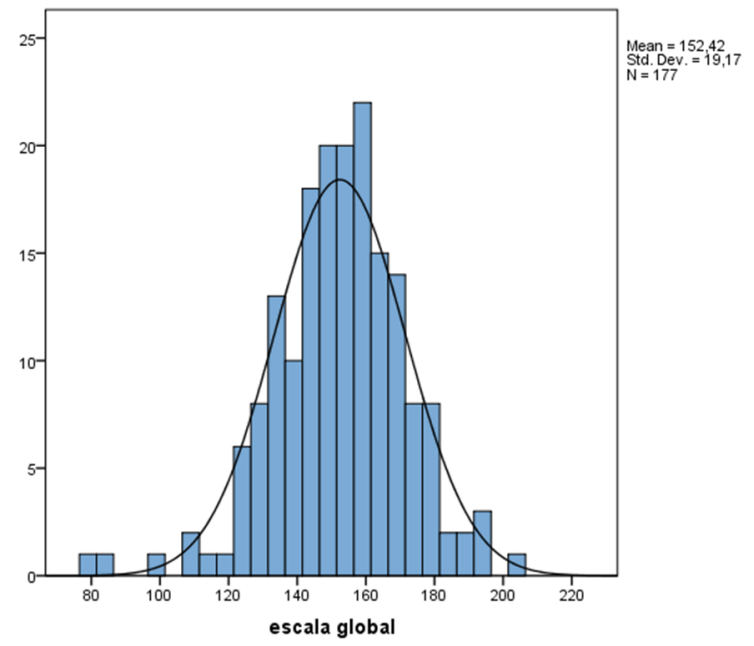

Figura 15. Distribuição da normalidade na escala de atitudes global frente à Estatística

\subsection{Estudo da dimensionalidade das Escalas corrigidas de Estrada (2002) e Cazorla et al (1999)}

Para evaluar la dimensionalidad de las escalas se realizó un análisis fatorial con rotación varimax. A Tabela 53 presentan as cargas fatoriales superiores en los diferentes fatores identificados así como los valores propios y porcentajes de variancia explicados por cada Fator para cada una de las escalas analizadas. Se identificaram 7 fatores principais na escala Global. A distribuição dos itens nos fatores é observada na seguinte Tabela: 
Tabela 53. Análise Fatorial da Escala Global de Atitudes frente à Estadística

\begin{tabular}{|c|c|c|c|c|c|c|c|}
\hline Itens & F1 & F2 & F3 & $\mathrm{F} 4$ & F5 & F6 & F7 \\
\hline $\mathrm{p} 7$ & 0.40 & & & & & & \\
\hline p8 & 0.19 & & & & & & \\
\hline p16 & 0.48 & & & & & & \\
\hline p17 & 0.18 & & & & & & \\
\hline $\mathrm{p} 22$ & 0.22 & & & & & & \\
\hline $\mathrm{p} 28$ & 0.67 & & & & & & \\
\hline p29 & 0.73 & & & & & & \\
\hline p30 & 0.59 & & & & & & \\
\hline p34 & 0.54 & & & & & & \\
\hline p36 & 0.63 & & & & & & \\
\hline p39 & 0.75 & & & & & & \\
\hline $\mathrm{p} 40$ & 0.79 & & & & & & \\
\hline $\mathrm{p} 43$ & 0.69 & & & & & & \\
\hline $\mathrm{p} 44$ & 0.72 & & & & & & \\
\hline $\mathrm{p} 45$ & 0.72 & & & & & & \\
\hline p31 & & 0.54 & & & & & \\
\hline p32 & & 0.38 & & & & & \\
\hline p35 & & 0.48 & & & & & \\
\hline p37 & & 0.67 & & & & & \\
\hline p38 & & 0.78 & & & & & \\
\hline $\mathrm{p} 41$ & & 0.64 & & & & & \\
\hline $\mathrm{p} 42$ & & 0.72 & & & & & \\
\hline p6 & & & 0.21 & & & & \\
\hline p15 & & & 0.22 & & & & \\
\hline $\mathrm{p} 21$ & & & 0.53 & & & & \\
\hline $\mathrm{p} 23$ & & & 0.59 & & & & \\
\hline p26 & & & 0.60 & & & & \\
\hline $\mathrm{p} 27$ & & & 0.70 & & & & \\
\hline p33 & & & 0.47 & & & & \\
\hline $\mathrm{p} 4$ & & & & 0.66 & & & \\
\hline p10 & & & & 0.58 & & & \\
\hline p24 & & & & 0.72 & & & \\
\hline p5 & & & & & 0.46 & & \\
\hline p9 & & & & & 0.64 & & \\
\hline $\mathrm{p} 14$ & & & & & 0.62 & & \\
\hline $\mathrm{p} 25$ & & & & & 0.56 & & \\
\hline p18 & & & & & & 0.73 & \\
\hline p19 & & & & & & 0.38 & \\
\hline p20 & & & & & & 0.48 & \\
\hline $\mathrm{p} 11$ & & & & & & & 0.47 \\
\hline p12 & & & & & & & 0.48 \\
\hline p13 & & & & & & & 0.67 \\
\hline Cargas & 10.8 & 3.4 & 2.4 & 1.9 & 1.5 & 1.4 & 1.3 \\
\hline $\begin{array}{l}\text { \% } \\
\text { Variância }\end{array}$ & 23.9 & 7.6 & 5.4 & 4.2 & 3.4 & 3.2 & 2.9 \\
\hline $\begin{array}{l}\% \\
\text { Variância } \\
\text { acumulada }\end{array}$ & 23.9 & 31.6 & 36.9 & 41.1 & 44.5 & 47.7 & 50.7 \\
\hline
\end{tabular}


Na Tabela 53 se observa a distribuição de itens nos sete fatores iniciais que arrojo a análise fatorial para a AEE final. Os resultados para este caso sugerem que a escala é multidimensional e se distribui da seguinte maneira: Fator 1: formado por 15 itens: 7, 8, 16, 17, 22, 28. 29,30, 34, 36, 39, 40, 43, 44, 45, pode ser denominado como "Valoração positiva da Estatística”. O Fator 2, está formado por 7 itens: 31, 32, 35, 37, 38, 41, 42. Que pode ser chamado como “Aversão à Estatística”. O Fator 3, formado por 7 itens 6, 15, 21, 23, 26, 27, 33. Que pode ser denominado "Valoração negativa da Estatística". O Fator 4 formado por 3 itens 4, 10, 24. Que pode ser chamado como "Utilidade da Estatística”. O Fator 5 formado por 4 itens: 5, 9, 14, 25. Que pode ser denominado de "Entendimento da Estatística". O Fator 6, está formado por 3 itens: 18, 19 e 20, que pode ser denominado como "habilidade em Estatística" e o Fator 7 formado por 3 itens: 11, 12 , 13, que pode ser denominado de "Gosto pela Estatística".

\subsection{Comparação das atitudes frente à estatística segundo a área e o gênero dos avaliados}

Se faz uma análise comparativa através de diferenças de médias das atitudes para a estatística considerando características de interesse da mostra como área e gênero. Os resultados são mostrados nas Tabelas 54 e 55.

Em geral os resultados indicam-nos que as atitudes dos avaliados diferem com respeito à área à que pertence. Os avaliados que estudam cursos mais relacionados com ciências tem uma melhor atitude à estatística que aqueles que estejam em um curso da área de humanas ou social. As áreas foram formadas por motivo de análises classificando os cursos más afines à área de ciências e os mais afines à área de humanas.

Com respeito ao gênero se observa diferenças na atitude em frente à estatística onde são os avaliados de gênero masculino os que têm melhores atitudes frente a seus colegas de gênero feminino.

A distribuição das médias na atitude segundo a área e gênero dos avaliados é melhor apreciada na figura 16 e 17. 
Tabela 54. Comparação de médias nas atitudes usando T de Student considerando a área do curso dos avaliados

\begin{tabular}{llccccc}
\hline & \multicolumn{2}{l}{ Área do } & & & \multicolumn{2}{c}{ Significancia } \\
& curso & $\mathrm{N}$ & Media & $\mathrm{DS}$ & $\mathrm{T}$ & \\
\hline \multirow{2}{*}{ EGlobal } & Ciências & 122 & 157.36 & 16.43 & & $0.00^{* *}$ \\
& Humanas & 55 & 141.45 & 20.38 & 5.09 & \\
EE & Ciências & 122 & 88.7 & 8.35 & & \\
& Humanas & 55 & 80.58 & 9.74 & 5.34 & $0.00^{* *}$ \\
EC & Ciências & 122 & 68.69 & 9.75 & 4.23 & \\
\cline { 2 - 6 } & Humanas & 55 & 60.87 & 12.06 & & $0.00^{* *}$ \\
\hline
\end{tabular}

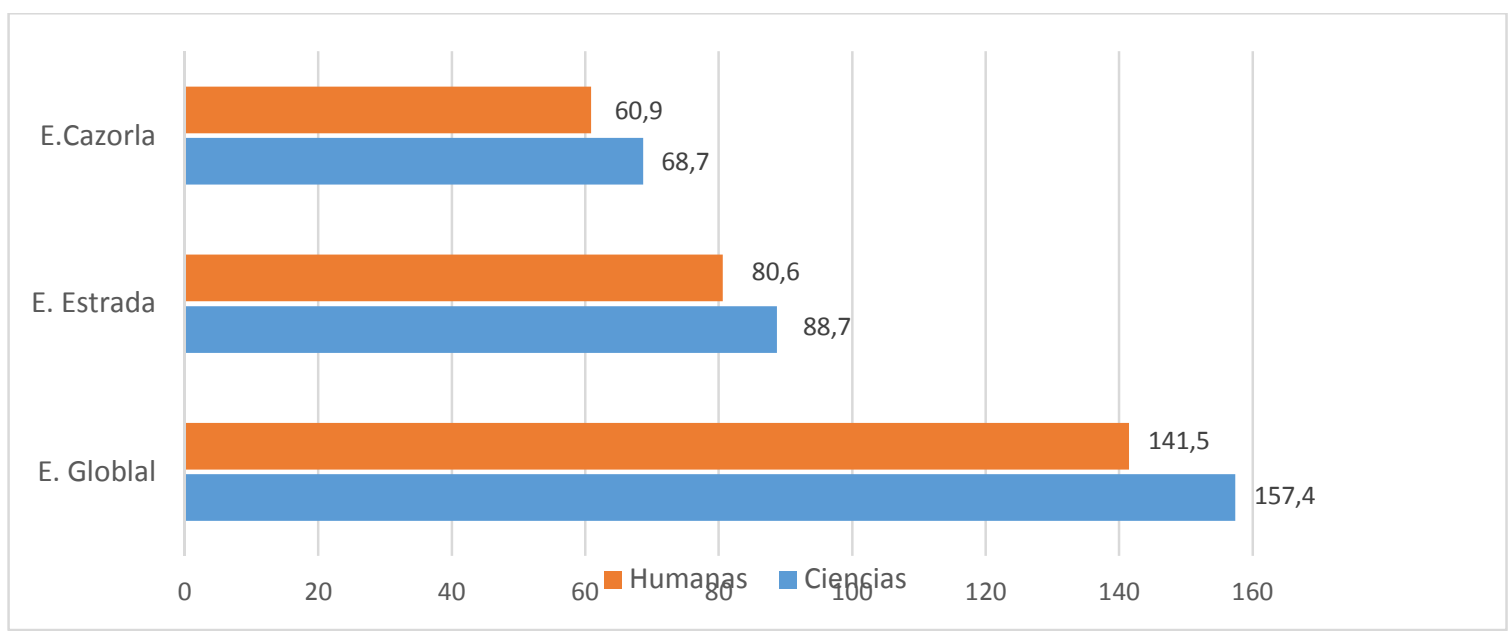

Figura 16. Distribuição de médias nas atitudes de acorda à área do curso

Tabela 55. Comparação de médias nas atitudes usando T de Student considerando o gênero dos avaliados

\begin{tabular}{llccccc}
\hline & Gênero & $\mathrm{N}$ & Media & $\mathrm{DS}$ & $\mathrm{T}$ & Significância \\
\hline EGlobal & Masculino & 100 & 155.25 & 16.48 & 2.19 & $0.03^{*}$ \\
& Feminino & 77 & 148.74 & 21.75 & & \\
EE & Masculino & 100 & 87.82 & 7.9 & 2.58 & 0.08 \\
& Feminino & 77 & 84.00 & 10.9 & & \multirow{2}{*}{0.11} \\
EC & Masculino & 100 & 67.43 & 9.9 & & \\
& Feminino & 77 & 64.74 & 12.3 & 1.56 &
\end{tabular}




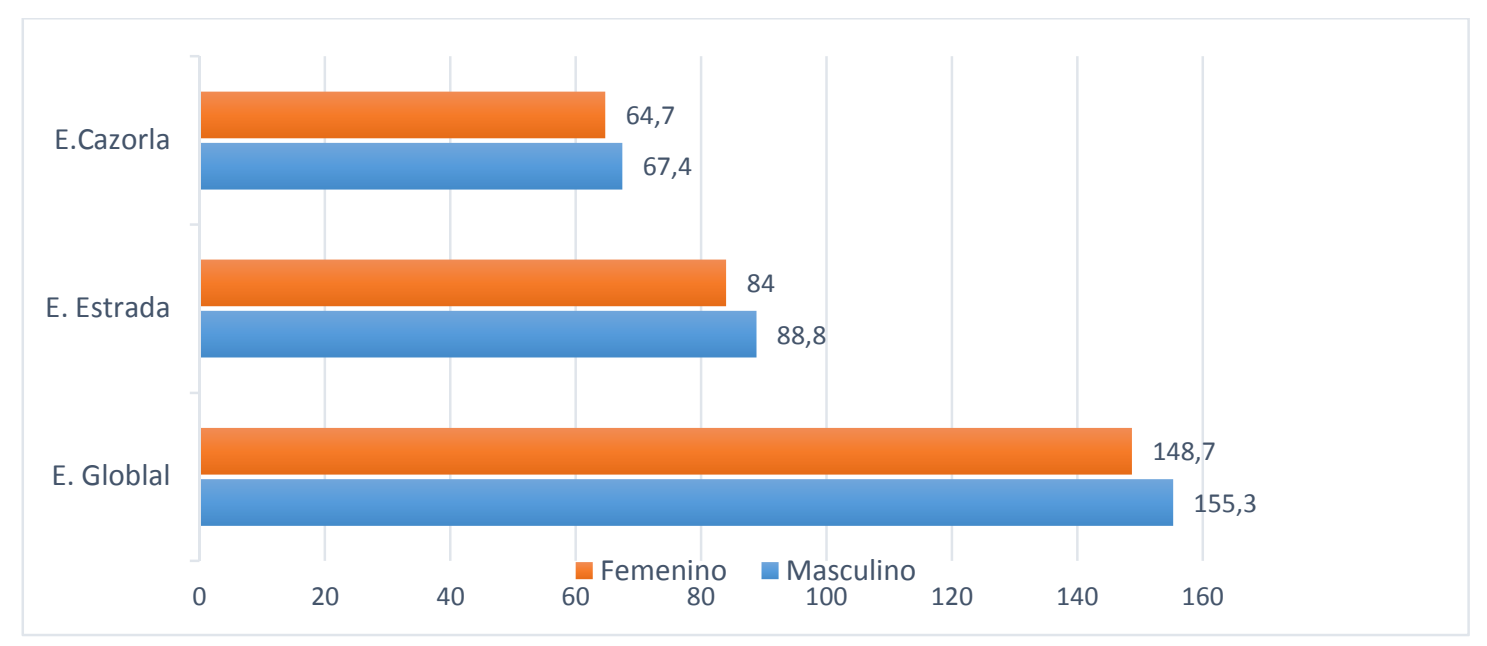

Figura 17. Distribuição de médias nas atitudes de acordo ao gênero dos avaliados

\subsection{Comentários finais}

Esta pesquisa se focou na avaliação das atitudes frente à Estatística de ingressantes universitários de uma universidade pública de Brasil ao iniciar o primeiro semestre acadêmico, estabelecendo diferencias em nas respostas de acordo ao género e a área do curso.

Os resultados nos permitem concluir que o estudo dos itens das escalas usadas tem uma adequada consistência interna com um alpha maior a 0.90 na escala global e uma versão final de 43 itens.

Os avaliados dos cursos mais afines a ciências tem uma atitude mais positiva que $\mathrm{s}$ avaliados dos cursos más afines a humanas. Também se viu que os avaliados homes têm melhor atitude que suas colegas de gênero feminino. 


\section{CAPITULO VII}

\section{COMPARAÇÃO INTEGRADA PERU-CHILE-COLOMBIA E BRASIL : ATITUDES FRENTE A ESTATÍSTICA DE ALUNOS INICIANTES NA GRADUAÇÃO}

No capítulo anterior temos feito as análises psicométricos, descritivos é comparativo nos grupos de participantes independentemente. Existem deferências em alguns casos nos métodos usados, já que foram trabalhos desenvolvidos em conjunto com outros colegas. Embora se tenham um formato semelhante, os resultados podem diferir pelas características das amostras em cada grupo participante. Em resumo só apresentamos os resultados achados na escala global de atitudes frente à Estatística.

Assim, com respeito ao estudo psicométrico, se faz análises de itens para certificar a qualidade dos itens que formavam a escala. No Peru, este analise foi baseado num enfoque da Teoria Clássica dos Test (TCT) e através da Teoria de Resposta ao item (TRI). Em Chile, Colômbia e Brasil estas análises se realizam só através do enfoque clássico.

$\mathrm{Na}$ análise com os estudantes avaliados no Peru foram identificados dois itens com pouca discriminação e correlação com a escala global. Estes foram os itens 3 ("Através da Estatística pode-se manipular a realidade") e 18 ("Compreendo melhor sobre o resultado das eleições quando aparecem representações gráficas”). Os índices de fiabilidade com a nova versão de 43 itens aumento de 0.88 para 0.93 .

Em Chile o analise de itens identifica 4 itens com baixa correlação $(<0.20)$ que foram os itens 1 ("Incomoda-me a informação Estatística que há em alguns programas da TV”), 3 (“Através da Estatística pode-se manipular a realidade”), 17 (“A Estatística é fácil”) e 18 (“Compreendo melhor sobre o resultado das eleições quando aparecem representações gráficas"). Os índices de fiabilidade com a nova versão de 41 aumento de 0.94 para 0.95 . 
Em Colômbia: o analise de itens identifica dois itens que não satisfazem os critérios indicados e com baixa correlação $(<0.20)$ que foram os itens 1 ("Incomoda-me a informação Estatística que há em alguns programas da TV”) e o 3 (“Através da Estatística pode-se manipular a realidade"). A eliminação desses itens fez com que o valor da fiabilidade na escala global aumentara de 0.92 para 0.93 e uma versão final da escala de 41 itens.

No Brasil a análise de itens da escala global elimina três itens com baixa correlação, estes foram o 1 ("Incomoda-me a informação Estatística que há em alguns programas da TV"), o 2 (“A estatística ajuda a compreender o mundo de hoje”) e o 3 (“(“Através da Estatística pode-se manipular a realidade"). O índice de fiabilidade da escala aumento de 0.91 a 0.92 , com uma nova versão da escala de 42 itens.

O item que foi eliminado em todos os grupos avaliados foi o 3 (“(“Através da Estatística pode-se manipular a realidade") e o item 1 ("Incomoda-me a informação Estatística que há em alguns programas da TV"), só não foi eliminado do grupo de Peru.

Quando se analisa se tem diferencias na atitude frente á estatística considerando o gênero dos avaliados, na maioria dos grupos não se tem encontrado diferencias nas respostas entre homes e mulheres, só se encontro diferencias com médias mais altas nos homes no grupo de Brasil.

Por outro lado quando se quere ver se tem diferencias significativas na atitude frente à Estatística considerando variáveis como a especialidade ou curso se reportam diferencias significativas a favor de especialidades ou cursos afines a ciência que aos relacionados com cursos de licenciatura ou humanas. Este resultado também tem a ver com o uso e a utilidade que a Estatística tem em sua formação. Para este analise se tem usado a prova de comparação de médias ANOVA e de comparações múltiplas de Tukey.

Em Peru há diferencias significativas entre as atitudes dos estudantes nas quatro especialidades de engenharia. Onde a Engenharia Industrial tem atitudes mais positivas e a Engenharia de Telecomunicações e Redes tem atitudes menos positivas. 
Em Chile, a comparação das médias das atitudes frente à Estatística segunda as especialidades se reportam diferencias significativas na atitude. A especialidade de Ing. Estatística tem as médias mais altas e as especialidades de Ing. Matemática, Licenciatura em computação e Pedagogia em matemática as médias mais baixas.

Em Colômbia, se encontraram diferencias significativas nas médias da Atitude segundo programa seguido pelos estudantes. As médias mais altas são obtidas pelo programa de Ing. Ambiental e os mais baixos o programa de Marketing e Negócios Internacionais. Também se encontraram diferencias significativas nas médias da atitude segundo a Escola dos avaliados, sendo mais altos na escola de Economia e os mais baixo na Escola Internacional de Administração e Marketing (EIAM).

No Brasil, se encontra diferencias nas atitudes dos avaliados com respeito à área à que pertence. Os avaliados que estudam cursos mais relacionados com ciências presentam uma melhor atitude à estatística que aqueles que estejam em um curso da área de humanas ou social.

Por último analisamos se a escala global de atitudes frente à estatística apresentava dimensionalidade. Isto é, se os itens se agruparam em fatores de acordo as características entre os itens. Este analise não foi feito no grupo de Peru.

Se utilizo um analise fatorial usando o método de máxima verosimilitude com rotação varimax através da matriz de correlações policóricas com o programa $\mathrm{R}$ no caso de Chile e uma análise fatorial exploratório com o programa SPSS nos outros países.

Em todos os grupos analisados se encontra uma escala global com características de multidimensionalidade. No Chile se tem quatro fatores, na Colômbia cinco fatores e no Brasil sete fatores principais.

Logo deste resumo do capítulo anterior faremos as análises considerando a Escala Global de Atitudes frente à Estatística com todos os grupos participantes dos diferentes países que totalizam uma amostra efetiva de 972 avaliados. 


\subsection{Analise integrado}

\subsubsection{Características gerais da amostra integrada por países}

A amostra integrada por países está conformada por um total de 972 participantes. A maior percentagem é formada por homes com $65.3 \%$ e $34.7 \%$ de mulheres. Tem um $56 \%$ da Colômbia, $18 \%$ de Brasil, $14 \%$ de Peru e $12 \%$ de Chile. A orientação dos cursos tem um $70 \%$ com mais afinidade as ciências e um 30\% com humanas.

Tabela 56. Características gerais da amostra integrada $(\mathrm{N}=972)$

\begin{tabular}{llll}
\hline \multicolumn{2}{c}{ Características Generais } & $\mathrm{N}$ & $\%$ \\
\hline \multirow{2}{*}{ Pais } & Chile & 113 & 11.6 \\
& Peru & 137 & 14.1 \\
& Brasil & 177 & 18.2 \\
& Colômbia & 545 & 56.1 \\
Gênero & & & \\
& Masculino & 635 & 65.3 \\
& Feminino & 337 & 34.7 \\
\multirow{2}{*}{ Orientação } & Ciência & 682 & 70.2 \\
& Humanas & 290 & 29.8 \\
\hline
\end{tabular}

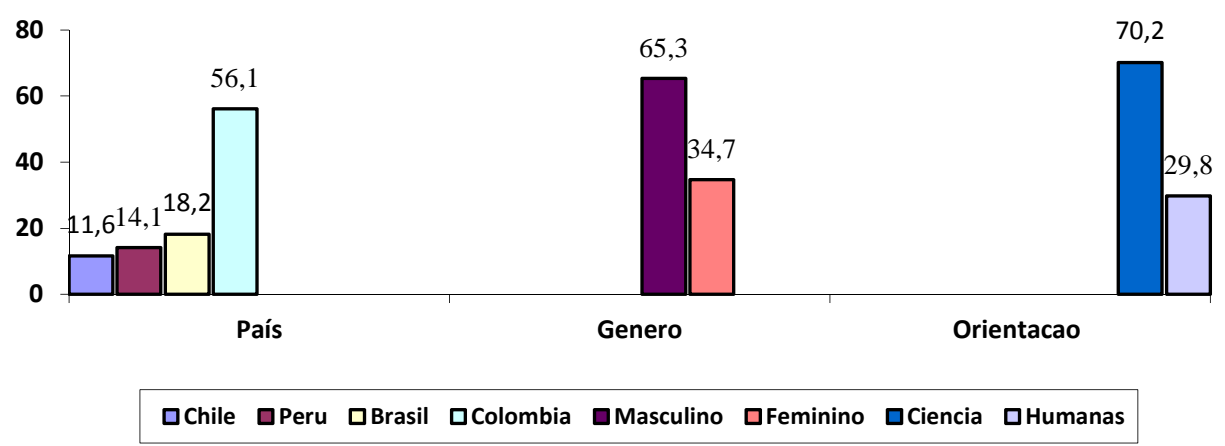

\subsubsection{Analises Globais e de itens das atitudes frente à estatística}

A continuação apresentamos os resultados globais considerando a amostra integral ( $\mathrm{N}=972)$ da escala de atitudes frente a estatística, assim como as análises considerando as variáveis comparativas como país, gênero e orientação do curso, que para fines de análise temos separado em curso mais a fines a ciências humanas e mais afines a ciências exatas. 


\section{Analises de itens da Escala Global de Atitudes frente a Estatística}

Para este analise temos considerado as médias (Me) e desvio padrão (DS)em cada item Isso pode ser observado na Tabela 57. Logo desta análise faremos o analises dos itens tanto da escala global (com 45 itens) como considerando as escalas por separado de Estrada (2002) e de Cazorla et al (1999). Cabe lembrar que a escala global é formada por estas duas escalas que por motivos de pesquisa foi considerada globalmente na avaliação dos participantes.

\section{Análise das valorações médias obtidas nos itens que conformam a escala}

Lembremos que para cada item se solicitava aos participantes expressar seu grado de concordância que poderia variar entre "discordo totalmente" e "concordo totalmente", com um total de cinco categorias.

Assim os itens com melhores escores médias são o item 21 ("A Estatística não serve para nada"), com uma média de 4.37. O segundo item mais valorado é o item 6 ("Na universidade não deveriam ensinar Estatística"). O terceiro e o item 19 ("A Estatística só serve para as pessoas de ciências") e o último melhor valorado é o item 2 ("A estatística ajuda a compreender o mundo de hoje").

De acordo com o encontrado no parágrafo superior embora os estudantes reconheçam que a estatística ajuda a compreender o mundo (item 2), tem sentimentos negativos. Isso pode dever-se a que muitos dos avaliados são da área de humanas, por considerar que a estatística só deve ser ensinada para a área de ciências. Isto pode ser interpretado como uma falta de relação entre a profissão que eles estão estudando é a utilidade que a estatística poderia ter para eles.

Neste aspecto é importante reforçar a ideia (de professores para os alunos) de que a estatística não só é útil nas ciências mas se em todas as áreas da pesquisa independente da profissão.

Por outro lado os itens menos (médias menores) valorados são o item 3 ("Através da Estatística pode-se manipular a realidade"). O item 14 ("Utilizo pouco a Estatística fora da instituição de estudo"); o item 43 ("Eu fico mais feliz na aula de Estatística que na aula de qualquer outra matéria ") e o item 40 (A Estatística é uma das matérias que eu realmente gosto de estudar na universidade"). 
Estes itens expressam que o estudante tem respondido menos frequentemente as alternativas de concordância com a preposição. Assim estão em desacordo que com a estatística se possa manipular a realidade e expressam o pouco uso e gosto que eles têm da estatística y certa rejeição as aulas recebidas ao descordar com o item 43 e 44, a pesar de reconhecer a importância dela para compreender o mundo de hoje expressado no parágrafo anterior.

Estes resultados podem ser observados na tabela 56.

Tabela 57. Médias e Desvios Padrão da Escala Global de atitudes frente à Estatística

\begin{tabular}{|c|c|c|c|}
\hline & Enunciado do item & Médias & DS \\
\hline 1 & Incomoda-me a informação Estatística que há em alguns programas da TV & 3.34 & 0.991 \\
\hline 2 & A estatística ajuda a compreender o mundo de hoje & 3.92 & 0.956 \\
\hline 3 & Através da Estatística pode-se manipular a realidade & 2.49 & 1.131 \\
\hline 4 & A estatística é fundamental na formação básica do futuro cidadão & 3.52 & 0.966 \\
\hline 5 & Eu uso a Estatística para resolver problemas da vida cotidiana & 3.27 & 1.046 \\
\hline 6 & Na universidade não deveriam ensinar Estatística & 4.07 & 1.066 \\
\hline 7 & Eu me divirto nas aulas em que se explica Estatística & 3.19 & 0.932 \\
\hline 8 & Acho que os problemas da Estatística são fáceis & 3.04 & 0.991 \\
\hline 9 & Não entendo as informações Estatísticas que aparecem no jornal & 3.66 & 0.989 \\
\hline 10 & $\begin{array}{l}\text { Eu gosto da Estatística porque me ajuda compreender mais profundamente a } \\
\text { complexidade de certos temas }\end{array}$ & 3.53 & 0.888 \\
\hline 11 & Eu me sento intimidado com os dados estatísticos & 3.64 & 0.999 \\
\hline 12 & Eu acho interessante o mundo da Estatística & 3.48 & 0.923 \\
\hline 13 & Eu gosto dos trabalhos sérios onde apareçam estudos estatísticos & 3.64 & 0.917 \\
\hline 14 & Utilizo pouco a Estatística fora da instituição de estudo & 2.79 & 1.109 \\
\hline 15 & Na aula de Estatística nunca entendo do que estão falando & 3.69 & 0.930 \\
\hline 16 & Eu adoro a Estatística porque ajuda a ver os problemas objetivamente & 3.29 & 0.944 \\
\hline 17 & A Estatística é fácil & 3.02 & 1.046 \\
\hline 18 & $\begin{array}{l}\text { Compreendo melhor sobre o resultado das eleições quando aparecem representações } \\
\text { gráficas }\end{array}$ & 3.75 & 1.025 \\
\hline 19 & A Estatística só serve para as pessoas de ciências & 4.06 & 1.022 \\
\hline 20 & Eu gosto de fazer problemas quando uso a Estatística & 3.08 & 0.879 \\
\hline 21 & A Estatística não serve para nada & 4.37 & 0.943 \\
\hline 22 & Muitas vezes explico a meus colegas problemas de Estatística que eles não entenderam & 2.83 & 0.893 \\
\hline 23 & Se pudesse eliminar algum curso seria a Estatística & 3.82 & 1.058 \\
\hline 24 & A Estatística ajuda a tomar decisões mais fundamentadas & 3.80 & 0.903 \\
\hline 25 & Evito as informações Estatísticas quando as leio & 3.67 & 0.925 \\
\hline 26 & Eu fico sob uma terrível tensão na aula de Estatística & 3.61 & 0.962 \\
\hline 27 & Eu não gosto de Estatística e me assusta ter que fazer essa matéria & 3.71 & 1.007 \\
\hline 28 & Eu acho a Estatística muito interessante e gosto das aulas de Estatística & 3.40 & 0.902 \\
\hline 29 & A Estatística é fascinante e divertida & 3.12 & 0.867 \\
\hline 30 & A Estatística me faz sentir seguro(a) e é, ao mesmo tempo, estimulante & 3.06 & 0.849 \\
\hline 31 & $\begin{array}{l}\text { "Dá um branco" na minha cabeça e não consigo pensar claramente Quando estudo } \\
\text { Estatística }\end{array}$ & 3.70 & 0.976 \\
\hline
\end{tabular}


32 Eu tenho a sensação de insegurança quando me esforço em Estatística

33 A Estatística me deixa inquieto(a), descontente, irritado(a) e impaciente

34 O sentimento que eu tenho com relação à Estatística é bom

35 A Estatística me faz sentir como se estivesse perdido(a) em uma selva de números e sem

36 A Estatística é algo que eu aprecio grandemente

37 Quando eu ouço a palavra Estatística, eu tenho um sentimento de aversão

38 Eu encaro a Estatística com um sentimento de indecisão, que é resultado do medo de não ser capaz em Estatística

39 Eu gosto realmente da Estatística.

40 A Estatística é uma das matérias que eu realmente gosto de estudar na universidade

41 Pensar sobre a obrigação de resolver um problema Estatística me deixa nervoso(a)

42 Eu nunca gostei de Estatística e é a matéria que me dá mais medo

43 Eu fico mais feliz na aula de Estatística que na aula de qualquer outra matéria

44 Eu me sinto tranquilo(a) em Estatística e gosto muito dessa matéria

45 .Eu tenho uma reação definitivamente positiva com relação a Estatística. Eu gosto e

\section{Análises de itens da Escala Global e das escalas de Estrada (2002) e Cazorla et al (1999)}

Para avaliar a fiabilidade da escala global temos optado pelo método de consistência interna. Seu cálculo está baseado no analise relativo da variância do escore total da escala e das variâncias dos itens e o coeficiente que mede isso é o Alpha de Cronbach.

Na Tabela 58, temos obtido um valor alpha de 0.92 para a escala global, que nos indica uma fiabilidade ótima. Embora através da análise dos itens se identificaram dois itens com correlações baixas com a escala. Estes foram o item 3 e o item $1(p<0.20)$. Estes itens também demonstraram uma baixa correlação nas análises feitos no capítulo anterior considerando separadamente a amostra por países. 
Tabela 58. Analise de itens da Escala global de atitudes frente à Estatística (N=972)

\begin{tabular}{cccccc}
\hline Item & rit & Alpha & Item & rit & Alpha \\
\hline $\mathbf{1}$ & $\mathbf{0 . 1 8 6}$ & 0.927 & 26 & 0.512 & 0.924 \\
2 & 0.278 & 0.926 & 27 & 0.588 & 0.924 \\
$\mathbf{3}$ & $\mathbf{- 0 . 1 0 5}$ & 0.931 & 28 & 0.652 & 0.923 \\
4 & 0.326 & 0.926 & 29 & 0.579 & 0.924 \\
5 & 0.307 & 0.926 & 30 & 0.500 & 0.924 \\
6 & 0.386 & 0.926 & 31 & 0.588 & 0.924 \\
7 & 0.455 & 0.925 & 32 & 0.495 & 0.924 \\
8 & 0.438 & 0.925 & 33 & 0.571 & 0.924 \\
9 & 0.308 & 0.926 & 34 & 0.579 & 0.924 \\
10 & 0.495 & 0.924 & 35 & 0.580 & 0.924 \\
11 & 0.425 & 0.925 & 36 & 0.536 & 0.924 \\
12 & 0.535 & 0.924 & 37 & 0.570 & 0.924 \\
13 & 0.485 & 0.925 & 38 & 0.533 & 0.924 \\
14 & 0.273 & 0.927 & 39 & 0.634 & 0.923 \\
15 & 0.484 & 0.925 & 40 & 0.558 & 0.924 \\
16 & 0.498 & 0.924 & 41 & 0.478 & 0.925 \\
17 & 0.340 & 0.926 & 42 & 0.574 & 0.924 \\
18 & 0.234 & 0.927 & 43 & 0.357 & 0.926 \\
19 & 0.373 & 0.926 & 44 & 0.591 & 0.924 \\
20 & 0.480 & 0.925 & 45 & 0.601 & 0.924 \\
21 & 0.495 & 0.924 & & & \\
22 & 0.310 & 0.926 & & & \\
23 & 0.610 & 0.923 & & & \\
24 & 0.392 & 0.925 & & & \\
25 & 0.489 & 0.924 & & & \\
\hline & & Alpha: 0.92 & & \\
\hline & & & & & \\
\hline
\end{tabular}

$\mathrm{Me}=$ media, $\mathrm{De}=$ desvio padrão, rit $=$ correlação item - total eliminando o item alpha $=$ alfa de Cronbach da escala sem considerar o item

Na Tabela 59, temos obtido um valor alpha de 0.83 para a escala de Estrada (2002) e de 0.92 para a escala de Cazorla et al (1999) que nos indica uma boa fiabilidade para a primeira y uma ótima fiabilidade para a segunda. Já as análises dos itens identificaram novamente dois itens com correlações baixas com a escala. Estes foram o item 3 e o item $1(\mathrm{p}<0.20)$ da escala de Estrada (2002). Os itens da escala de Cazorla et al (1999) tem todos uma boa correlação com a escala.

O item que tem a mais baixa correlação e negativa é o item 3. Este item foi eliminado de todos os estudos feitos separadamente por países. No caso do item 1, que tem uma 
correlação inferior a 0.20, mas podemos considerar não eliminá-lo já que não incrementa a confiabilidade é a correlação dele chego a 0.19 .

A continuação se faz um novo analise de itens desconsiderando o item 3 para a escala global com 44 itens.

Tabela 59. Análise de itens das Escalas AEE e AEC por separado (N=972)

\begin{tabular}{|c|c|c|c|c|c|}
\hline \multicolumn{3}{|c|}{ AEE } & \multicolumn{3}{|c|}{$\mathrm{AEC}$} \\
\hline Item & rit & Alpha & Item & rit & Alpha \\
\hline 1 & 0.194 & 0.830 & 26 & 0.516 & 0.913 \\
\hline 2 & 0.321 & 0.825 & 27 & 0.587 & 0.912 \\
\hline 3 & -0.157 & 0.846 & 28 & 0.624 & 0.911 \\
\hline 4 & 0.357 & 0.823 & 29 & 0.603 & 0.911 \\
\hline 5 & 0.324 & 0.825 & 30 & 0.510 & 0.913 \\
\hline 6 & 0.411 & 0.821 & 31 & 0.593 & 0.911 \\
\hline 7 & 0.419 & 0.821 & 32 & 0.538 & 0.913 \\
\hline 8 & 0.374 & 0.823 & 33 & 0.599 & 0.911 \\
\hline 9 & 0.327 & 0.825 & 34 & 0.566 & 0.912 \\
\hline 10 & 0.514 & 0.818 & 35 & 0.601 & 0.911 \\
\hline 11 & 0.403 & 0.822 & 36 & 0.531 & 0.913 \\
\hline 12 & 0.540 & 0.816 & 37 & 0.578 & 0.912 \\
\hline 13 & 0.518 & 0.817 & 38 & 0.548 & 0.912 \\
\hline 14 & 0.248 & 0.828 & 39 & 0.648 & 0.910 \\
\hline 15 & 0.443 & 0.820 & 40 & 0.553 & 0.912 \\
\hline 16 & 0.488 & 0.818 & 41 & 0.538 & 0.913 \\
\hline 17 & 0.268 & 0.827 & 42 & 0.597 & 0.911 \\
\hline 18 & 0.272 & 0.827 & 43 & 0.389 & 0.916 \\
\hline 19 & 0.406 & 0.821 & 44 & 0.614 & 0.911 \\
\hline 20 & 0.436 & 0.821 & 45 & 0.631 & 0.911 \\
\hline 21 & 0.514 & 0.817 & & & \\
\hline 22 & 0.265 & 0.827 & & & \\
\hline 23 & 0.573 & 0.814 & & & \\
\hline 24 & 0.411 & 0.821 & & & \\
\hline 25 & 0.486 & 0.818 & & & \\
\hline \multicolumn{3}{|c|}{ Alpha: 0.83} & \multicolumn{3}{|c|}{ Alpha: 0.92} \\
\hline
\end{tabular}

\section{Análises de itens da Escala Global corrigida de 44 itens}

Na Tabela 60, se observa o novo analise de itens feito com uma versão de 44 itens na escala global. Temos obtido um valor alpha incrementado de 0.93 que nos indica uma ótima fiabilidade. 
Esta análise nos dá uma escala mais confiável para uma mostra de participantes de características variadas por pertencer a países diferentes. Esta versão da escala global de atitudes frente à Estatística é uma versão valida e fiável para medir as atitudes na amostra integrada de Peru, Chile, Colômbia e Brasil.

Tabela 60. Analise de itens da Escala global de atitudes frente à Estatística (N=972)

\begin{tabular}{cccccc}
\hline Item & rit & Alpha & Item & rit & Alpha \\
\hline 1 & 0.179 & 0.932 & 26 & 0.511 & 0.929 \\
2 & 0.292 & 0.931 & 27 & 0.587 & 0.928 \\
4 & 0.338 & 0.930 & 28 & 0.652 & 0.928 \\
5 & 0.313 & 0.931 & 29 & 0.577 & 0.928 \\
6 & 0.391 & 0.930 & 30 & 0.500 & 0.929 \\
7 & 0.458 & 0.929 & 31 & 0.587 & 0.928 \\
8 & 0.438 & 0.929 & 32 & 0.494 & 0.929 \\
9 & 0.310 & 0.931 & 33 & 0.569 & 0.928 \\
10 & 0.500 & 0.929 & 34 & 0.580 & 0.928 \\
11 & 0.424 & 0.930 & 35 & 0.579 & 0.928 \\
12 & 0.537 & 0.929 & 36 & 0.534 & 0.929 \\
13 & 0.487 & 0.929 & 37 & 0.570 & 0.928 \\
14 & 0.275 & 0.931 & 38 & 0.534 & 0.929 \\
15 & 0.483 & 0.929 & 39 & 0.635 & 0.928 \\
16 & 0.500 & 0.929 & 40 & 0.558 & 0.928 \\
17 & 0.339 & 0.930 & 41 & 0.475 & .929 \\
18 & 0.238 & 0.931 & 42 & 0.572 & .928 \\
19 & 0.375 & 0.930 & 43 & 0.355 & .930 \\
20 & 0.481 & 0.929 & 44 & 0.589 & .928 \\
21 & 0.498 & 0.929 & 45 & 0.598 & .928 \\
22 & 0.307 & 0.930 & & & \\
23 & 0.611 & 0.928 & & & \\
24 & 0.395 & 0.930 & & & \\
25 & 0.490 & 0.929 & & & \\
\hline & & Alpha: 0.93 & & \\
\hline & & & & &
\end{tabular}

$\mathrm{Me}=$ media, $\mathrm{De}=$ desvio padrão, rit $=$ correlação item -total eliminando o item alpha = alfa de Cronbach da escala sem considerar o item

\subsubsection{Análise comparativo das atitudes frente à Estatística considerando o gênero,} o pais e a orientação do curso.

A comparação de médias na atitude frente à Estatística segundo as variáveis como país de pertença, gênero e orientação do curso feito pelos avaliados e feita através das provas T para o caso de gênero e de ANOVA para as variáveis país e orientação. 


\section{Comparação das atitudes em todos os participantes considerando o gênero}

Como é observado na Tabela 61 não tem diferencias significativas na Atitude frente à Estatística considerando a variável gênero. Tanto homes como mulheres têm atitudes similares frente a Estatística. Este resultado é acorde com os análises feitas anteriormente com as amostras independentes por países, onde só se viu diferencias na atitude segundo gênero no grupo de Brasil.

Tabela 61. Comparação de médias nas atitudes usando T de Student considerando o gênero dos avaliados $(\mathrm{N}=972)$

\begin{tabular}{llccccc}
\hline & Gênero & $\mathrm{N}$ & Media & $\mathrm{DS}$ & $\mathrm{T}$ & Significância \\
\hline EGlobal & Masculino & 635 & 155.47 & 20.55 & 0.75 & 0.46 \\
& Feminino & 337 & 154.42 & 21.56 & & \\
EE & Masculino & 635 & 87.19 & 10.97 & 0.74 & 0.46 \\
& Feminino & 337 & 86.64 & 10.65 & & \\
EC & Masculino & 635 & 68.29 & 11.02 & 0.66 & 0.51 \\
& Feminino & 337 & 67.78 & 12.27 & & \\
\hline & & $*: \mathrm{p}>0.05 * * \mathrm{p}>0.01$ & &
\end{tabular}

\section{Comparação das atitudes em todos os participantes considerando os paises}

$\mathrm{Na}$ Tabela 62 observamos que há diferenças significativas na atitude frente à Estatística considerando a variável país. O grupo avaliado de Peru é quem apresenta maior escore na atitude (162.19) seguido do grupo de Chile (159.14), o grupo de Brasil (153.37) e o grupo da Colômbia (152.42). Os maiores escores significam uma melhor atitude geral. 
Tabela 62. Comparação de médias nas atitudes usando T de Student considerando o país dos avaliados

\begin{tabular}{|c|c|c|c|c|c|c|}
\hline \multicolumn{7}{|c|}{$(\mathrm{N}=972)$} \\
\hline & Gênero & $\mathrm{N}$ & Media & DS & $\mathrm{F}$ & Significância \\
\hline \multirow[t]{4}{*}{ EGlobal } & Chile & 113 & 159.14 & 22.972 & 9.11 & $0.00 * *$ \\
\hline & Peru & 137 & 162.19 & 20.793 & & \\
\hline & Colômbia & 177 & 152.42 & 19.170 & & \\
\hline & Brasil & 545 & 153.37 & 20.561 & & \\
\hline \multirow[t]{4}{*}{$\mathrm{EE}$} & Chile & 113 & 89.51 & 11.244 & 9.96 & $0.00 * *$ \\
\hline & Peru & 137 & 90.66 & 10.812 & & \\
\hline & Colômbia & 177 & 86.16 & 9.549 & & \\
\hline & Brasil & 545 & 85.83 & 10.926 & & \\
\hline \multirow[t]{4}{*}{$\mathrm{EC}$} & Chile & 113 & 69.63 & 13.470 & 6.81 & $0.00 * *$ \\
\hline & Peru & 137 & 71.53 & 11.279 & & \\
\hline & Colômbia & 177 & 66.26 & 11.095 & & \\
\hline & Brasil & 545 & 67.54 & 10.999 & & \\
\hline
\end{tabular}

\section{Comparação das atitudes em todos os participantes considerando orientação do curso feito pelo avaliado}

Por motivo de comparação temos formado duas categorias a partir dos cursos feitos pelos avaliados. Os mais afines com Ciência e os mais afines com Humanas.

De acordo com a Tabela 63 encontramos diferencias significativas na atitude segunda esta variável. O grupo de Ciências (158.14) tem uma média maior na atitude que o grupo de Humanas (147.97), tanto quando a escala é considerada globalmente como quando é analisada separadamente (AEE e AEC).

Estes resultados são acordes aos encontrados nos analises feitos com os grupos de países separadamente onde em todos os casos se encontra esta diferença na atitude. 
Tabela 63. Comparação de médias nas atitudes usando T de Student considerando orientação do curso

\begin{tabular}{lcccccc}
\multicolumn{7}{c}{ dos avaliados (N=972) } \\
\hline EGlobal & Gênero & $\mathrm{N}$ & Media & DS & F & Significância \\
\hline & Ciências & 682 & 158.14 & 20.01 & 50.69 & $0.00^{* *}$ \\
& Humanas & 290 & 147.97 & 21.25 & & \\
EE & & & & & \\
& Ciências & 682 & 88.49 & 10.40 & 45.02 & $0.00^{* *}$ \\
& Humanas & 290 & 83.49 & 11.11 & & \\
EC & & & & & \\
& Ciências & 682 & 69.66 & 11.17 & 43.30 & $0.00^{* *}$ \\
& Humanas & 290 & 64.48 & 11.36 & & \\
& & & & &
\end{tabular}

\subsubsection{Análises de multidimensionalidade da escala global de atitudes frente à Estatística}

A continuação temos feito uma análise fatorial exploratório com rotação varimax, para confirmar que há escala pode medir as atitudes agrupada em fatores. Assim a análise fatorial permite que um pequeno número de fatores possa incorporar quase toda a informação geral e simplifica da descrição das características medidas e ter uma melhor visualização dos dados e maior facilidade da interpretação dos resultados.

As análises dão como resultado 5 fatores principais. O fator 1 " Gosto pela Estatística" esta formado de 15 itens (p7, p10, p12, p13,p16, p28, p29, p30, p34, p36, p39, p40, p43, p44, p45). O fator 2 " Ansiedade frente à Estatística" está formado por 11 itens (p15,p26, p27, p31, p32,p33, p35, p37,p38, p41, p42). O fator 3 “ Valorações Negativa da Estatística", esta formado por 6 itens (p1, p9, p11, p21, p23, p25). O fator 4 " Utilidade da Estatística", formado por 4 itens (p2, p4, p5, p24) e o fator 5 " Habilidade em Estatística", formado por 6 itens (p8, p17, p18, p14, p20, p22). 
Tabela 64. Análise Fatorial da Escala Global de Atitudes frente à Estadística $(\mathrm{N}=972)$

\begin{tabular}{|c|c|c|}
\hline \multirow[t]{2}{*}{ Itens } & \multicolumn{2}{|l|}{ Fatores } \\
\hline & Fator 1: Gosto pela Estatística & $\begin{array}{c}\% \text { da } \\
\text { Variância }\end{array}$ \\
\hline $\mathrm{p} 7$ & Eu me divirto nas aulas em que se explica Estatística & 23.9 \\
\hline p10 & $\begin{array}{l}\text { Eu gosto da Estatística porque me ajuda compreender mais profundamente a } \\
\text { complexidade de certos temas }\end{array}$ & \\
\hline p12 & Eu acho interessante o mundo da Estatística & \\
\hline p13 & Eu gosto dos trabalhos sérios onde apareçam estudos estatísticos & \\
\hline p16 & Eu adoro a Estatística porque ajuda a ver os problemas objetivamente & \\
\hline $\mathrm{p} 28$ & Eu acho a Estatística muito interessante e gosto das aulas de Estatística & \\
\hline p29 & A Estatística é fascinante e divertida & \\
\hline p30 & A Estatística me faz sentir seguro(a) e é, ao mesmo tempo, estimulante & \\
\hline p34 & O sentimento que eu tenho com relação à Estatística é bom & \\
\hline p36 & A Estatística é algo que eu aprecio grandemente & \\
\hline p39 & Eu gosto realmente da Estatística. & \\
\hline $\mathrm{p} 40$ & $\begin{array}{l}\text { A Estatística é uma das matérias que eu realmente gosto de estudar na } \\
\text { universidade }\end{array}$ & \\
\hline $\mathrm{p} 43$ & Eu fico mais feliz na aula de Estatística que na aula de qualquer outra matéria & \\
\hline p44 & Eu me sinto tranquilo(a) em Estatística e gosto muito dessa matéria & \\
\hline \multirow[t]{2}{*}{$\mathrm{p} 45$} & $\begin{array}{l}\text { Eu tenho uma reação definitivamente positiva com relação a Estatística. Eu } \\
\text { gosto e aprecio essa matéria }\end{array}$ & \\
\hline & Fator 2: Ansiedade frente à Estatística & $\begin{array}{c}\% \text { da } \\
\text { Variância }\end{array}$ \\
\hline p15 & $\mathrm{Na}$ aula de Estatística nunca entendo do que estão falando & 7.5 \\
\hline p26 & Eu fico sob uma terrível tensão na aula de Estatística & \\
\hline p27 & Eu não gosto de Estatística e me assusta ter que fazer essa matéria & \\
\hline $\mathrm{p} 31$ & $\begin{array}{l}\text { "Dá um branco" na minha cabeça e não consigo pensar claramente Quando } \\
\text { estudo Estatística }\end{array}$ & \\
\hline $\mathrm{p} 32$ & Eu tenho a sensação de insegurança quando me esforço em Estatística & \\
\hline p33 & A Estatística me deixa inquieto(a), descontente, irritado(a) e impaciente & \\
\hline p35 & $\begin{array}{l}\text { A Estatística me faz sentir como se estivesse perdido(a) em uma selva de } \\
\text { números e sem encontrar saída }\end{array}$ & \\
\hline p37 & $\begin{array}{l}\text { Quando eu ouço a palavra Estatística, eu tenho um sentimento de aversão } \\
\text { Eu encaro a Estatística com um sentimento de indecisão, que é resultado do } \\
\text { medo de não ser capaz em Estatística }\end{array}$ & \\
\hline p41 & $\begin{array}{l}\text { Pensar sobre a obrigação de resolver um problema Estatística me deixa } \\
\text { nervoso(a) }\end{array}$ & \\
\hline \multirow[t]{2}{*}{$\mathrm{p} 42$} & Eu nunca gostei de Estatística e é a matéria que me dá mais medo & \\
\hline & Fator 3: Valoração Negativa da Estatística & $\begin{array}{c}\% \text { da } \\
\text { Variância }\end{array}$ \\
\hline $\mathrm{p} 1$ & Incomoda-me a informação Estatística que há em alguns programas da TV & 5.4 \\
\hline p9 & Não entendo as informações Estatísticas que aparecem no jornal & \\
\hline p11 & Eu me sento intimidado com os dados estatísticos & \\
\hline $\mathrm{p} 21$ & Estatística não serve para nada & \\
\hline $\mathrm{p} 23$ & Se pudesse eliminar algum curso seria a Estatística & \\
\hline p25 & Evito as informações Estatísticas quando as leio & \\
\hline
\end{tabular}




\begin{tabular}{|c|c|c|}
\hline & Fator 4: Utilidade da Estatística & $\begin{array}{c}\% \text { da } \\
\text { Variância }\end{array}$ \\
\hline $\mathrm{p} 2$ & A estatística ajuda a compreender o mundo de hoje & 4.1 \\
\hline $\mathrm{p} 4$ & A estatística é fundamental na formação básica do futuro cidadão & \\
\hline p5 & Eu uso a Estatística para resolver problemas da vida cotidiana & \\
\hline \multirow[t]{2}{*}{$\mathrm{p} 24$} & A Estatística ajuda a tomar decisões mais fundamentadas & \\
\hline & Fator 5: Habilidade em Esatística & $\begin{array}{c}\% \text { da } \\
\text { Variância }\end{array}$ \\
\hline $\mathrm{p} 8$ & Acho que os problemas da Estatística são fáceis & 3.4 \\
\hline p17 & A Estatística é fácil & \\
\hline p18 & $\begin{array}{l}\text { Compreendo melhor sobre o resultado das eleições quando aparecem } \\
\text { representações gráficas }\end{array}$ & \\
\hline p14 & Utilizo pouco a Estatística fora da universidade & \\
\hline p20 & Eu gosto de fazer problemas quando uso a Estatística & \\
\hline $\mathrm{p} 22$ & $\begin{array}{l}\text { Muitas vezes explico a meus colegas problemas de Estatística que eles não } \\
\text { entenderam }\end{array}$ & \\
\hline
\end{tabular}

\subsection{Considerações finais}

A amostra contou com 972 estudantes de diferentes grupos de universidades (Peru, Chile, Colômbia e Brasil), sendo todos universitários que cursavam uma disciplina de estatística pela primeira vez.

A escala global de atitudes apresentou uma alta consistência interna (Alfa de Cronbach $=$ 0,93), antes e logo do estudo dos itens (se elimino um item com baixa correlação). Estes resultados são semelhantes aos encontrados nos estudos de Tarazona et al (2013), Aliaga (2009) e Aparicio et al (2006). Ainda as correlações item total foram consistentes.

Foi encontrada uma escala com multidimensionalidade ( 5 fatores) responsáveis pelo $45 \%$ da variância total, relacionados com os aspectos afetivos tanto positivos das atitudes frente à estatística (gosto, utilidade, habilidade) como aspectos negativos (ansiedade, valoração negativa) das atitudes frente à estatística. A geração de fatores pode estabelecer futuros análises em novas pesquisas, onde sejam considerados como variáveis de estudo e possam possibilitar analises mais profundos.

Cada item da Escala Global de Atitudes apresentou aos avaliados uma afirmação, frente a qual eles deveriam se posicionar, assim, encontramos que os itens a pesar de expressar reconhecimento a importância da estatística para compreender o mundo de hoje (item 3), a maior parte deles expressava atitudes negativas como por exemplo o Item 21:"A 
Estatística não serve para nada" ou o item O item 14:"Utilizo pouco a Estatística fora da instituição de estudo".

Os resultados no presente estudo refletem a predisposição desfavorável com que muitos alunos, que iniciam o curso, percebem a disciplina de estatística. Os avaliados mostraram mais atitudes negativas que positivas frente à Estatística. Assim os professores têm o desafio de cambiar estas atitudes negativas com que muitos alunos encaram a disciplina.

Achamos que Instrumentos de avaliação como as escalas usadas neste trabalho vão poder ajudar a um diagnóstico inicial das atitudes dos alunos de, permitindo uma ação estratégica do professor no decorrer do curso. Como é afirmado por Silva et al. (2002), o uso de escalas de avaliação é parte de uma estratégia para que os professores lidem com os aspectos afetivos das atitudes.

A melhoria das atitudes negativas poderá influenciar no ambiente da aula, no aprendizado e na predisposição no futuro. E conhecido que saber mais sobre as atitudes dos alunos possibilita que professores em conjunto com suas instituições trabalhem no sentido de criar condições favoráveis para o desenvolvimento de atitudes também favoráveis. (Turik, 2010).

Nesse sentido, Moura (2008) expressa a necessidade de a instituição de ensino atentar para as atitudes dos alunos, refletindo e efetuando ações que melhorem e encaminhem os desejos dos estudantes para que a aprendizagem ocorra satisfatoriamente.

Como é encontrado na amostra de estudo os alunos não percebem a aplicabilidade da Estatística em suas profissões o que pode reforçar esta predisposição negativa. É importante por isso no ensino da disciplina transmitir os conhecimentos acompanhados de significância.

Os alunos precisam reforçar a ideia de que a disciplina vai ter uso prático tanto na profissão na hora de desenvolver pesquisas e também na recepção de informação dada diariamente no cotidiano acadêmico, laboral e cotidiano. 


\section{CAPITULO VIII REFLEXÕES FINAIS}

Como já foi dito no nosso trabalho a disciplina de Estatística estão presentes nos da maioria dos estudos universitários, fruto do importante papel concedido à mesma na formação científica e técnica de profissionais de muito variado perfil mas a falta de um desempenho adequado nesta área por parte dos estudantes, em especial de especialidades não matemáticas, entre outros, é um tópico recorrente que docentes e pesquisadores tem pondo de manifesto nos contextos culturais mais diversos.

Como em outras áreas da investigação educativa, no âmbito estatístico se justificou a necessidade de prestar atenção às atitudes dos estudantes principalmente por considerar que estas têm uma importante influência sobre processos de ensino e aprendizagem e sobre o desempenho acadêmico imediato. Também podem ser vistas em si mesmas como um resultado da formação, constituindo um componente essencial da bagagem com o que, ao termo dos processos formativos, se fará frente ao desempenho futuro de atividades e tarefas acadêmico profissionais (Auzmendi, 1991; Gal y Ginsburg, 1994, Gal, Ginsburg y Schau, 1997).

Achamos que tanto a estatística como a matemática constituem um desafio a todos os educadores e, considerando a estatística tem uma linguagem que faz uso essencialmente de números, ela vem muitas vezes carregada de predisposições desfavoráveis envolvidas pelos estereótipos socioculturais que consideram a matemática uma disciplina difícil e diante da necessidade de tornar os cidadãos letrados em estatística, face à crescente importância da informação quantitativa e gráfica no cotidiano das pessoas; as comunidades científica e acadêmica vêm redobrando esforços tanto na pesquisa e na busca da compreensão dos fatores interferentes no processo de ensino e aprendizagem de estatística, quanto na implementação de diretrizes norteadoras de ensino nos diferentes níveis de ensino. Um desses fatores interferentes é o fator afetivo, que pode ser identificada através de uma avaliação certeira das atitudes com instrumentos psicometricamente validos. Que permitam a identificação de atitudes negativas e 
posterior planejamento de estratégias que contribuam a melhorarlas. O sentimento que o aluno tem em relação à disciplina fará com que tenha uma boa ou má predisposição para a aprendizagem desta. Assim, uma aula que tenha atividades relacionadas com as vivências e interesse dos alunos pode incrementar as atitudes positivas destes em relação à estatística e também seu desempeno acadêmico.

Os déficits motivacionais e atitudinais constatados na área, bem como a importância concedida à dimensão atitudinal no desempenho competente, têm alentado o desenvolvimento de uma área de investigação bem definida, ainda que relativamente recente, ocupada do domínio afetivo-atitudinal nos processos de ensino-aprendizagem da Estatística. Podemos falar então, que as atitudes para a Estatística têm ido recebendo uma crescente atenção,

Assim, os aspectos cognitivos e afetivos no processo de ensino e aprendizagem podem possuir um papel fundamental na qualidade do ensino da estatística nos diferentes cursos dados nas universidades. Assim, a investigação das atitudes dos alunos frente às disciplinas de Estatística pode ser um diferencial para o planejamento de adequadas estratégias de ensino.

Nesse contexto, se torna fundamental a utilização de instrumentos válidos e confiáveis para a avaliação das atitudes dos estudantes frente à estatística. A validade não pode ser considerada como uma característica do instrumento per se, e sim do instrumento aplicado a uma amostra. Portanto, as características da população de estudo podem influenciar diretamente a estrutura de uma escala.

Nosso presente estudo procurou analisar as atitudes frente à estatística de alunos universitários, dada a influência que essa compreensão pode ter nos rumos do ensino e aprendizado desta ciência. Considerando também a importância da qualidade do instrumento de medida.

As escalas trabalhadas na nossa pesquisa provou ter índices adequados de fiabilidade e confiabilidade quando foi analisada em cada um dos grupos por países e quando é analisada integrando os quatro grupos (Estudantes de Peru, Chile, Colômbia e Brasil) 
como uma grande amostra de estudo. $\mathrm{O}$ valor de fiabilidade na escala global tem sido maiores a 0.90 em todos os grupos e o mesmos ocorre considerando a analise com a amostra integrada. Este valor indica uma alta fiabilidade.

Assim, achamos que nossa pesquisa pode abrir mais caminhos no estudo das atitudes e que deve ser continuado em outras pesquisas de caráter transcultural, onde participem avaliados e instituições com diferentes características sociais e acadêmicas. Permitindo uma melhor comparação nos analises tanto das partes comuns como das diferenças entre os avaliados e no comportamento dos instrumentos de avaliação empregados, fazendo com que estes sejam adaptados ao contexto onde são utilizados com ótimas propriedades de fiabilidade e confiabilidade

A análise dos dados do presente estudo corrobora a visão de que a educação estatística tem um desafio pela frente: cambiar a predisposição desfavorável com que muitos alunos encaram esta disciplina. Assim finalmente, através de nosso trabalho esperamos motivar a que outros pesquisadores se interessem por este tipo de pesquisa e ampliem suas amostras e variáveis de comparação, além de acompanhar-se de trabalhos mais empíricos dirigidos a criar estratégias que melhorem a predisposição frente à disciplina de estatística. 


\section{Referencias}

1. Adaniya, A; Timana J. (2000): “Gestión estratégica y tecnología “, Presentación del grupo Gerens en el Taller de Gestión Estratégica organizado por ANR Las universidades del Perú. Lima.

2. Adam, F. (1970). Andragogía: ciencia de la educación de adultos. Caracas: Federación Interamericana de Educación de Adultos (FIDEA).

3. Afifi, A. A., \& Clark, V. (1990). Computer-aided multivariate analysis. Londres, Inglaterra:Chapman and Hall.Evaluación de una escala de actitudes hacia la estadística 18 AIEM, número 3, mayo de 2013

4. Aiken, L. R. (1974). Two scales of attitude toward mathematics. Journal for Research in Mathematics Education, 5, 67-71.

5. Agne, K. J., Greenwood, G. E., \& Miller, L. D. (1994). Relationships between teacher belief systems and teacher effectiveness. The Journal of Research and Development in Education, 27(3), 141 - 152.

6. Aliaga, R. E. (2009). Actitud hacia la estadística en estudiantes universitarios de ciencias y de educación (Tesis de maestría). Pontificia Universidad Católica del Perú, Lima, Perú.

7. Aliaga, R. E., \& Bazán, J. L (2009). Fatores del dominio cognitivo, conativo y afectivo en relación a la actitud hacia la Estadística en estudiantes universitarios. En Gaita, C. (editora). Actas del IV Coloquio Internacional de la Enseñanza de la Matemática. IREM-PUCP.

8. Andrich, D. (1978). A rating formulation for ordered response categories. Psychometrika, 43, 561-574.

9. Anastasi A., \& Urbina S. (2000). Testagem Psicológica. Porto Alegre: Artes Médicas Sul

10. Aparicio, A. (2006). Aspectos afetivos na aprendizagem da Estatística: atitudes e suas formas de avaliação (Tese Mestrado). Universidade de São Paulo. Brasil.

11. Aparicio, A., Bazán, J. L., \& Abdounur, O. J. (2004). Atitude e desempenho em relação à estatística em professores de ensino fundamental no Peru: primeiros resultados. VII EPEM: Encontro Paulista de Educação Matemática, São Paulo. http://www.sbempaulista.org.br/epem/anais/.

12. Aparicio A. y Bazán J. L. (1997). "Actitudes hacia la matemática en ingresantes a la UNALM". Mas Luz, Revista de Psicología y Pedagogía Niñez y Adolescencia en el Perú. Lima-Perú. Vol 3, Nro 2, pp 351-380. http://www.ime.usp.br/ jbazan/download/ArticuloMasLuz.pdf

13. Aparicio, A. \& Bazán, J. L. (2006a). Actitud y rendimiento en Estadística en profesores peruanos. En Acta Latinoamericana de Matemática Educativa, 19, 644-650. Clame2005.www.ime.usp.br/ jbazan/download/ALME19.pdf

14. Aparicio, A. \& Bazán, J. L. (2006b). Actitudes hacia la estadística en profesores de nivel primario. En González, M., Bazán, J. L., Sánchez, R. (eds). Coloquios sobre Matemática Educativa 2005, parte 2., 127-133. Reporte de Investigación 19. Serie C. Sección Matemática. Pontificia Universidad Católica del Perú

15. Aparicio, A. \& Bazán, J. L (2008). Aspectos afectivos intervinientes en el aprendizaje de la estadística: actitudes y sus formas de evaluación. En Acta Latinoamericana de Matemática Educativa, 21, 180-189. Clame 2007.

16. Aparicio, A. Bazán, J.L (2010b). Una propuesta metodológica de las prácticas de evaluación del proceso de enseñanza-aprendizaje en la educación superior. VI Congreso Iberoamericano de Docencia Universitaria (VI CIDU) PUCP. 
17. Aparicio, A. \& Bazán, J. L. (2005). Actitud y rendimiento académico en profesores que cursan una asignatura de Estadística en la complementación académica en Perú. Décimo Novena Reunión Latinoamericana de Matemática Educativa (RELME). Montevideo. Uruguay (en prensa).

18. Aparicio, Ana; Bazán, J.L., Estrada, A (2011). Avaliação psicométrica de uma escala de atitudes em relação a estatística. II Congreso Brasileño de Teoría de Respuesta al ítem. Salvador-Bahía. Asociación Brasileña de Estadística (ABE). Ara, A.; Louzada, F.(20129. Descrição de Algumas das Dimensões que compõem o Perfil do Corpo Docente dos Departamentos de Estatística do Brasil. Bolema. Boletim de Educação Matemática v. 26, p. 23-38. (UNESP. Rio Claro. Impresso).

19. Asamblea Nacional de Rectores de Peru -ANR (2002). Resumen Estadístico 2001, Asamblea Nacional de Rectores. Lima. Perú

20. Artiles, I. Mendoza y Yera, M. (2008). "La evaluación del aprendizaje, un indicador para elevar la efectividad del tutor en el contexto de Universalización de la Educación Superior". Revista Iberoamericana de Educación, 46(4). Organización de Estados Iberoamericanos para la Educación, la Ciencia y la Cultura (OEI).2008. http://www.rieoei.org/deloslectores/2265Olivera.pdf

21. Arregui, P. (2002): Dinámicas de transformación de los sistemas educativos en América Latina. El caso del Perú. Disponible em http://www.iacd.oas.org/Interamer/Interamerhtml/PuryearBr40html/PurArregui.htm

22. Auzmendi, E. (1992). Las actitudes hacia la matemática estadística en las enseñanzas medias y universitarias. Bilbao: Mensajero.

23. Barreyro, G. B. (2008) De exames, rankings e mídia. Avaliação, , v. 13, n. 3, p. 863-868, Campinas; Sorocaba.

24. Barreyro, G. B.; Rothen, J.C.(2006). SINAES contraditórios: considerações sobre a elaboração e implantação do Sistema Nacional de Avaliação da Educação superior. Educação \& Sociedade, v. 27-96, p. 955-977.

25. Barreyro, G. B.(2006). Evaluación de La educación superior brasileira. El SINAES. Revista de la educación superior, año/vol XXXV(1). Nro 137. Asociación Nacional de Universidades e Instituciones de Educación Superior (ANUIES). DF. México. Pp 63-73

26. Batanero, C. (1999). Cap on va l’educació estadística. Biaix, 15, 2-13.

27. Batanero, C. (2009). Retos para la formación estadística de los profesores. II Encontro de Probabilidade e Estatística na Scola. Universidade do Minho, 2009, Braga, Portugal. Disponible http://www.ugr.es/ batanero/ARTICULOS/Formprofesores.pdf

28. Bazán, J. L (2008). Actitudes hacia la matematica-estadistica: Una revisión de trabajos. En Gaita, C. (editora). Actas del III Coloquio Internacional de la Enseñanza de la Matematica. IREM-PUCP. Fondo Editorial. 1-13 http://irem.pucp.edu.pe/publicaciones_archivos/Actas-2008.pdf

29. Bazán, J. L. (2006a). Actitud y rendimiento en Estadística en profesores peruanos. En Acta Latinoamericana de Matemática Educativa, 19, 644-650. Clame 2005.

30. Bazán, J. L. (2006b). La estadística llega a la escuela en el Perú. En Gonzales, M., Bazán, J. L., Sánchez, R. (eds). Coloquios sobre Matemática Educativa 2005, parte 2., 87-109. Reporte de Investigación 19. Serie C. Sección Matemática. Pontificia Universidad Católica del Perú.

31. Bazán, J. L. y Aparicio, A. (2007). Las actitudes a la Matemática-Estadística dentro de un modelo de aprendizaje. Educación. Revista Semestral. Pontificia 
Universidad Católica del Perú. Lima-Perú. Marzo 2006. 15 (28). 7-19. http://revistas.pucp.edu.pe/index.php/educacion

32. Bazán, J.L; Aparicio, A. (2010a).“Una aproximación para el diagnóstico de la evaluación del proceso de enseñanza-aprendizaje en una institución educativa". Informe de Consultoría. Colegio Bertolt Brecht.

33. Bazán, J., Espinosa, G. y Farro, Ch. (2001). Rendimiento y actitudes hacia la Matemática en el sistema escolar peruano. Documento de trabajo No 13. Programa MECEP (Medición de la Calidad Educativa Peruana). Ministerio de Educación. Lima-Perú, 55-70

34. Brasil (2004). Ley nro 10861/04 Institui o Sistema Nacional de Avaliação da Educação Superior SINAES. Diário Oficial da União, Seção, 15 de Abril. Disponível em http://www.planalto.gov.br/ccivil_03/_ato20042006/2004/lei/110.861.htm

35. Brito, M. R. (1998). Adaptação e validação de uma Escala de Atitudes em relação à Matemática. Zetetiké, 6(9), 109-162.

36. Brito Márcia (2008). O SINAES e o ENADE: da concepção à implantação. Avaliação (Campinas), Nov 2008, vol.13, no.3, p.841-850.

37. Bittencourt, Hélio R.; Casartelli, Alam O.; Rodrigues, Alziro C. M (2009). Sobre o índice geral de cursos (IGC). Avaliação (Campinas), Vol. 14, no.3, p.667-682.

38. Bittencourt, Hélio R.; Casartelli, Alam O.; Rodrigues, Alziro C. M (2008). Uma análise da relação entre os conceitos ENADE e IDD. Estudos em Avaliação Educacional, v. 19, p.247-262. São Paulo.

39. Brito, M., \& Vendramini, C. (2001). Avaliação de uma escala de atitudes em relação à Estatística e sua relação com o conceito e a utilidade da Estatística. $28^{\circ}$ Congresso Interamericano de Psicologia, Vol. 1, pp.11-32, Santiago, Chile.

40. Bonafé, F. S., Loffredo, L. C., \& Campos, J. A. (2010). Atitudes em relação à Bioestatística de discentes e docentes da Faculdade de Ciências Farmacêuticas de Araraquara-UNESP. Revista de Ciências Farmacêuticas Básica e Aplicada, 31(2), 143-147. ISSN 1808-4532

41. Blanco, A. (2004). Enseñar y aprender Estadística en las titulaciones universitarias de Ciencias Sociales: apuntes sobre el problema desde una perspectiva pedagógica. En Torre, J.C. y Gil, E. (Eds.). Hacia una enseñanza universitaria centrada en el aprendizaje (pp. 143-190). Madrid: Servicio de publicaciones de la Universidad Pontificia Comillas.

42. Bond, T.G. \& Fox, C.M. (2001). Applying the rasch model: Fundamental measurement in the human sciences. Mahwah, New Jersey: Lawrence Erlbaum Associates, Inc.

43. CAFME (2003). Informe sobre el proceso de Acreditación de Facultades o Escuelas de Medicina. Comunicado, № 002-CAFME-2003. Lima, Perú.

44. Catani, A.M; Oliveira, J.F; Dourado, L.F (2002). A política de avaliação da Educação superior no Brasil em questão. In: Sobrinho, J.; Ristoff, D. (Org.) Avaliação Democrática para uma Universidade cidadã. Florianópolis: Insular, p.99-118.

45. Charter, Roger (2002). Os desafios da escrita. Tradução de Fulvia M. L. Moretto. São Paulo:UNESP Cordani, L. K. (2001). O ensino da estatística na universidade e a controvérsia sobre os fundamentos da inferência. Tese apresentada para a obtenção do Doutorado em Educação. Faculdade de Educação. Universidade de São Paulo. FEUSP. 154 pp. 
46. Consorcio de Universidades Peruanas (1999): "Autoevaluación Institucional. Manual para instituciones de educación superior", Fondo Editorial de la Universidad del Pacífico. Lima, Perú.

47. Caraballo, R. (2007). La andragogía en la educación superior. Investigación y Postgrado, 22 (2), 187-206. ISSN 1316-0087

48. Cardoso, E.; Cerecedo, M.; Ramos, J.(2012). Actitudes hacia las matemáticas de los estudiantes de posgrado en administración: Un estudio diagnóstico. REXE. Revista de Estudios y Experiencias en Educación, vol. 11, núm. 22, agostodiciembre, 2012, pp. 81- 98 Universidad Católica de la Santísima Concepción Concepción, Chile

49. Carmona, J. (2004). Una revisión de las evidencias de fiabilidad y validade de los cuestionarios de actitudes y ansiedad hacia la estadística. Statistics Education Research Journal, 3 (1), 5-28. actitudes hacia la estadística en la formación de los profesores. Milenio. Lleida

50. Cazorla, I. M., Silva, C. B., Vendramini, C., \& Brito, M. R. (1999). Adaptação e validação de uma escala de atitudes em relação à estatística. En: Conferencia Internacional "Experiências e Perspectivas do Ensino da Estatística - Desafios para o Século XXI”, Florianópolis, Santa Catarina, 45-57.

51. Cabral, A. \& Nick, E. (2003). Dicionário técnico de Psicologia. $13^{a}$ Ed. São Paulo:

52. Cultrix.Carmona, J. (2004). Una revisión de las evidencias de fiabilidad y validez de los cuestionarios de actitudes y ansiedad hacia la estadística. Statistics Education Research Journal, 3 (1), 5-28.

53. Dantas, C. (2009). Desenvolvimento da Estatística na Universidade de São Paulo, In: Associação Brasileira de Estatística, História da Estatística no Brasil. Disponível em http://www.redeabe.org.br/historia.htm. Acesso em 23 de dezembro de 2009. ABE biênio 32000/2002

54. Dias Sobrinho J. (1998). Avaliação Institucional da Educação Superior: fontes externas e interna. Avaliação, v.3, $n^{\circ} 34$, Campinas.

55. Dias Sobrinho, J. (2007). Evaluación de la Educación Superior en Brasil: políticas y prácticas. Universidade de Sorocaba-UNISO.

56. Debellis, V. A.; Goldin, G. (2006). Affect and meta-affect in mathematical problem solving: a representational perspective. Educational Studies in Mathematics, v. 63, p. 131-147.

57. Elmore, P. B., \& Vasu, E. S. (1980). Relationship between selection variables an statistics achievement. Journal of Educational Psychology, 72, 457-467.

58. Elmore, P. B., \& Vasu, E. S. (1986). A model of statistics achievement using spatial ability feminist attitudes and mathematics. Related variables as prediction. Educational and Psychological Measurement, 46, 215-222.

59. Estrada, A. (2002). Análisis de las actitudes y conocimientos estadísticos elementales en la formación del profesorado (Tesis doctoral). Universitat Autònoma de Barcelona.

60. Estrada, A. (2002). Análisis de las actitudes y conocimientos estadísticos elementales en la formación del profesorado (Tesis doctoral). Universitat Autònoma de Barcelona.

61. Estrada, A. (2007). Actitudes hacia la estadística: un estudio con profesores de educación primaria en formación y en ejercicio. En M. Camacho, P. Flores, \& P. Bolea (Eds.), Investigación en educación matemática (pp. 121-140). San Cristóbal de la Laguna, Tenerife: Sociedad Española de Investigación en Educación Matemática, SEIEM. 
62. Estrada, A. (2009). Las actitudes hacia la estadística en la formación de los profesores. Milenio. Lleida

63. Estrada, A., \& Batanero, C. (2008). Explaining teachers' attitudes towards statistics. En C.Batanero, G. Burrill, C. Reading, \& A. Rossman (Eds.), Proceedings of the ICMI Study 18 Conference and IASE 2008 Round Table Conference. [CD-ROM]. Monterrey,California: International Commission on Mathematical Instruction e International Association for Statistical Education.

64. Estrada, A., Batanero, C., \& Fortuny, J. (2003). Actitudes y Estadística en profesores en formación y en ejercicio. En: Edicions de la Universitat de Lleida. Actas del 27 Congreso Nacional de Estadística e Investigación Operativa. CD ROM. Lleida, España.

65. Estrada, A., Batanero, C., \& Lancaster, S. (2011). Teachers' attitudes towards statistics. En C.Batanero, G. Burrill, \& C. Reading (Eds.), Teaching statistics in school mathematics. Challenges for teaching and teacher education. A Joint ICMI/IASE Study (pp. 163-174). Nueva York, EEUU: Springer

66. Estrada, A., Bazán, J. L, \& Aparicio, A. (2010). A cross-cultural psychometric evaluation of the attitude toward Estrada's statistic scale in teachers. En C. Reading (Ed.), Data and context in statistics education: Towards an evidencebased society. Proceedings of Eighth International Conference on Teaching of Statistics (ICOTS 8). Ljubljana, Voorburg, The Netherlands: International Statistical Institute

67. Estrada, A., Bazán, J.L, \& Aparicio, A. (2013). Evaluación de las propiedades psicométricas de una escala de actitudes hacia la estadística en profesores. Avances de Investigación en Educación Matemática (AIEM), 3, 5-23. http://www.aiem.es/index.php/aiem/article/view/61/17

68. Evan Robert; Lys Vinhaes (2005). Avaliação da Educação Superior no Brasil: do Provão ao ENADE. Documento preparado para o Banco Mundial Gerente responsável: Alberto Rodriguez. $\quad$ Disponível em http://www.isp.ufba.br/avalia\%C3\%A7\%C3\%A30\%20da\%20Ed\%20Superior\% 20do\%20Provao\%20ao\%20ENADE.pdf

69. Evangelista, C, \& Arno B. (2012). Atitudes em Relação à Estatística e sua Influência na Escolha Profissional dos Alunos Concluintes do Ensino Médio http://matematica.ulbra.br/ocs/index.php/ebrapem2012/xviebrapem/paper/viewF ile/595/422

70. Ferreiro, O.; Prado, C. (1991). Historia de la estadística en Chile. Revista Estadística Espanola. Vol 33. Nro 128. Pp 575-586.

71. Fishbein, M., \& Ajzen, I. (1975). Belief, Attitude, Intention, and Behavior: An Introduction to Theory and Research.Reading, MA: Addison-Wesley.Freiberg, A.; Stover, J.; Guadalupe de la Iglesia, Fernández, M (2013). Correlaciones policóricas y tetracóricas en estudios Fatoriales exploratorios y confirmatorios. Cienc. Psicol. vol.7 no.2 Montevideo nov. 2013. Disponible en http://www.scielo.edu.uy/scielo.php?pid=S168840942013000200005\&script=sci_arttext

72. Friz, M.; Rodriguez, F.; Sanhueza, S.; Cardona, M. (2010). Concepciones de los futuros profesores de matemática sobre las competencias profesionales implicadas en la enseñanza de la estadística. CiDd: II Congrés Internacional de Didàctiques 2010: L'activitat del docent: Intervenció, Innovació, Investigació. Universitat de Girona; Edición: 1.

73. Freedman, J. L., Carlsmith, J. M., \& Sears, D. O. (1970). Psicologia social. São Paulo:Cultrix. 
74. Fox, V. (2005). Análisis documental de contenido: principios y prácticas. Buenos Aires: Alfagrama.

75. Gal, I., \& Garfield J. B. (1997). Monitoring attitudes and beliefs in statistics education. En I. Gal, \& J. B. Garfield (Eds.), The assessment challenge in statistics education (pp. 37-51). Voorburg, Holanda: IOS, Press.

76. Gal, I., \& Ginsburg, L. (1994). The role of beliefs and attitudes in learning statistics: towards an assesment framework. Journal of Statistics Education, 2(2). Recuperado de http://www.amstat.org/publications/jse/v2n2/gal.html

77. Gattuso, L., \& Pannone, M. (2002). Teacher's training in a statistic teaching experimentation. En B. Phillips (Ed.), Proceedings of the Sixth International Conference on Teaching Statistics, (pp. 685-692). Ciudad del Cabo, Sudáfrica: International Association for Statistical Education.

78. Gil, J. (1999). Actitudes hacia la estadística. Incidencia de las variables sexo y formación previa. Revista Española de Pedagogía, Vol. LVII, 214. 567590

79. Giolo, J. (2008). "SINAES” intermitentes. Avaliação, v. 13, n. 3, p. 851-856, Campinas; Sorocaba

80. Godino, J. D. Batanero,C.; Font, V. (2007). "The onto-semiotic approach to research in mathematics education. ZDM." The International Journal on Mathematics Education, Vol. 39 (1-2), 127-135.

81. Godino, J. D. Batanero,C.; Font, V. (2008). "Un enfoque ontosemiótico del conocimiento y la instrucción matemática. Departamento de Didáctica de Matemática. Universidad de Granada. http://www.ugr.es/local/jgodino/indice_eos.htm

82. Godino, J. D.; Font, V. (2007). "Algunos desarrollos de la teoría de significados sistémicos". http://www.ugr.es/ jgodino/indice_eos.htm

83. Gómez, I. (2000). Matemática emocional. Los afectos en el aprendizaje matemático. Madrid: Narcea, S.A, Ediciones.

84. Gonzales, M. (2001). "La evaluación del aprendizaje: tendencia y reflexión crítica". Revista Cubana Educación Media Superior, vol. 20, n. ${ }^{\circ}$ 1, pp. 47-67. en Internet: URL: http://www.bvs.sld.cu/revistas/ems/vol15_1_01/ems10101.pdf

85. Gonzales Rey, F. (1989). “La personalidad, su educación y desarrollo”. La Habana: Ed. Pueblo y Educación.

86. Hafsteinsson, L. G., Donovan, J. J., \& Breland, B. T. (2007). An item response theory examination of two popular goal orientation measures. Educational and Psychological Measurement, 67, 719-739.

87. Heaton, R. (2002). The learning and teaching of statistical investigation in teaching and teacher education. Journal of Mathematics Teacher Education, 5, 3559.

88. Hernández, J. (2013). Breve historia de la estadística. Universidad nacional de Colombia.

89. INEP (2004). SINAES - Sistema nacional de avaliação da educação superior: da concepção à regulamentação. 2 ed., Brasília: Instituto Nacional de Estudos e Pesquisas Educacionais Anísio Teixeira, 155p.

90. Jáuregui, R.; Carrasco del Carpio, L.; Montes, I. (2003). "Evaluando, evaluando: ¿Qué piensa y qué hace el docente en el aula?". Universidad Católica de Santa María. Consorcio de Investigación Económica y Social. Arequipa. 81 pp. http://www.consorcio.org/CIES/html/pdfs/R0204.pdf

91. Kline, P. (1998). The new psychometrics: science, psychology and measurement. London: Routhledge. 
92. Linacre, J. M. (2004). Rasch model estimation: Further topics. Journal of Applied Measurement, 5(1), 95-110.Evaluación de una escala de actitudes hacia la estadística 20 AIEM, número 3, mayo de 2013

93. Linacre, J. M. (2008). A user's guide to winsteps/ ministep: Rasch-model computer programs. Chicago, EEUU: Winsteps.

94. Louzada, F.; Ara, A. ; Oliveira, C. Z. ; Gonçalves, C. (2010). Diagnóstico do Ensino da Estatística nas Universidades Públicas Brasileiras: Uma Descrição de Algumas das Dimensões que Compõem o Perfil do seu Corpo Docente. Revista Brasileira de Estatística, v. 71, n. 234, p.7-42, jan./dez.2010 Rio de Janeiro.

95. Lunn, D., Thomas, A., Best, N., \& Spiegelhalter, D. (2000). WinBUGS - a Bayesian modeling framework: concepts, structure, and extensibility. Statistics and Computing, 10: 325-337.

96. Martínez-Arias, R. (1995). Psicometría: Teoría de los tests psicológicos y educativos. Madrid, España: Síntesis.

97. Ministerio de Educación de Colombia (2012). La educación Superior en Colombia. En: http://www.mineducacion.gov.co/cvn/1665/articles317375_recurso_1.pdf

98. Ministerio de Educación de Peru (2003): “Anteproyecto de la Ley del Sistema de Educación Universitaria Nacional". Documento de Trabajo. Perú.

99. Ministerio de Educación de Chile (2012). Evaluación de la OCDE del Sistema Nacional de Aseguramiento de la Calidad de la Educación Superior en Chile. En: http://www.consejoderectores.cl/web/pdf/Sesion_Extraordinaria_Diciembre/Ane xos_Sesion_Extraordarian_N_5/Evaluacion_OCDE_SINAC-ES-Sintesis.pdf

100. Mendonça, T., Coutinho, C. y Almouloud, S. (2006). Mathematics education and statistics education: meeting points and perspectives. En A. Rossman y B. Chance (Eds.), Proceedings of the Seventh International Conference on Teaching Statistics. CD ROM. Salvador (Bahia), Brazil: International Association for Statistical Education and International Statistical Institute.

101. McLeod, D.B. (1989) Beliefs, attitudes, and emotions: new view of affect in mathematics education. En D.B. McLeod y V.M. Adams (Eds.), Affect and mathematical problem solving: A new perspective (pp. 245-258). New York: Springer-Verlang.

102. McLeod, D.B. (1992). Research on affect in mathematics education: A reconceptualization. En Douglas A. Grouws (Ed.), Handbook of Research on mathematics Teaching and Learning (pp.575-598). New York: Macmillan.

103. Morales, P. (1988). Medición de actitudes en psicología y educación. San Sebastián, España: Ediciones Universidad de Comillas.

104. Moura, Graziela (2008). As atitudes dos estudantes com relação à disciplina geografia. Travessias: pesquisa em educação, cultura, linguagem e arte, v. 2, p. 10-15, 2008.

105. Muñiz, J. (2010). Teoría de los tests: teoría clásica y teoría de respuesta a los itens. Papeles de psicólogo, 31(1), 57-66.

106. Nasser, F. M. (2004). Structural model of the effects of cognitive and affective Fators on theachievement of arabic-speaking pre-service teachers in introductory statistics. Journal of Statistics Education, 12(1). Recuperado de: www.amstat.org/publications/jse/.

107. Nunnally J. C., \& Bernstein, I. H. (1994). Psychometric theory. Nueva York, EEUU: McGraw-Hill. 
108. Nava, Hugo (2OO2): "Situación de la educación superior en ciencias agrarias en el Perú" en CEIBA Enero-Junio 2002, Vol. 43(1):27-33. Tegucigalpa. Honduras.

109. Oliveira, A. (2011). Avaliação de atitudes, características pessoais, utilização de tecnologias e prática docente de professores de graduação em estatística. Educação Matemática Pesquisa, 13 (2), 253-272.

110. Onwuegbuzie, A. J. (1998). Teachers`attitudes toward statistics. Psychological Reports, 83, 1008-1010.

111. Onwuegbuzie, A. J. (2003). Modeling statistics achievement among graduate students. Educational and Psychological Measurement, 63(6), 1020-1038.

112. Oskamp, S. 1991. Attitudes and opinions. Englewood Cliffs, NJ: Prentice Hall

113. Pasquali, L. (2003). Psicometria. Teoria dos testes na psicologia e na educação. Petrópolis, RJ: Editora Vozes.

114. Polidori, M.; Marinho,C.;Barreyro, G. (2006). SINAES: perspectivas e desafios na avaliação da educação superior brasileira. Ensaio: aval.pol.públ.Educ. vol.14 no.53. Rio de Janeiro. Disponível em http://www.scielo.br/scielo.php?script=sci_arttext\&pid=S010440362006000400002

115. Pozo, J.I., Gomez Crespo, M.A. (1998). "Aprender y enseñar ciencia. Del conocimiento cotidiano al conocimiento científico". Madrid, MORATA.

116. Pozo, J.I. (1997). "El cambio sobre el cambio: hacia una nueva concepción del cambio conceptual en la construcción del conocimiento científico". Rodrigo y J. Amay (Eds). La construcción del aprendizaje escolar, (pp. 155-176). Barcelona. PAIDOS.

117. Pozo, J.I. (2001).“Humana mente. El mundo, la conciencia y la carne”. Madrid, MORATA.

118. Phillips, J. L. (1980). La lógica del pensamiento estadístico. México: El Manual Moderno.

119. Phillips, R. (1993). Teacher attitude as related to student attitude and achievement in Elementary School Mathematics. School Science and Mathematics, 73(6), 501 - 507.

120. Prieto, G., y Delgado, A.R. (2003). Análisis de un test mediante el modelo de Rasch. Psicothema, 15, 94-100.

121. Ribeiro, C.; Lorenzetti, M.; Jacobini, O. (2010). Educação Estatística - Teoria e prática em ambientes de modelagem matemática. Grupo Editorial Autêntica.

122. Ristoff, D.; Giolo, J. (2006). O SINAES como Sistema. RBPG, Brasília, v. 3, n. 6, p. 193-213. Relatório de divulgação dos resultados finais da avaliação TRIENAL 2004, 2007, 2010. CAPES. Disponível em: http://trienal.capes.gov.br

123. Roberts, D.M., \& Bilderback, E. W. (1980). Reliability and validity of a statistics attitude survey. Educational and Psychological Measurement, 40, 235238.

124. Rodríguez, N. (2006). Necesidad de la educación andragógica y gerontológica en la formación profesional del docente peruano. Revista del Instituto de Investigaciones Educativas, 10(17), 43 - 50. ISSN 17285852.

125. Rocha, J., Bayer, A., Bittencourt, H. R. \& Echeveste, S. (2004). A estatística e sua história. Trabalho apresentado no XII Simpósio Sulbrasileiro de Ensino de Ciências, Canoas-RS.

126. Samejima, F. (1969). Estimation of latent ability using a response pattern of graded scores. Psychometrica Monograph 17: 1-100. 
127. Silva, C. B. (2000). Atitudes em relação à estatística: um estudo com alunos de graduação. 2000. 157 f. Dissertação (Mestrado em Educação); Faculdade de Educação, Universidade Estadual de Campinas, Campinas.

128. Silva, et al.(2002). Atitudes em relação à estatística e à matemática. PsicoUSF v.7 n. 2 Itatiba dez. 2002.

129. Silva, L. (1989). A Fundação Instituto Brasileiro de Geografia e Estatística IBGE e a produção das estatísticas. In: Revista Brasileira de Estatística - RBEs, Ano 50, n.193. Rio de Janeiro

130. Sánchez Díaz, M.; Vega Valdés, J. (2003). Algunos aspectos teóricoconceptuales sobre el análisis documental y el análisis de información. Ciencias de la Información, 34 (2): 49-60.

131. Schlickmann, R.; Roczanski, C.; Azevedo, P. (2008). PROVÃO X ENADE: Uma análise comparativa. Disponível em http://repositorio.ufsc.br/xmlui/handle/123456789/61488.

132. SINAES (2004). Bases para uma nova proposta de avaliação da educação superior. Disponível em http://www.unifesp.br/reitoria/orgaos/comissoes/avaliacao/sinaes.pdf

133. Schau, C., Stevens, J., Dauphine, T., \& Vecchio, A. (1995). The development and validationof the survey of attitudes towards statistics. Educational and Psychological Measurement, 55(5), 868-875.

134. Smith, A. B., Rush, R., Fallowfield, L. J., Velikova, G., \& Sharpe, M. (2008). Rasch fit statistics and sample size considerations for polytomous data. BMC Medical Research Methodology, 8, 33.

135. Tarazona, E. G. (2013). Modelos alternativos de respuesta graduada con aplicaciones en la calidad de servicios (Tesis de maestría). Pontificia Universidad Católica del Perú, Lima, Perú.

136. Tarazona, E., Bazán, J.L., Aparicio, A. (2013). Actitudes hacia la estadística en universitarios peruanos de mediana edad. RIDU - Año 7 Nro. 1.pg 57-76. En http://revistas.upc.edu.pe/index.php/docencia/article/view/187/143

137. Turik, Claudia (2010). Análise de atitudes de alunos universitários em relação à Estatística por meio da teoria da resposta ao item. Tese de Mestrado em Educação em Ciências e Matemática, da Pontifícia Universidade Católica do Rio Grande do Sul.

138. Vasquez, Adolfo (2002). Ética. Trad. João Dell'Anna. 23.ed.Rio de Janeiro: Civilização Brasileira.

139. Vendramini, C. M. M. (2000). Implicações de atitudes e das habilidades matemáticas na aprendizagem de conceitos de estatística. Tese de Doutorado em Educação, Universidade Estadual de Campinas, Campinas-SP.

Vendramini, C.; Brito, M.(2001). Relações entre atitude, conceito e utilidade da Estatística. Psicologia Escolar e Educacional, João Pessoa, v. 5, n. 1, p. 59-63, jun. 2001.

140. Vendramini, C., \& Silva, F. (2012). Evidências de validade para a escala informatizada de atitudes frente à estatística eSATSportuguês. Revista Digital de Investigación en Docencia Universitaria, 6(1), 121-142.

141. Watson, J. M. (2001) Profiling teachers' competence and confidence to teach particular mathematics topics: The case of chance and data. Journal of Mathematics Teacher Education, 4(4), 305-337.

142. Verhine, R.; Dantas, L.; Soares, J. (2006). Do provão ao ENADE: uma análise comparativa dos exames nacionais utilizados no Ensino Superior Brasileiro. Ensaio, v. 14, n. 52, p. 291-310. Rio de Janeiro. 
143. Vianna, Heraldo M. (2003). Avaliações nacionais em larga escala: análises e propostas. São Paulo: 41p. (Textos FCC, n. 23).

144. Wise, S. L. (1985). The development and validation of a scale measuring attitudes toward statistics. Educational and Psychological Measurement, 45, 401405.

145. Wright, B.D., y Linacre, J.M. (1998). WINSTEPS: A Rasch computer program. Chicago: MESA Press. 


\title{
ANEXO
}

\section{ESCALA GLOBAL DE ATITUDE FRENTE À ESTATÍSTICA**}

\author{
Idade: Sexo: Universidade: Ano de estudos: Faculdade:
}

Instruções: Cada uma das seguintes frases expressa o sentimento que as pessoas tem com relação à Estatística. Você deve comparar o seu sentimento pessoal com aquele expresso em cada frase, assinalando com um $\mathbf{X}$ numa das cinco possibilidades colocadas à direita da frase Discordo totalmente: DT; Discordo: D; Indiferente: I; Concordo: C e Concordo totalmente: CT. De modo que você indique com a maior precisão possível, o sentimento que você tem com relação à Estatística.

\begin{tabular}{|c|c|c|c|c|c|c|}
\hline & & DT & D & I & C & CT \\
\hline 1 & Incomoda-me a informação Estatística que há em alguns programas da TV & & & & & \\
\hline 2 & A estatística ajuda a compreender o mundo de hoje & & & & & \\
\hline 3 & Através da Estatística pode-se manipular a realidade & & & & & \\
\hline 4 & A estatística é fundamental na formação básica do futuro cidadão & & & & & \\
\hline 5 & Eu uso a Estatística para resolver problemas da vida cotidiana & & & & & \\
\hline 6 & Na universidade não deveriam ensinar Estatística & & & & & \\
\hline 7 & Eu me divirto nas aulas em que se explica Estatística & & & & & \\
\hline 8 & Acho que os problemas da Estatística são fáceis & & & & & \\
\hline 9 & Não entendo as informações Estatísticas que aparecem no jornal & & & & & \\
\hline 10 & $\begin{array}{l}\text { Eu gosto da Estatística porque me ajuda compreender mais profundamente a } \\
\text { complexidade de certos temas }\end{array}$ & & & & & \\
\hline 11 & Eu me sento intimidado com os dados estatísticos & & & & & \\
\hline 12 & Eu acho interessante o mundo da Estatística & & & & & \\
\hline 13 & Eu gosto dos trabalhos sérios onde apareçam estudos estatísticos & & & & & \\
\hline 14 & Utilizo pouco a Estatística fora da universidade & & & & & \\
\hline 15 & $\mathrm{Na}$ aula de Estatística nunca entendo do que estão falando & & & & & \\
\hline 16 & Eu adoro a Estatística porque ajuda a ver os problemas objetivamente & & & & & \\
\hline 17 & A Estatística é fácil & & & & & \\
\hline 18 & $\begin{array}{l}\text { Compreendo melhor sobre o resultado das eleições quando aparecem } \\
\text { representações gráficas }\end{array}$ & & & & & \\
\hline 19 & A Estatística só serve para as pessoas de ciências & & & & & \\
\hline 20 & Eu gosto de fazer problemas quando uso a Estatística & & & & & \\
\hline 21 & A Estatística não serve para nada & & & & & \\
\hline 22 & $\begin{array}{l}\text { Muitas vezes explico a meus colegas problemas de Estatística que eles não } \\
\text { entenderam }\end{array}$ & & & & & \\
\hline 23 & Se pudesse eliminar algum curso seria a Estatística & & & & & \\
\hline 24 & A Estatística ajuda a tomar decisões mais fundamentadas & & & & & \\
\hline 25 & Evito as informações Estatísticas quando as leio & & & & & \\
\hline 26 & Eu fico sob uma terrível tensão na aula de Estatística & & & & & \\
\hline 27 & Eu não gosto de Estatística e me assusta ter que fazer essa matéria & & & & & \\
\hline 28 & Eu acho a Estatística muito interessante e gosto das aulas de Estatística & & & & & \\
\hline 29 & A Estatística é fascinante e divertida & & & & & \\
\hline 30 & A Estatística me faz sentir seguro(a) e é, ao mesmo tempo, estimulante & & & & & \\
\hline 31 & "Dá um branco" na minha cabeça e não consigo pensar claramente Quando & & & & & \\
\hline 32 & Eu tenho a sensação de insegurança quando me esforço em Estatística & & & & & \\
\hline 33 & A Estatística me deixa inquieto(a), descontente, irritado(a) e impaciente & & & & & \\
\hline 34 & O sentimento que eu tenho com relação à Estatística é bom & & & & & \\
\hline
\end{tabular}




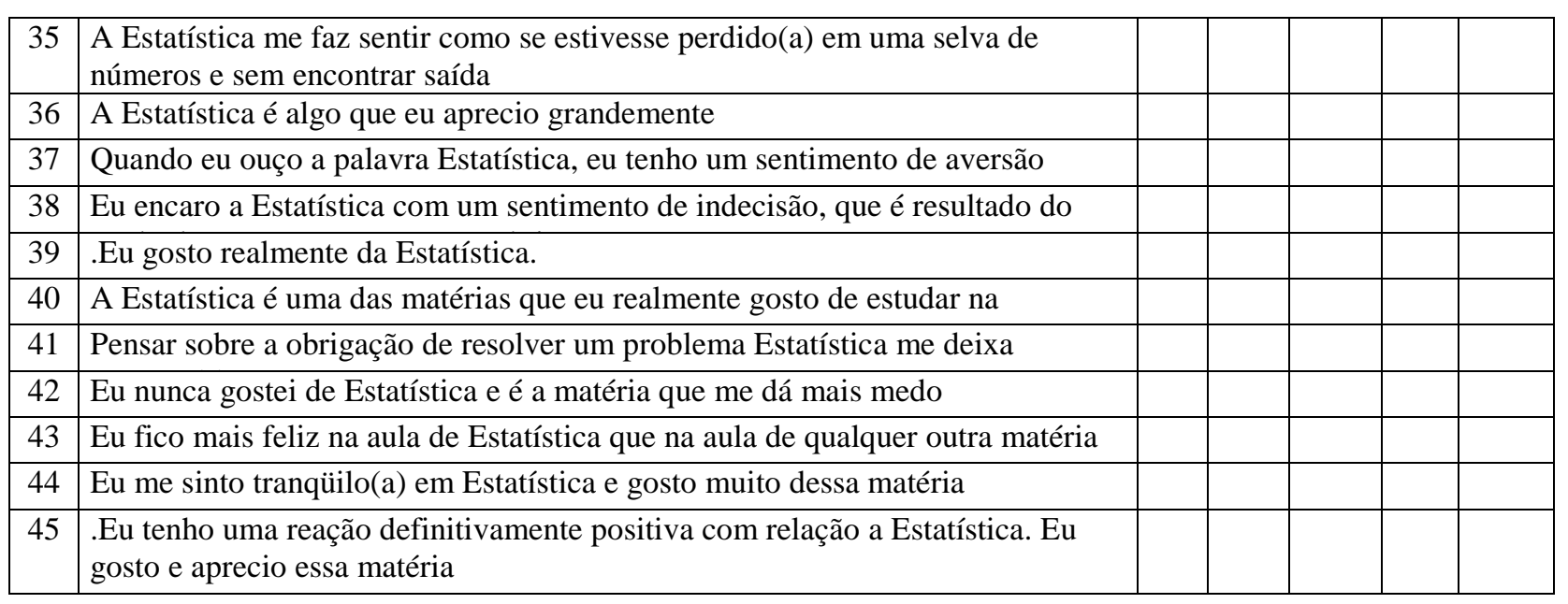

\section{OBRIGADOS PELA AJUDA}

** Nota: Os itens 1 a 25 são itens da Escala de Atitudes frente à Estatística de Estrada (2002) e os itens 26 a 45 são itens da Escala de Atitudes frente à Estatística de Cazorla et al (1999) 